\title{
Socioeconomic consequences of ankylosing spondylitis
}

Citation for published version (APA):

Boonen, A. E. R. C. H. (2002). Socioeconomic consequences of ankylosing spondylitis. [Doctoral Thesis, Maastricht University]. Datawyse / Universitaire Pers Maastricht. https://doi.org/10.26481/dis.20021218ab

Document status and date:

Published: 01/01/2002

DOI:

10.26481/dis.20021218ab

Document Version:

Publisher's PDF, also known as Version of record

\section{Please check the document version of this publication:}

- A submitted manuscript is the version of the article upon submission and before peer-review. There can be important differences between the submitted version and the official published version of record.

People interested in the research are advised to contact the author for the final version of the publication, or visit the DOI to the publisher's website.

- The final author version and the galley proof are versions of the publication after peer review.

- The final published version features the final layout of the paper including the volume, issue and page numbers.

Link to publication

\footnotetext{
General rights rights.

- You may freely distribute the URL identifying the publication in the public portal. please follow below link for the End User Agreement:

www.umlib.nl/taverne-license

Take down policy

If you believe that this document breaches copyright please contact us at:

repository@maastrichtuniversity.nl

providing details and we will investigate your claim.
}

Copyright and moral rights for the publications made accessible in the public portal are retained by the authors and/or other copyright owners and it is a condition of accessing publications that users recognise and abide by the legal requirements associated with these

- Users may download and print one copy of any publication from the public portal for the purpose of private study or research.

- You may not further distribute the material or use it for any profit-making activity or commercial gain

If the publication is distributed under the terms of Article $25 \mathrm{fa}$ of the Dutch Copyright Act, indicated by the "Taverne" license above, 
Socioeconomic consequences of ankylosing spondylitis 
(c) Annelies Boonen, Maastricht 2002

ISBN 9052783616

Praduction: Datawyse | Universitaire Pers Maastricht

The publication of this thesis was financially supported by Shering-Plough bv, MSD bv, Bio-Imaging ine. Pharmacia, Aventis Pharma bv, NV Organan Oss, Amgen bv, Wyeth Pharmaceuticals, Boehringer Ingelheim bv and Novartis Pharma bv. 


\title{
Socioeconomic consequences of ankylosing spondylitis
}

\author{
PROEFSCHRIFT \\ ter verkriging van de graad van doctor \\ aan de Universiteit Maastricht, \\ op gezag wan Prof. dr. A.C. Nieuwenhuijen Kruseman, \\ Rector Magnificus, \\ volgens het besluit van het College vam Decanen, \\ in het openbaar te verdedigen \\ op woensdag 18 december 2002 om 14.00 uur
}

door

Anna Elisa Boonen

Geboren op 18 februari 1963 te Maaseik

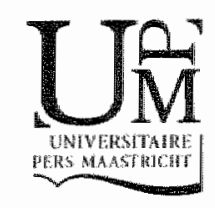




\section{Promotores}

Prof. dr. J.M.J.P. van der Linden

Prof. dr. D.M.F.M. van der Heijde

\section{Co-promotor}

Dr. M.P.M.H. Rutten-van Mölken

\section{Beoordelingscommissie}

Prof. dr. I.L. Severens (voorzitter)

Prof. dr. J.Th.M. van Eijk

Prof. dr. F.J.N. Niphuis

Prof. dr. L.B.A. van de Putte (Katholieke Universiteif Nijmegen)

Prof. dr. C.P. van Schayck 
Socioeconomic Consequences of Ankylosing Spondylitis

but never forget, more important than the price is the value... 


\section{Contents}

Chapter 1 Introduction and glossary

PART I Labour force participation in ankylosing spondylitis 19

Chapter 2 Working status and its determinants among patients with ankylosing spondylitis. A systemic review of the literature

Chapter 3 Employment, work disability and work days lost in patients with ankylosing spondylitis. A cross-sectional study of Dutch patients

Chapter $4 a$ Withdrawal from the labour force due to work disability in patients with ankylosing spondylitis

Chapter $4 \mathrm{~b}$ Manual professions increase risk to withdraw from the labour force in ankylosing spondylitis, also when compared with the general population

Chapter 5 Employment perspectives of patients with ankylosing spondylitis

PART II Cost-of-illness in ankylosing spondylitis.

Chapter 6 Direct costs of ankylosing spondylitis and its determinants. A comparison among three European countries

Chapter 7 Work status and productivity casts due to ankylosing spondylitis. A comparison among three European countries

Chapter 8 Costs of ankylosing spondylitis in three European countries. The patient's perspective

Chapter 9 A tale of two cifies. A comparison of the hospitalisation costs in 1897 and 1997 
PART III Cost-effectiveness in ankylosing spondylitis

Chapter 10 Cost-effectiveness of combined spa exercise therapy in ankylosing spondylitis. A randomised controlled trial

Chapter 11 Discussion and proposal for research

Summary

Samenvalting

Dankwoord

Curriculum Vitae

List of publications 


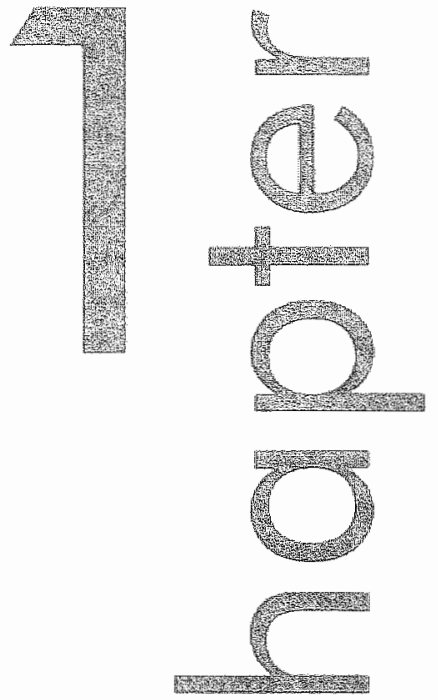

\section{Introduction and glossary}


10 Chapter 


\section{Introduction}

The disease we nowadays call ankylosing spondylitis (AS) has a history of more than 3,000 years. According to recent paleopathologic studies the pharaons Ahmenhotep II and Ramses II, living in the 14 th and 12th century B.C., suffered from severe AS. ${ }^{1.2}$ However, it was anly in 1693 that Conner, an English student in Paris, described for the first time accurately the anatomic features of an ankylosed spine ${ }^{3}$ and it took until November 24,1824 that the Lancet published the first clinical description of a patient with inflammatory back pain and limited spinal mobility. The relationship between the clinical symptoms and the anatomic features of an ankylosed spine, was suggested in about 1850 by the English surgeon Brody. It was Pierre Marie who formulated in 1898 this disease entity had to be regarded as a "morbus sui generis", distinct from rheumatism or spondylosis deformans. "Over the years several names for this disease were used such as rheumatoid spondylitis, spondylose rhyzomélique or pelvispondylitis ossificans and also the eponyms Bechterew's and Pierre-MarieStrumpell's disease were introduced. In about 1904 the German pathologist Fraenkel proposed the name spondylarthritis ankylopoetica.' The etymology of this term accurately describes the disease process of this chronic rheumatic disorder: inflammation of the spine ( $\sigma \pi \circ \delta \delta \cup \lambda_{0 \sigma}$ : backbone, spine) leading to ankylosis (aykvior: crooked, curved).

The socioeconomic consequences of diseases receive increasing attention during the past 25 years and have become a recognized outcome measure. ${ }^{8}$ The socio. economic impact of a disease refers to the effect of the illness on the ability to perform paid or unpaid work and on the effect on health resource utilisation. Such consequences can be presented by describing the effect on ability to work or on health resource use, but can also be valued in monetary terms resulting in an economic analysis. For the patient the sacioeconomic impact is important since it is known that inability to work adversely affects self esteem and quality of life." Moreover, the financial consequences of the disease can be substantial for the patient and his familly. For society, socioeconomic consequences are relevant because of the increasing financial burden of diseases on a limited budget.

Within outcome research in AS, the socioeconomic consequences of this disease have received limited attention. It is possible that the formerly reported low prevalence of about $0.1 \%$, its assumed good clinical outcome in addition to the absence of effective treatments contributed to this limited interest. Recent studies showed the prevalence of the disease might have been underestimated and new figures vary bewween $0.86 \%$ in a German population study " and $1.4 \%$ in the adult Norwegian population. ${ }^{12}$ It has also been shown that the functional impact of the disease is as important as in theumatoid arthritis. ${ }^{13}$ In addition, the first symptoms of AS occur at an early age, usually in the third decade of life $1.3-15$ 
when people start their professional career and the extraspinal disease manifestations such as peripheral arthritis, inflammatory bowel disease, uveltis and psoriasis can contribute substantially to the morbidity of AS. Taken together, these factors illustrate the impontance to study the socioeconomic impact of the disease for patient and society.

\section{Outline of the thesis}

In this thesis, we aim to explore the full socioeconomic consequences of AS.

In: Part $\|$, the effect on labour force participation is described in conjunction with the possible explanatory factors associated with withdrawal from the labour force. Chapter 2 comprises a systemalic literature review of the avalable literature on labour force participation. Chapters 3 to 5 describe extensively the effect on labour force participation from a cross-sectional study among 658 patients with AS, designed to assess employment and withdrawal from work in AS in The Netherlands. Chapter 3 reports prevalent employment, work disability and workdays lost in patients compared with the general Dutch population. Chapter $4 \mathrm{a}$ addresses the issue of withdrawal from the labour force in those with a paid job at onset of disease and explores the characteristics of patients who had withdrawn from work. Chapter $4 \mathrm{~b}$ explores if the adverse effect of manual jobs on withdrawal from work was specific for AS or similar as in the general population. Since type of job was an important predictor of withdrawal from work, Chapter 5 explores which specific work related factors are associafed with withdrawal from wark.

In Pan ll the results of a cost-of-illness study, designed to assess the costs of AS are presented. It concerns a two years' longitudinal cost-of-illness study completed by 209 patients and performed in three European countries, The Netherlands, France and Belgium. A multinational design was chosen to enhance the generalisability of the health economic data. Chapter 6 compares the direct healthcare and non-healthcare costs from societal and financial perspective among the three countries and Chapter 7 the productivity costs. Chapter 8 reports out-of-pocket-costs and intangible costs for the patients. In all these chapters, possible predictors of costs were assessed. In addition to the studies on socioeconomic consequences of AS, a historical search was done to compare the costs of hospital care 100 years ago with the present costs and to find out the method to calculate the hospital day price at that time. These results can be read in Chapter 9.

Part III concerns the question if the benefits of an intervention in AS can be reached within an acceptable range of costs. Chapter 10 presents a cost. effectiveness and costutility analysis of spa treatment in patients with AS.

Chapter 11 summarises the findings described in chapters 2 to 10 and discusses the overall conclusions from this thesis. In addition, a proposal for a
research agenda is presented. 


\section{References}

1. Harris JE, Wente EF. An X-ray atlas of the royal mummies. Chicago London: Universily of Chicago press, 1980.

2. La momie de Ramses II. Paris, 1985.

3. Connor B. An extract of a letter to Sir Charles Waldgrave published in French at Paris: Given an account of an extraardinary humane skeleton, whose vertebrae of the back, the ribs and several bones down to the os sacrum, were all firmly united into one spolid bone, without fointing or cartilage. Philosophical Transactions $1694 ; 19$.

4. Travers $M$. Curivos case of anchylosis of a great pait of the vertebral column; probably praduced by an assification of the intervertebral substance. The Lancet $1824,5: 254$.

5. Brodie SBC. On some coses which are liable to be mistaken for those of caries of the spine. London: Longman, Brown, Green and Longmans; 1850.

6. Marie P. Sur le spondylose rhizomelique. Revue de Medecine 1898; 18:285-315.

7. Fraenkel E. Uber chronische ankylsioierende Wirbelsaulenversteifung. Forthschrithe auf dem Gebiete der Ronthenstrahlen 1903-1904;11:171-195.

8. Elixhauser A, Luce BR, Taylor WR, Reblando J. Health care CBA/CEA: on update on the growth and composition of the literature. Med Care 1993,31(7 Suppl) Is 1-11. Is $18-1149$.

9. Warr P. Wark, unemploymemt and mental health. Oxford: Clarendon Press; 1987.

10. van der Linden $S M$, Valkentourg $H A$, de Jongh $B M$, Cats $A$. The risk of developing ankylosing spondylitis in HLA-B27 positive individuals. A comparison of relatives of spondylitis patients with the general population. Arthritis Rheum 1984;27:241-249.

11. Braun J, Bollow $M$, Remlinger $G$, Eggens U, Rudwaleit $M$, Distler $A$, et al. Prevalence of spondylarthropathies in HLA-B27 positive and megative blood donors. Arshritis Rheurn 1998:41:58-67.

12. Gran JT, Husby $G$, Hordvik M. Prevalence of ankylosing spondylitis in moles and females in a young middle-aged population of Tromsa, northern Norway. Ann Rheum Dis 1985;44:359-367.

13. Zink A, Broun J, Listing J, Wollenhaupt J. Disability and handicap in rheumatoid arthritis and ankylosing spondylitis. Results from the German rheumatological database. German Collaborative Authritis Centers. J Rheumatal 2000;27:613-622.

14. Braun J, Sieper J, Elixhauser A, Luce BR, Taylor WR, Reblando J. Inzeptionskohorte fur Spondylarthropathien. Health care CBA/CEA: an update on the growth and camposition of the literature. Z Rheumatol 2000;59:117-121.

15. Feldkkeller Es Mau W, Zeidler H, Mau R, Majewski A, Freyschmidt J, et al. Erkrankungsalter und Diagnoseverzogerung bei Spondylarthropathien. Clinical features and prognosis of patients with possible ankylasing spondylitis. Resulis of a 10-year followup. Z Rheumatol 1999;58:21-30. 


\section{Glossary to appreciate the economic analyses}

\section{Botum-up approoch}

Refers to method of collecting resources, costs and patient characteristics from individual patients (usually through diaries, questionnaires or patient files).

\section{Cost category}

Three main categories of casts are distinguished; the direct healthcare and non healthcare costs, the indirect costs and the intangible costs. For all these cost categories several subcategaries of costs can be defined.

Direct costs: categary of costs comprising the direct healthcare and the direct non-heallhcare costs.

- Direct healthcare costs: (sub-)category of costs that are part of the healthcare sector, and are related to detection, treatment and rehabilitation of the health impaiment or its effect.

- Direct non-healthcare costs: (sub-) category of costs that are related to the health impaiment but are no part of the healthcare sector such as expenses for transport to healthcare providers, costs of extra heating or clothing, contributions to patient societies, payments for private household help.

Indirect costs: category of costs comprising the indirect healthcare costs and the productivity costs (previously called indirect non-healthcare costs).

- Indirect healthcare casts: heatthcare costs incurred during the life years gained as a consequence of an intervention

- Productivity cost: costs related to impaired ability to perform paid work, to engage in leisure activities because of morbidity or death. Classically, these costs are calculated following two major methods, the friction costs method (see there) or the human capital approach (see there).

Intangible costs: category of costs representing the deterioration of quality of life and psychological well being of the potients and their caregivers. Since such effects are difficult to quantify in monetary values, they are offen not expressed as cost.

\section{Cost diary}

Instrument to measure health resource use and in which resource utilisation per day has to be reported.

\section{Cost estimate}

Estimation of the cost of one unit of the healthcare resaurce considered (see also unit cosit. 
Cost-of-illness (COI) study

Type of economic analysis aiming at identifying and measuring all costs of a particular disease.

Prevalence based cost-of-illness: cost-of-illness of a crass-sectional group of patients over a defined period.

Incidence based cast-of-illness: cost-of-illness of a group of newly diagnosed patients over a defined period.

Lifetime costs: cost-of-illness of a disease from the start until the end of the disease which can be cure or death.

\section{Cost questionnaire}

Instrument to measure health resource use, in which resource utilisation has to be reported retrospectively over a for each question defined period of time.

\section{Direct costs}

See cost category.

\section{Discounting}

Mathematical adjustment of the costs or health effects for differential timing expressing preference in time for costs or effects. Usually costs and health effects in the future are valued less than costs and health effects in the present time.

\section{Disease specific resource use or costs}

Resources or costs due to the disease studied, excluding all other health related resource use or costs.

\section{Economic questionnaire}

Instrument to measure health resource use, which has to be completed by the patient retrospectively, evaluating past resource use over a time period defined at the start of the study (usually one, three or six months).

\section{Financial perspective}

See perspective of the cost analysis.

\section{Friction cost method}

Specific method to assess the productivity costs. Limits the casts of lost productivity to the period the production is not replaced. This period is called the friction period. In case inability to perform paid work the friction period depends on the unemployment rate on the labour market and was 92 days in The Netherlands in the time of the study reported in chapter 7. 
Full economic evaluation

Type of economic analysis measuring costs but also consequences of a particular intervention or diagnostic strategy. In cost-effectiveness analyses consequences are expressed as health gain (such as improvement in pain), in cost-utility analyses the consequences are expressed as a preference for the health state reached (quality adjusted life years) and on cost-benefit analyses the consequences are expressed in monetary values.

\section{Human capital approach}

Specific method to assess the productivity costs. Considers the entire period the diseased person is unable to perform paid or unpaid work from the first till the last day (return to work, retirement or death whatever comes first).

Incidence based cost-of-illness study

See cost-of-illness study.

Incremental cost(-effectiveness) calculation

The extra costs compared to cost(-effectiveness) of another disease or program.

Indirect costs

See cost categories.

Intangible costs

See cost categories.

Lifetime cost-of-illness

See cost-of-illness study.

Opporiunity cost

See unit cost.

Out-of-pocket costs

See unit cost.

Patient's contribution

See unit cost.

Patient's perspective

See perspective of the cost analysis. 
Perspective of the cost analysis

System, organisation, institution or person who incurs the costs. The perspective has implications for the (sub-) categories included and for the unit cost applied to each of the resources. The main perspectives are:

Sociefal perspective: all cost categories are relevant and the unit cost reflects the true price.

Financial perspective: only cost categories that are paid for by the specific (healthcare) payer are included. Usually the (healthcare payer) is the health insurance company but it can also be the hospital or the home-care organisation. The unit cost is the cost (usually a charge or tariff) paid by this organisation/institution.

Patient perspective: (sub-)categories of costs for which the patient has personal expenses are relevant. The unit cost is the patient (out-of-pocket) contribution.

\section{Prevalence based cost-of-illness study}

See cost-of-illness study.

Productivity costs

See cost categories.

\section{Purchaising power parities}

Exchange values of different currency, adjusted for differences in purchasing power (goods that can be bought) of the currencies considered.

\section{Resource}

The smallest unit within a (sub-)category of costs which is measured. Examples of resources are one day in the hospital, one visit to a general practitioner, and one radiological examination. How small this unit is can differ among studies. A "technical procedure" can be further specified as a "radiological examination" or even more specific as a "conventional nadiograph of the lower spine" etc.

\section{Societal perspective}

See perspective of cost analysis.

\section{Tariff}

See unit cost.

\section{Top-down approach}

Refers to the method of collecting resources, costs and patient characteristics, collected from groups of patients (usually through large data-bases).

Total direct costs

$\Sigma$ [number of resources of each (sub-) category $X$ unit cost of the resource]. 


\section{True price}

See unit cost.

\section{Unit cost}

The price of one resource. For one resource several prices can be distinguished. The true (market) price, which can be calculated by several methods. The true (market) cost is closely related to the opportunity cast, referring to the best (market) value in the best alfernative circumstance the cost is used.

The tariff reflecting the price paid by the third party payer.

The patient's contribution, reflecting the price the patient pays for the resource.

The unit cost (one hour or one day) of lost productivity is estimated by variable methods. For example, for valuation of loss of paid work commonly used production values are: personal wage per hour, the national mean wage per hour (sometimes adjusted for age, gender or type of job) can be used, estimated true production value per hour).

\section{Sensitivity analysis}

Statistical method to adjust for uncertainty introduced in the economic analyses by using estimates for costs or for health effects, or by the distribution of the data. 


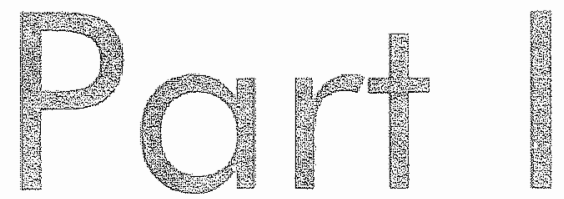

\section{Labour force participation in ankylosing spondylitis}



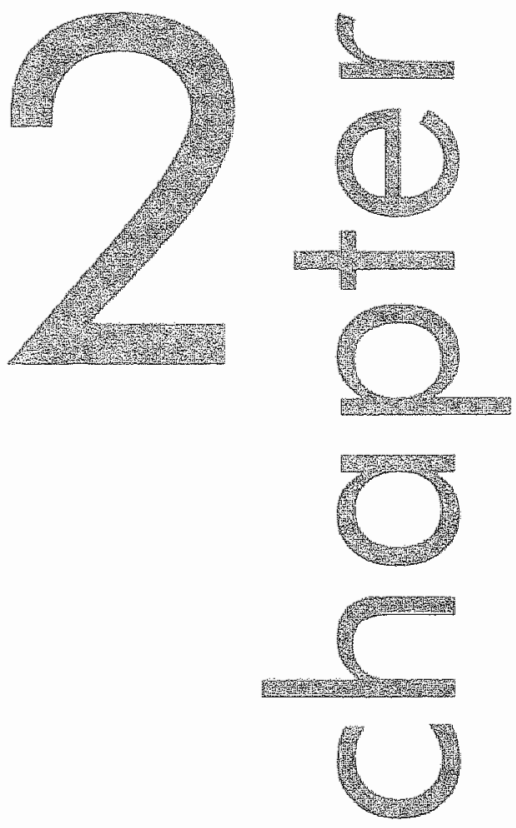

Working status and its determinants among patients with ankylosing spondylitis

A systematic review of the literalure

Boonen $A$, de Vet $H$, von der Heilde $D$. von der Linden 5

J Rheumatol 2001;28:1056-1062 


\section{Abstract}

Aim

To evaluate work status and its determinants among patients with ankylosing spondylitis (AS).

\section{Methods}

We performed a systematic review of the literature of original studies published after 1980 in which work status in AS was an outcome. Medline was searched and the references of the retrieved papers were checked for additional studies.

\section{Results}

Sixteen full articles and 2 abstracts were identified, describing work status in 14 patient groups. Employment ranged from 34 to $96 \%$ after 45 and after 5 years disease duration, respectively, and work disability from 3 to $50 \%$ of 78 and 45 years disease duration respectively. Days of sick leave varied from 12 to 46 days per patient per year among thase who had a paid job. Determinants of work status were reported in 9 studies. Age, education and physical function were shown to be associated with work disobility, while peripheral joint disease was associated with sick leave.

\section{Conclusion}

Results on work status show considerable variobility due to heterogeneity of patient populations studied, but also because of large variation in choices and definitions of endpoints. The absence of data referring to a reference population and failure to adjust results for age and gender are striking. Although standardisation in analysing and reporting data on work status are badly needed, it is nonetheless clear that work disability and sick leave in AS are substantial. 


\section{Introduction}

In the broader concept of patient outcome, work status is important not only because it contributes to quality of life of the individual patient but also because of its economic consequences. The costs attributable to loss of productivity (indirect casts of disease) are the major component of the toral costs of musculoskeletal diseases." Insight into the magnitude and determinants of impaired work status for specific rheumatologic conditions might help to keep patients in the labour force by adequate professional counseling and vocational rehabilitation. Ankylosing spondylitis (AS) affects people, mostly men, at young age $^{2}$ and can lead to important functional impairment not only because of spinal disease, but also because of extraspinal manifestations. ${ }^{3}$ We reviewed the literature on work status and its determinants in patients with AS.

\section{Materials and Methods}

\section{Selection criteria}

Original studies in adult patients with AS including work status among the endpoints and published after 1980 in English, French, Dutch or German were selected. Work status refers to the ability or inability to perform a paid job. Endpoints considered were employment, work disability, early retirement, and withdrawal from the labour force, unemployment and sick leave for those having a paid jab. The search was limited to publications within the last 20 years since we were interested in present work status and since economic developments over time as well as changes in social security systems might influence the labour force participation in AS and the general population differentially.

\section{Search strategy}

MEDLINE was searched from 1980 up to March 2000. The combination of MESH-terms [ankylosing spondylitis or spondylitis or arthritis] and [work or labor or labour or economics or employment or indirect costs or burden of illness or job] as headings and subheadings was used. Additionally, abstracts of the annual scientific meeting of the American College of Rheumatology (ACR) and the references from the section Epidemiology and Health Services Resecrch of Current Opinion in Rheumatology were hand searched from 1995 till 2000 to find data from recent, yet unpublished, studies. Finally, references of selected articles were checked. 


\section{Data collection and analysis.}

Data were extracted by one evaluator (AB) and in cases of doubt independenty by a second reader $(H d V)$. A self-composed list of itens over 6 domains was used (appendix). These domains were 1) identificalion of the study, 2) study design, 3) characteristics of the patient group, 4) endpoints related to work, 5) deferminants of work status and 6) appropriateness of defining and reporting work related endpoints. Whenever possible, we recalculated data on work status for patients in working age ${ }^{4.5}$ in order to improve comparabilify among studies.

\section{Results}

\section{Search and selection of articles}

The MEDLINE search provided 1,535 citations. Most articles could be eliminated after reading the title or the abstract. For 28 citations the entire article had to be checked. Finally, only 16 articles fulfilled our requirements. ${ }^{4.18}$ Two articles ${ }^{18,19}$ dealt with the same study. The publication with the more extensive data was included. 19 One additional article 20 was found in the references. ${ }^{10}$ Hand-search of Current Opinion in Rheumatology did not provide additional articles. Hand. search of ACR-abstract books revealed wo not yet published abstracts from Mexico dealing with the same population, of which the second reported results offer 5 years' fallow-up. ${ }^{21,22}$ In total 18 publications were included. ${ }^{4-18,20-22}$

\section{Patient groups and endpoints}

Table 2.1 presents characteristics of the selected studies whille Table 2.2 pravides some results of the critical appraisal of the articles. All studies were done in European countries except for two Mexican studies 21.22 and one from New Zealand. "15 Four patient groups were followed longitudinally.10,18,20,22 and only one was an inception cohort. ${ }^{10,20}$ The 18 articles dealt with 14 palient groups. Two groups were reported again when longer follow-up became avalable $10,20.22$, another group was analysed a second time after inclusion of more women to compare work status between male and female patients. ${ }^{16.17} \mathrm{~A}$ fourth group first compared hospital and community samples and later male and female patients after inclusion of mare patients. ${ }^{11,12}$ The number of patients with AS included varied from $20^{10}$ to $739^{5}$, mean age from 35 years ${ }^{21}$ to 48 years and mean disease duration from 10 years" to 45 years. "However. mean age ${ }^{14,18,20}$, age range $e^{5,6,8,11,13,15,21}$ and mean disease duration 14, 1á, wy were nat always provided and information on disease activity, presence of extraspinal disease and educational level was often insufficient. Mast studies reponted on several endpoints related to work status. Terminology used to refer to patients without paid employment or having some type of disability varied importantly:

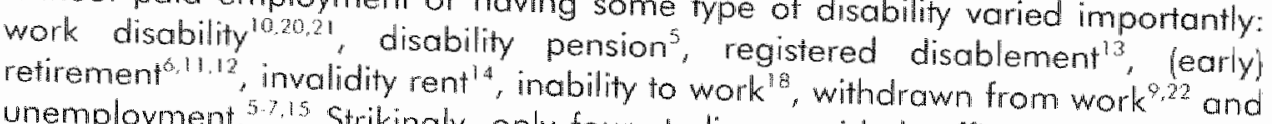
unemployment. 57,15. Strikingly, only four studies provided sufficient definition of 
at least one of these endpoints. 10.21 .22 When reporting futher in this article on endpoints, we classified the terms used in the original articles into three categories: employed, unemployed and work disobled comprising: work disability, disability pension, registered disablement, (early) retirement, invalidity rent, inability to work and withdrawn from work. In the Tables 2.3 and 2.4 terminology as used in the original articles is respected. Also, reporting endpoints was not uniform. Sick leave, for example, was sometimes presented as proportions of patients experiencing sick leave in the past year ${ }^{14,21}$ or during a certain follow-up period" and sometimes as the number of days absent at work per year ${ }^{14,22}$ or per month. ${ }^{22}$ It often remained unclear if the porticular endpoint was assessed AS specific. Data were never adjusted for age or gender and only one study provided reference data on employment in the general population." Nine studies analysed determinants of work status by uni- or multivariate statistics. $5,9,12-1421,22$ Costs associated with loss of productivity were never calculated.

\section{Work status and sick leave}

Table 2.1 also provides the results of the separate studies. For seven studies if was not possible to recalculate data on work status for patients in working age. $6,11,13,15,18,21$ Overall, employment ranged from 34 to $96 \%$ in patients with 45 and 5 years disease duration, respectively. Both figures came from the same Finnish cohort ${ }^{10}$. Excluding this study, employment varied from $61 \%$ both in a Slovak ${ }^{14}$ and Mexican study 21 to $89 \%$ in second Finnish cohort ${ }^{20}$. Mean disease duration in the Mexican graup was 10 years opposed to 3 years in the Finnish cohort. Disease duration in the Slovak group was not provided. Work disability, (reported under various terms) ranged from 3 to $50 \%$. The lower figure came from a Swiss study ${ }^{5}$ dealing with a group of patients belonging to the national society of patients with AS who had an awerage disease duration of 18 years. The Finnish group reported the higher figure of $50 \%$ after 45 years of disease. ${ }^{18}$ Overall, the influence of disease duration on work status remains unclear. Three studies provided data on employment ${ }^{4,15,18}$ or work disability ${ }^{4,18}$ in relation to disease duration. One of these studies showed a clear adverse effect of disease duration on work status ${ }^{18}$, while this effect was only minimal in another study ${ }^{15}$ and absent in a third study." When looking at influence of disease duration on work status across studies, no clear relation could be seen, probably reflecting the differences in patients studied, differences in endpoints used and differences. in the year the studies were conducted. For the five studies reporting on unemployment $5,6,7,13.15$ figures ranged from 0.2 to $18 \%$. 5.6 However, clear definition of unemployment was not provided and in wwo studies ${ }^{6.7}$ this probably does not refer to those having economically an official unemployment benefit, but to those having no paid job, whatever the reason. Excluding these wo studies, unemployment ranged from 0.2 to $9 \%, 5,15$ 
26 Chapter 2

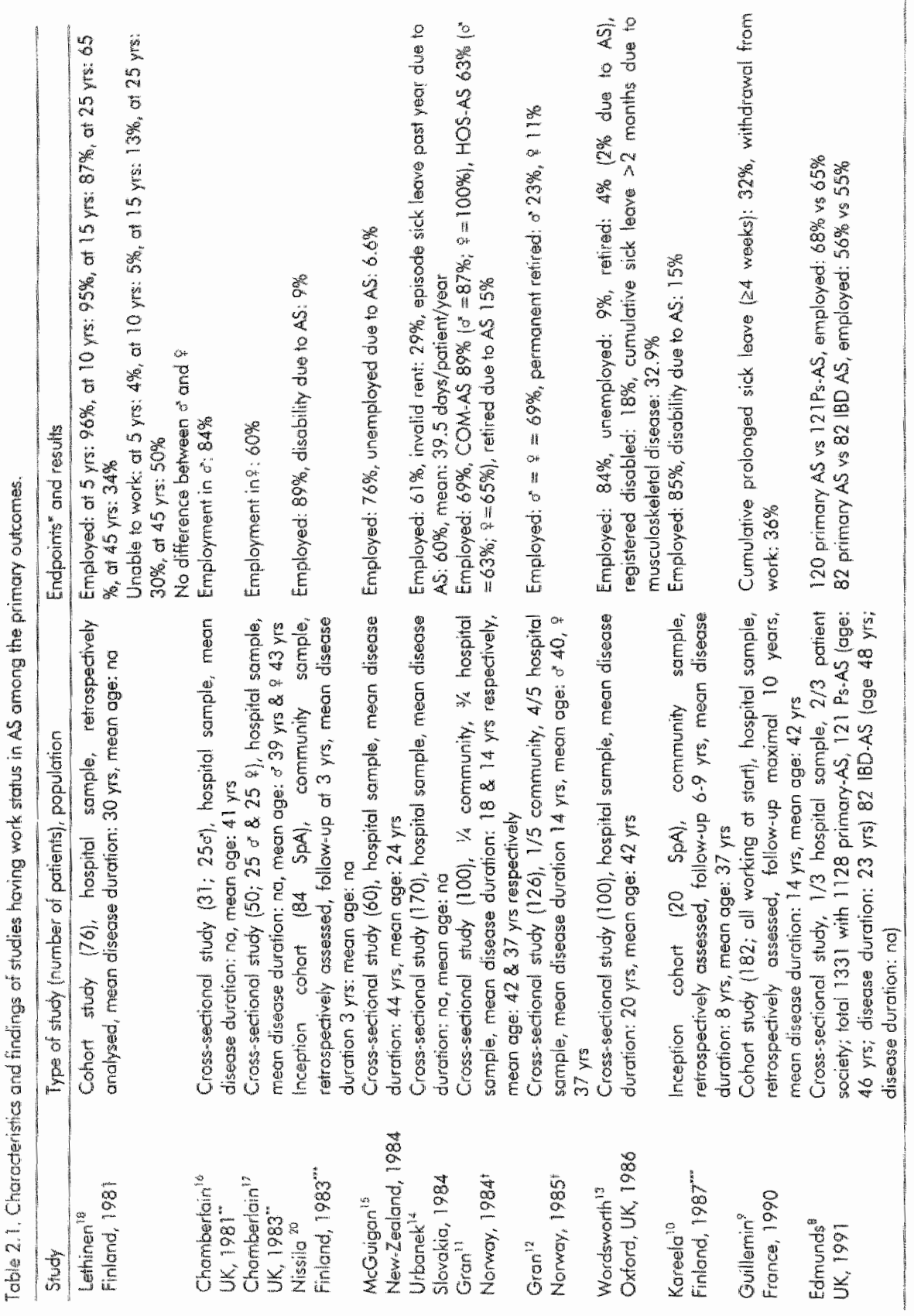




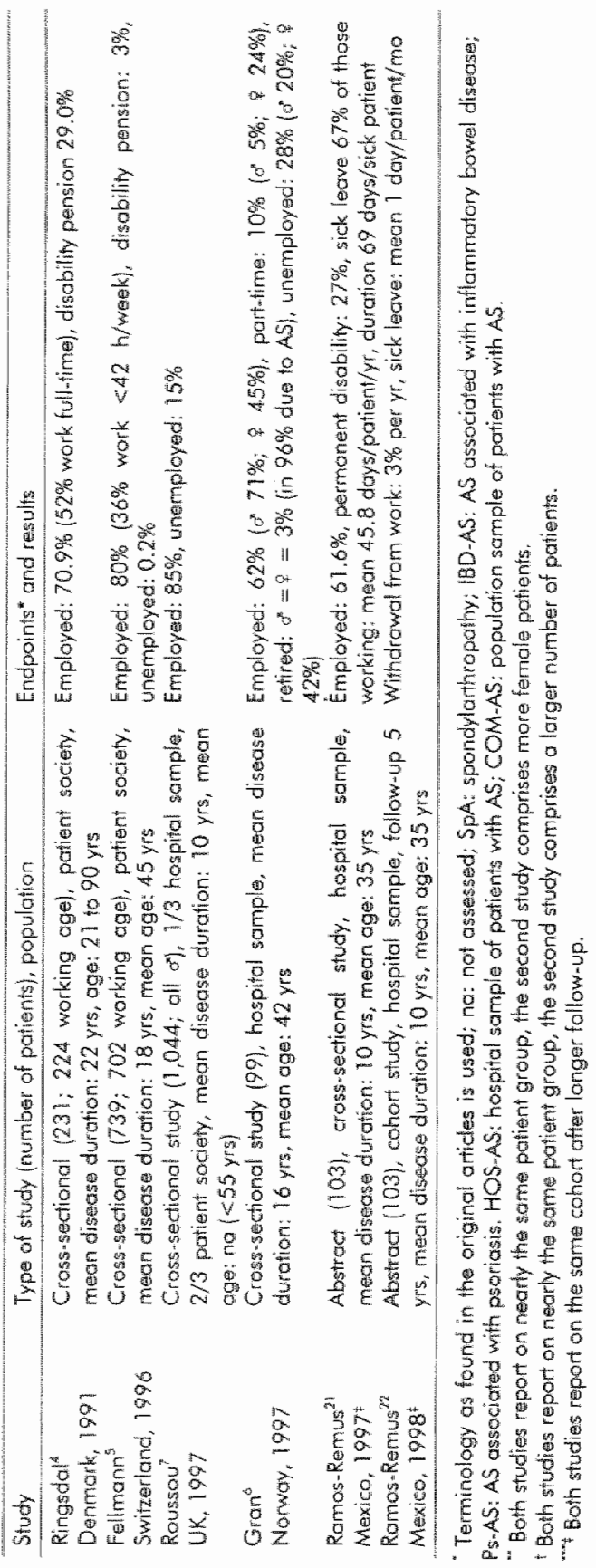


28 Chopter 2

Table 2.2 Crifical appraisal of 18 studies on work status in AS.

\begin{tabular}{|c|c|c|}
\hline Domain & $\begin{array}{l}\text { Reported in sufficien detoll } \\
\text { Numbers indicate references }\end{array}$ & $\begin{array}{l}\text { Reported but insutficiently } \\
\text { Numbers indicate references* }\end{array}$ \\
\hline \multirow[t]{3}{*}{ AS diagnosis ascerfained } & $4-13$ & \\
\hline & 15.17 & \\
\hline & $20-22$ & \\
\hline \multirow[t]{3}{*}{ Calendar year of study } & 4 & \\
\hline & 9 & \\
\hline & 22 & \\
\hline \multirow[t]{5}{*}{ Age range of patients } & 5 & 7 (<55 years $)$ \\
\hline & 4 & 13 lonly working agel \\
\hline & 11 & 20 (only working age) \\
\hline & 14 & \\
\hline & 16 & \\
\hline \multicolumn{3}{|l|}{ Extraspinal manifestations } \\
\hline \multirow[t]{4}{*}{180} & 6 ("IBD excluded") & \\
\hline & 11 ("IBD ecluded") & \\
\hline & $12(" 1 B D$ excluded") & \\
\hline & $13(8 \%)$ & \\
\hline \multirow[t]{6}{*}{ Peripheral arthritis } & $4(40 \%)$ & $5162 \%$ ever pain in \\
\hline & $8(27 \%)$ & peripheral joints) \\
\hline & $9(72 \%)$ & \\
\hline & $12(29 \%)$ & \\
\hline & $14(23 \%)$ & \\
\hline & $20(30 \%)$ & \\
\hline \multicolumn{3}{|l|}{ Endipoint defined } \\
\hline \multirow{3}{*}{ Work disobility } & 9 & \\
\hline & 10 & \\
\hline & $21-22$ & \\
\hline \multicolumn{3}{|l|}{ Endpoint AS specific } \\
\hline \multirow[t]{3}{*}{ Work disability } & $6(96 \%$ due to $A S)$ & 4 \\
\hline & 10 (some due to other diseases) & \\
\hline & 11 (because of AS) & \\
\hline Unemployment & $15(44 \%$ due to $A S)$ & \\
\hline \multirow[t]{2}{*}{ Sick leave } & 14 (due to As) & \\
\hline & 13 (AS or associated disease) & \\
\hline Adiusted for age and gender & None & \\
\hline \multicolumn{2}{|l|}{ Reference data prowided } & \\
\hline Employment & $\begin{array}{l}7(90-93 \%) \\
6(3 \%)\end{array}$ & 144 \\
\hline Unemployment & $\begin{array}{l}6(3 \%) \\
13(8 \%)\end{array}$ & \\
\hline Sick leave & $21(8.8$ days/year) & \\
\hline
\end{tabular}

*References not mentioned did not report on a particular domain. BBD: Inflammatory Bowel Disease.

Several studies compared work status in subgroups of potients with AS. Differences in emplayment between male and female patients were reponted in five studies. In two graups employment was lower among female patients $6,16,17$, but this was not confirmed in three other groups. "1.12.18 Work disability was lower 
in fermale patients in one study' but equal between male and female patients in another one ${ }^{6}$. A Norwegian study ${ }^{12}$ compared employment between patients with AS from a hospital population and patients with AS from the general population.

In the latter group employment was $89 \%$, which was $26 \%$ higher than in the hospital group. A UK study examined differences in employment among patients with primary AS compared with psoriatic AS and with AS associated with inflammatory bowel disease (IBD). No differences in employment rate were noted between primary and psoriatic AS (68\% versus 65\%) nor between primary AS and IBD-AS $(56 \%$ versus $55 \%)$. The $12 \%$ difference in employment between both groups with primary AS might be explained by the fact that each group of patients with primary AS was matched for age and gender to the psoriatic or IBD group respectively. For example, in the group comparing primary and psoriatic AS $78 \%$ were male, opposed to $49 \%$ in the group comparing primary AS and AS associated with IBD.

Sick leave was substantial in all studies ${ }^{9,12,14,21,22}$ ranging from $12^{22}$ to 46 days per working patient per year. ${ }^{21}$ In a French study $32 \%$ of patients had experienced sick leave of more than four weeks duration after 5 years disease?. In a study from the UK $33 \%$ of patients had been on sick leave longer than two months after 20 years of disease. ${ }^{13}$

Table 2.3 presents results of work status across several countries. It is clear that even for studies within the same country results vary importantly. For example, employment ranges from 56 to $86 \%$ amang the 5 UK studies. ${ }^{7,8,13,16,117}$

\section{Determinants of work status}

Nine articles used uni- or multivariate statistical methods to explore determinants of work status. ${ }^{5-7,9,12-14,21}$ Only 2 studies were prospective. ${ }^{9,22}$ Different dependent variables were studied (Table 2.4). We classified independent variables into 4 domains: sociademographic characteristics; disease characteristics; job characteristics and psychological characteristics. Only one study stated which variables were used in the statistical model". In no study variables of each domain were included. Two studies used a multivariate analysis. ${ }^{9,22}$

Table 2.4 summarises determinants of work status for several countries. Overall, employment or work disability were associated with age ${ }^{6,12,21,22}$, education ${ }^{6,14,21}$, job characteristics ${ }^{9}$, physical functioning ${ }^{7.21}$, disease duration ${ }^{21}$, disease activity pain and depression", spinal fusion ${ }^{6}$, acute anterior uveitis ${ }^{6}$, comorbidity $^{6}$, peripheral arthritis ${ }^{6}$, hip replacement ${ }^{6}$, psychosocial functioning ${ }^{6.7}$ and anxiety. An association between gender and work status was seen in one study but not in another ${ }^{12}$. Sick leave and problems at work were associated with education ${ }^{5}$, job characteristics such as carrying heavy loads and exposure to cold", peripheral joint disease ${ }^{9.13}$, hip involvement ${ }^{5}$, psoriasis ${ }^{13}$, disease activity ${ }^{22}$, physical functioning ${ }^{22}$, but not with age ${ }^{13}$ "disease duration ${ }^{13}$, inflammatory bowel disease ${ }^{22}$ and involvement of knee or shoulder joints. ${ }^{.3}$ 
30 Chopter 2

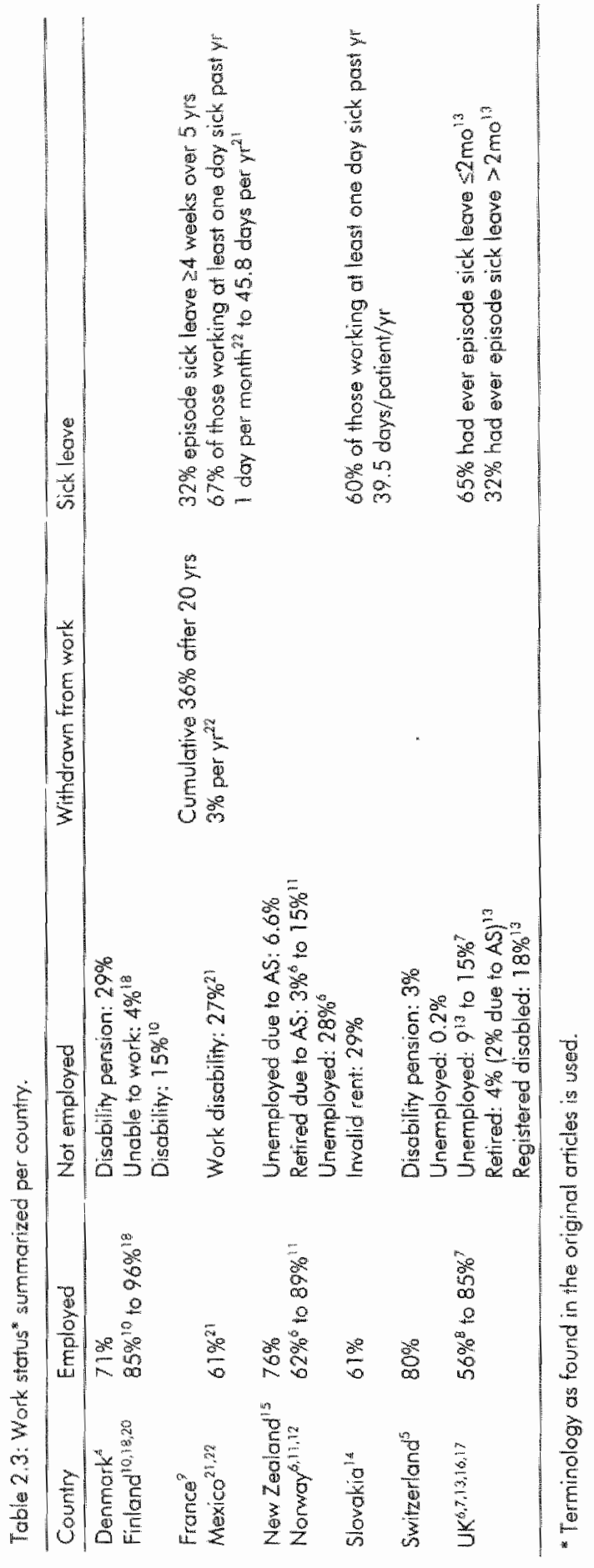




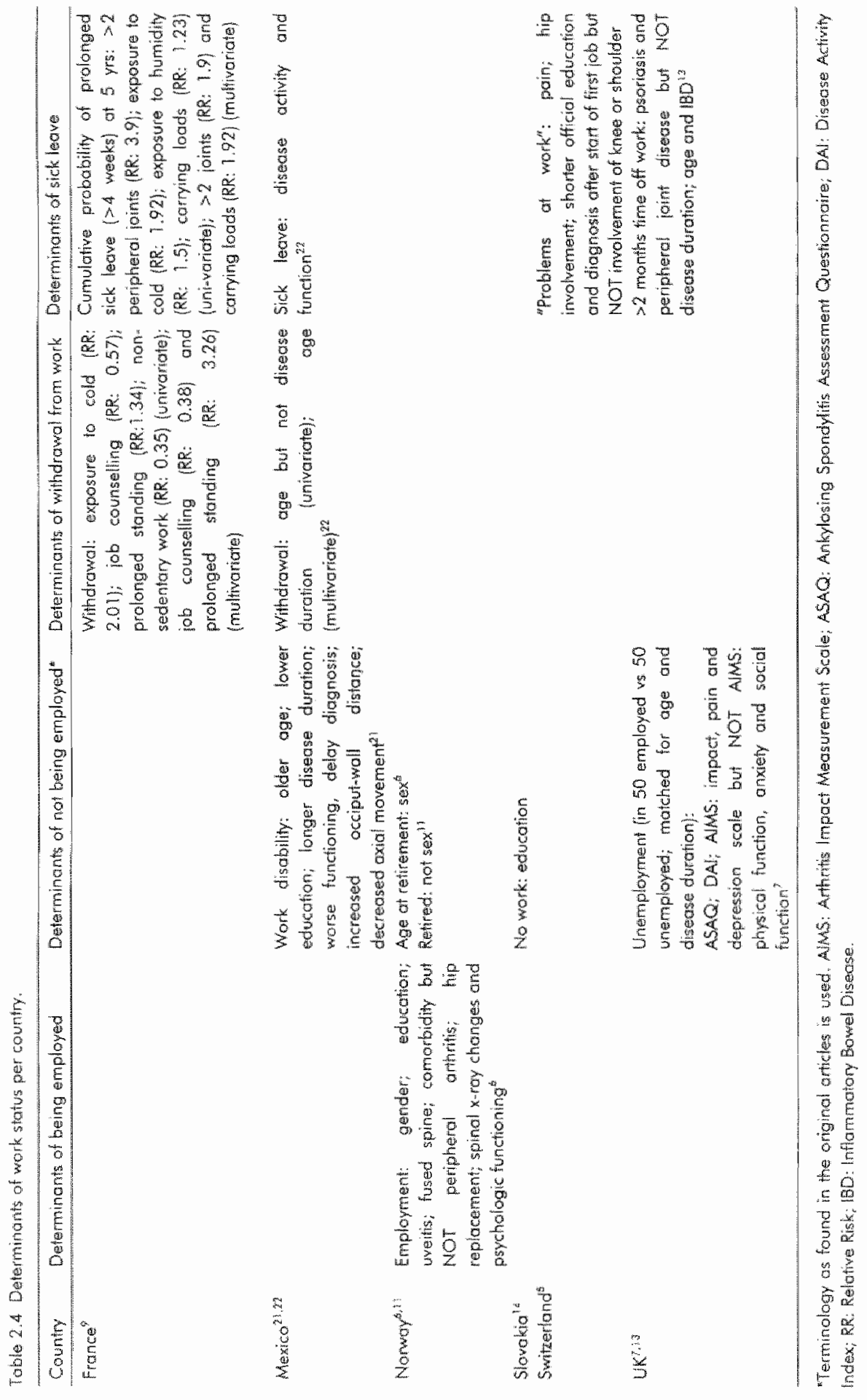




\section{Discussion}

Employment in AS ranged from 34 to $96 \%$ with half of the studies reporting employment below $70 \%, 6,8,1,12,14,17,18,21$ Work disability varied from 3 to $50 \%$ with half of the studies reporting work disability in more than $20 \%$ of patients $^{4,6,12,14,18,21}$ as compared with around $10 \%$ in the general population of most European countries. ${ }^{23}$

The striking variation in employment and work disability can at least partly be attributed to heterogeneity of patient populations, differences in definitions of endpoints related to work status and differences in employment rates among countries. Clear definitions of endpoints in the context of the social security system are essential to assess the possible influence of different systems on work status and to improve generalisability of data on work status over countries. Gender, age, educational level but also disease characteristics such as disease duration, physical function and presence of extraspinal disease might influence work status. Surprisingly these data were aften lacking. The relative contribution of these variables can only be reliably assessed by collecting unbiased data in prospective studies and analysing these data multivariatly. Disease duration, for example, had an effect increasing the risk of work disability in one study providing data for groups of patients with different disease duration ${ }^{16}$, while this could not be seen in two other studies. ${ }^{4.15}$ In a multivariate analysis in which age was included ${ }^{22}$ it was shown that age but not disease duration had an effect on work status. Therefore, it seems that age is a stronger determinant of work status than disease duration. The influence of gender on work status is still conflicting. ${ }^{0.11 .12 .16 .18}$ Since also in the general population work status differs among men and women, possibly the lower employment rate in female patients with AS as reported in some studies ${ }^{6,16.17}$, might reflect such population differences. Clearly, firm conclusions on this subject cannot yet be drawn. Interestingly, neither peripheral arthritis ${ }^{6,8.9}$ nor inflammatory bowel disease $e^{8}$ as comorbidity did increase work disability. Notably, patients from community samples fared better than patients from hospital samples, despite older age and longer disease duration". This has important implications for generalisibility of findings on work status among patients with AS.

Limitations also apply to the interprefation of data on sick leave in those with a paid job. Findings varied from 12 to 46 days per patient per year..$^{21,22}$ It is important to define whether sick leave is assessed AS specific and whether findings apply to those with a paid job or to all patients included in the sample. Contrary to findings for work disability, sick leave was associated with hip involvement and peripheral joint disease ${ }^{5,9,13}$. Possibly, availability of treatment for peripheral arthritis such as more effective drugs and especially hip replacement therapy could be related to sick leave but can prevent permanent work disability.

In the literature, data were not adjusted for age and gender and reference data on work status were usually lacking. Such data of course are often useful to interpret results meaningfully. For example, in a study among 658 Dutch 
potients with AS we showed that employment rate fell from 62,9 10 $54.2 \%$ after adjusting for age and gender. In comparison to the general Dutch population this would mean a reduction of only $2.3 \%$ for unadjusted data but of $11.0 \%$ after adjustment. ${ }^{24}$

Despite limitations in methodology in papers encountered, this review shows that work disability and sick leave in AS are substantial. Reliability of data on wark status in AS would be improved if a large multinational inception cohort was followed for many years, while collecting regularly demographic, socioeconomic and disease variables. As long as such large prospective dafaboses are not yet available, minimal requirements for siudies on work status should be: precise characterisation of the patients included with respect to age, social class, disease duration, presence of comorbidity or extraspinal disease but also clear definitions of work related endpoints (including whether or not assessed disease specific). Data have to be adjusted for age and gender, whereas reference data will be helpful in interpreting the relevance of the findings. 


\section{References}

1. Yelin E, Callahan LF. The economic cost and social and psychological impact of musculoskeletal conditions. National Arthritis Data Work Groups. Arthritis Rheum $1995 ; 38: 1351-1362$.

2. wan der Linden SM, Valkerburg HA, de Jangh BM, Cals A. The risk of developing ankylosing spondylitis in $4 \mathrm{LA} . \mathrm{B} 27$ positive individuals. A comparison of relatiwes of spondylitis patients with the general population. Arthritis Rheum 1984;27:241-249.

3. Dalyan $M$, Guner A, Tuncer $S$, Bilgic A, Arasil T. Disability in ankylosing spondylitis. Disabil Rehabil 1999:21:74-79.

4. Ringsdal VS, Helin P. Ankylosing spondylitisueducation, employment and invalidity. Dan Med Bull 1991,38:282-284.

5. Fellmann $J_{s}$ Kissling $R$, Baumberger $\mathrm{H}$. [Sacia-professional aspects of ankylosing spondyitis in Switzerland]. Z Rheumatol 1996;55:105-113.

6. Gran JT, Skomsvall JF. The oulcome of ankylosing spondylitis: a study of 100 palients. Br J Rheumatol 1997;36:766-77\%.

7. Roussou E, Kennedy LG, Gorrett $\mathrm{S}$, Calin A. Sorioeconomic status in ankylosing spondylitis: relationship between occupation and disease activity. I Rheumatol $1997 ; 24: 908-911$.

8. Edmunds L. Elswood J, Kennedy LG, Calin A. Primary ankylosing spondylitis, psoriatic and enteropathic spondyloarthropathy: a controlled analysis. I Rheumatol $1991 ; 18: 696-698$.

9. Guillemin F, Briancon S, Pourel J, Gaucher A. Long-term disability and prolonged sick leave as outcome measurements in ankylosing spondylitis. Possible predictive factors. Anthritis Rheum 1990,33:1001-1006.

10. Kaarela $K$, Lehtinen $K$, Luukkainen $R$. Work capacity of patients with inflammatory joint diseases. An eight-year follow-up study. Scand J Rheumatol 1987; 6:403-406.

11. Gran JT. Husby G. Ankylosing spondylitis: a comparative sludy of patients in an epidemiological survey, and those admitted to a department of theumatology. I Rheumotol 1984; 11:788-793.

12. Gran JT, Ostensen M, Husby G. A clinical comporison between males and females with ankylosing spondylitis. I Rheumatol 1985; 12:126-129.

13. Wordsworth BP, Mowat AG. A review of 100 patients with ankylosing spondylitis with particular reference to socio-economic effects. Br J Rheumatol 1986;25:175-180.

14. Urbanek T, Sifaiowa H, Hudakova G. Problems of rheumatoid arthritis and ankylosing spondylitis patients in their labor and life environments. Czech Med 1984:7:78-89.

15. McGuigan LE, Han HH, Gow PJ, Kidd BL, Grigor RR, Moore TE. Employment in ankylosing spondylitis. Ann Rheum Dis 1984;43:604-606.

16. Chamberlain MA. Socioeconomic effecis of ankylosing spondylitis. Int Rehabil Med $1981,3: 94.99$.

17. Chamberlain MA. Socioeconomic effects of ankylasing spondylitis in females: a comparison of 25 female with 25 male subjects. Int Rehabil Med 1983,5:149-153. 


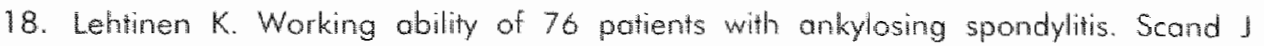
Rheumatol $1981 ; 10: 263-265$.

19. Lehtinen K. 76 patients with ankylosing spondylitis seen after 30 years of disease. Scand J Rheumatol 1983;12:5-11.

20. Nissila $M$. Isomaki $H$, Kaarela $K_{*}$ Kiviniemi P. Martio J, Sama S. Prognasis of inflammatory joint diseases. A three-year follow-up study. Scand I Rheumatol $1983 ; 12: 33-38$.

21. Ramos-Remus C, Macios MA, Suarez Almazor ME, R.E. Prieto RE, Gutierrezurenom S. Labor status and warking-days lost in a consecutive sample of 103 patients with anlylosing spondylitis [AS). Arthritis Rheum [S] 1997:1392.

22. Ramos-Remus C, Prieto-Parra RE, Michel-Diaz J, Gutierrez-Urena S, Suarez-Almazor ME. A five-year cumulative analysis of labor-status and lost working days in patients with ankylosing spondylitis. Arthritis Rheunn 1998(S):1136.

23. Eurostat European official statistics, a guide to databases. Luxembourg: Office for official publications of the European communities; 1997.

24. Boonen $A$, Chorus, $A$, Miedema $H$, van der Helide $D$, van der Tempel $H$, wan der Linden Si. Employment, work disability and work days lost in patients with ankylosing spondylitis: a cross-sectional study of Dutch patients. Ann Rheum Dis $2001 ; 60: 353-358$. 


\section{APPENDIX}

Iterns of data extraction applied on the articles selected after search of the literature.

1. Identification of the study

- Country where the study was done

- Year the study was done

- Year the study was published

- Aim of the study

2. Study design

- Prevalence or incidence based study

- Cross-sectional or cohort

- Inception cohort

- Duration of follow-up

- Prospective or retrospective study design

3. Characteristics of the patient group

- Sample size and response rate

- Community selected or hospital selected group

- Validation of diagnosis

- Proportion of males and females

- Age: mean and range (proportion in working age)

- Educational level (how assessed)

- Professional class (how assessed)

- Disease duration diagnosis (since diagnosis or symptoms)

- Extraspinal and extra-articular disease included (proportions)

- Comorbidity 
4. Endpoints

- Choice of endpoint:

- Employment - Full-fime versus part-time separately

- Men and women separately

- Work disability pension (or related endpoint)

- Full versus partial separately

- Men and women separately

- [Early] retirement (if applicable)

- Men and women separately

- Withdrawal from work [after onset disease]

- Sick leave - Proportion of patients having sick leave

- Work days lost

proportion of work days

number days/pt/yr

duration of sick leave

- Endpoint sufficiently defined

- How was endpoint assessed self-report

(questionnaire/interview) register

- Endpoint disease specific or non-specific

5. Determinants of wark status

- Dependent variable(s)

- Independent variable(s)

sociodemographic characteristics

disease characteristics

job characteristics

psychological well-being

- How was strength of relationship assessed

- Pro- or retrospective data; univariate or multivariate analyses

6. Appropriateness of defining and reporting work related endpoints

- Definition of the endpoints present

- Short description of the social security system

- Endpoint assessed disease-specific or non-specific

- Results presented for patients in working age category

or total age range

- Data adjusted for age and gender

- Data referring to general population or other patient

groups. [Including source of these data]

- Indirect costs calculated. If yes, by which method 

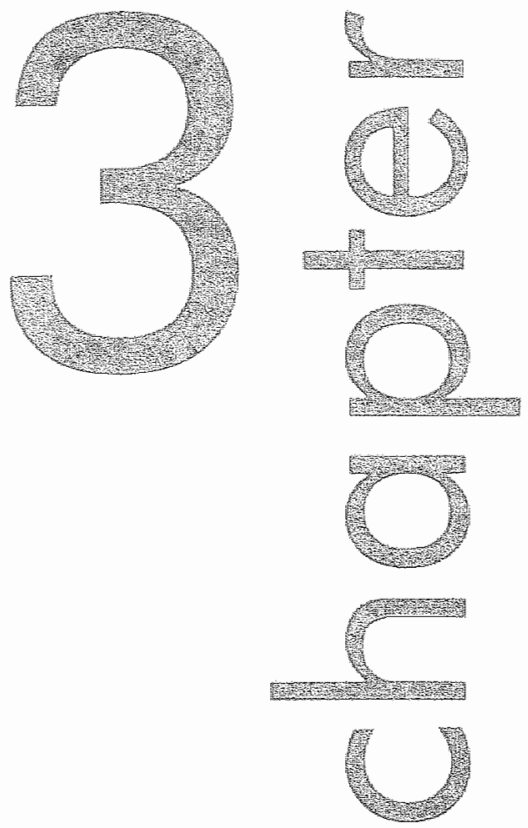

Employment, work disability and work days lost in patients with ankylosing spondylitis A cross-sectional study among Dutch patients

A Boonen, A Chorus, H Miedome,

D van der Heide, H won der Tompal.

Sivon der Linden 


\section{Abstract}

Aim

To evaluate employment, work disobility and wark days los in patients with ankylosing spondyitis (AS).

Methods

A questionnaire wos sent to 709 patients with AS aged 761060 . The results of 658 patients could be analysed.

Results

After adjusting for age, labour force participation was decreased $15.4 \%$ in male and $5.2 \%$ in female patients compared with the general Dutch population. Work disability (all causes) was $15.7 \%$ and $16.9 \%$ higher than expected in the general population for male and temale patients respectively. In particular the proportion of those with a partial work disability was increased. Patients with a paid job lost $5.0 \%$ of warkdays as the result of howing AS, accounting for a mean of 10.1 days of sick leave due to AS per patient per year in addition to the national average of 12.3 disease non-specific days of sick leave.

\section{Conclusion}

This study on work status in AS provides data adjusted for age and gender and the differences with the reference population were significant. The impact of AS on employment and work disability is considerable. Work status in patients with AS needs more attention as an outcome measure in future research. 


\section{Introduction}

In a broader concept of palient outcomes in chronic diseases, psychosocial and economic endpoints need to be considered in addition to traditionally defined outcome measures. Important economic endpoints are health resource utilisation and labour force participation. Labour force participation is important from a societal point of view because it is a major determinant of the economic burden of illness. From the patient's point of view it is also relevan because of its influence on social contacts and self-esteem and therefore on quality of life. It is known that the entire group of musculoskeletall diseases in the US are the leading cause of work disability. ${ }^{2-6}$ The same holds true for the Netherlands, where musculoskeletal diseases and neuro-psychiatric disorders, are the most important causes of sick leave and work disability, each accounting for $29 \%$ of all causes of prolanged sick leave and permanent work disability at the time of the study. About the relative comtribution of different subgroups of musculoskeletal diseases to the total wark disability much less information exists. For rheumatoid arthritis (RA) several studies on labour force participation and its determinants are published. 321 For ankylosing spondylitis (AS), however, few and inconsistent data on labour force participation exist ${ }^{22.36}$ and no data are available for the Netherlands. The prevalence of AS in the Netherlands is estimated to be 0.08 to $0.1 \%$ accounting for about 11,700 patients with $\mathrm{AS}^{37}$ The disease affects men about 3 times as often as women and usually starts in the third decade of life..$^{37}$ AS may lead to important functional limitations not only because of spinal disease but also because of extraspinal disease manifestations such as peripheral arthritis, inflammatory bowel disease (IBD) or uveitis. In this study, we investigated cross-sectionally prevalent employment, work disability and sick leave in patients with AS aged 16 to 60 years who regularly visit a rheumatologist.

\section{Methods}

\section{Patients}

Patients were selected from the nationwide Dutch Standard Diagnosis Register of Rheumatic Diseases (SDR) in which more than $37(66 \%)$ of all Dutch theumatology practices ( $80 \%$ of rheumatologists) participate. ${ }^{38}$ Rheumatologists register all outpatients ance a year. Based on the proportion of rheumatologists participating in the SDR, the number of patients in the SDR with the diagnosis AS and an estimated number of patients with AS in the Netherlands of 11,700, probably 40 to $50 \%$ of the patients with AS are followed by a rheumatologist. A geagraphically representative sample of fifteen practices was invited to participate in this study and all agreed. Two of the eight Dutch academic 
practices were included. The number of practices was chosen in order to obtain a large enough sample of patients. Selected patients had consulted their theumatologist in 1995 or 1996, had to be between 16 and 60 years of age and had to hove the diagnosis AS.

\section{Questionnaire}

In Seplember 1997 patients received a pastal questionnaire on sociodemagraphic, disease related and wark related variables. Sociademographic factors comprised gender, age, race, marital stalus, family situation, education, profession, income and work status. Disease related questions assessed age at diagnosis, comorbidity, medication, extra-articular manifestations of $A S$, the Bath Ankylosing Spondylitis Functional Index (BASFl) measuring functional status ${ }^{39}$, the Bath Ankylosing Spondylitis. Disease Activity Index (BASDAl) measuring disease activity ${ }^{40}$, the Bath Ankylosing Spondylitis Global Assessment (BASG) measuring patient global assessment ${ }^{4 !}$ and the Self Assessment Joint Score. ${ }^{42}$ Questions about career history and on characteristics of the present job were also asked. The job classification system as used by Statistics Netherland (CBS) was used distinguishing agricultural, industrial, transportation, administrative, servicing and specialistic or managerial professions. ${ }^{39}$ For statistical purposes job classification was dichotomised into manual and nonmanual professions. Jobs in agricultural, industrial and thansport sector were considered to be manual jobs. Finally, madule I of the Health and LabourQuestionnaire was included. This questionncire assesses at one point in time the absence from paid work during the past two weeks. Construct validity and feasibility of module 1 of the questionnaire were tested in the general Dutch population and in some chronic diseases. ${ }^{43}$

\section{Definition of endpoints on work status.}

Employment or labour force participation in this study refers to the ability to perform paid production. This study does not address the issue of the ability to perform unpaid production, nor the quality of paid production. Full-time work was defined as working 32 hours per week or more. Work discability was defined as official disability under the Dutch Social Security System. Six categories of work disability exist and work disobility between 80 and $100 \%$ is regarded as full work disability while the other categories are considered as partial work disability. The reported wark discability is from "all causes" and not exclusively attributable to AS. Unemployment is defined as receiving an official unemployment benefit. Sick leave for those with a paid job was assessed by the Health and Labour Questionncire at one point in time and was defined as at leasi half a day absence from paid work due to AS.

\section{Description of the social security system in the Netherlands}

The Dutch Socia! Security Benefit Program applies to all individuals below 65 years who hove an employment. In the Netherlands, as in many other European 
countries, but in contrast to the situation in the US, a distinction is to be mode between sick leave (work incapacity having an employment contract) and work disability (employment contract stops). The Dutch Social Security Benefit program is executed by the employer in callaboration with Occupational Health and Safety Organizations for the first 52 weeks of sick leave and by public Social Security Associations for the work disability. For the entire first year of sick leave the employer is responsible for the provision of the sickness benefit, which may vary between $70 \%$ and $100 \%$ of the former gross wage. In order to claim a sickness benefit, medical certification is not required. After three months of continuous sick leave, the Occupational Health and Safety Organization of the employer is legally obliged to evaluate if a rehabilitation program is possible. Part-time work can be part of the rehabilitation plan.

After one year of continuous sick leave, the Social Security Assaciation must decide on eligibility for permanent work disability, which can be full or partial, and ranges from 0 to $100 \%$. In august 1993 the eligibility criteria changed. Work disability is allowed if the patient has objective medical restrictions in performing any type of work, independent of age and profession. In case percentage of the disability exceeds $15 \%$ a benefit will be allowed ranging from 25 to $70 \%$ of the former gross wage. Benelits are financed through social contributions from employees and employers. Persons who do not have an income through employment or from the Social Security System may receive a Social Benefit Allowance.

\section{Comparison with the general Dutch population}

Data on sociodemographic characteristics, labour force participation and unemployment of the Dutch population were retrieved from CBS. Data on work disability in the Dutch population are retriewed from the National Organization of Social Security Associations. (LISW). "Since in our sludy the upper age limit for inclusion was set at 60 years, while in the general population working age officially continues until 65 years, we recalculated the CBS and LISV data for ages up to 60 . Data on sick leave in the study population are compored with the results of a cross-sectional study with the same instrument in the general Dutch population. ${ }^{* 3}$ Reference data for the Dutch population were from 1997 for labour force participation and work disability and from 1996 for data on sick lecre.

\section{Statistical method}

We aimed to demanstrate a difference in employment of at least $10 \%$ and in work disability of at least $5 \%$ in comparison to the Dutch population. By using formulae for comparison of proportions", the required sample size was 247 and 338 patients for employment and work disability respedively. With an assumed response rate of at least $50 \%$ in questionnaires we decided to invite 1000 patients with AS. Data were analysed using SPSS 8.0 or Excel soltware. Proportions were calculated for fully completed questions. Job classification was adjusted for age and gender. The data on employment and disability were 
adiusted by indirect standardisation and presented as adjusted ratios and as adjusted rates. ${ }^{25}$ for the adiusted rotios the $95 \%$ confidence intervals were calculated.

\section{Results}

\section{Response rate}

Of the 1,092 patients, the correct address of 152 could not be retrieved. Of the 940 remaining patients 709 agreed to participate and received the avestionnaire, which was completed by 658 patients. This accounts for a total response rate of $70.0 \%$. Panticipants did not differ in age and gender from non. participants. Mean age was 43.5 years and 42.3 years and proportions of male patients $70 \%$ and $69 \%$ in participants and non-participants respectively.

\section{Description of the potient population}

The sociodemographic and disease characteristics of the study group are shown in Table 3.1. In a subgroup of patients ( $n=137$ ) belonging to two of the participating centres, the diagnosis AS as stated in the SDR was confirmed according to the radiologic New York criteria for sacroilitis by an independent reader in $99.3 \%$ of these patients. The gender ratio of the study population compares well with other existing data ${ }^{4 ?}$. The prevalence of inflammatory bowel disease and peripheral arthritis is more difficult to compare with the literature because different definitions are used and different populations studied. Our results fall within the reported figures. ${ }^{25,26,47.49}$ Based upon the Statistics Netherlands job classification, the age adjusted propartion of patients with AS having a manual job was higher than in the general Dutch population.

\section{Work status}

Altogether $4.1 \%$ of the patients $(3.0 \%$ of male and $6.6 \%$ of female patients) never had a jab. The unemployment rate was $4.4 \%$, both in male and fernale patients and $2.5 \%$ received a social benefit allowance $12.8 \%$ in male and $2.5 \%$ in temale patients). In the Dutch population the unemployment rate for those in warking age was $4.1 \%(3.8 \%$ in male and $5.2 \%$ in fernale patients) and $5.4 \%$ received of social benefit allowance at the time of the study. In Table 3.2 employment and full employment are presented as proportions of the total group per age and gender category together with the reference data for the Dutch population. In Table 3.3 these figures are shown for work disability and full work disability. Both tables also provide the adjusted ratios with the $95 \%$ confidence intervals and the adjusted rates for patients with AS. Clearly employment is decreased in both male and female patients but only statistically significant in male patients. Fult-time employment is more decreased in men while in female patients with AS the decrease in employment has to be attributed to a decrease in partime employment. In both genders significantincrease in 
work disability rates was observed. This increase was more pronounced for partial than for full work disability.

Table 3.1. Patient characteristics for the total group and by gender compared with the Dutch population.

\begin{tabular}{|c|c|c|c|c|}
\hline Potident characteristics & $\begin{array}{l}\text { Dutch Population } \\
\qquad \begin{array}{l}15-60 \text { yrs }\end{array}\end{array}$ & $\begin{array}{c}\text { Total Group } \\
n=658\end{array}$ & $\begin{array}{c}\text { Men } \\
n=461\end{array}$ & $\begin{array}{l}\text { Women } \\
n=197\end{array}$ \\
\hline Male: \% & 50.9 & 70.0 & & \\
\hline Age: years; mean (SD), [rangel & - & $\begin{array}{l}43.5(9.4) \\
{[18-60]}\end{array}$ & $\begin{array}{c}44.0(9.3) \\
{[18-60]}\end{array}$ & $\begin{array}{c}42.5(9.4] \\
{[19-60)}\end{array}$ \\
\hline Disease duration: years; mean (SD) & - & $12.2(8.0)$ & $12.4(8.4)$ & $10.0(7.5)$ \\
\hline Living with o partner; $\%$ & 79.8 & 83.1 & 81.8 & 86.3 \\
\hline Peripheral orthritis" "\% & - & 25.8 & 34.0 & 22.2 \\
\hline Total hip replacements; $\%$ & - & 3.6 & 2.8 & 5.6 \\
\hline$\| B D \%$ & - & 4.3 & 5.2 & 3.5 \\
\hline $\mathrm{BASF}$; mean $\{\mathrm{SD}\}$ & - & $3.4(2.5)$ & $3.5(2.5)$ & $3.9(2.4)$ \\
\hline BASDAl; mean (SD) & - & $3.9(2.4)$ & $3.7(2.4)$ & $4.4(2.4)$ \\
\hline BASG; mean (SD) & - & $4.1(2.6)$ & $4.0(2.6)$ & $4.3(2.6)$ \\
\hline$>12$ years formal education; \% & 25.5 & 19.3 & 22.6 & $\pi i .8$ \\
\hline Marvual workers $\%$ & 18.2 & 22.4 & 35.6 & 9.3 \\
\hline
\end{tabular}

" of least one joint on the Self Assessment Joint Score (swollen joints); "adive inflammatory bowel disease (BD) last three months for which drug therapy was needed; BASFI: Bath AS Functional Index; ronge 0-10, higher values indicate worse function); BASDA: Bath AS Disease Activity Index; range 0. 10, higher values indicate higher disease activity; BASG: Bath AS Globol Assessment; range 0.10, higher values indicate worse global assessment.

Work days lost

Module 1 of the Health and Labour Questionnaire was completed by 389 $(92.5 \%)$ patients with a paid job. Five questionnaires were not interpretable resulting in a total of $385(90.9 \%)$ questionnaires that could be analysed. Twenty-five $(6.5 \%)$ patients $(5.2 \%$ of male and $11.4 \%$ of femole patients) reported sick leave during the past two weeks. Of all the work days, $5.0 \%(4.1 \%$ in male and $9.1 \%$ in female patients) were lost due to sick leave because of AS. Extrapolating these data to days of sick leave per patient results in $10.1 / 8.8$ days in male and 15.3 days in female patients) days of sick leave due to AS per year. For the general Dutch population the mean number of non-specific days of sick leave per person per year is 12.3 (12.2 days for male and 14.1 days for female patients). In the Netherlands, employees with continuous sick leave for more than three months, are likely to be waiting for their disability assessment, but are still officially registered as employees. Eliminating these patients ( 3 men and 4 womenl from the analysis, $4.3 \%$ of men and $6.7 \%$ of women reported an episode of sick leave and $3.3 \%$ of possible workdays were lost due to AS. 

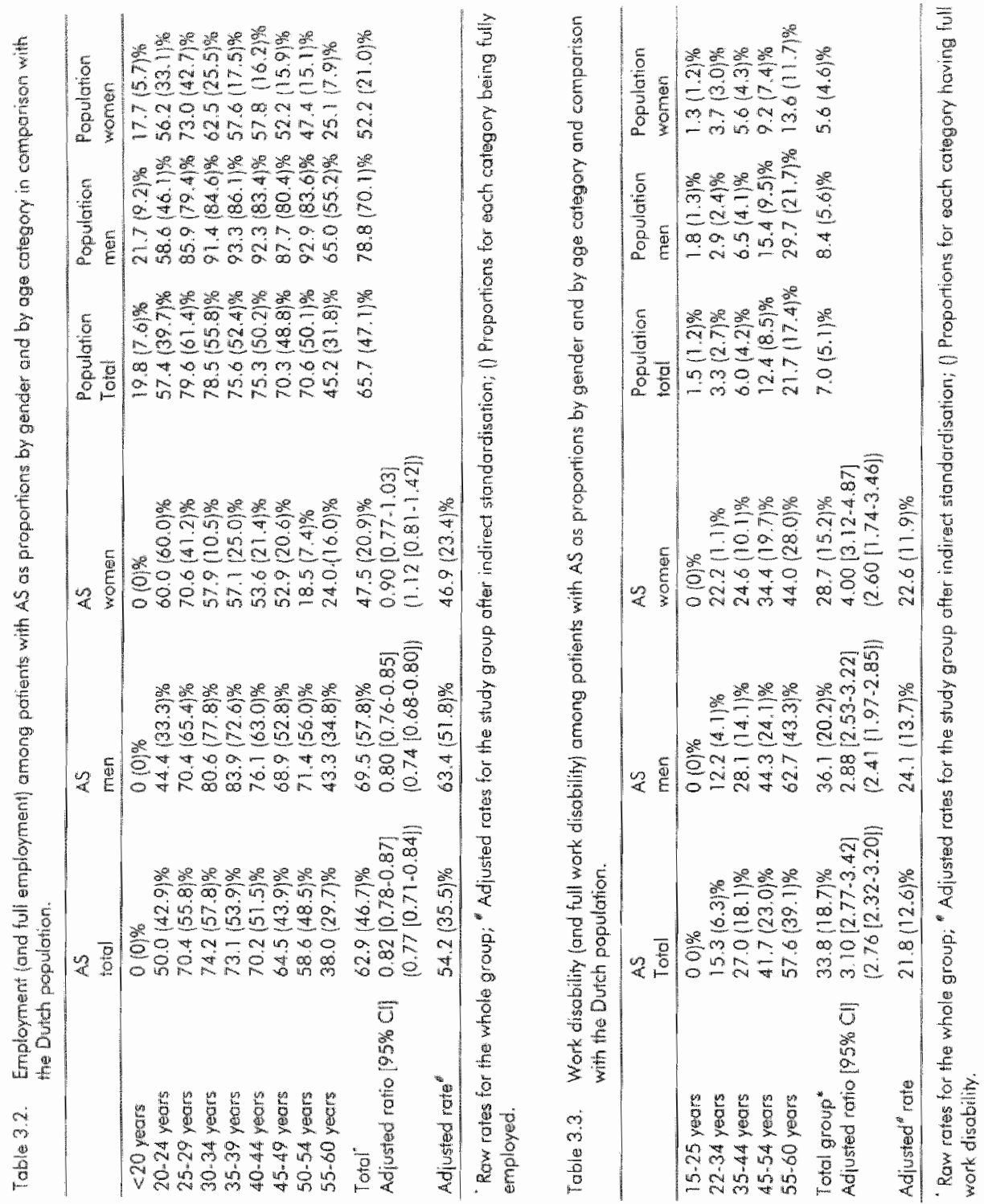
Extrapolating these data to the number of days of sick leave would result in 6.5 extra days of sick leave per patient per year $(6.9$ for male and 5.7 for female patients).

Table 3.4. Employment and work disability as raw rates, adjusted rates after indirect standardisation for age (and gender) and as the difference in percent between the patients and the Dutch population.

\begin{tabular}{|c|c|c|c|c|c|c|}
\hline & Total & Difference: & Men & Difference & Women & Difference \\
\hline \multicolumn{7}{|l|}{ Employment } \\
\hline Population & $65.2 \%$ & & $78.8 \%$ & & $52.2 \%$ & \\
\hline AS: now dato & $62.9 \%$ & $-2.3 \%$ & $69.5 \%$ & $.9 .3 \%$ & $47.5 \%$ & $-4.7 \%$ \\
\hline AS; indirect standardisation & $54.2 \%$ & $-11.0 \%$ & $63.4 \%$ & $-75.4 \%$ & $46.9 \%$ & $.5 .2 \%$ \\
\hline \multicolumn{7}{|l|}{ Work disobility } \\
\hline Population & $7.0 \%$ & & $8.4 \%$ & & $5.6 \%$ & \\
\hline AS; raw data & $33.8 \%$ & $+26.8 \%$ & $36.1 \%$ & $+27.7 \%$ & $28.7 \%$ & $+23.1 \%$ \\
\hline AS; indirect standardisation & $21.8 \%$ & $1.4 .8 \%$ & $24.7 \%$ & $+15.7 \%$ & $22.6 \%$ & $+16.9 \%$ \\
\hline
\end{tabular}

Difference in percent between patients and the population.

\section{Discussion}

Among Dutch patients with AS labour force participation is reduced, work disability increased and extra sick leave substantial. We feel that $11 \%$ decrease in employment and $15 \%$ increase in wark disability are relevant from the clinical and societal point of view. The reduction in labour force participation is more pronounced in males than in females. Sick leave in those with a paid jab, however, is more substantial in female patients.

Our findings on employment and work disability were obtained after adjusting for age and gender, which seemingly has not been done in other studies. In Table 3.4 we compare the raw and adjusted rates of labour force participation and work disability and present the difference for each method with the general population. Clearly, total labour force participation fell from $62.9 \%$ to $54.2 \%$ after adjusting for age and gender.

Data from the literature on work status in AS are conflicting. Figures on labour force participation vary from $34 \%$ to $96 \% 22,26,23,31,34,34,36,50$ and for work disability from $3 \%$ to $36 \%, 22.25 .29,31,32,34,35,51$ The literature, however, is difficult to interpret. Disease characteristics are not always pravided and sample sizes are usually small. Moreover, data were never adjusted for age and gender and clear reference data on employment for the general population were only provided in one study. ${ }^{50}$

We might have introduced bias to some degree by examining parients with AS under specialised outpatient care of a theumatologist. This is supported by the literature, where employment of patients with AS from a hospital setting ${ }^{26} 35$ is in general lower than in populations obtained from patient societies or from 
community studies. ${ }^{2829,50}$ Also a study from Norway which compares work status and disease severity between hospital and community patients with $\mathrm{AS}^{24}$ showed that hospital patients with AS had lower employment and more severe disease. It should also be nated that, in comparison to the Dutch population, our patients had more often manual professions and an average lower social class based on educational level and job-classification. Since it has been shown that withdrawal from work in AS is associated with jobs characterised by prolonged standing" this might hove influenced our results. We do not know whether the overrepresentation of manual workers in our group is a true reflection of Dutch patients with AS or due to sampling. Usually, those who do not respond to questionnaire studies have on average lower educational level and more manual jobs. ${ }^{5250}$ Applying this to our findings would argue for underrepresentation of manual workers and therefore underestimate the impact of AS on work status. Alternatively, it is also possible that the usual underrepresentation of llower social class did not occur in our sample, which would result in overestimation of the impact of AS on work status.

It should be noted that reported work disability in this sudy is for all causes and not solely attributable to AS. Most studies in the literature did not mention if they recorded work disability disease specific, which contributes to the difficulties in comparing different studies. The Dutch social security system allows a combined (partial) disability pension and (part-time) job. Seemingly patients with AS in the Netherlands rather frequently receive a partial work disability. In female patients this was not associated with a corresponding increase in part-time jobs.

Although the number of AS related days of sick leave for those with a paid job is substantial, our data seem more favorable than in other studies. We report 8.8 and 15.3 days sick leave per patient per year for male and female patients respectively, in addition to the non-specific absence of 12 days per year for men and 14 days per year women reported from the general population. ${ }^{3}$ However, a Slovak study ${ }^{35}$ reports even 39.5 days of disease specific sick leave per patient per year and a Mexican study 45.8 days per year (for all causes) in the crosssectional part of the study $y^{22}$ but only 1 day per patient per month in the prospective study. ${ }^{23}$ Some remarks need to be made. First, there is no plausible reason to believe that AS attributable sick leave has a seasonal variation. The questionnaire was sent in the month of September. Ongoing studies in our group on weekly variation in disease activity or on sick leave in another cohort didn't show any seasonal influence (unpublished data). Therefore we think the results of the Health and Labour Questionnaire can reliably be extrapolated to one year. Second, it is known that sick leave varies with age and is influenced by professionat class. Since the number of patients having sick leave in the study group was quite small and since the Health and Labour Questionnaire has no reference data for sick leave by age or profession, we could not adjust for these variables. Because our study population is somewhat older and has an overrepresentation of manual professions, sick leave might be somewhat overestimated. Finally, we instructed patients to answer the question on sick leave disease specific. However, one might question if patients can really distinguish between illness due to AS or to other causes. Moreover, it has not 
been studied whether patients with a chronic disease have the same disease non-specific sick leave as persons without chronic disease. Although we are somewhat reluctant to accept relative proportions of disease specific and nonspecific sick leave as presented here, it is clear that absence from work in patients with AS is increased. For comparison, disease specific sick leave in migraine is four days per year for women and one day for men. ${ }^{43}$

In contrast to AS, work status in RA has received considerable attention over the past two decades. Various studies reported a reduction of the labour force participation of 40 to $50 \%$ after disease duration up to 10 years. ${ }^{13,13,17,19,21,57}$ Also in The Netherlands labour force participation in RA was reduced after a mean disease duration of 12 years in comparison to the general population." However, figures on work status in RA and AS are difficult to compare. There are major differences in age and gender between the two types of patients and published results are not adjusted for age and gender.

In the past work status in AS has received insufficient attention. Our study shows that the impact on this outcome measure is considerable, at least in those patients who are treated by rheumatologists. It is important to assess differences with reference populations. Clearly, prospective studies on wark status need to be done as well as research into factors influencing this endpoint. 


\section{References}

1. Warr P. Work, unemploymemt and mental heaith. Oxtord: Clarendon Press; 1987.

2. Kramer 1S, Yein EH, Epstein WV. Social and economic impacts of tour musculaskeletal conditions. A study using national community-based data. Anthritis Rheum 1903:26:901-907.

3. Fells W, Yelin E. The economic impad of the rheumatic diseases in the United States. J Rheumato $7989 ;, 6: 867-884$.

4. Yelin EH. Henke Cl, Epstein W. Work disability among persons with musculoskeletal conditions. Arthritis Rheum 1986;29:1322-1333.

5. Yelin E, Callahan LF. The economic cost and sacial and psycholagical impact of musculoskeletal conditions. National Arthritis Data Work Groups [see comments]. Arthrits Rheum 1995:38:1351-1362.

6. Velin $E$. The costs of rheumatoid arthritis: absolute, incremental, and marginal estimates. J Rheumatol Suppl 1996,44:47.51.

7. Statistisch Jaarboek 1998. Voorburg/Heerlen: Centrad Bureau voor Statistiek; 1998.

8. Yelin $E$, Meenan $R$, Nevilt M, Epstein W. Work disability in meumatoid arthitis: effects of disease, social, and work foctors. Ann Intern Med 1980:93:551-556.

9. Reisine ST, Grady KE, Goodenow C, Fifield J. Work disability among wamen with theumatoid arthritis. The relative importance of disease, sacial, work, and family factors. Arthritis Rheum 1989:32:538-543.

10. Pincus $T$, Callohan LF, Sale WG, Brooks AL, Powne LE, Voughn WK. Severe functional declines, work disability, and increased moriality in seventy-five rheumatoid arthrits patients studied over nine year's. Arthritis Rheum 1984;27:864. 872 .

11. Reisine S, MCQuillan 1. Fifield J. Predictors of work disability in theumaioid arthritis patients. A five-year followup. Arthritis Rheum 1995;38:1630-1637.

12. Reisine $S$, Fifield J. Fomily work demands, employment demands and depressive symptoms in women with rheumatoid arthritis. Women Health 1995:22:25-45.

13. Callahan LF, Bloch DA, Pincus T. Identification of work disability in rheumatoid anthritis: physical, adiographic and laboratory variables do not add explanatory pawer to demographic and functional variables. J Clin Epidemiol 1992;45:127-138

14. Fifield J, Reisine ST, Grady K. Work disability and the experience of pain and depression in rheumatoid arthritis. Soc Sci Med 1991:33:579-585.

15. Pincus T. Longwerm autcomes in theumatoid arthritis. Br J Rheumatol 1995,34 $152]: 59-73$

16. Pincus T. The underestimated long term medical and economic consequences of theumatoid arthritis. Drugs 1995;50 (S) I): $1-14$.

17. Doeglas D, Suumeijer T, Krol B, Sanderman R, van Leeuwen M, van Rijswilk M. Work disability in early theumatoid arthritis. Ann Rheum Dis 1995,54:455-460.

18. Chorus AMJ, Miedema HS, Wevers CWJ, Linden vd S. Labour force participation among theumatoid arthrits patients. Amn Rheum Dis 2000. 
19. Wolfe F. Hawley DJ. The longlem outcomes of theumatoid arthritis: Work disability: a prospective 18 year study of 823 patients. IRheumatol 1998;25:2108-2117.

20. Sokka T, Kautiainen H, Mottonen T. Hannonen P. Wark disability in rheumatoid arthritis 10 years after the diagnosis. I Rheumatol 1999;26:1681-1685.

21. Makisara GL, Makisara P. Prognosis of functional capacity and wark capacity in rheumatoid arthritis. Clin Rheumatol 1982;1:117-125.

22. Ramos-Remus C, Macias MA, Suarez-Almazor ME, R.E. Prieto RE, Gutierrez-urenam S. Labor status and working-days lost in a consecutive sample of 103 polients with anlylosing spondylitis (AS). Anthritis Rheum [S] $1997: 1392$.

23. Ramos-Remus C, Prieto-Parra RE, Michel-Diaz J, Gutierrez-Urena S, Suarez-Almazor ME. A five-year cumulative analysis of labor-status and lost working days in patients with ankylosing spondylitis (AS). Anthritis Rheumat [S] 1998:1136.

24. Gran IT, Husby G. Ankylasing spondylitis: a comparative study of patients in an epidemiological sumey, and those admitted to a department of rheumatology. I Rheumatol 1984; 11:788-793.

25. Gran JT, Ostensen $M$, Husby $G$. A clinical comparison between males and females: with ankylosing spondylitis. J Rheumatol 1985;12:126-129.

26. Gran IT, Skomsvall JF. The outcome of ankylosing spondylitis: a study of 100 patients. Br J Rheumatol 1997;36:766-771.

27. Guillemin F, Briancon S, Pourel J, Gaucher A. Long-term disability and prolonged sick leaves as outcome measurements in ankylasing spondylitis. Possible predictive factors. Anthritis Rheum 1990;33:1001-1006.

28. Fellmann J, Kissling $R$, Baumberger $H$. [Sociomprofessional aspects of ankylosing spondylitis in Switzerland]. Z Rheumatol 1996,55:105-11 13.

29. Ringsdal VS, Helin P. Ankylosing spondylitis--education, employmentt and invalidity. Dan Med Bull 1991;38:282-284.

30. Edmunds L, Elswood J, Kennedy LG, Calin A. Primary ankylosing spondylitis, psoriatic and enteropathic spondyloarthropathy: a controlled analysis. I Rheumalol $1991 ; 18: 696-698$.

31. Kaarela K, Lehtinen K, Luukkainen R. Wark capacity of patients with inflammalory joint diseases. An eight-year follow-up study. Scand IRheumatol 1987; 6:403-406.

32. Lehtinen $K$. Working ability of 76 potients with ankylosing spondylitis. Scand $J$ Rheumatol 1981; 10:263-265.

33. MoGuigan LE, Hart HH, Gow PJ, Kidd BL, Grigor RR, Moore TE. Employment in ankylosing spondylitis. Ann Rheum Dis 1984;43:604-606.

34. Wordswonth BP, Mowat AG. A review of 100 patients with ankylosing spondylitis wilh poricular reference to socio-economic effects. Br J Rheumatol 1986;25:175-180.

35. Urbanek T, Silajova H. Hudakova G. Problems of rheumatoid arthritis and ankylosing spondylitis patients in their labor and lite emviromments. Czech Med I. $98,7: 78-89$.

36. Chamberlain Ma. Socioeconomic effects of ankylosing spondylitis in females: a comparison of 25 female with 25 male subjects. Int Rehabil Med 1983,5:149-153.

37 van der Linden SM, Volkenburg HA, de Jongh BM. Cats A. The risk of developing ankylosing spondylitis in HLA.B27 positive individuals. A comprarison of relatives of spondylitis potients with the general population. Arthritis Rheum 1984;27:241-249. 
38. Miedema HS, van der Linden SM, Rasker JJ, Valkenburg HA. National database of patients visiting theumatologists in the Netherlands: The standard diagnosis register of rheumatic diseases. A report and preliminary analysis. Br \& Rheumalol 1998,37:555-56́1.

39. Calin A, Garret $S$, Whitelock $H$, Kennedy LG, OHea 1, Mallorie P, et al. A new approach to defining functional ability in ankylosing spondylitis: the development of the Bath Ankylosing Spondylitis Functional Index. J Rheumatal 1994;21:2281-2285.

40. Garretf $S$, Jenkinson T, Kennedy $1 G$, Whitelack $H$, Gaisford $P$, Calin A. A new approach to defining disease status in onkylosing spondylitis: the Bath Ankylosing Spondylitis Disecse Activity Index. J Rheumatol 1994;21:2286-2291.

41. Jones SD, Steiner A, Garrett SL, Calin A. The Bath Ankylosing Spondylitis Patient Global Score (BAS-G). Br J Rheumalol 1996;35:66-71.

42. Stucki G, Stucki S, Bruhlmann P, Maus S, Michel BA. Comparison of the validity and reliability of self-reported articular indices. Br $\mathbb{R}$ Rheumatol 1995;34:760-766.

43. van Roijen L. Essink Bot ML, Koopmanschap MA, Bonsell G, Rutten FF. Labor and health status in economic evaluation of health care. The Health and Labor Questionnaire. Int I Technol Assess Health Care 1996;12:405.415.

44. Kroniek van de saciale werzekeringen. Zoetermeer; 1997.

45. Kirkwood RB. Essentials of Medical Statistics. Oxford: Blackwel Scientific Publications: 1988.

46. Dale K. Radiographic gradings of socrailitis in Bechterew's syndrome and allied disorders. Scand J Rheumatology 1979,32 (S):92-97.

47. Will R, Edmunds L, Elswood J, Calin A. Is there sexual inequality in ankylosing spondylitis? A study of 498 women and 1202 men. J Rheumatol 1990;17:16491652.

48. Marks SH, Barnett M, Calin A. Ankylosing spondylitis in women and men: a casecontral study. J Rheumatol 1983;10:624-628.

49. Dekker Saeys AJ, Keat AC. Fallow-up study of ankylosing spondylitis over a periad of 12 years (1977-1989). Scand J Rheumatol Suppl 1990;87:120-121.

50. Roussou E, Kennedy LG, Garrett S, Calin A. Socioeconomic status in onkwasng spondylitis: relationship between occupation and disease activity. I Rheumatol $1997: 24: 908-911$.

51. Nissila $M$, Isomaki $H$, Kaarela K, Kiviniemi $P$, Martio 1, Sarna S. Prognosis of inflammatory joint diseases. A three-year follow-up study. Scand $I$ Rheumatol $198 ; ; 12: 33-38$

52. Criqui $M H$, Barrett Connor $E$, Austin M. Differences between respondents and nonrespondents in a population-based cardiovascular disease study. Am I Epidemial $1978 ; 108: 367-372$.

53. Gorkin L, Schron EB, Handshaw K, Shea S, Kinney MR, Branyon $M$, el al. Clinical trial enrollers ws. nonenrollers: the Cordiac Aprhythnia Suppression Triall (CAST) Recruiment and Enrollment Assessment in Clinical Trials (REACT) project. Control Clin Trials 1996;17:46-59.

54. Harlan WR, 3rd, Sandler SA, Lee KL, Lam LC, Mark DQ. Importance of baseline functional and socioeconomic factors for participation in cardiac rehabilitation. Am J Cardial 1995:76:30-39. 
55. Pietila AM, Rantakallia P, Laara E. Background factors predicting non-response in a health survey of nothern Finnish young men. Scand J Soc Med 1995;23:129.136.

56. Smith $P$, Arnesen $H$. Non-respondents in a post-myocardial infarction trial: characteristics and reasons for refusal. Acta Med Scand 1988;223:537-542.

57. Mau W, Bommann M, Weber H, Weidemann HF, Hecker H, Rospe HH. Prediction of permanent work disability in a follow-up study of early theumatoid arthritis: results of a tree structured analysis using RECPAM. Br I Rheumatol 1996, 35 : $652-659$. 

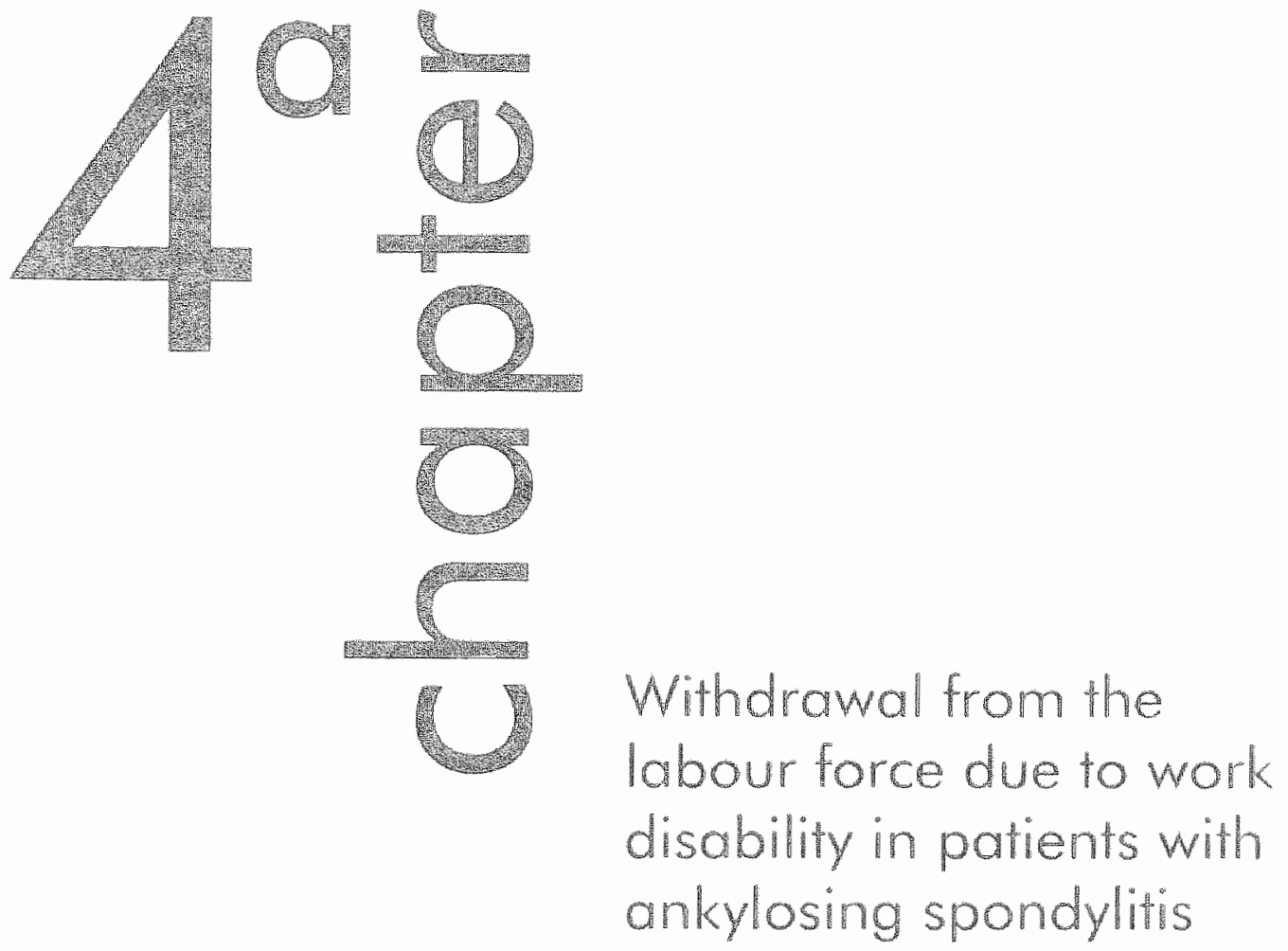

A Boonen, A Chons, H Midena,

D von der Helde, R Londewe, H Schoulat, H van der Tempel, Si van der Linden 


\section{Abstract}

\section{Aim}

To describe withdrawal from the labour force because of work disability due to ankylosing spondylitis (AS) and to determine characteristics of patients having no job because of AS atributable work disability.

\section{Methods}

A postal questionnaire was sent to 709 patients with AS aged 16 to 60 years and followed by a rheumatologist. Kaplan-Meier survival stafistics were used to assess time lapse from diagnosis unfil withdrawal from work. Standardised incidence ratios were calculated to compare withdrawal from the labour force in AS with the general population. Determinants of withdrawal were assessed by proportional Cox's hazard regression analysis using variables assumed to be time independent. Crass-sectional characteristics of patients without a job due to work disability were futher analysed by simple and multiple regression analyses.

\section{Results}

In total 658 patients returned the questionnaire. Of 529 palients with a paid job before diagnosis of AS, $5 \%$ had left the labour force within the first year after the diagnosis, $13 \%$ after 5 years, $21 \%$ after 10 years, $23 \%$ affer 15 years and $31 \%$ after 20 years. Age and gender adiusted risk for withdrawal was 3.1 (95\% Cl 2.5-3.7) times higher compared with the general population. In patients with AS, delerminants of withdrawal from work were older age at diagnosis, manual work and coping strategies choracterised by limiting or adapting activities. Patients with work disabilily at the time of the study were older, had a lower social class and were more likely to have total hip replacement, peripheral arthritis or comorbidity. Moreover, they reported worse physical function (Bath Ankylasing Spondylitis Functional Index [BASF]], experienced lower quality of life and had more often extraspinal disease compared with those having a job.

\section{Conclusion}

Willdrowal from work in AS is 3.1 limes higher than expected in the general population. Within patients, higher age at diagnosis, manual job and unfavourable coping strategies are important determinants of withdrawal. Patients without a job experience lower quality of life. 


\section{Introduction}

Ankylosing spondylitis (AS) is a chronic rheumatic disorder with an estimated prevalence ranging between 0.08 to $0.86 \%$. The disease usually starts in the third decade of life and affects men three times as often as women. ${ }^{2}$ Spinal and extraspinal manifestations may contribute to functional limitations. ${ }^{3}$ Work disability is an important socioeconomic outcome, since it is associated with psychosocial $^{4}$ and financial ${ }^{5}$ consequences for patients as well as for society. In a recent cross-sectional study we found that age and gender adjusted employment in AS was $11 \%$ (15\% in males and $5 \%$ in females) lower and work disability $15 \%$ (in both genders) higher than in the general Dutch population. ${ }^{6}$ This impact on work status has led us to study withdrawal from labour force due to AS in those patients who had a jab before the diagnosis was established. In addition, factiors associated with withdrawal and characteristics of patients with work disability attributable to AS were analysed.

\section{Methods}

\section{Patients}

Patients were selected from the nationwide Dutch Standard Diagnasis Register of Rheumatic Diseases (SDR) in which $37(66 \%)$ rheumatology practices and $80 \%$ of all Dutch rheumatologists participated at the time of the study.? Thirteen regional and two academic practices, geographically spread throughout the country, were invited and agreed to participate. Selected patients had to have a definite diagnosis of AS and had to be between 16 and 60 years of age. The estimated tatal number of patients with AS in the Netherlands is $11,700 .^{8}$ Probably 40 to $50 \%$ are followed by a rheumatologist when taking into account the proportion of rheumatologists participating in the SDR and the number of patients with AS in this register.

\section{Questionnaire}

In September 1997 patients received a postal questionnaire on sociodemographic, disease related and work related variables. Saciodemographic factars comprised gender, age, race, marital status, family situation, education, protession, income, work status and conditions at the work place. Educational level was dichotomised into more than twrelve years of formal education as opposed to twelve years or less. For classification of professions, the Statistics Netherlands Jab Classification System was applied. Professions were recoded into manual work (jobs in agricultural, industrial and transport sectors) and nonmanual work (jobs in administrative, servicing and specialist or managerial sectors). Disease related questions assessed age at diagnosis, comorbidity, 
medication, extraspinal manifestations of AS (inflammatory bowel disease (IBD) and peripheral arthritis), presence of total hip replocement (THR), function measured by Bath Ankylosing Spondylitis Functional Index (BASFI) ${ }^{19}$, disease activity measured by the Bath Ankylosing Spondylitis Disease Activity Index (BASDAl)" and patient's global well-being measured by the Bath Ankylosing Spondylitis Global Assessment (BASG). ${ }^{12}$ BASFI, BASDAI and BASG are scored on a visual analogue scale ranging from 0 to 10. Higher values indicate worse status. Comorbidity was assessed by a list with 19 comorbid conditions. Peripheral athrifis was defined as having at least one swallen joint indicated on the Self Assessment Joint Score. ${ }^{13}$ IBD was cansidered to be present if the patient indicated chronic bowel disease for which he had consulted a specialist within the past three months. Coping strategies were assessed by the Coping with Rheumatic Stressors Questionnaire (CORS). This validated questionnaire distinguishes eight coping strategies in patients with rheumatic diseases: three on coping with pain, three on coping with limitations in activities of daily living and two on coping with dependence." As generic health assessment questionnaire the RAND-36, which closely resembles the SF-36, was added ${ }^{15.15}$ and as measure of fatigue the Multifactorial Fatigue Inventory (MFI) was included. "Presence of psychopathology was measured by the 12 items General Health Questionnaire (GHQ-12), using three as cut off level. ${ }^{18}$

\section{Definitions of endpoints on work status}

In this study work disability is defined as officially recognised inability to perform paid production because of AS. Withdrawal from the labour force refers to those who had a paid jab before diagnosis of disease and had to leave their job completely because of AS related work disability. In the Netherlands, after one year of continuous sick leave, the Social Security Association decides on eligibility for work disability. Six categories of work disability are distinguished. Disability between 80 and $100 \%$ is regarded as full, while the other categories are considered as partial work disability. In case percentage of disability exceeds $15 \%$ a benefit is allowed incrementally ranging from $25 \%$ to $70 \%$ of the former gross wage. Benefits are financed through social coniributions from employees and emplayers. Patients with partial work disability can continue in part-fime jabs. In 1993 disability criteria changed in the Netherlands in order to reduce the work disability rates. Before 1993 work disability was allowed if a person could not perform his or her profession because of medical restrictions, taking into account age and unemployment figures in the region where the person was living. Since 1993, work disability is allowed if there are objective medical restrictions to earn the wage of one's present job, independent of age. In addition, the method to calculate the disability benefit changed and the period of attributed disability was restricted to a maximum of 5 years.

\section{Statistics}

Kaplan-Meier analysis was applied to patients with a paid job before diagnosis of AS. Leaving the labour force completely because of AS related work disability 
was cansidered an event. Patients who received partial work disability but continued to work were not considered to have an event and patients who had left the labour force but for other reasans than AS were censored. The risk for withdrawall from the labour force in AS was compared with the general population by calculating standardised risk rates (SRR) for 5 age categories in male and female patients separately, using incidence rates of complete work disability benefits in the general Dutch population in 1998 (Dutch Central Bureau of Statistics; data on file). Determinants of withdrawal from the labour farce were assessed in a Cox's proportional hazard regression analysis with backward elimination according to the likelihood ratio test (probability for removal 0.1$)$ with age at diagnosis of disease (dichotomised at 35 years). gender, educational level, profession and the eight coping strategies as covariates. To assess the influence of the change in work disability criteria in 1993, a time dependent Cox's regression was performed with number of years working while suffering from AS before or after 1993 as time dependent covariate. Possible interactions between the faur variables of the final model were assessed in a new Cox's proportional hazard regression, forcing the main effects into the model and selecting all possible interactions by backward elimination. Finally, by using the Cox's regression equation, three subgroups of patients with different risk for withdrawal from the labour force were formed and for each group Kaplan-Meier survival statistics were computed.

To assess characteristics of those work disabled at the time of the survey we first compared characteristics of patients in each group of the three groups: 11 ) those having a job without disability, (2) those having a (part-time) job and (partial) work disability and (3) those having work disability but no job. Next, we contrasted those having a job without disability to those having work disability without a paid job. Differences between groups were analysed by t-test, Chisquare and by multiple logistic regression with backward elimination according to the likelihood ratio test. Interactions between the variables of the final regression model were sought. Finally, the contribution of work disability to variation in BASFI, BASDAI, BASG, RAND-36, GHQ and MFI was analysed in multiple linear regressions while controlling for demographic (age, gender and social class) and disease characteristics (disease duration, extraspinal disease and comorbidity). Statistical tests were performed using SPSS 9.0.

\section{Results}

\section{Response}

Aliogether 1,092 patients with AS of the 15 rheumatology practices were sompled. The current postal address of 152 patients could nat be retrieved. Of the 940 remaining patients 709 agreed to participate and received the questionnaire, which was completed by 658 patients. This accounts for a response rate of $70 \%$. Non-participants did not differ in age and gender from 
participants. Results on labour force participation and work disability have been described in detall recently.

\section{Withdrawal from the labour force}

Of all 658 patients, $529(80.4 \%$ ) had a paid job before diagnosis of AS. Mean age af diagnosis was 32.7 years (SD: 8.6 ), mean disease duration at the time of the study was 12.0 (SD: 7.8 ) years and $77 \%$ were male. After adjusting for age and gender, $79 \%$ followed 12 years or less formal education compared with $74 \%$ in the general Dutch population and $24 \%$ performed a manual job compared with $18 \%$ in the general Dutch population. Further, $24 \%$ had peripheral arthritis, $3.4 \%$ had IBD, 3.2\% had undergone THR, $40.6 \%$ had a comorbid condition and $82.8 \%$ used currently NSAIDs. To ascertain that the type of profession is stable over time, we analysed change of profession in a subgroup of 85 patients who take part in a more extensive follow-up study. Seven ( $8.2 \%)$ patients changed profession because of AS. In two (2.4\%) this was a change from a manual to a non-manual profession.

In the total group, 123 patients left the labour force because of AS related work disability and 59 patients force for other reasons. Kaplan-Meier survival statistics ( 9 excluded because of missing daia) showed that withdrawal from the labour force because of AS related work disability was $5 \%$ within the first year after diagnosis, $13 \%$ after 5 years, $21 \%$ after 10 years $21 \%, 23 \%$ after 15 years and $31 \%$ after 20 years. Age and gender adjusted risk to withdraw from work was 3.1 (95\% Cl: 2.5-3.6) times increased compared with the general Dutch population. This was more pronounced for younger than for older patients (Table 4a.1) and tended to be more important in male than in female patients with AS. However, the gender difference has to be interpreted with caution because of the low number of abservations among female patients. The change in disability criteria in the Netherlands in 1993 had no statistically significant influence on the withdrawal rate as shown by time dependent Cox's regression $(p=0.47)$. Table 4a.2 shows determinants of withdrawal as assessed by Cox"s proportional hazard regression analysis. Older age at diagnosis, manual work and two specific coping strategies but not gender and educational level, were associated with withdrawal from the labour force. Figure $4 a .1$ illustrates the influence of these factors on the Kaplan-Meier survival curves. There were no interactions among these variables. Three different groups at risk for withdrawal from the labour force could be distinguished according to the Cox's regression equation. The first group with high risk for withdrawal ( $36 \%$ of patients) has both unfarourable coping strategies (limiting activities when faced with pain and reducing activities when faced with limitations). The second group with low risk for withdrawal (38\% of patients) has both favourable coping strategies (not limiting activities when faced with pain and not reducing activities when faced with limitations) and the group with intermediate risk for withdrawal (26\% of patients) has one of two unfavourable coping strategies. The Kaplan-Meier survival curves of these three risk groups are shown in Figure 4a.2. 

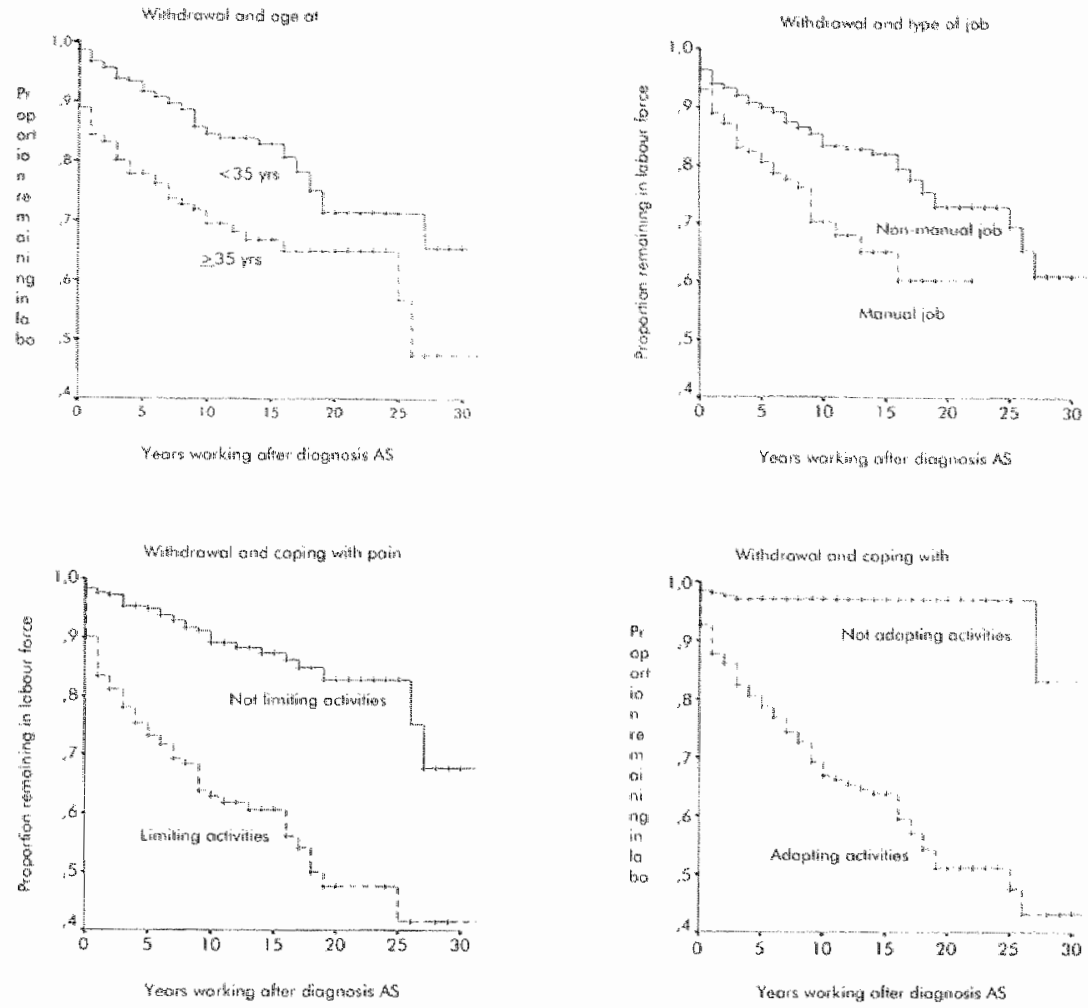

Figure 4a.1. Kaplan-Meier curves illustrating probability to remain in the labour force for each of the risk factors in the Cox's regression analysis.

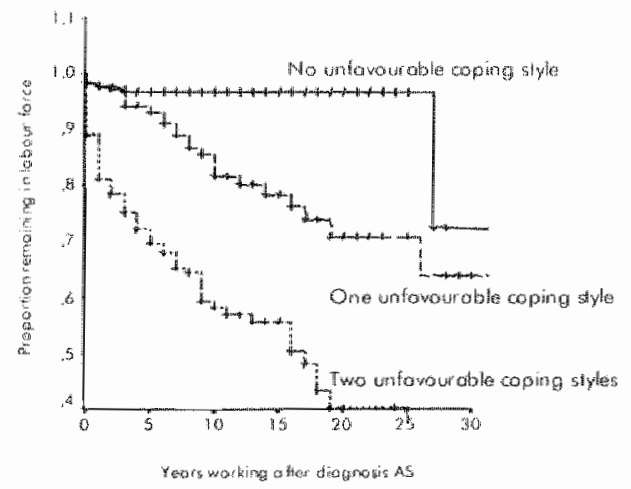

Figure 4a.2. Kaplan-Meier survival curve illustrating withdrawall from the labour force for three different risk groups of patients with AS. 
Table 4a.1. Age and gender adjusted risk ratios $995 \%$ Cl for withdrawal from the labour force in AS compared with the general Dutch population.

\begin{tabular}{|c|c|c|c|}
\hline & Obsened & Expected & $\mathrm{RR} 195 \% \mathrm{CH}$ \\
\hline \multicolumn{4}{|c|}{ Male potienis with AS } \\
\hline$<25$ years & 3 & 0.36 & $8.3(1.7-24.3)$ \\
\hline $25-34$ years & 31 & 5.28 & $5.9(4.0-8.3)$ \\
\hline 35.44 years & 27 & 7.52 & $3.6(2.4-5.2)$ \\
\hline $45-54$ years & 23 & 8.19 & $2.8(1.8-4.2)$ \\
\hline$\geq 55$ years & 2 & 2.03 & $0.98(0.1-3.6)$ \\
\hline All pollients & 86 & 23.38 & $3.7(2.6-3.7)$ \\
\hline \multicolumn{4}{|c|}{ Femole potients with AS } \\
\hline$<25$ years & 1 & 0.24 & $4.2(0.1-23.3)$ \\
\hline $25-34$ years & 9 & 4.66 & $1.9(0.9-3.7)$ \\
\hline $35-44$ years & 12 & 5.53 & $2.2(1.1-3.8)$ \\
\hline 45.54 years & 6 & 2.58 & $2.3(0.4-5.1)$ \\
\hline$\geq 55$ years & 0 & 0.30 & - \\
\hline All patients & 28 & 13.32 & $2.1(1.4-3.0)$ \\
\hline \multicolumn{4}{|c|}{ All patients with AS } \\
\hline$<25$ years & 4 & 0.59 & $6.7(1.8-17.1)$ \\
\hline $25-34$ years & 40 & 9.94 & $4.0(2.9 .5 .5)$ \\
\hline $35-44$ years & 39 & 13.05 & $3.0(2.1-4.1)$ \\
\hline $45-54$ years & 29 & 10.77 & $2.7(1.8-3.9)$ \\
\hline$\geq 55$ years & 2 & 2.33 & $0.85(0.1-3.1)$ \\
\hline All patients & 114 & 36.69 & $3.1(2.6-3.7)$ \\
\hline
\end{tabular}

RR: Standardised Risk Ratio.

Table 4a.2. Variables associated with withdrawal from the labour force because of AS related work disability, assessed by Cox"s proportional hazard regression andysis.

\begin{tabular}{lcc} 
& HR $(95 \% \mathrm{Cl})$ & p Value \\
\hline Age at diagnosis (cut aff $\geq 35$ years) & $1.98(1.30-3.03)$ & 0.002 \\
Manual profession & $2.27(1.52-3.38)$ & 0.0001 \\
Coping with poin by limiting activities & $2.32(1.48-3.64)$ & 0.0002 \\
Coping with limitations by adapting activities & $6.99(3.13-15.63)$ & $<0.0001$ \\
\hline
\end{tabular}

HR: Mazand Ratio.

Characteristics of work disabled patients.

At the time of the study, 338 of the 658 patients had a paid jab without work disability, 83 patients had a (part-time) job and (partial) work disabillity and 136 had work disability but no job. In addition, 27 patients had never had a job and 110 patients had left the labour force but for other reasons than AS related work disability. Sociodemographic and disease characteristics of the three groups with a job and/or work disability are compared in Table 4a.3. Older age, longer 
disease duration, lower social class (educational level and type of job), presence of comorbidity, extraspinal disease (IBD and peripheral arthritis) and total hip replacement were characteristics of patients without a job. In multiple logistic regression analysis, patients with a job but no work disability were contrasted to those who left the labour force because of work disability. The result of the multiple logistic regression analysis with age, gender, disease duration, education, profession, comorbidity, THR and extraspinal disease (IBD and peripheral arthritis) are presented in Table 4a.4. Not only gender but also disease duration and IBD were eliminated as independent discriminator. Having a THR was highly associated with being work disabled. Between the variables of the final model, no interactions were found. The group without a job because of work disability reported increased frequency of psychopathology (GHQ-12), worse physical function (BASFI), higher disease activity (BASDAl), worse perceived health (BASG and RAND-36) and higher levels of fatigue (MFI) (Table 4a.5). Also when adjustments were made for differences in demographic characteristics, comorbidity, THR and extraspinal disease, work disability remained significantly associated with each of these outcome variables (data nat shown separately). Patients still at work reported not more adlaptations at the work place than those with work disability in their last jab.

Table 4a.3. Characteristics of patients with AS having a job (without work disability) compared with those with a part-time jab and partial work disability and those with work disabillity without a job.

\begin{tabular}{|c|c|c|c|}
\hline & $\begin{array}{l}\text { Work, } \\
\text { no disability } \\
(n=338)\end{array}$ & $\begin{array}{l}\text { Work and } \\
\text { disability } \\
(n=83)\end{array}$ & $\begin{array}{c}\text { Work disabillily, } \\
\text { no job } \\
(n=136)\end{array}$ \\
\hline Male; \% & 77.2 & 78.3 & 72.7 \\
\hline Age: years; mean (SD) & $41.5(8.9)$ & $45.6(7.3)$ & $48.7(7.7)$ \\
\hline Disease duration: years; mean (SD) & $11.4(7.8)$ & $13.3(8.0)$ & $12.4(8.1)$ \\
\hline Education $\leq 12$ years; $\%$ & 71.0 & 90.4 & 90.4 \\
\hline Manual protession; \% & 29.1 & 36.1 & 47.8 \\
\hline Living with partner; $\%$ & 85.2 & 83.1 & 87.5 \\
\hline NSAID use; $\%$ & 79.7 & 85.5 & 87.9 \\
\hline $\mathrm{IBD} ; \%$ & 3.8 & 1.2 & 8.8 \\
\hline Peripheral orthritis; \% & 16.3 & 27.7 & 34.6 \\
\hline $\mathrm{THR}_{i} \%$ & 2.1 & 2.4 & 8.8 \\
\hline Comorbidity; $\%$ & 30.8 & 34.9 & 65.4 \\
\hline BASFI $(0-10)$; mean (SD) & $2.4(2.1)$ & $4.7(1.9)$ & $6.0(2.1)$ \\
\hline BASDAI $(0-10)$; mean (SD) & $3.0(2.1)$ & $4.6(2.0)$ & $5.4(2.5)$ \\
\hline BASG (0-10); mean (SD) & $3.2(2.4)$ & $5.3(2.1)$ & $6.0(2.3)$ \\
\hline
\end{tabular}

NSAID: non-steroidal anti-inflammatory drug; IBD: inflarmatory bowel disease; THR: total hip replacement; BASFI: Bath AS Functional Index; BASDAI: Bath AS Disease Activity index; BASG: Bath AS Global Assessment. 
64. Chavter $4 a$

Table 4a.4. Multiple logistic regression analysis with sociodemographic lage, gender, aducation and profession) and disease related variables (disease duration, inflammatory bowel disease, peripheral arthritis and tolat hip replacement) 10 asssess characteristics of work disabled patients with AS $(n=136)$ as opposed lo potients with AS having a paid job without work disability $(n=338)$ at the lime of the survey.

\begin{tabular}{lccc} 
& OR & $95 \% \mathrm{Cl}$ & p Value \\
\hline Age & 1.09 & $1.06-1.13$ & $<0.00001$ \\
$\leq 12$ years formal educafion & 3.17 & $1.55-6.48$ & 0.001 \\
Manual profession & 1.80 & $1.10-2.97$ & 0.02 \\
Comorbidify & 3.15 & $1.96-5.09$ & $<0.0001$ \\
Peripheral onthritis & 2.02 & $1.19-3.43$ & 0.004 \\
Total hip replacement & 6.52 & $2.15-19.83$ & $<0.0001$ \\
\hline
\end{tabular}

OR: odds ratio.

Table 4a.5. Simple regression analyses in order to characterise patients with AS having a job without disability to patients with AS having work disability without a job.

\begin{tabular}{|c|c|c|c|}
\hline & $\begin{array}{c}\text { Work, } \\
\text { no disability } \\
n=338\end{array}$ & $\begin{array}{c}\text { Disability } \\
\text { No work } \\
n=136\end{array}$ & p Value \\
\hline Adaptations at work place" & $76 / 338(22 \%)$ & $31 / 136(23 \%)$ & 0.9 \\
\hline BASFI (O-10) & $2.4(2.1)$ & $6.0(2.1)$ & $<0.0001$ \\
\hline BASDAI $(0.10)$ & $3.0(2.1)$ & $5.4(2.5)$ & $<0.0001$ \\
\hline BASG $(0-10)$ & $3.2(2.4)$ & $6.0(2.3)$ & $<0.0001$ \\
\hline \multicolumn{4}{|l|}{ RAND-36 $(0-100)$} \\
\hline Physical function & $78.3(16.3)$ & $42.1(22.9)$ & $<0.0001$ \\
\hline Social function & $85.0(19.4)$ & $57.4(25.9)$ & $<0.0001$ \\
\hline Physical role & $73.7(36.2)$ & $29.3(37.8)$ & $<0.0001$ \\
\hline Social role & $88.2(27.3)$ & $62.7(43.2)$ & $<0.0001$ \\
\hline Mental health & $76.2(17.2)$ & $64.2(20.0)$ & $<0.0001$ \\
\hline Reduced witality & $59.4(18.7)$ & $42.8(18.9)$ & $<0.0001$ \\
\hline Pain & $68.4(18.9)$ & $43.6(19.6)$ & $<0.0001$ \\
\hline General health & $59.2(20.2)$ & $38.2(20.5)$ & $<0.0001$ \\
\hline Health change & $39.3(13.3)$ & $30.2(17.9)$ & $<0.0001$ \\
\hline \multicolumn{4}{|l|}{ GHQ } \\
\hline GHQ $23 ;$ number; $\%$ & $77 / 337(23)$ & $66 / 134(50)$ & $<0.0001$ \\
\hline \multicolumn{4}{|l|}{$M F(0.20)$} \\
\hline General fatigue & $11.4(3.5)$ & $14.6(3.5)$ & $<0.0001$ \\
\hline Physical fatigue & $10.6(3.8)$ & $14.2(3.5)$ & $<0.0001$ \\
\hline Reduced activity & $8.5(3.3)$ & $12.7(3.9)$ & $<0.0001$ \\
\hline Reduced motivation & $8.5(3.3)$ & $11.2(3.7)$ & $<0.0001$ \\
\hline Mental fatigue & $8.1(3.7)$ & $10.2(4.2)$ & $<0.0001$ \\
\hline
\end{tabular}

Values ore given in mean (SD); GHQ: General Health Questionnaire; MFI: Multifactorial Fotigue Inventory; "in present or last job; BASFI: Bath AS Functional Index; BASDAI: Bath AS Disease Activity Index; BASG: Bath AS Global Assessment. 


\section{Discussion}

The risk of withdrawel from work because of AS related work disability increases steadily over time resulting in one third of patients having left the labour force after 20 years of disease. Comparing withdrawal rates with the general population shows a 3 -fold increased risk to leave the labour force for patients with AS.

It should be stressed that we studied only withdrawal due to official work disability. It is possible some patients left the labour force because of AS but did not receive official work disability. Therefore, there may be hidden work disability, especially in women. Moreover, only complete withdrawal from the labour force was studied. Patients can receive partial work disability while continuing in a (part-time) job. Therefore, total withdrawal rates may be higher than withdrawal rates becouse of complete official work disability. ${ }^{19}$

Despite the retrospective design of our study, we think survival analysis can be performed meoningfully, although the results have to be interpreted with some caution. Several types of selection bias should be considered. Firstly, in the Netherlands only 40 to $50 \%$ of patients with AS are followed by a rheumatologist. It has been shown that hospital sampled patients have somewhat more severe disease and are more often work disabled compared with population sampled patients with AS. ${ }^{20}$ This would result in overestimation of withdrawal rate. Secondly, if patients with more severe disease have higher mortality, they might not have been sampled in our retrospective study and this would have resulted in underestimation of withdrawal rate. Since mortality due to AS seems only slightly increased ${ }^{21}$, it is unlikely this will have influenced our patient population considerably. Thirdly, it can be argued that patients with problems at the work place are more likely to consult a rheumatologist, which might have infllated the observed withdrawal rate. However, in The Netherlands the rheumatologist has only a minor role in decisions on eligibility for work disability, reducing the chance that those patients with difficullies at the work place more often consult a rheumatologist. Apart from selection bias, the change in disability criteria in the Netherlands in 1993 posed an additional problem in our retrospective study. A time dependent Cox's analysis demonstrated this change had no measurable influence on the withdrawal rate for patients with AS. Further, given the design of this study, variables to assess determinants of withdrawal were selected carefully. Age at diagnasis, gender. education, type of profession and coping strategies ${ }^{22}$, although assessed at the time of the survey, are unlikely to have changed affer diagnosis of disease and therefore can be used in predictive models. However, information on peripheral arthritis, THR, IBD, comorbidity, disease activity and severity and quality of life was only available for the fime of the survey and could therefore not be used to analyse predictors for wark disability in this retrospective study. 
The withdrawal rate in our population was slightly lower than in both a Mexican prospective study $(n=103)$, that observed a withdrawal rate of $15 \%$ after 5 years ${ }^{23}$ in patients with a mean disease duration of 10 years and a French longitudinal study $(n=186)$, which reponted a cumulative withdrawal of $36 \%$ after 20 years of disease. ${ }^{24}$ A Finnish inception cohort $(n=76)$ showed lower withdrawal rates in the first years of disease (5\% after 10 years), but equal withdrawal after longer disecse duration (30\% after 25 years). ${ }^{25}$ These studies did not explicitly state whether or not they assessed AS attributable withdrawal while we studied specifically withdrawal due to AS. This difference might contribute to our somewhat more favorable results. In addition, the French cohort included only patients admitted to the hospital and might have dealt with severe disease. On the other hand, a very low withdrawal rate due to AS related work disability of $13.2 \%$ after a median of 21.4 years of disease is reported in a recent US study on 234 patients with AS. ${ }^{19}$ Compared with our patients the proportion hoving a job as a professional/manager was higher. The contribution of differences in the social security system can only be speculated on.

As in the French and the US cohort, we showed that type of job is associated with withdrawal. 24,19 Interestingly, in our study two behavioral coping strategies were strongly associated with leaving the labour force: copirg with pain by limiting activities and coping with limitations by adapting activities. Coping strategies and their influence on outcome have not yet been thoroughly investigated in AS. Coping measured by the CORS, an athritis specific coping scale, is considered to be a personality ${ }^{22}$ and therefore stable over time. In other musculoskeletal diseases it has been shown that coping strategies are associated with the amount of experienced pain, level of physical functioning, disease activity and quality of life. 26,27 To our knowledge this is the first time that coping strateglies are found to be associated with withdrawal from the labour force in musculoskeletal disease. It is clear that unfavourable coping strategies, in the same way as manual professions, may be disease independent risk factors for withdrawal. However, no data are available from the general population or other diseases to analyse this issue in more depth currently.

This study demanstrates the importance to analyse withdrawal from the labour force not only within patients with AS but also in comparison to the general population. Higher age was positively associated with withdrawal within the AS group but negatively with withdrawal when compared with the general population.

Withdrawal rates in AS seem lower than in rheumatoid arthritis (RA). In RA studies published within the last 5 years and investigating withdrawal from the labour force among patients with a paid job showed that withdrawal rates were higher than $30 \%$ after 10 years of disease while in studies among parients with AS withdrawal of $30 \%$ is only seen after 20 years. ${ }^{23} 34$ in a case-control cohort study in the UK, the odds ratio to become economically inactive was 32.0 195\%Cl: 5.4.1303) for RA cases compared with controls, which is about 10 fold higher than in our $\$ 40 d y .{ }^{34}$ In RA, similar to AS, higher age at onset of disease, 
lower social class, higher disease activity and worse physical function were associated with withdrawal from work in several of these studies. ${ }^{29.32,3.34}$

Comparing patients having a job at the time of the survey with those having work disability, work disabled patients were characterised by higher age, lower social class, comorbidity, peripheral arthritis and most THR. Notably, gender, disease duration and IBD were no independent characteristics. Work disability was significantly associated with worse quality of life (RAND-36), higher levels of fatigue (MFI) and presence of psychopathology (GHQ), independent of age, gender, disease duration, comorbidity, THR and peripheral arthritis. Again, the retrospective study design does not allow us to conclude that patients who become work disabled will loose quality of life or are likely to develop psychopathology. Indeed, the reverse could be true. Prospective studies in other chronic diseases suggest that loss of work results in worse perceived health." Patients still working reported not more often adaptations at the work place than those who had left employment in their last job.

In the literature, several cross-sectional studies in AS report higher age, lower education and worse physical function to be associated with present work disability. ${ }^{35.37}$ One other study also concludes that patients without employment more often report depression. ${ }^{35}$ In contrast to our findings, a Norwegian study among 99 patients showed that female gender, but not peripheral arthritis, hip replacement or presence of psychopathology (GHQ) were associated with inability to work. ${ }^{37}$ Comparing dato on work status from different countries is however difficult. Not only demographic and disease characteristics can vary, but also changes in the local labour market or differences in the social security systems can pose varying incentives to leave or remain in the labour force.

In conclusion, withdrawal from the labour farce in AS is substantial. Coping strategies may contribute to withdrawal. Work disabled patients with AS report worse quality of life. This aspect should not be neglected in any holistic approach of the patient. 


\section{References}

1. Braun J, Bollow M, Remlinger $G$, Eggens U, Rudwaleit M, Distler $A$, et al. Prevalence of spondylarthropothies in HLA-B27 positive and negative blood donors. Arthritis Rheum 1998;41:58-67.

2. Linden van der $S M$, Valkenburg $H A$, de Jongh BM, Cars $A$. The risk of developing ankylosing spondylitis in HLA-B27 positive individuals. A comparison of relatives of spondylitis patients with the general population. Arthritis Rheum 1984;27:241-249.

3. Dalyan M, Guner A, Tuncer S, Bilgic A, Arasil T. Disability in ankylasing spondylitis. Disabil Rehabil 1999;21:74-79.

4. Warr P. Work, unemploymemt and mental health. Oxford: Clarendan Press; 1987.

5. Yelin EH, Henke CJ. Epstein W. Work disability among persons with musculoskeletal conditions. Arthritis Rheum 1986,29:1322-1333.

6. Boonen $A$, Chorus $A$, Miedema $H$, van der Heijde D, van der Tempel $H$, van der Linden Si. Employment, work disability and work days lost in patients with ankylosing spondylitis: a cross-sectional study of Dutch patients. Ann Rheum Dis $2001: 60: 353-358$

7. Miedema HS, Van der Linden SM, Rasker Jj, Valkenburg HA. National database of patients visiting theumatologists in the Netherlands: The standard diagnosis register of theumatic diseases. A report and preliminary analysis. $\mathrm{Br} J$ Rheumatol. May $1998 ; 37: 555-561$

8. Miedema HS. Reuma in Nederland: de ciffers. Het aantal patienten met chronische reumatische aandoeningen in Nederland. Leiden: Tho Preventie en Gezondheid; 1997.

9. Statistisch Jaarboek 1998. Voorburg/Heerlen: Centraal Bureau woor Statistiek; 1998.

10. Calin A, Garrett S, Whitelock H, Kennedy LG, OHea J, Mallorie P, ef al. A new approach to defining functional ability in ankylosing spondylitis: the development of the Bath Ankylosing Spondylitis Functional Index. I Rheurnatal 1994;21:2281-2285.

11. Garrett S, Jenkinson T, Kennedy LG, Whitelock H, Gaisford P, Colin A. A new approach to defining disease status in ankylasing spondylitis: the Bath Ankylosing Spondylitis Disease Activity Index. A Rheumatol 1994;21:2286-2291.

12. Jones SD, Steiner A, Garrett SL, Calin A. The Bath Ankylosing Spandylitis Patient Global Score (BAS-G). Br J Rheumatol 1996;35:66-71.

13. Stucki $G$, Stucki S, Bruhlmann $P$, Maus S, Michel BA. Comparison of the validity and reliability of self-reported anticular indices. Br J Rheumatal 1995;34:760-766.

14. van Lankveld W, van't Pad Basch P, wan de Putte L, Naring G, van der Stack C. Disease-specific stressars in rheumatoid arthritis: coping and well-being. $\mathrm{Br} J$ Rheumatol 1994;33:1067-1073.

15. McHorney CA, Ware JE, ${ }^{2}$.. LU JF, Sherboume CD. The MOS 36-item Short-Form Heath Survey (SF-36): lll. Tests of data quality, scaling assumptions, and reliability across diverse patient groups. Med Care 1994;32:40-66. 
16. Ware JE, Jr. Sherbourne CD. The MOS 36-ifem short-form hed th survey (SF-36). I. Conceptual framework and item selection. Med Care 1992;30:473-483.

17. Smets EM, Garssen B, Bonke B, De Haes JC. The Multidimensional Fatigue inventory (MFI) psychometric qualities of an instrument to assess fatigue. J Psychosom Res 1995; $39: 315-325$.

18. Bonks MH. Validation of the General Health Questionnaite in a young community sample. Psychol Med 1983;13:349-353.

19. Ward $M$, Kuzis $S$. Rusk Factars for work disability in patients with ankylosing spondylitis. I Rheumatol $2001 ; 28: 315-321$.

20. Gron JT, Husby G. Ankylosing spondylitis: a comparative study of patients in an epidemiological survey, and those admitted to a department of theumatology. I Rheumatol 1984; 1 1:788-793.

21. Lehtinen $K$. Mortality and causes of death in 398 patients admitted to hospital with ankylosing spondylitis. Ann Rheum Dis 1993;52:174-176.

22. Gunther $V$, Mur E, Kurz M, Meise U. Stable pattern of stress coping in patients with rheumatoid arthritis. Clin Exp Rheumatol 1994:12:35-43.

23. Ramos-Remus C, Prieto-Parra RE, Michel-Diaz J, Gutierrez-Urena S, Suarez-Almazor ME. A five-year cumulative analysis of labor-status and lost working days in patients with ankylosing spondylitis (AS). Arthritis Rheumat [S] 1998:1136.

24. Guillemin F, Briancon S, Pourel J, Gaucher A. Long-term disability and prolonged sick leaves as outcome measurements in ankylosing spondylitis. Possible predictive factors. Arthritis Rheum 1990,33:1001-1006.

25. Lehtinen $K$. Working ability of 76 patients with ankylosing spondylitis. Scand J Rheumatol 1981; 10:263-265.

26. Evers AW, Kracimaat FW, Geenen R, Bijlsma JW. Psychosacial predictors of functional change in recently diagnosed rheumatoid arthritis patients. Behav Res Ther 1998;36:179.193.

27. wan Lankveld W, Naring $G$, van if Pad Bosch P, wan de Putte L. Behavioral coping and physical functioning: the effect of adjusting the level of activity on observed dexterity. J Rheumatol 1999;26:1058-1064.

28. Albers JM, Kuper HH, wan Riel PL, Prevoo ML, van "t Hof MA, van Gestel AM, el al. Socio-ecomomic consequences of rheumatoid athritis in the first years of the disease. Rheumatology 1999;38:423-430.

29. Fex E, Larsson BM, Nived $K$. Eberhardt $K$. Effect of rheumaloid arthritis on work status and sacial and leisure time activities in patients followed 8 years from anset. $J$ Rheumatol 1998;25:44-50.

30. Jantti $J$, Aho $K$, Kaarela $K$, Kautiainen $H$. Work disability in an inception cohort of patients with seropositive theumatoid arthritis: a 20 ysar sudy. Rheumatology $1999,38: 1138 \ldots 1141$.

31. Mau W, Bornmann M, Weber H, Weidemann HF, Hecker H, Raspe HH. Prediction of permanent work disability in a follow-up study of early rheumatoid arthritis: results of a tree structured analysis using RECPAM. Br J Rheumatol 1996;35:652659.

32. Wolfe F, Hawley DJ. The longterm outcomes of rheumatoid arthritis: Work disability: a prospective 18 year study of 823 patients. J Rheumatol $1998 ; 25: 2108.2117$. 
33. wan J aorsweld CHM, Jacobs JWG, Schripers AJP, Van Albada Küpers GA, Hofmon DM, Bijlsma JWJ. Effects of theumatoid arthritis on employment and social participation during the first years of disease in The Netherlands. Br J Rheumatol $1998 ; 37: 848 \cdot 853$

34. Barrett EM, Scot DGI, Wiles NJ, Symmons DPM. The impact of rheumatoid arthritis on employment status in the early years of disease: a UK community-based study. Rheumatology 2000;39:1403-1409.

35. Roussou E, Kennedy LG, Garrett S, Calin A. Socioeconomic status in ankylosing spondylitis: relationship between occupation and disease activity. I Rheumatol $1997 ; 24: 908-911$

36. Ramos-Remus C, Macias MA, Suarez-Almazor ME, R.E. Prieto RE, Gutierrez-urenam 5. Labor status and working-days lost in a consecutive sample of 103 patients with anlylosing spondylitis (AS). Arthritis Rheum [S] 1997:1392.

37. Gran IT, Skomswoll IF. The autcome of ankylosing spondylitis: a study of 100 patients. Br J Rheumatol 1997;36:766-771. 

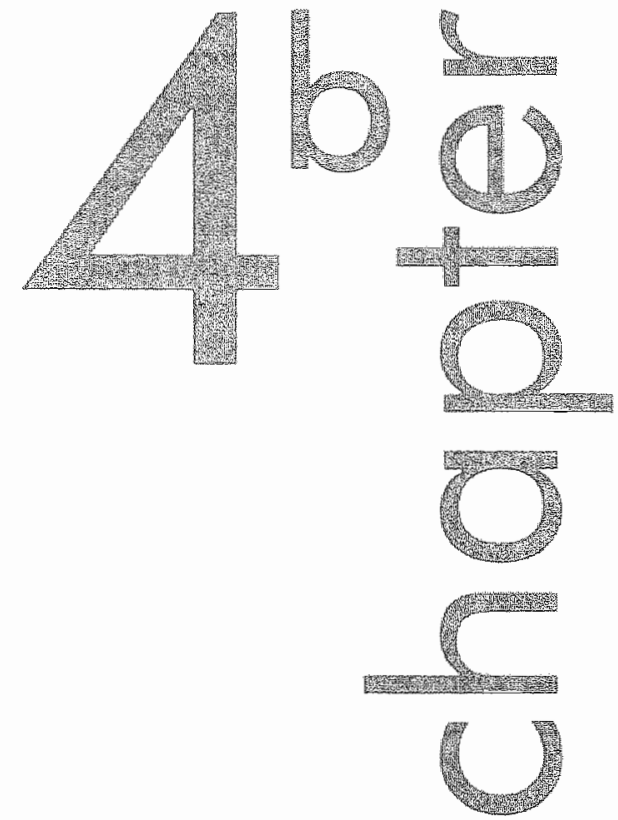

Manual professions increase risk to withdraw from the labour force in ankylosing spondylitis, also when compared with the general population

\author{
A Boonen, A Choms, R Londewé, \\ Dvan der Heide. H Mirdoma. \\ Hvan der Tompel, Sy won der Linden




\section{Letter}

In 1997, we studied labour force participation among 658 Dutch potients with ankylosing spondylitis (AS). 'In those who had a paid profession before onset of disease $(n=529)$, age and gender adiusted withdrawal rate was 3.0 times $(95 \%$ Cl: 2.5-3.6) higher than expected in the general Dutch population. "Within patients with $\mathrm{AS}$, those with a manual profession had a $2.3(95 \% \mathrm{Cl}: 1.5-3.4)$ times increased risk of withdrawal compared with those with a non-manual profession after correction for age at onset of disease, gender, educational level and coping strategies. ${ }^{2}$ However, the question remained if a manual profession was a specific risk factor for withdrawal from work in patients with AS or if a manual profession is a non-specific risk factor for withdrawal in every working subject.

Recently, Dutch population figures for 1998 on withdrawal from the labour force for the same professional categories as used in our study, became available. 3 Therefore, we were now able to calculate the profession-adjusted ratios for withdrawal from the labour force in patients with AS by comparing the profession-specific annual withdrawals in patients with those from the general population. Five major classes of profession were distinguished: agriculture, industry, transport, commerce and services/management. The first three classes were later grouped as manual professions and the last two classes as nonmanual professions. This classification has some limitations because professions like housekeeper and waiter are also included within the servicing professions and therefore considered as nom-manual professions. However, this was similar in patients and in controls. All data were stratified by gender. The $95 \% \mathrm{Cl}$ for the ratios were calculated using Poisson's distribution.

Table $4 \mathrm{~b}$ presents for each professional class, the observed rates of withdrawal from the labour force as well as the ratios when compared with general population. While the overall risk for a patient with AS to withdraw from the labour force is $3.0(95 \% \mathrm{Cl}: 2.5 .3 .6)$ times higher than expected in the general population, this risk is $4.9(95 \% \mathrm{Cl}: 3.5-5.9)$ times higher for those with a manual profession versus $2.2(95 \% \mathrm{Cl}: 1.6-2.7)$ times higher for those with a non-manual profession. The observed effect was stronger in male than in female patients, probably because of the smaller number of femate patients in the study sample. In the general population withdrawal rates were not significantly different among the distinguished professional classes in men as well as in women.

We conclude that patients with AS which have a manual profession increased risk of withdrawal from the labour force, also when adjusted for job related withdrawal in the general population. 


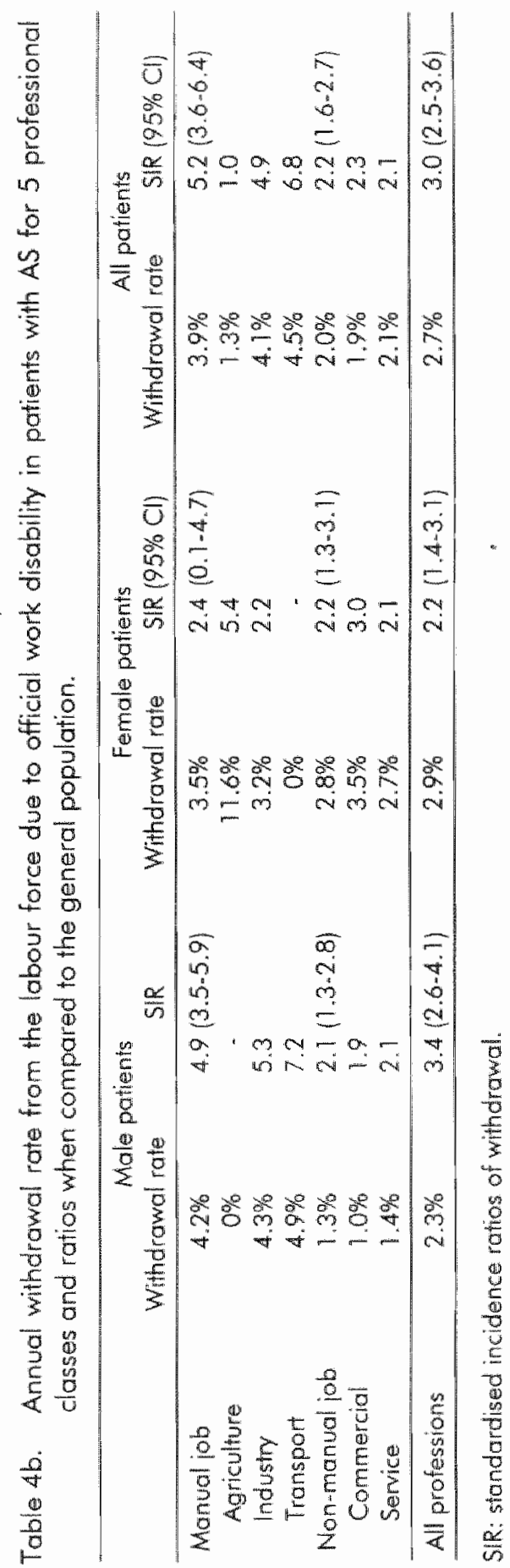




\section{References}

1. Boonen $A_{\text {, }}$ Chorus $A_{\text {, }}$ Miedema $H$, wan der Heijde $D$, wan der Tempel $H$, wan der Linden Si. Employment, work disability and work days lost in patients with ankylosing spondylitis: a cross-sectional study of Dutch patients. Ann Rheum Dis $2001 ; 60: 353-358$.

2. Boonen $A$, Chorus $A$, Miedema $H$, van der Heijde $D$, Landewé $R$, Schouten $H$, van der Linden 5 . Withdrawal from labor force due to work disability in patients with ankylosing spondylitis. Ann Rheum Dis 2001;60:1033-1039.

3. Dutch Bureau of Statistics: data on file. 

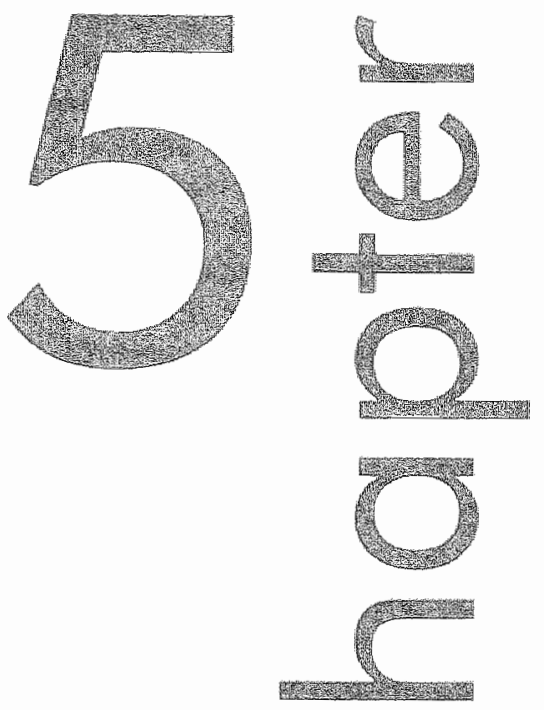

Employment perspectives of patients with ankylosing spondylitis

A Chorus, A Boonen, HMiedemo,

Si wan der Linden

Ann Rheum Dis 2002,61:693-699 


\section{Abstract}

Aim

To assess the labour market position of patients with ankylasing spandylitis (AS) in relation to disease duration and to identify potential factors in relation to withdrawal from the labour force.

\section{Methods}

A crossusectional mail survey was conducted among 658 patients with AS. Labour force participation was defined as having a paid job. The independent effect of disease duration was examined by an indirect method of standardisation. A braad variety of risk factors were examined separately and in combined analysis, including sociodemographic factors, disease related variables, coping styles and work related factors. Attributable and preventable fractions were calculated from the combined andyses to assess the relative importance of the contributing factors.

\section{Results}

Probability of labour force participation was simitarly reduced in patients with AS with different disease duration. Pacing in order to cope with limitations was the most relevant factor in terms of increasing the risk of withdrawal from the labour force, accounting for $73 \%$ of withdrawals. Coping with limitations by frequently seeking creative solutions, high disease activity, increased age and insufficient supporf from colleagues or managemenf were also positively associated with withdrawal from the labour force. Technical or erganomic adiustments of the work place, working in large companies and coping with dependency style through frequent acceptance were negatively associated. Of these factors, technical or ergonomic adjustment was the rnost relewant in terms of reducing the risk.

\section{Conclusion}

Sociodemographic factors, disease related factors, coping styles and work related factors contribute simultaneously to withdrawal from the labour force. 


\section{Introduction}

Ankylosing spondylitis (AS) is a chronic systemic inflammatory theumatic disorder that primarily affects the axial skeleton, with sacrailitis as its hallmark. Inwolvemen of the limb joints other than hips and shoulders is present in $30 \%$ of patients with AS. Clinical manifestations of the disease usually begin in late adolescence or early aduthood. Onset after the age of 40 is rare. The disease has both skeletal and extraskeletal manifestations and is clinically three times more common in men than in women. Pain, stiffmess and fatigue are the most frequently reported symptorns of patients with AS. ${ }^{12}$ As in most rheumatic diseases, the severity of symptoms varies greally among patients and varies over time in individual patients.

After rheumatoid arthritis (RA), AS is the major type of inflammatory rheumatic disease. In contrast to RA, knowledge about the burden of illness in AS is less well established. Generally, AS is considered to be a disease in which relatively good functional capacity and working ability are maintained. Previous studies of working ability among patients with AS reported employment rates of between 34 to $96 \%$ after mean disease duration of 12 years or more. 13,4 Despite this, none of the studies investigated the independent effect of disease duration on labour force participation. Since age, gender, educotion and demand in the labour market may influence the likelinoad of people stopping work, it is important to consider these factors when studying work disability. In patients with AS educational level may be influenced by the onset of the disease at a relatively young age. So in a previous study we controlled for age and gender and found that labour force participation (LFP) was decreased by $11 \%$ compared with reference data for the general population of working age. The comparison with reference data of the same time period for the general population allowed for an indirect control for demand in the labour market. ${ }^{4}$

Most studies of risk factors for work disability in patients with AS have considered a limited range of possible risk factors. Factors found to be associated with continued employment include younger age, higher socioeconomic stafus, prolonged standing, vacational counselling, and indicators of less disease activity ${ }^{1,5}$ Only two studies are known which use multivariate statistical techniques to determine the independent effect of different sociademagraphic and work factors on the risk of work disability. ${ }^{6,7}$ ln a previous study, behavioural coping was idenlified as a relatively new known potential risk factor in relation to work?

The purpose of this study is to explore the employment prospects for patients diagnosed with AS by exploring modifiable factors, which could be used to construct vocational interventions to prevent or postpone early withdrawal from the labour force. We therefore examined the influence of disease duration on labour force participation compared with the general Dutch population. We also studied a broad range of work related variables in relation to withdrowal from 
$78 \mid$ Chapter 5

the labour force and we assessed the relative importance of work related factors in combination with sociodemographics, disease related faclors and coping styles.

\section{Methods}

\section{Sample selection}

The present study was conducted in a Duich notion-wide study group of 658 patients aged 18-59 years diagnased by a theumatiologist. Eligible patients were identified using the national Standardised Diagnosis Register of Rheumatic diseases (SDR), a representative database with infarmation on diagnoses of the patient population of $80 \%$ of all rheumatologists in the Netherlands. From this database a random sample of patients with AS aged $16-59$ years was selected from a geographically representative sample of 34 theumatologists $134 \%$ of all in the SDR participating rheumatologists, $27 \%$ of all rheumatologists in the Netherlands), working in 15 practices (42\% of all SDR practices) throughout the Netherlands. All patients were contacted by mail by their own rheumatolagist, and $658(60.3 \%$ of the initial cohort, $70.0 \%$ of the patients traceable) agreed to participate in the study. All patients filled out a self-administered questionnaire adiusted to their current employment status (having a paid job, having no paid jab, but had a paid job in the past, and never had a paid jobl and containing several standardised instruments. Data were obtained on sociodemagraphics, disease characteristics, functional abilities, health related quality of life, present and past working conditions and coping with the disease. We limit our description of variables to those, which were assessed to address our present study purpose. The design of the present study has also been described in detail elsewhere. 4,7

\section{Sociodemograhic voriables}

Year of birth, gender and highest attained level of education were identified as sociodemographic variables. Educational level was classified into three categories based on the Dutch educational system (primary education 10.8 years), secondary education $(9-16$ years), and higher wocational education/university $(17$ years and more $))$.

\section{Disecse characteristics}

Disease activity was assessed using a Dutch version of the Bath Ankylosing Spondylitis Disease Activity Index (BASDAl), containing six questions focussing on fatigue (1 item), axial pain (1 item), peripheral pain (1 item), enthesopathy (1 item) and morning stiffness (2 items). Each question is scored on a Visual Analogue Scale (VAS). The BASDAl score (0-10) is calculated as the mean value of the mean of the sum of the first four items and the mean of the sum of the last wo items referring to morning stiffness. A higher score indicates more 
disease activity. Patients were asked about the year in which AS was diagnosed. Furthermore, patients reported their current use of medication, whether they had undergone a total hip replacement and whether they suffered from AS related comorbidity and other chronic disorders.

\section{Activities in daily life}

To assess functional abilities in daily life, a Dutch version of the Bath Ankylosing Spondylitis Functional Index (BASFl) was used, containing 8 questions regarding function in AS and 2 questions reflecting the patients' ability to cope with everyday life. ${ }^{10}$ Each question was scored on a VAS, the mean of which gives the BASFI score (0-10). A higher score indicates worse outcome.

\section{Employment situation}

All patients reported on their employment history using a Dutch generic structured instrument, the Vocational Handicap Questionnaire (VHQ), that was validated in previous studies among Dutch chronically ill people. ${ }^{11.13}$ This instrument assesses present occupational situation, vocational handicaps, past employment history and income compensation in case of work disability pensions. Furthermore, data were collected on the year of the first real paid job and job changes. To describe the present or last job, data were callected on field of work, jab demands, adjustments, size of company, accessibility of the work place and transportation mobility, job adjustments, social support from colleagues and management in the work place. Patients who had withdrawn from the labour force were asked to indicate in which year they had stopped working and whether they had left for work-related reasons, disease-related reasons or other personal reasons. For patients who left the labour force after being diagnosed, the duration of employment after diagnosis was calculated.

\section{Coping}

Behavioural coping styles were assessed using the Coping with Rheumatic

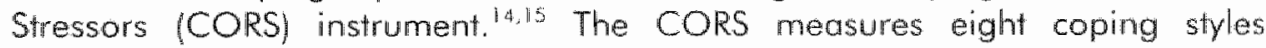
directed at the most important chronic stressors of inflammatory rheumatic diseases, i.e. pain, limitations and dependence. Three scales refer to pain: comforting cogmitions (9 items), decreasing activities ( 8 items), and diverting attention (8 items). Three scales measure styles of coping with limitations: optimism (5 items), pacing e.g. adapting one's level of activity (10 items), and creative solution seeking ( 8 items). Two scales refer to dependence: making efforts to accept one's level of dependency ( 6 items), and showing consideration (7 items). For each item, patienls report how often they made use of that particular coping strategy (seldom or never, sometimes, often, wery often).

\section{Global well-being}

The instrument used to assess global well-being was the disease-specific Dutch version of the Bath Ankylosing Spondylitis Global Health Index (BASG). 
containing two questions on the impact of AS on global well-being in the past week and in the past six months. "Each question is scored on a VAS, the mean of which gives the BASG score (0-10). A higher score indicates more impact of the disease on the global well-being of the patient.

\section{Daia andysis}

The influence of disease duration on labour force participation of patients with AS was studied by comparing age-and gender-specific levels of employment in our AS population with those in the general population using an indirect standardisation method. We therefore calculated, for our study group, ratios of the observed (O) and expected (E) number of working people for evenly spaced categories of five years disease duration. Our study design meant that the first category ranges from one to five years of disecise duration. Expected levels of labour force participation were computed using reference data for the general Dutch population relating to age and gender-specific levels of employment." The O/E natio can be interpreted as the relative chance of patients with AS having a paid job compared with the general population, adjusted for age and gender. A rate ratio of 1.0 indicates an equal chance, a rate ratio of less than 1.0 a decreased chance and a rate ratio of more than 1.0 an increased chance. To examine statistically significant differences between the $A S$ group and the general population, we abtained the variances of the O/E ratios, and estimated their $95 \%$ confidence intervals $(\mathrm{O} / \mathrm{E} \pm 1.96 \times \mathrm{V}$ var $(\mathrm{O} / \mathrm{E}))$. If a rate ratio of 1.0 is included in the interval, then the estimate is not statistically significant at the alpha level of $0.055^{\text {is }}$

In evaluating sociodemographics, disease related variables, coping styles and various work related factors in rellation to withdrawal from the labour force, we compared characteristics of patients who had withdrawn from the labour force anytime after being diagnosed with AS and patients still employed at the time of the study. With respect to employment factors "we examined the characteristics of the last job position of the patients who had withdrawn and the characteristics of the present job of the employed patients. First, all variables were analysed univariately using $\chi^{2}$ tests to determine proportional variance between groups and l-tests were conducted to analyse differences between group means. In addifion, we assessed the relative importance of sociodemographic, disease related factors and work related factors in the relationship with withdrawal from the labour force in a multivariate context. A multiple logistic regression analysis with a forward stepwise procedure was therefore performed to assess the simultaneous associations of thase sociodemographic disease related and work related factors that were found to be significant at the $P \leq 0.05$ level, when tested univariately. A variable was entered into the equation when the alpha level for reiecting the null hypothesis was 0.20 . This level was chosen to ensure adequate power for the selection of variables in order to have acceptable performance for statistical testing. For implementation of the results in practice, each continuous variable was dichotomised at the median score of the total group of patients who performed a job anytime after diagnosis. 
On the basis of the final logistic regression model of the stepwise procedure, attributable and preventable fractions were subsequently calculated to estimate the overall proportion of withdrawals from the labour force that could be either attributed to, or prevented by, sociodemographic, disease related or work related factors. The adjusted attributable fraction is the proportion of withdrawals from the labour force, which is attributed to exposure by that factor. It is calculated as the exposed proportion of patients. withdrawn from the labour force multiplied by (aOR-1)/aOR.

aOR is the odds ratio for that risk factor, adjusted for all other factors in the final model. The adjusted preventable fraction is the proportion of withdrawals in a situation of non-exposure that could be prevented by exposure to that factor. It is calculated as the unexposed proportion of patients withdrawn multiplied by (1-aOR).

To examine possible recall bias, we performed the same stepwise forward multiple regression analysis with a subsample of patients who had withdrawn from the labour force during the 5 years prior to the study and a subsample of patients with 5 or fewer years of disease. The cut-off point of 5 years was chosen to ensure adequate statistical power for the logistic regression. ${ }^{13}$ All statistical analyses were performed using SPSS for Windows, version 10.0.7.

\section{Results}

Overall labour force participation in this cohort of patients with AS with a mean disease duration of 12.4 years, standardised for age and gender, was $54.2 \%$ $(63.4 \%$ in males and $46.9 \%$ in females), which is a significant reduction of $11.0 \%(15.4 \%$ in males and $5.2 \%$ in fernales) compared with the Dutch general population of working age. Data about averall labour force participation was presented extensively in a previous paper. ${ }^{4}$ In further exploring the labour market position of these patients, we studied whether disease duration had an effect on the chance of having a paid job among patients with AS compared with the chance of having a paid job given a patient's age and gender according to reference data from the general population in the working age. Figure 5.1 shows rate ratios and their $95 \%$ confidence intervals for the relative chance of labour force participation in patients with AS for 5-year categories of disease duration. It was found that all of the rate ratios were statistically significant reduced, which implies that the probability of participating in the labour market was reduced in patients with relatively short disease duration as well as in patient with long disease duration. Moreover, rate ratios of patients with longer disease duration did not differ significantly from patients with short disease duration i.e. having the disease influences the probability of holding a paid jab, but the duration of the disease has no additional influence.

Of the total study group of 658 patients with AS, 71 patients had either stopped working before diagnosis $(n=44$ patients $(8.3 \%)$ or had no work history at all $(n=27$ patients $(4.1 \%))$, while 577 patients $(87.6 \%)$ held a paid job, at least 
temporarily, at some lime after being diagnosed with AS. Work history of the total study group previously has been described in more detail.?

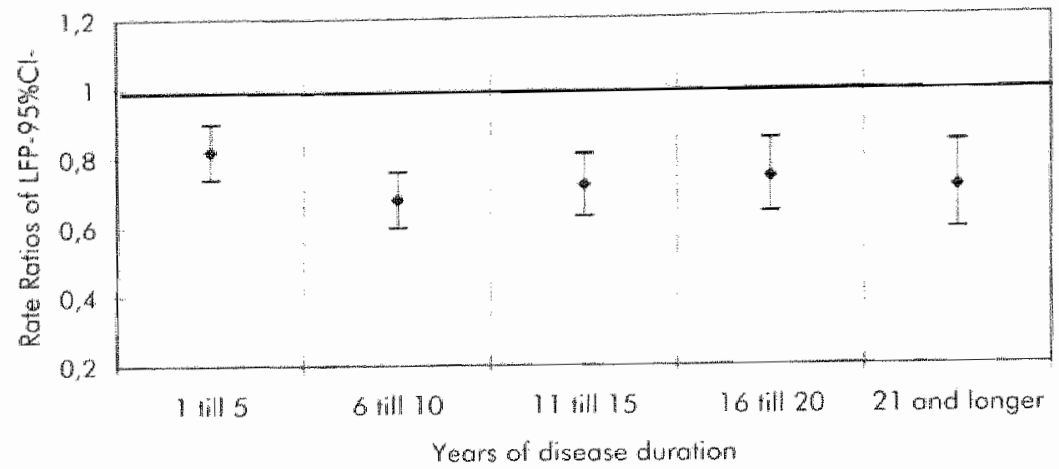

Figure 5.7. Relation between disease duration and labour force participation (LFP) among patients with ankylosing spondylitis (AS), standeurdised for age and gender, expressed as rate ratios.

For studying determinants of withdrawal from the labour force, we restricted our study group to those 577 patients with a paid job sometime after diagnosis. Of these patients, $156(27.0 \%)$ had withdrawn from the labour force after a mean disease duration of 6.3 years. $94,9 \%$ of these patients indicated that they stopped working for medical reasons. Most cited AS related reasons for withdrawal were physical limitations ( $86.1 \%$ of the patients withdrawn due to AS) and suffering from fatigue at work (77.4\% of the patients withdrown due to AS). Only $3.2 \%$ of the withdrawals had stopped working because of retirement. Table 5.1 presents patient characteristics, disease status, and outcome of the group of patients that stopped working at any time after being diagnosed with AS compared with the group that was working at the time of assessment.

On the basis of univariate comparisons, it was found that, on average, patients with AS who were younger, male or more highly educated were more likely to be employed at the time of assessment, which trend is similar to the general population in the working age. Patients who had withdrawn from the labour force had significantly longer disease duration, showed higher disease activity, experienced mare disabilities in daly life and used more medication and had undergone more often hip prothesis. In general, the group of patients who had withdrawn had different coping strategies and experienced less favourable global well-being compared with patients who were still in employment. 
Table 5.1. Patient characteristics and disease status and outcome of patients with a paid job a assessment compared with patients withdrawn from the labour force anytime affer diagnosis.

\begin{tabular}{|c|c|c|c|}
\hline & $\begin{array}{l}\text { Patients with AS } \\
\text { withdrown from } \\
\text { the labour force } \\
\text { ofter diagnosis } \\
\qquad(n=156)\end{array}$ & $\begin{array}{l}\text { Potients with As } \\
\text { with a paid job } \\
\text { at assessment } \\
\quad(n=421)\end{array}$ & p Volwe \\
\hline Age: years; mean (se) & $46.6(0.7)$ & $42.3(0.4)$ & $<0.001$ \\
\hline Gender; \% men & 66.7 & 77.4 & 0.008 \\
\hline High vocational colleges/University: $\%$ & 9.6 & 25.2 & $<0.001$ \\
\hline Age al time of diagnosis: years; mean (se) & $31.8(0.8)$ & $30.6(0.4)$ & 0.163 \\
\hline Disease duration: years; mean (se) & $14.8(0.7)$ & $11.8(0.4]$ & $<0.001$ \\
\hline Disease activity (BASDAV, 0-10), mean (se) & $5.1(0.2)$ & $3.3(0.1)$ & $<0.001$ \\
\hline Disability score (BASF, 0-10); mean (se) & $5.3(0.2)$ & $2.9(0.1)$ & $<0.001$ \\
\hline Hip Prosthesis; \% & 7.7 & 2.9 & 0.010 \\
\hline \multicolumn{4}{|l|}{ Medicatian use at time of assessment; \% } \\
\hline pain medication other than NSAID & 32.1 & 20.0 & 0.002 \\
\hline NSAID & 73.7 & 70.8 & 0.488 \\
\hline DMARD & 12.2 & 7.8 & 0.106 \\
\hline Other non-specified & 7.7 & 4.5 & 0.133 \\
\hline \multicolumn{4}{|l|}{ Coping with pain, mean (se) } \\
\hline Comforting cognition $(9-36)$ & $26.3(0.4)$ & $27.1(0.2)$ & 0.049 \\
\hline Decreasing activity $(8-37)$ & $21.4(0.3)$ & $16.8(0.2)$ & $<0.001$ \\
\hline Diverting altention $(8-30)$ & $18.4(0.4)$ & $17.4(0.2)$ & 0.012 \\
\hline \multicolumn{4}{|l|}{ Coping with limitations, mean (se) } \\
\hline Optimism $(5-20)$ & $14.7(0.2)$ & $14.9(0.2)$ & 0.432 \\
\hline Pacing $(10-40)$ & $29.6(0.4)$ & $23.5(0.3)$ & $<0.001$ \\
\hline Creative solutions $(8.32)$ & $21.4(0.4)$ & $19.7(0.2)$ & $<0,00:$ \\
\hline \multicolumn{4}{|l|}{ Coping with dependency } \\
\hline Accepling $(6-24)$ & $13.8(0.3)$ & $12.7(0.2)$ & 0.002 \\
\hline Consideration $(7.28)$ & $19.5(0.3)$ & $18.6(0.2)$ & 0.015 \\
\hline Global well-being (BASG, 0-10), mean (se) & $5.810 .2\}$ & $3.6(0.1)$ & $<0.001$ \\
\hline \multicolumn{4}{|l|}{ Official work disablement pension; \% } \\
\hline $80.100 \%$ & 63.5 & n.c. & $<0.001$ \\
\hline $15-80 \%$ & 13.5 & 18.3 & 0.170 \\
\hline
\end{tabular}

Differences in proportions tested by Chimsquare test; group means tested by Student's itest; BASDAl: Bath Ankylosing Spondylitis Disease Activity Index; BASFl: Bath Ankylosing Spondylitis Functional Index; NSAID: Nori-Specific Anti-inflammatory Drugs; DMARD: Disease Modifying Anti-Rheumatic Drugs: BASG: Bath Ankylosing Spondylitis Globol Assessment.

More than three quarters of the patients who had withdrawn from the labour force had been officially recognised as to some extent, since they received income compensation in the form of a work disablement benefit. In the Dutch social security system, employees who are on full or partial sick leave for more than one year are entitled to a work disablement benefit after work disability has been officially recognised on the basis of a medical and ergonomic 
examination. This pension provides income compensation up to a maximum of $70 \%$ of the last income eamed for a maximum period of five years. At the end of that periad, the person's ability to wark has to be reassessed. The level of compensation is dependent on age, number of years worked and levels of work disablement. People whose ability to work is impaired by $80-100 \%$ ore entitled to full work disablement benefit. People whose ability to work is impaired by 15 $80 \%$ are entitled to partial work disablement benefit. In the Netherlands, it is therefore possible to receive work disablement benefit and to remain in employment, usually on a part-time basis. In our study population, $18.3 \%$ of the patients with a paid job had been officially recognised as having a work discablement.

The associations between various employment factors and withdrawal from the labour force are presented in Table 5.2.

Patients with AS who had withdrawn from the labour force were more often active in the industrial sector and less active as professionals (e.g. physicians, teachers and policy makers) than currently employed patients. Fewer pattents who had withdrawn were specially trained for their last job position, fewer of them had followed any job training at all and more of them had performed a physically demanding jab at some time during their working career.

Patients who were still in employment worked more often in larger companies and more often had technical or ergonomic work adjustments.

Patients who had withdrawn from the labour force reported difficult access to the work place and reduced transport mobility al the work place more often than currently employed patients. With respect to the social environmental factors at the work place, patients who had withdrawn were much more dependent on their colleagues. Compared with patients still in employment, they also felt more often that colleague and management attitudes were negative and that there was insufficient support from both colleagues and management.

Table 5.3 lists the results of the stepwise forward logistic regression for the combined effect of sociodemographic, disease related factors and work related factors. Since functional ability, use of medication and global well-being were highly correlated to disease activity and field of activity correlated highly to educational level $(r>0.6)$, we chose to enter only the variables for disease activity and educational level into the models to prevent colinearity.

Variables listed in Table 5.3 were entered into the final regression model in sequence as presented. The following variables, which are univariately significant, were excluded during the forward stepwise procedure: gender. educational level, diverting attention in order to cope with pain, speciall training for the last job position, performed a physically high demanding job at some time during working career. Overall, the model shows that coping styles and disease related, sociodemographic and work related factors contribute substantially to withdrawal from the labour force. 
Toble 5.2. Work related factors of potients with AS withdrawn from the labour force after diagnosis compared with patients with AS with a paid job ot assessment

\begin{tabular}{|c|c|c|c|}
\hline & $\begin{array}{l}\text { \% of potients } \\
\text { with AS } \\
\text { withdrown from } \\
\text { the labour force } \\
\text { atter diagnosis } \\
\text { (n= } 156)\end{array}$ & $\begin{array}{l}\text { of potients } \\
\text { with AS still } \\
\text { holding a poid } \\
\text { job at } \\
\text { assessment } \\
(n=421)\end{array}$ & p Volue \\
\hline \multicolumn{4}{|l|}{ Job characteristics } \\
\hline \multicolumn{4}{|l|}{ Field of activity } \\
\hline administration & 17.3 & 18.5 & 0.736 \\
\hline transport & 7.1 & 5.2 & 0.402 \\
\hline makeling and sales & 12.8 & 12.6 & 0.941 \\
\hline service & 14.7 & 14.3 & 0.881 \\
\hline industry & 35.2 & 25.2 & 0.006 \\
\hline professional or management & 12.2 & 24.0 & 0.022 \\
\hline Parth-time jab & 21.6 & 27.6 & 0.154 \\
\hline Special training for the presen//ast jab & 46.2 & 55.6 & 0.044 \\
\hline Additional job training after diagnosis & 50.0 & 67.0 & $<0.001$ \\
\hline Changed field of activity after diagnosis & 49.4 & 55.5 & 0.189 \\
\hline AS influenced choice on last/present job & 25.6 & 30.6 & 0.241 \\
\hline Executive job position & 30.1 & 34.9 & 0.279 \\
\hline Ever performed a physically demanding job & 69.2 & 55.1 & 0.002 \\
\hline Ever performed a mentally demanding job & 51.9 & 57.7 & $0.2 \pi 3$ \\
\hline Size of company (less than 100 employees) & 68.2 & 48.9 & $<0,001$ \\
\hline \multicolumn{4}{|l|}{ Work adjustiments } \\
\hline Adjusted morking hours & 17.9 & 20.4 & 0.507 \\
\hline Adjusted jab demands & 13.5 & 14.3 & 0.808 \\
\hline Technical/ergonomic adjustments & 8.3 & 17.6 & 0.006 \\
\hline \multicolumn{4}{|l|}{ Physical and sacial enwironmental factors } \\
\hline Difficult access to work place & 13.7 & 3.3 & $<0.001$ \\
\hline Reduced transportation mobility at work place & $14 . \pi$ & 2.4 & $<0.001$ \\
\hline Colleagivies informed on AS & 69.2 & 76.0 & 0.098 \\
\hline Dependent on colleagues & 49.4 & 23.5 & $<0.001$ \\
\hline Negative attitude of colleagues to patient & 24.4 & 7.6 & $<0.001$ \\
\hline Negative attitude of management to patient & 17.3 & 3.6 & $<0.001$ \\
\hline Insufficient support colleagues or management & 41.0 & 12.8 & $<0.001$ \\
\hline
\end{tabular}

"Differences in proportions tested by Chi-squere test. 
86 Chapter 5

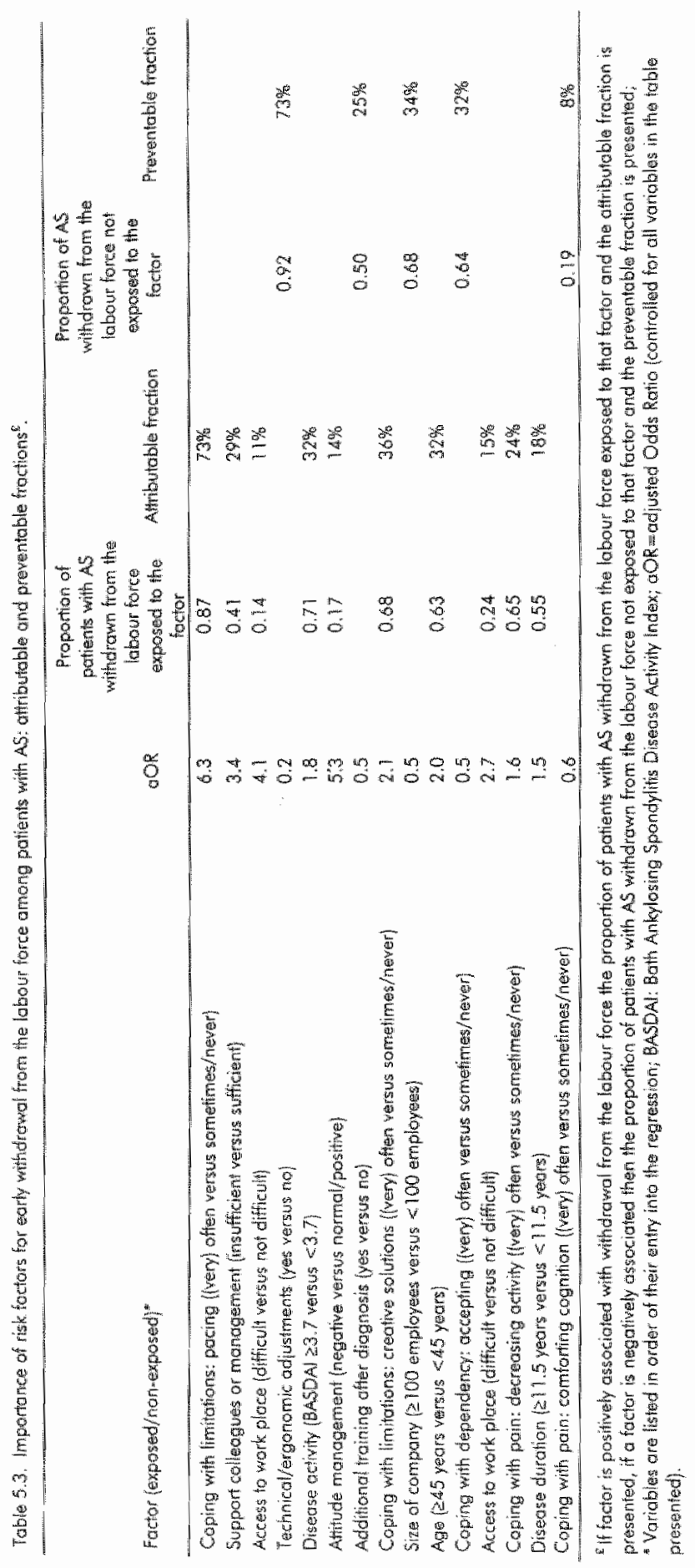


When the proportion of patients who had withdrawn from the labour force was calculated in terms of each factor, it emerged that pacing in order to cope with limitations accounted for $73 \%$ of the withdrawals. On the other hand, it was found that $73 \%$ of the withdrawals could still have been employed if technical or ergonomic adjustments of the work place had been arranged. Other important factors increasing the risk were: often/very often seeking of creative solutions in order to cope with limitations $(36 \%)$, a high disease activity $(32 \%)$, older age $(32 \%)$ and insufficient support from colleagues or management (29\%). Other important factors reducing the risk were: working in large company $(34 \%)$ and frequent/very frequent acceptance in order to cope with dependency $(32 \%)$.

In subsample analyses of patients who had withdrawn from the labour force within five years prior to the study and of patients with 5 or fewer years of disease, the same factors were identified. The following variables were stronger in the subsample of patients with 5 or fewer years of disease compared with patients in the full sample or in the subsample of patients withdrawn within five years prior to the study: pacing in order to cope with limitations, disease activity, attitude of the management and access to work place.

\section{Discussion}

Despite the fact that the overall labour force participation of the patients with AS under study was lower compared with the general population ${ }^{4}$, the present study indicates that the probability of participating in the Dutch labour force is already reduced in patients with AS with relatively short disease duration, and labour force participation is not additionally influenced by disease duration in patients with AS. In contrast with our study, most other reports on labour force participation and disease duration among patients with AS deal with groups with a work history, which found employment rates which still ranged from $79 \%$ to $85 \%$ after 20 years of AS, and still from $53 \%$ to $81 \%$ affer 30 years of AS. ${ }^{19.21}$ Our study also considered patients without a work history and controlled for the common risk factors of labour force participation: age and gender. Therefore, our results give a deeper understanding of the labour market position of patients with AS among the general working population in relation to their disease duration.

We report that sociodemographic factors, coping styles, disease related factors and various work related factors substantially contribute to withdrawal from the labour force in patients with AS. In a previous study we alleady identified coping as an important factor related to work among patients with AS. In this study, we further explored behavioural coping simultaneously with other factors. Pacing in order to cope with limitations, e.g. adapting one's level of activity indicated by "I take more time for my activities', 'I stop doing my activities in time', or 'll take full account of my limitations' was the major positively correlated factor. This implies that a passive way of coping with the limitations is associated with withdrawing from the labour force in these patients. Moreover, we found that 
five of the eight different coping styles assessed in this sudy significantly contributed to withdrawal from the labour force. With exception of our previous study, we know of no earlier study that has covered the effect of behavioural coping in relation to employment in patients with. AS. In foct, with respect fo patients with rheumatic diseases in general, only a few studies have examined the independent effect of behavioural coping on illness outcome, and only wo studies in rheumatoid arthritis found that patients use behavioural coping strategies when dealing with problems at work ${ }^{22.25}$ Earlier studies indicated that patients with AS use adaptive coping mechanisms in order fo cope with stressful situations and that these patients were comparable to patients with other rheumatic diseases in the use of active or passive coping mechanisms. ${ }^{26,27} 50$, our findings in patients with AS stresses the importance of behavioural coping in the relation with employment in patients with rheumatic diseases in general and in patients with $A S$ in particular.

The major employment factor negatively associated with withdrawal from the labour force was technical or ergonomic adjustment of the work place. One earlier study by Fellman et al. found that $62 \%$ of patients with AS had pain when working which was induced by a wrong or monotonous posture, long working times and untavourable climatic factors at work ${ }^{28}$ Guillemin et al. found that exposure to cold conditions and prolonged standing increased the risk of longterm work disability. Yelin et al, on the other hand, found no relation between getting equipment and the improvement of employment stotus of persons with musculoskeletal conditions. Compared with our study, Yelin et al. found a relatively low frequency of people getting special equipment $(5.3 \%)$ in a relatively old population with various musculoskeletal conditions. ${ }^{29}$ On the basis of those earlier studies and our study, we conclude that the ergonomic and climatic conditions at the work places of patients with AS specifically should be analysed at an early stage and adjusted to the needs of these patients in order to prevent problems at work.

Other major work related factors with negative correlation were working in a large company and additional job training after diagnasis, while insufficient support from colleagues or management, difficult access to the work place, and negative attitude of the management were positively correlated. Only few of these factors have been investigated in a multivariate context among patients with AS betore. 5 in line with our finding, wocational counselling and job training was already identified as a protective factor against long-term disability by Guillemin et al.

AS is generally considered to be a disease in which relatively good functional capacity and working ability is maintained. However, when adjusted for age and gender it is found that labour force participation in Dutch patients with AS is lower than in the population as a whole." Our study therefore prowides important information for developing and evaluating effective vocational intervention programmes to postpone or prevent early withdrawal from the labour force among patients with AS. Of course, effectiveness of intervention programmes should be evaluaied corefully. 
It should be pointed out that our study has some methodological limitations. Data were collected by a self-administered questionnaire and we did not validate this data using objective measures. However, the questionnaire included several well-validated instruments for assessing disease activity and outcome independently of employment status. ${ }^{9.16}$ So it is not likely that our results were substantially and systematically affected in any direction by differential misclassification, in other words a systematic difference in rating of disease activity and outcome between patients who had withdrawn and patients who still had a paid job.

Although data about employment were collected retrospectively, we think that considerable recall bias is less likely, because we found that work related factors were equally important in a subsample of patients who had recently withdrawn from the labour force.

With respect to coping, the cross-sectional design of our study does not allow us ta state that the explanatory variables have a causal relationship with withdrawal from the labour force. Our study does not rule out the competing explanation that withdrawal from the labour force invokes passive coping styles such as "pacing" as a way of coping with limitations or that behavioural coping and withdrawal from the labour force is reciprocally interrelated. On the other hand, research on coping in AS found that the coping mechanisms used did mot vary with the duration of AS', meaning that patients with AS may already develop a coping style early in the illness and use their favourite strategies to deal with stressful situations. A more longitudinal approach is needed to assess whether the association between coping and withdrawal from the labour force in AS is one of effect rather than cause.

To provide information on the extent to which withdrawal from the labour force is due to a specific factor, and to estimate potential maximum effect of intervention programmes in the light of these factors, we calculated attribulable and preventable fractions. Application of this technique is relatively new in this field of research. It is only found in two other studies in patients with RA. ${ }^{23,30}$ Considering our results with respect to, for instance, pacing in order to cope with limitations (accounting for $73 \%$ of the withdrawals) and disease activity (accounting for $32 \%$ of the withdrawals), it can be calculated that the sum of the fractions exceeds $100 \%$. Despite being aware that any withdrawal from the labour force could be caused or prevented by various factors, there might be a tendency to believe that the sum of these fractions should be $100 \%$. In fact, separate components of the underlying mechanism are not mutually exclusive. Therefore, the upper limit of the total of all fractions of all the components is not $100 \%$ but infinity. Onlly a fraction of withdrawal from the labour force atributable to ar preventable from a single component cannot exceed $100 \%{ }^{19}$ This is also the case in our study.

In summary, our findings show that it is important to consider sociodemographic factors, disease related factors, behavioural coping styles and work related factors in both research and vocational management of patients with AS. Research on the subject should give more attention to the study of behavioural coping and attitudes towards work depending on the nature and conditions of 
the work and on the social work enviromment and their effects on employment. Therefore, we emphasize those developers of intervention programmes dealing with work problems in patients with AS should consider and evaluate the involvement of a multidisciplinary team of professionals with medical, paramedical, psychosocial and occupational health expertise. Furthermore, we think that co-operation from employers and from colleagues is important to achieve moximum reduction in early withdrawal from the labour force among these patients. In practice, patients should be encouraged to remain active despite the stressors of their disease. Moreover, patients should be encouraged and guided to recognize and develop their talents, and if possible, should extent their education. In general, companies should be encouraged to promote positive attitudes towards people with disabilities. 


\section{References}

1. Ward MM. Quality of life in patients with ankylosing spondylitis. Rheum Dis Clin North Am 1998;24:815-27.

2. Ward MM. Health-related quality of life in ankylosing spondylitis: a sumey of 175 potients. Anthritis Care Res 1999;12:247-255.

3. Zink A, Braun J, Listing J, Wollenhaupt 1. Disability and handicap in rheumatoid arthritis and ankylosing spondylitis-results from the German rheumatological database. German Collaborative Arthritis Centers. J Rheumatol 2000;27:613-622.

4. Boonen $A$, Chorus $A_{*}$ Miedema $H$, wan der Heijde $D$, van der Tempel $H$, van der Linden Si. Employment, work disabillity, and work days lost in patients with ankylosing spondylitis: a cross sectional study of Dutch patients. Ann Rheum Dis $2001: 60: 353-358$.

5. Boonen $A$, de Vet $H$, van der Heijde $D$, van der Linden Si. Work status and its determinants among patients with ankylosing spondylitis. A systematic literature review. J Rheumatal 2001;28:1056-1062.

6. Guillemin F, Briancon S, Pourel J, Gaucher A. Long-term disability and prolonged sick leaves as outcome measurements in ankylosing spondylitis. Possible predictive factors. Arthritis Rheum 1990;33:1001-1006.

7. Boonen A, Chorus $A_{\text {, Miedema }} H$, van der Heijde D, Landewe R. Schouten $H$ et al. Withdrawal from labour force due to work disability in patients with ankylosing spondylitis. Ann Kheum Dis 2001;60:1033-1039.

8. Miedema HS, van der Linden SM, Rasker JJ, Valkenburg HA. A national database of patients visiting rheumatologists in the Netherlands: The Standard Diagnosis Register of Rheumatic Diseases. A repart and prelimimary analysis. Br I Rheumatol $1998 ; 37: 555-561$.

9. Calin A, Nakache JP, Gueguen A, Zeidler $H$, Mielants $H$, Dougados $M$. Defining disease activity in ankylasing spondylitis: is a combination of variables (Bath. Ankylosing Spondylitis Disease Activity Inciex) an appropriate instrument? Rheumatology 1999;38:878-882.

10. Calin A, Garrett S, Whitelock $H$, Kennedy LG, OHea J, Mallorie $P$, ef al. A new opproach to defining functional ability in ankylosing spondylitis: the development af the Bath Ankylosing Spondylitis Functional Index. J Rheumatol 1994;21:2281-2285.

11. Andries F, Wevers CW, Wintzen AR, Busch HF, Howeler CJ, de Jager AE, ef al. Vocalional perspectives and neuromuscular disorders. Int I Rehobil Res $1997 ; 20: 255-273$

12. Wevers CW, Brouwer OF, Padberg GW, Niijboer ID. Job perspectives in facioscapulohumeral muscular dystrophy. Disabil Rehabil 1993;15:24-28.

13. Niboer ID, Wevers CJ. Vocational rehabilitation of young adults with a disability of one arm or hand. In J Rehabil Res 1993;16:45-47.

14. van Lankveld W, yan't Pad B, van de Putte $L$, Naring $G$, van der Staak C. Diseasespecific stressors in rheumatoid arthritis: coping and well-being. Br J Rhew matol $1994 ; 33: 1067-1073$. 
15. wan Lankweld W. Naring $G$, van der Stack $C$, van "t Pad-Bosch, wan de Putte $L$ Stress caused by theumatoid arthritis: relation among subjective stressars of the disease, disease status, and well-being. J Behow Med 1993:16:309-321.

16. Jones SD, Steiner A, Garrett SL, Calin A. The Bath Ankylosing Spondylitis Patient Global Score (BAS-G). Br J Rheumatol 1996;35:66-71.

17. Statistics Netherlands (CBS). Survey of general population in the working age 1997 . The Hague: Statistics Netherlands, 1998.

18. Rothman KJ, Greenland S. Modern Epidemiology. Second ed. Philadelphia: Lippincott-Roven Publishers, 2000.

19. Ringsdal VS, Helin P. Ankylasing spondylitismeducation, employment and inwalidity. Don Med Bull 1991,38:282-284.

20. Lehtinen $K$. Working ability of 76 patients with ankylosing spondylitis. Scand J Rheumatol 1981,10:263-265.

21. McGuigan LE, Hart HH, Gow PS, Kidd BL, Grigor RR, Moore TE. Employment in ankylosing spondylitis. Ann Rheum Dis 1984:43:604-606.

22. Blalock SJ. DeVellis $B M$, Holt K, Hahn PM. Coping with theumatoid arthritis: is one problem the same as another? Heath Educ Q 1993;20:119-132.

23. Chorus AM, Miedema HS, Wevers CW, van der Linden Si. Work factors and behovioural coping in relation to withdrawal from the labour force in patients with rheumatoid arthritis. Ann Rheum Dis 2001;60:1025-1032.

24. Harter M. [Psychosomatic aspects of theumatic diseases]. Psychother Psychosom Med Psychol 1993;43:100-109.

25. Basler HD, Rehfisch HP. Cognitive-behavioral therapy in patients with ankylosing spondylitis in a German self-help organization. I Psychosom Res 1991;35:345-354.

26. Gunther $V$, Mur E. Traweger $C$, Hawel R. Stress coping of potients with ankylosing spondylitis. I Psychosom Res 1994,38:419-427.

27. Mengshoel AM, Forre $O$. Pain and fatigue in patients with rheumatic disonders. Clin Rheumatol 1993; 12:515-521.

28. Fellmann J, Kissling $R$, Baumberger $H$. [Socio-professional aspects of ankylasing spondylits in Swizerlandl Soxin professonelle Aspekte der Spondylitis ankylosans in

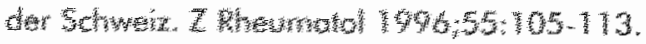

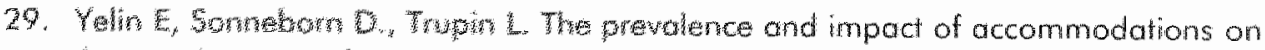

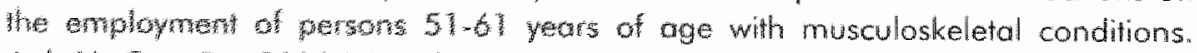

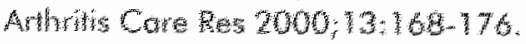

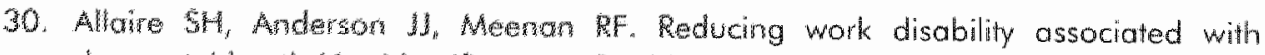

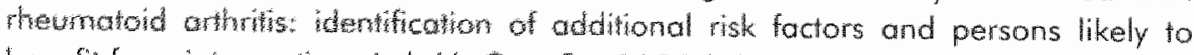
bendfut from intervention. Arthits Core Res 1996;9:349-357. 


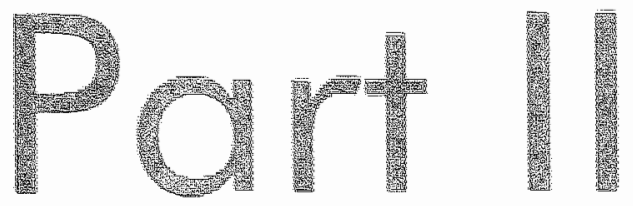

Cost-of-illness in ankylosing spondylitis 

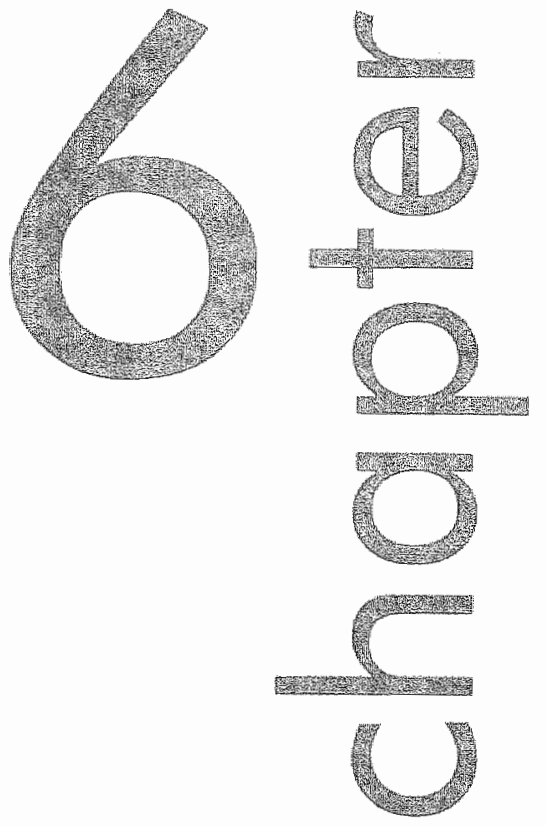

Direct costs of ankylosing spondylitis and its determinants

A companison among three European countries

A Boonen, D von der Heijde. R Londewt. FGullemin, M Ruten von Molken. M Dougados, H Melants, K de Vam, H von der Tempel, 5 Boesen, A Spoorenberg. H Schouten. Sivon der Linden

Submited for publication 
96 Chopter 6

\section{Abstract}

\section{Aim}

To assess the direct costs associated with ankylosing spondylitis (AS). To determine which variables, including the country providing the health core, predicts these costs.

\section{Methods}

216 patients with As from The Netherlands, France and Belgium participated in a two years observational study and filled in bimanthly economic questionnaires. For each country, disease related heath resaurce utilisation was measured and direct healthcore and direct non healthcare costs were calculated from a societal perspective (using true cast estimates) and from a finoncial perspective (using country specific tariffs). Predictors of costs were assessed using Cox"s proportional hazord regression analysis with costs as outcone.

\section{Resuls}

209 patients provided sufficien data for cost analysis. Mean annual socielah direct costs per patient were $€ 2,640$ (median $E 1,242$ ) of which $82 \%$ were direct healthcare costs and $18 \%$ direct non-healthcare costs. Longer disease duration (HR: $0.97 ; 95 \% \mathrm{Cl}: 0.95$. 0.98 ), lower education (HR $0.67 ; 95 \% \mathrm{Cl}: 0.46-0.96$ ), worse physical function (BASFI) at entry into the study (HR: $0.91 ; 95 \% \mathrm{Cl}: 0.84 .0 .99$ ), and higher disease activity (BASDAI) at entry into the study $(\mathrm{HR}: 0.79 ; 95 \% \mathrm{Cl}: 0.71 .0 .89)$, were predictors of higher direct societal costs (HRs $<1$ indicate higher costs). Athough there were differences in several cost categories among the countries, the total direct costs did not differ significantly among the countries studied. Mean annual direct costs fram a financial perspective were $€ 2,122$ (median $\in 747$ ), $€ 1,402$ (median $€ 989$ ) and $€ 94 \pi$ (median $€ 631$ ) per patient in The Netherlands, France and Belgium respectively. Costs from a financial perspective were significantly lower than costs from a societal perspective.

\section{Conclusion}

The direct costs for AS are substantial in three European countries. The large differences in cost calculation from a societal and a financial perspective were significant, indicaling the importance to state clearly the viewpoint of the economic analysis. Since worse physical function and higher disease activity are important determinants of the direct costs, it can be expected that better disease control can substantially reduce the costs of AS. 


\section{Introduction}

Cost-of-illness (COI) studies can contribute to a more complete understanding of the impact of a disease. The results can be used to identify the cost categories, which contribute most to the total costs of the disease, to explore determinants of costs and to compare costs of different diseases. In addition, data can be imputed in cost-effectiveness or cost-utility models. In national policy making, results can be helpful to set priorities for research and treatment options in national policymaking. ${ }^{1.5}$ Despite the growing attention for cost studies, also in rheumatic diseases, only few data exist on the direct casts of ankylosing spondylitis (AS). ${ }^{6.7}$ This is surprising since the disease accurs not infrequently, with on estimated prevalence varying from 0.08 to $0.8 \%$, starts at early age (usually in the third decade), and has important consequences on physical function. ${ }^{10.13}$ There is much interest in international comparisons of healthcare expenditures. Apart from telling what is known about the costs of the disease, cross-country comparisons potentially allow to assess the country's performance on cost containment. In 1997 and 1998 we performed a prospective burden-of-illness study in AS in three countries: The Netherlands, France and Belgium. These European countries share scientific standards on medical care and have comparable economic prosperity. There are, however, some differences in the organisation of health care. We already reported the productivity costs and the contribution of differences in social security systems to variation in these costs. ${ }^{14}$ Here, we compare AS related direct costs of a crosssectional group of patients in the three countries. Direct costs were calculated from a societal point of view, comprising all the costs due to disease or its treatment, and from a financial point of view, comprising costs of disease incurred by the official healthcare payer in order to estimate the actual national expenditure on AS. In addition, determinants of costs were explored.

\section{Methods}

\section{Patients}

Patients were obtained from the rheumatology departments of four hospitals in three countries, the University Hospital Maastricht and the Maasland Ziekenhuis Sittard in The Netherlands, L'Hôpital Universitaire Côchin Paris in France and the University Hospital Ghent in Belgium. The detailed description of patient recruitment has been published before. All patients had radiological sacroilititis according to the modified New York criteria for AS. The hospitals of Maastricht, Paris and Ghent have a regional and referral (academic) function. Sittard is a regional hospital co-operating in research projects with the University Hospital Mcastricht. Traditionally, in all three countries patients with a chronic rhoumatic 
disease are referred to a rheumatologist. Patienis were included between september 1996 and March 1997 and were followed for wo years.

\section{Questionnaires}

At baseline and every six months patients underwent a climical examination and completed questionmaires comprising (1) sociodemographics induding (changes in) protessional and working status, (2) disease characteristics including AS related comorbidity and $A S$ specific physical function measured by the Bath Ankylosing Spondylitis Functional Index (BASFI) (range 0-10; higher walles indicating worse function $)^{10}$ and (3) an economic questionnaire asking about aids and appliances purchased, adaptations at home, spa treatments and financial contributions to health related organisations in the past six months. Every 2 months patients completed the Bath Ankylasing Spondylitis Disease Activity Index (BASDAl), measuring AS specific disease activity (range 0.10; higher walues indicating higher disease activityl ${ }^{15}$ and an economic questionnaire asking about the number of visits to all kinds of healthcare providers, kinds and dosages of medications used, numbers and kinds of technical procedures performed, numbers of days of inpatient care, number of days absent from paid work, number of weekly hours of formal and informal household care received because of AS in the past two months. The economic questionnaires concerned resource use or costs related to $A S$ and were developed for this study, using examples from other cost studies in rheumatic disease as a guide. 16.18 Because of the international character of the study, questionnaires were adapted for each country with respect to language, educational system, currency of costs and health insurance system. For the purpose of statistical analysis educational level was dichotomised into more than twelve years formal education as opposed to twelve years or less. Presence of peripheral arthritis was defined as presence at baseline of at least one swollen joint out of 44 passible joints (including the shoulders) assessed the physician" and inflammatory bowel disease (IBD) was defined as self-reported presence at baseline of IBD for which a visit to the specialist had been necessary the year preceding entry into the study.

\section{Financing and organisation of healthcare}

The three countries have an obligatory heath insurance system since the middle of the 20 th century, reflecting essentially a Bismarkian model.

In The Netherlands, chronic in-patient care lelderly, psychiatric potients and handicapped) is financed through taxes and amounts to $10.25 \%$ of the gross wage of employees (Algemene Wet Bïzondere Zorg [AWBZ]). Ambulatory and acute in-patient care is financed through premiums to heath insurance companies. For people with a lower income, a public insurance system exists. These premiums are $7.4 \%$ of the gross wage $15.85 \%$ paid by the employer and $1.55 \%$ by the employeel. People with a higher income, hove a private insurance with higher premiums. The Dutch law obliges the many competing health insurance companies to guarantee a basic insurance package against a unform premium lopproximately $E 1,036$ per year for one individuall. in the 
Wetherlands, wo thirds of the population are public insured and one third private. For provisions included in the basic insurance package there is no or minimal patient contribution for public as well as for privately insured patients. For healthcare provisions not reimbursed, reinsurance is possible for all subjects through an additional (private) insurance. Premiums, risks covered and level of coverage differ greatly among kind of insurance chosen and among the health insurance companies. Approximately $90 \%$ of the Dutch subjects have some kind of additional health insurance. Patients with chronic diseases may have to pay higher premiums for this additional (re-) insurance. In general, the health care providers are paid directly by the health insurance companies and patients have no direct payments. Healthcare providers working in academic hospitals are usually paid through salaries. General practitioners and non-academic physicians are paid on a capitation basis for the public insured patients and an fee per service basis for private insured patients. Physiotherapists working in the ambulatory sector are paid per service basis. All other healthcare providers are salaried. Historically, in The Netherlands there is a strong primary care organisation acting as gatekeeper towards access to secondary and tertiary care.

In France, healthcare costs as well as sickness and work disability benefits are paid by the Securite Sociale (SS), which is financed through social contributions by employers and employees. The social contribution equals $19.6 \%$ of the employee's gross wage $112.8 \%$ paid by the employer and $6.8 \%$ by the employee) but these include contributions to pay for sick lleave and work disability. Patient contributions for healthcare are substantial and can be as ligh as $40 \%$ of the total costs. Therefore, $80 \%$ of the French patients have on additional private health insurance at one of the many competing insurance companies. Premiums, risks covered and level of coverage of the risks differ greatly among kinds of insurance chosen and among the health insurance companies. Patients with a chronic disease may have to pay higher premiums for the additional private health insurance. On the other hand, some patients with a chronic disease (among which severe AS) can be exempted from out of. pocket comtributions imposed by the SS and disease related healthcare costs will be rully reimbursed. Physicians and other healthcare providers working in academic hospitals are salaried. General practitioners, non-academic physicians and physiotherapists are paid on a fee per service basus. Patients pay their own contribution direcly (ticket moderateur) to the healthcare provider. In contrast to the situation in The Netherlands, access to specialist care is not limited by the gatekeeper role of primary care.

In Belgium, healthcore provisions are mainly paid by a limited number of health insurance companies, which ore financed partly by social contributions $17.35 \%$ of the gross wage; $3.55 \%$ by the employer and $3.80 \%$ by the employee) and a (small) premium by the members. In addition, there are important patient contributions, which are maximised. For elderly, severely handicapped, widows without income and orphans the level of patient contribution is lower. Possibilities for re-insurance for patient contribution are limited to the costs of hosplalisation. Physicians and other healthcare providers working in academic hospitals are salaried. Genenal practitioners, non-academic physicians and 
physiotherapists are paid on a fee for service basis. Depending on the service consumed, patients pay only the personal contribution (technical procedures and drugs) or pay the whole amount and are reimbursed atterwards (physician visits:. Access to specialist care is not limited by the gatekeeper rale of the general practitioner. An overview of the macro-economic sources to finance healthcare in the three countries studied is provided in Appendix I.

\section{As related health resource utilisation}

Direct healthcare resource utilisation because of AS, including the extraspinal manifestations, comprised (1) the number of visits to the general practitioner, specialists (rheumatologist and other specialists), alternative medicine, physiotherapist and other paramedical care providers (rheumatology nurse practitioner, ergotherapist, social worker or psychotherapist); (2) the number of days of inpatient care lemergency department, hospitalisation and rehabilitation clinic); (3) the number of technical procedures performed (venal punctures, conventional radiographic examinations and all other technical procedures including CT-scan, MRI, ultrasound, all types of endoscopies, foint aspirates, fundoscopic exams, pre-operative ECGs, spirometry, etc; (4) all medications taken in tablets per day and number of prescriptions purchased; (5) number and duration of spa treatments, (6) number and type of assistive devices; (7) number of adaptations at the house or at the work place and (8) the weekly number of hours of formal home care. Since the questionnaires asked only about the number of venal punctures and number of radiographic sessions, without specifying which exams were performed, we did a small additional investigation among the rheumatologists of the different participating centres to ask them about their routine practice when ordering specific laboratory tests or conventional radiographic exams in different types of patients (with and without extraspinal manifestations; with and without NSAIDs; with and without disease madifying antirheumatic drugs). The country specific practice was then used to specify the type of laboratory examinations per venal puncture and the type of conventional radiographic fillms per session.

Direct non-healthcare resource utilisation because of AS or its extraspinal manifestations included (1) number of times a swirnming or exercise group was attended, (2) renewals of memberships to AS societies or healthcare providing organisations, (3) weekly number of hours of informal care by (paid) private household help or unpaid help from family or friends, and (4) kind of transport and distance to all healthcare providers (in- and outpatient). Health resource utilisation was not ascentained by comparison with other data-sources.

\section{Cost estimations}

Costs were calculated first from a societal and next from a financial perspective. In the societal perspective all cost categories are relevant to the total costs. In the financial perspective, costs accrued by the official national healthcare payers were considered. For each perspective, the appropriate unit cost for each resource had to be determined. 
When considering the societal perspective, the unit costs have bo reflect true costs and ideally these are represented by the opportunity costs. Therefore, as much as possible true (markety prices have to be used. However, it is well known that the tariffs (or charges) of most healthcare provisions (especially visits to healthcore providers, impatient core and technical procedures) are by no means a reflection of the true cast. In France and Belgium, true cost estimates for healthcare provisions have been performed for only a very limited number of resources and were insufficient for our analysis. In the scope of our study, it was not feasible to perform true cost calculations for each singlle health resource. We therefore decided to use in the societal perspective, the true cost estimates from The Netherlands and apply these to the country specific health resource use. The cost estimates from The Netheriands were not adapted by using healhoure purchasing parities because their validity is still insufficient. ${ }^{20}$ As a consequence, the differences in costs among countries in the societal perspective reflect differences in health resource uttilisation among countries. In The Netherlands, recenty Guidelines for Pharmaco-Economic Evaluations ${ }^{21}$ were published, which provide true cost estimates for a large number of healthcare provisions. Cost estimates include the direct attributable and non-direct atributable costs (including overhead) and aim to reflect average national cost estimates. For hospitalisations and visits to specialists a distinction between peripheral and university hospitals was made. For tectunical pracedures, however, the guideline refers still to the Dutch tariffs. Fortunately, the Financial and Economic Department of the University Hospital Maastricht performs true cost calculations for such procedures since 1997, which are yeally updated. Comparable to the cost estimates in the Dutch guidelines, calculations include direct attributable and not-direct attributable (including overhead) costs. Costs of alternative medicine were not available in the Guideline, but were derived from a Dutch study on the costs of alternative medicine. ${ }^{22}$ For cost valuation of medications. the patients hod insufficiently reported the number of prescriptions purchased at the pharmacy (reflecting the true expenditures for drugs). Therefore, the number of prescriptions purchased was estimated from the daily doses of each drug. recorded by the patient in the cost questionnaire. The official Dutch drug price was used to calculate the unit cost for each drug or tablet. ${ }^{2 a, 24}$ in addition, per prescribed item (with a maximal prescription period of three months) an additional fee of $€ 4.64$ has to be paid to the pharmacists (prescriplion rule), which was included in the total costs of drugs. Since 1985, in the Netherlands, several measures have been taken in order to reduce the drug costs and one of these measures was enhancing generic prescribing and stimulating parallel import of cheaper drugs. For each active drug substance, a maximal reimbursable price was set by the government and when the pharmacists can buy that diug at a cheaper price, he can keep the profit. This measure allows competition among pharmaceutical companies and results in some variation in the costs of drugs. The pharmacist is likely to buy the cheapest product since this provides him the largest personal benefit. In our analyses, we used the lowest avalable price in case multiple prices. For drugs prescribed in France and Belgium, we used the price of the Dutch generic drug, if the generic drug was marketed in The Netherlands. When a drug prescribed in France or Belgium 
was not available in The Netherlands, a substifute from a similar class of drugs was sought. For costs of spa therapy, aids and appliance or adaptations in the house and costs of private household, the costs as mentioned by the patients in the questionnaires were used. If these were missing, we used the cost of a similar resource from a patient from the same couniry. Following the Dutch Guideline, formal care was valued at $€ 17.25$ per hour and informal care at $€ 7.95$. Transport costs were valued at $€ 0.11$ per $\mathrm{km}$ (variable price per kilometre) for private or public transport and $€ 1.30$ per $\mathrm{km}$ for transport by taxi or special transport for chronically ill patients. Parking costs were valued at E T.14 per ticket.

When considering the financial perspective, a broad healthcare payer's point of wiew was chosen in order to provide the most complete estimate of the economic burden of the disease for the (national) healthcare payer. This included expenditures by health insurance companies, government, municipality and special funds for patients with chronic diseases. The official country-specific tariffs $^{25-28}$ or other sources if applicable and country specific drug prices ${ }^{23,24,29,30}$ were used. When applicable tariffs or prices were corrected far patient out-ofpocket contribution. In the Netherlands, differences for some tariffs between the private and public insured patients were taken into account. Also during the second year of the study, all patients in The Netherlands had an obligatory outof-pocket contribution of the first $€ 46.60$ per year for utilisation of medical resources included in the basic coverage packet. In The Netherlands and France but not in Belgium, pharmacists are allowed to substitute a brand drug by the cheaper generic drug. In Belgium, several specific regulations to calculate the tariffs for some technical procedures such as consultancy honoraria, forfaitary honoraria and non-cumulation regulations of some fechnical procedures had to be considered as well as maximum amount of copayment for drugs.

Costs within the two years' abservation were averaged and the unit costs for the year 1998 were applied without discounting the costs of the resource use in 1997. Where applicable, taxes were included in the cost estimates. All costs were expressed in Euro currency of December 31, 1998. One Euro was fixed to equal NLG 2.20, FF 6.56 and BEF 40.34. At the same date, $€ 1.00$ was worth
US\$ 1.17 .

Sources of the estimates of the unit costs for each resource for the societal and financial perspective and an abbreviated list comparing tariffs and prices among the countries are available in Appendix II of the online internet version.

\section{Statistical analyses}

Results are analysed for patients completing two years of follow-up and having filled-out at least 9 out of 12 bimonthly questionnaires. For missing values of health resource utilisation in these questionnaires, the mean of the completed questionnaires of the same patient was imputed. Demographic and disease characteristics are presented using descriptive statistics and differences among countries ore assessed by Chi-square for proportions and ANOVA for continuous variables. For health resource use, firstly the proportions of patients having used this resource over the study period were assessed, next the mean 
annual number of units of each particular resource category averaged over all patients and finally the annual costs per resource categary averaged over all patients. Since costs were skewed also medians and ranges are presented to reflect the distribution of the costs. To compare unadjusted differences in healthcare use or costs among the three countries, univariate analyses were performed using Chil-square (for proportions of potients having used that resource) or Kruskall-Wallis and Mann. Whitney $U$ test ffor the number of resources or costs). When comparing costs from societal and financial perspective within the same country, Wilcoxon test was used. To assess determinants of costs, Cox's proportional hazard regression analyses were performed with costs as dependent wariable. Several sociodemographic and disease characteristics were chasen as independent variables: gender, age, disease duration since diagnosis, educational level (dichatomised into $\leq 12$ years and $>12$ years of formal education), presence of baseline peripheral arthritis, presence of baseline inflammatary bowel, baseline BASFI, baseline BASDAl and country (dummy). Since our primary interest was to assess differences in costs among countries, the dummy-variable country was entered in a first bloc and all other independent variables in a second bloc using a backward likelihood elimination technique. Interactions between the final variables of each madel and the dummy country were sought entering the main effects and the interaction terms simultaneously in the model. Interactions between infllammatory bowel disease and France as a country could not be explored since non of the French patients suffered from IBD. Finally, regression analyses were repeated after excluding patients with extreme costs. Cox's proportional hazard regression analysis was chosen because costs were skewly distributed, even after log transformation. A hazard ratio (HR) below 1 indicates that high values of the independent variable (for example BASFl) go with high values of the dependent variable (for exomple costs). All procedures were performed using SPSS 9.0

\section{Results}

\section{Potients}

In total 216 (1355 Dutch, 54 French and 27 Belgian) patients with As fulfilled the modified New York criteria and started the study. In the course of the follow-up five Dutch, one French and one Belgian patient stopped participation. All patients who completed follow-up had filled out at least nine out of twelve questionnaires. The proportion of patients with a missing bimonthly questionnaire was $84 \%$ and the proportion of missing (or incomplete) questionnaires was $10 \%$. Sociodemographic characteristics of 209 patients who completed the study are presented for each country separattely (Table 6. 1). When comparing patient characteristics among countries, Dutch patients were older, had on average a lower educational level and reported worse physical function (BASFI). None of the French patients had concomitant inflammatory bowel disease. Of the Dutch patients, $77 \%$ were public insured and $23 \%$ private. 
Of the French patients, $72 \%$ were $100 \%$ reimbursed by the Securite Sociale. None of the Belgian patients had a special reimbursement status.

Table 6.7. Characteristics of patients completing the study.

\begin{tabular}{lcccc}
\hline & $\begin{array}{c}\text { Total } \\
n=209\end{array}$ & $\begin{array}{c}\text { The Netherlands } \\
n=130\end{array}$ & $\begin{array}{c}\text { France } \\
n=53\end{array}$ & $\begin{array}{c}\text { Belgium } \\
n=26\end{array}$ \\
\hline Male; \% & 70.3 & 70.8 & 67.9 & 73.1 \\
Age; mean years & 43.1 & 45.6 & 37.4 & 47.9 \\
[range] * & {$[18-77]$} & {$[23-77]$} & {$[19.67]$} & {$[18-74]$} \\
Education s12years"; $\%$ & 71.8 & 82.8 & 48.1 & 65.4 \\
Disease duration; mean & 11.1 & 11.9 & 9.2 & 10.8 \\
(sd) & $(8.9)$ & $(9.2)$ & $(7.4)$ & $(10.3)$ \\
IBD; \% & 7.2 & 10.0 & 0 & 7.7 \\
Peripheral arthritis; \% & 25.4 & 28.5 & 26.4 & 8.7 \\
BASFI baseline; mean & 3.3 & 3.9 & 2.5 & 2.6 \\
(sd) & $(2.6)$ & $(2.4)$ & $(2.9)$ & $(2.3)$ \\
BASDAl boseline; mean & 3.3 & 3.7 & 2.8 & 3.1 \\
(sd) & $(2.1)$ & $(2.1)$ & $(2.3)$ & $(1.9)$ \\
\hline
\end{tabular}

$P$ Walue for difference among countries $<0.05$ (tested by Chi-square for proportions and ANOVA for continuous variables); IBD: inflammatory bowel disease; BASFI: Bath Ankylosing Spondylitis Fundtional Index (range 0-10, higher values indicating worse function): BASDAl: Bath Ankylosing Spondylitis Disease Activity Index (range 0-10, higher values indicating higher disease activifyl.

\section{Health resource use and costs}

Table 6.2 presents proportions of patients having used a specific resource category, the average number of units per patient used each year for each resource category and the associated annual societal costs in Euro per patient. The average annual direct costs were $\in 2,640$ (median $\in 1,242$ ) per patient.

Direct healthcare costs accounted for $82 \%$ of the total direct costs and direct non-healthcare costs for $18 \%$. In decreasing order of importance, the largest contribulors to the tolal direct costs were inpatient care foverall $27 \%$ [hospitalisations $18 \%$, visits to emergency department $8 \%$ and costs of rehablitation clinic $1 \% 1 \%$, physiotherapy $(13 \%)$, combined formal and informal care $(22 \%)$, medication $(13 \%)$ and technical procedures $(8 \%)$. Reasons for hospitalisation during the course of the study were active AS for twelve out of 28 patients who had required an episode of hospitalisation, arthrascopy or joint replacement for six patients, active inflammatory bowel disease (IBD) for eight patients, $\mathrm{BD}$ related bowel surgery in one patient and $\mathrm{AS}$ related cataract surgery in one patient. In addition, one patient was admitted to a rehabilitation hospital becouse of paraplegia after spinal fracture. Table 6.3 illustrates the differences in resource use and costs among countries and Table 6.4 provides details on the usage of the different kinds of drugs among the countries. 


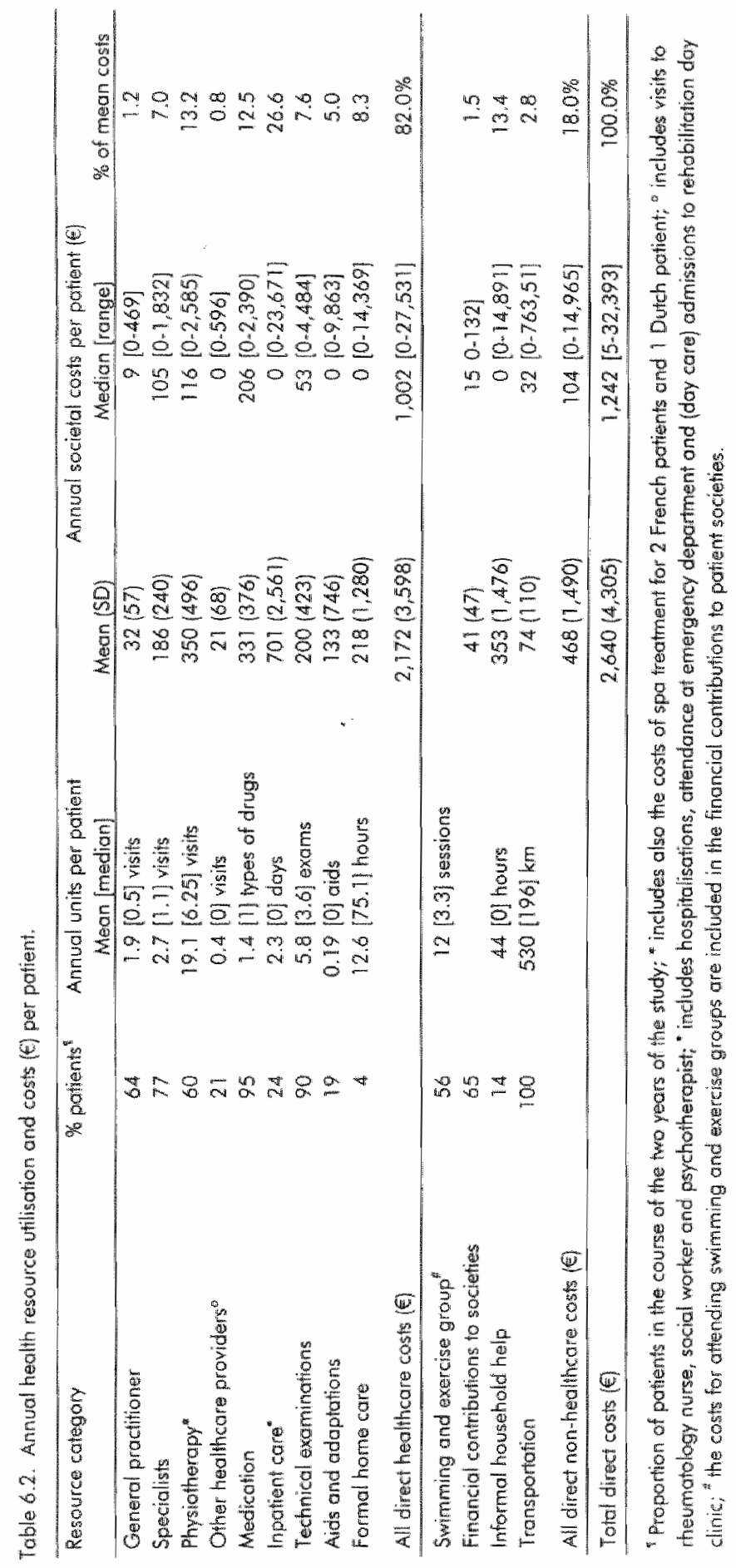


1061 chapter 6

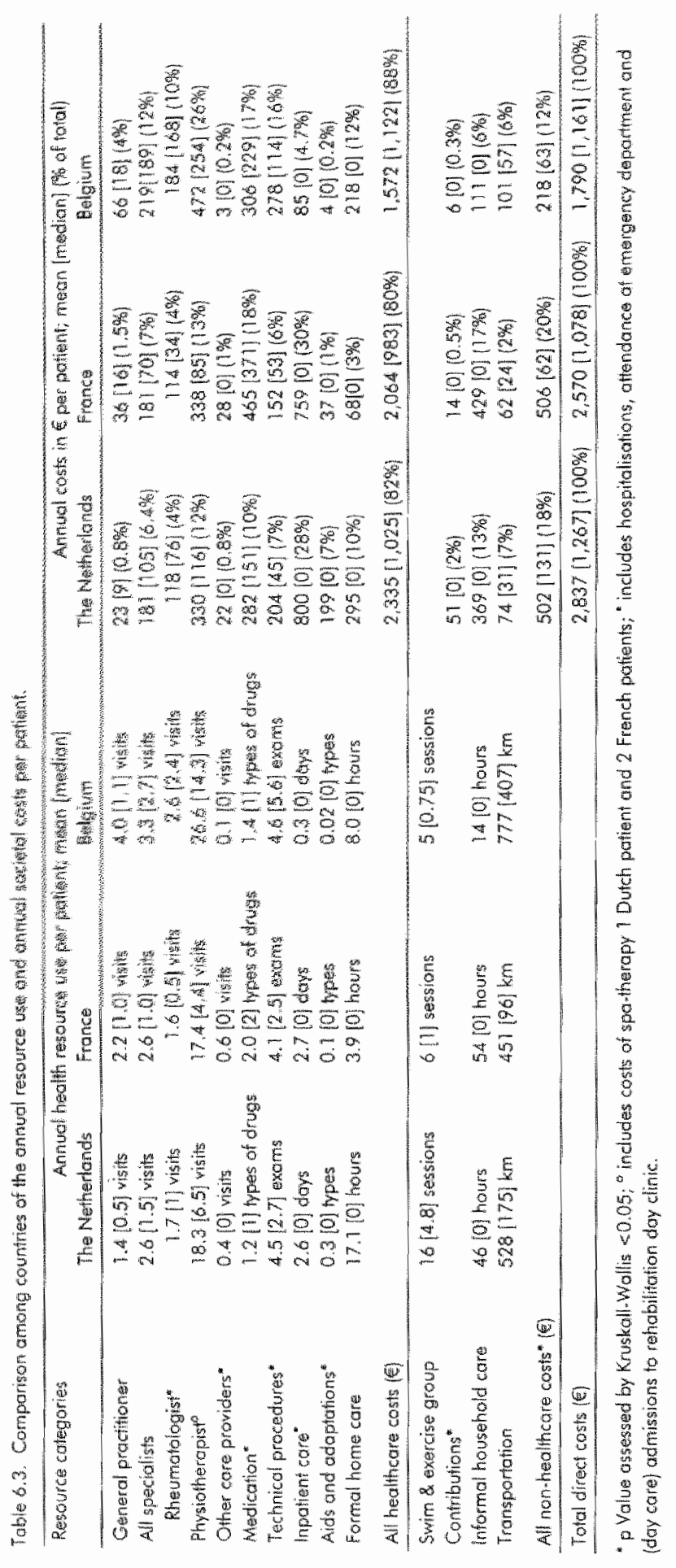


The mean total direct societal costs did not differ statistically among countries, as reflected by the comparable median costs. However, there were clear differences among countries for several cost categories, reaching statistical significance for costs of visits to theumatologists, visits to other care providers ineumatology nurse, psychotherapist and social worker), technical procedures, aids and appliances and financial contributions to patient societies.

Resource use of all outpatient care combined (visits to all care providers and technical procedures) and associated costs tended to be higher in the Belgian patients $(€ 1,038$ per patient per year compared with $€ 738$ and $€ 737$ in The Netherlands and France respectively), but this difference was offset by lower costs of inpatient care in the Belgian patients. In contrast to both other countries (diaycare) rehabilitation facilities, included in the cost category inpatient care, are not available in Belgium for patients with AS. French patients had remarkably higher medication costs. This could be explained by an overall higher use of drugs, especially of painkillers and (more expensive) gastro-protective drugs (Table 6.4). Also a large proportion of patients were prescribed a particular NSAID (meloxicam) that was relatively new at the time of the study and more expensive (no generic substifute) than the regularly prescribed drugs. Of all patients using regularly an NSAID, 32\% of French patients used meloxicam compared with $14 \%$ and $9 \%$ of Dutch and Belgian patients respectively. Costs for aids and adaptations and for contributions to patient societies were significantly higher in The Netherlands compared with both other countries.

Table 6.4. Proportion of patient using drugs at baseline.

\begin{tabular}{lcccc} 
& The Netherlands & France & Belgium & p Valve \\
\hline Analgetics & $9 \%$ & $25 \%$ & $7 \%$ & 0.03 \\
NSAIDs & $75 \%$ & $89 \%$ & $85 \%$ & 0.6 \\
DMARDs & $6 \%$ & $21 \%$ & $33 \%$ & $<0.0001$ \\
Gastroprofective drugs & $14 \%$ & $38 \%$ & $7 \%$ & 0.003 \\
Corticosteroids & $0.75 \%$ & $4 \%$ & $2 \%$ & 0.08 \\
Treatment for uveitis & $6 \%$ & $15 \%$ & $4 \%$ & 0.03 \\
\hline
\end{tabular}

"p Value for overall difference among the countries assessed by Chi-square; "proportion of patients treated for uvelitis in course of study.

When interpreting the costs from financial perspective (Table 6.5), it is clear that some cost categories disappear from the analyses because no external payer exists. For all countries, cosfs from financial perspective were significantly lower than costs from societal perspective $(p<0.0001$ for all countries; . For several costs categories the ranking of the countries for the level of costs for that particular cost category changed. For example, costs of physician visits were highest for Belgium in the societal perspective while they were the lowest in the financial perspective. Costs of drugs from the financial perspective for Belgium were significantly lower compared with societal perspective because of the large patient with the contribution for drugs in that country. 
los $\mid$ Chopter 6

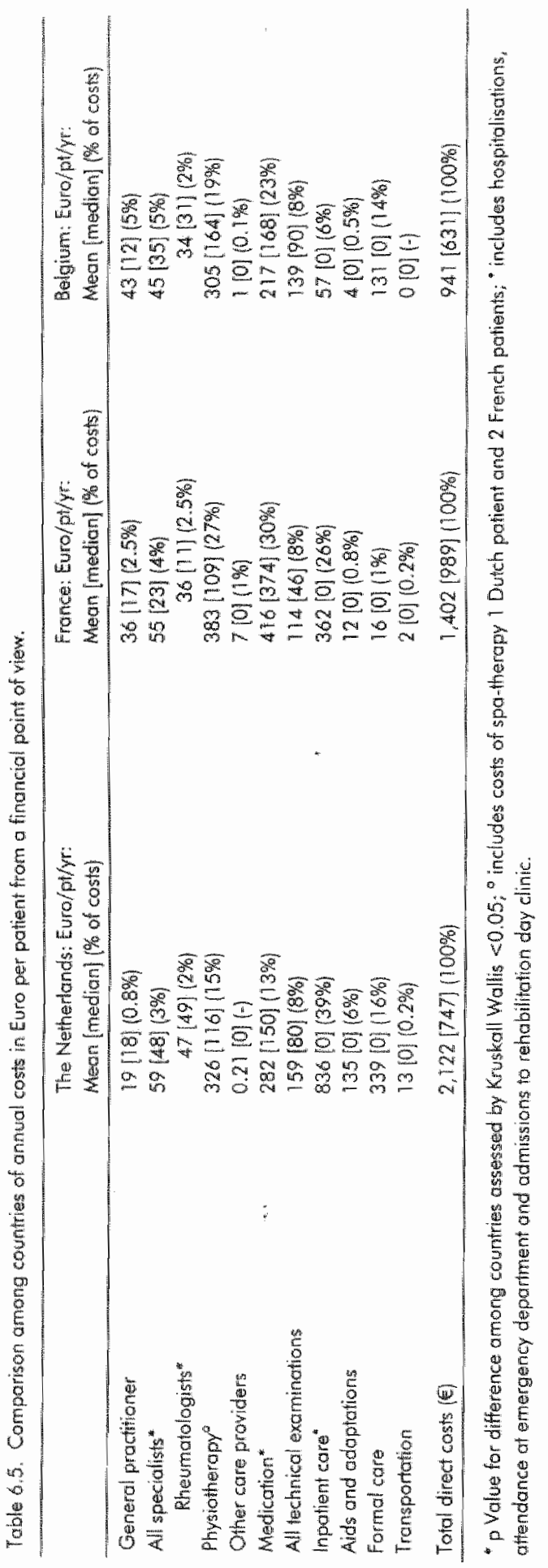


Table 6.6. Determinants of total direct annual costs from societal perspective assessed by Cox"s regression andyses.

\begin{tabular}{lcc} 
& HR $[95 \% \mathrm{Cl}]$ & PValue \\
\hline France opposed to The Netherlands & $0.99[0.68-1.96]$ & 0.67 \\
Belgium opposed to The Netherlands & $0.92[0.56-1.51]$ & 0.92 \\
Belgium opposed to France & $1.11[0.65-1.98]$ & 0.69 \\
Female gender & $0.75[0.54-1.05]$ & 0.09 \\
Disease duration in years & $0.97[0.95-0.98]$ & 0.002 \\
Education (SI2 years) & $0.67[0.46-0.96]$ & 0.03 \\
BASFI baseline & $0.91[0.84-0.99]$ & 0.03 \\
BASDAl baseline & $0.79[0.71-0.89]$ & $<0.0001$ \\
\hline
\end{tabular}

"HRs< 1 indicate higher costs: BASFI: Bath Ankylosing Spondylitis Functional Index lrange 0.10, higher values indicating worse function); BASDAl: Bath Ankylosing Spondylifis Disease Activity Index (range 0.10, higher values indicating higher disease activity).

\section{Determinants of costs}

Table 6.6 presents the determinants of the total direct costs from a societal perspective. Patients with longer disease duration, lower educational level, worse physical function and higher disease activity have higher costs. In addition, societal costs tended to be somewhat higher in female patients, who incurred $\in 3,439$ (median $€ 1,522$ ) direct societal costs compared with $\in 2,318$ (median $\in 1,126)$ in male patients. This could be attributed entirely to the higher costs of formal and informal home care $(p<0.0001)$ and for aids and adaptations $(p=0.04)$ for female patients. For all other cost categories, female patients tended even to have lower health resource use and costs, despite similar disease chanacteristics as male patients (data not shown separately). In patients with a lower educational level $(\leq 12$ years) total direct costs were $€ 2,830$ (median $€ 1,152$ ) compared with 2,146 (median $€ 942$ ) in those with higher educational lewel. Resource use and costs were higher for all cost categories in patients with a lower educational level. In univariate analysis this was significant for costs for physiotherapy $(\mathrm{p}=0.002)$, costs for "other" healthcore providers (including rheumatology nurse, psychotherapist and sacial worker) ( $p=0.04$ ), all nonhealthcare costs $(\rho=0.001)$ and nearly significant for costs of aids and adaptations $(p=0.09)$. Although patients with lower educational lewel had similar frequency of extraspinal disease manifestations as patients with a high educational level, they reported worse physical function (BASF: 3.81 versus 2.07; $p<0.0001$ ) and higher disease activity (BASDAl: 3.63 versus 2.47; $p<0.0001$ ) (data not shown separately). Disease activity at entry into the study was the most important predictor of direct societal costs. Figure 6.1 visualises. the relation between disease activity and the logarithmic transformed costs in a scatter-plot. Patients with a baseline BASDAll lower than four incurred $E 1,468$ (median: 1,053) societal costs opposed to $\in 4,722$ (median: 2,513 ) in patients with baseline BASDAl equal to or higher than four. Extraspinal disease manifestations were no independent predictors of direct cosls but their effect was fully explained by higher disease activity and worse physical function. Total annual direct societal cosis per patient in those without extraspinal disease was 
E 1,798 (median: 1,063) compared with 64.499 (median: 1,971) in those with extraspinal disease. No interactions beween country and the other determinanis of the final model could be detected, indicating that all determinants act similarly in each country separately. When repeating the analyses after exclusion of five patients (three Dutch and wo French patients) with extreme high costs, the results of the regression models did not change.

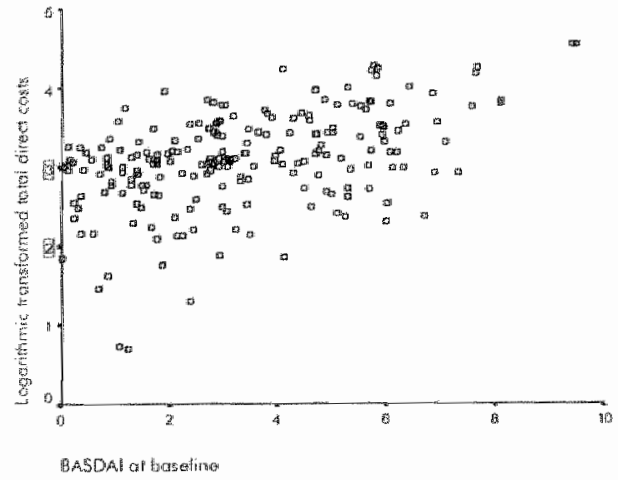

Figure 6.1. Scatter plof illustraling relation between baseline BASDAl and logarithmic transformed direct societal costs of ankylosing spondylitis.

Interestingly, determinants of costs from financial perspective were somewhat different. Female gender did not contribute to this model, reflecting the costs for (in) formal care are mainly paid out-of-pocket by the patients. Higher age (HR: 0.99; $95 \% \mathrm{Cl}: 0.97-0.99$ ), lower educational level (HR $0.56 ; 95 \% \mathrm{Cl}: 0.39$. 0.79 ). poor physical function (BASF) (HR: 0.92; $95 \% \mathrm{Cl}: 0.85-0.99$ ) and high disease activity (BASDAl) (HR: 0.88; 95\% Cl: 0.80-0.97) remained assaciated with higher costs from financial perspective. In addition, IBD (HR: $0.53 ; 95 \% \mathrm{Cl}$ : 0.31-0.92) was assaciated with higher casts. Total direct healfincare costs (financial perspective) in palients with extraspinal disease manifestations were $\epsilon$ 3,027 per patient per year Imedian $€ 1,340$ ) opposed to $€ 1,237$ Imedian $E$ 561 ) For patients without extraspinal disease. No interactions between country and the other determinants of the explanatory model were detected.

A separate regression was performed with costs of drugs as outcome. Also in multivariate analyses drug costs remained significantly higher in France (HR: $0.42 ; 95 \% \mathrm{Cl}: 0.25-0.59)$ and Belgium (HR: $0.53 ; 95 \% \mathrm{Cl}: 0.32-0,86)$ compared with The Netherlands. Not surprisingly, longer disease duration $H R$ : $0.98 ; 95 \% \mathrm{Cl}: 0,96.0 .99)$, presence of $\mathrm{IBD}$ (HR: $0.21,95 \% \mathrm{Cl}: 0.11-0.40)$ peripheral arthritis. (HR: $0.67,95 \% \mathrm{Cl}: 0.46-0.97$ ) and higher disease activity (BASDA) (HR: 0.87; 95\% Cl: $0.80-0.94$ ) contributed to higher drug costs. The analyses for drug costs from the financial perspective provided comparable results inot shown separately). 


\section{Effect on national expenditures}

Accepting in the population of the three countries a minimal point prevalence of patients with AS who are under control of a theumatologist, of $0.08 \%$ in each country ${ }^{9.31}$ and population sizes of 15.5 million for The Netherlands, 57.4 million for France and 10.2 million for Belgium ${ }^{32}$ the number of patients with AS in each country would be 11,250 pafients in The Netherlands, 43,062 in France and 7,646 in Belgium. Assuming the cross-sectional study sample would be representative for the national group of patients with $A S$, the total annual expenditures would be $€ 23.88$ million in The Netherlands, $€ 60.38$ million in France and $€ 7.20$ million in Belgium. This represents $0.83 \%, 0.51 \%$ and 0.39 $\%$ of the total national expenditures on healthcare for The Netherlands, France and Belgium respectively. In 1998 the proportion of the gross national product spent on health care was $8.6 \%$ in The Netherlands, $9.6 \%$ in France and $8.8 \%$ in Belgium and the annual healthcare expenditures per capita $€ 1,840$ in The Netherlands, $€ 2,036$ in France and $€ 1,826$ in Belgium. ${ }^{33}$

\section{Discussion.}

In this prospective cost-of-illness (COl) study of prevalent direct costs related to AS in three European countries, we have chosen to calculate costs from societal and firancial perspective. The mean annual societal direct costs were $€ 2,640$ (median $\in 1,242$ ) per patient. Inpatient care was the most important cost-driver, being $27 \%$ to the total direct costs. Remarkable was the high contribution of costs for physiotherapy $(13 \%)$ and costs for formal and informal home-care $(22 \%)$ to the total direct costs, reflecting the importance of exercise in the treatment of this disease but also the important disability in performing activities of daily living. In the analysis from a societal point of view, the difference in costs among the countries reflect country specific healthcare use, since Dutch unit-costs were applied to the country specific resource utilisation. Univariately, the total direct costs between the countries were not different, but within the distinguished cost categories, there were interesting differences. Costs for visits to general practitioners, specialists and physiotherapists as well as costs of technical procedures were substantially higher in Belgium. These differences were completely offset by the lower number of days of inpatient care in the Belgian patients. It is of note that inpatient care in this study included (day care) admissions to rehabilitation hospitals, a facility that does not exist in Belgium to the same extent as in both other countries. The higher costs of drugs in France, can partly be explained by the higher proportion of patients who receive /more expensive) gastro-protective and disease modifying drugs and partly because the majority of patients were prescribed a relatively new and more expensive NSAID (meloxicam). Moreover, French patients were more often prescribed an NSAIDs on a daily dosage sicheme compared with on demand usage in both other countries. For The Netherlands, the high participation in group exercise organised by the patient saciety, the high costs for aids and appliances and the higher usage of formal and informal care combined is striking. Explaining 
differences among countries remains controversial but cannot be attributed to the design of the present study. The care oriented healthcare, the gatekeeper role of the general practitioner and a more important fraction of payment on capitation basis in The Netherlands compared with cure orientation, unlimited access to healthcare and fee for service payment system in both other countries, can contribute to explain the observed differences.

The societal perspective reflects more accurotely the true economic burden of illness, whereas a financial perspective can provide additional information on the level of costs for a specific payer, in our case the official national healthcare payers. To our knowledge, this $\mathrm{COl}$ study is the first to compare societal and financial perspective in patients with rheumatic diseases. Within each country. the costs from financial perspective were significantly lower than from societal perspective. This illustrates the importance of the choice of perspective and the use of the appropriate unit costs in cost studies. Interestingly, for several cost categories the rank in countries for magnitude of costs changed when comparing costs from societal opposed to financial perspective. For example, costs for physician wisits from societal perspective were the highest in Belgium, while they were the lowest in the financial perspective. Differences between true costs and tariffs, but also level of patient out-of-pocket costs (such as specifically in the Belgian patients) explain the differences in costs from both perspectives. Projecting the costs from financial perspective to the national health expenditures revealed that $0.83 \%, 0.51 \%$ and $0.39 \%$ of the total health care budget in 1998 was spent on AS in The Netherlands, France and Belgium respectively. Extrapolating results of our COI study to national costs should however be done with coution, since it remains unclear for each country, which specific costs categories are included in the national figures on healthcare expenditure.

Longer disease duration, worse physical function and higher disease activity but also lower educational level were determinants of higher total direct costs from societal perspective. In addition, female gender tended to be associated with higher costs but this could be entirely attributed to higher costs for formal and informal care and costs for aids and adaptations. The effect of educational level on costs was identical in all countries studied. Lower educated patients with AS were similar in age, gender distribution, disease duration and proportions of patients with extraspinal disease compared with higher educated patients. However, they reported worse physical function (BASFI) and higher disease activity (BASDAl). Worse function and higher costs among patients from lower social classes is observed in other meumatic diseases. ${ }^{340}$. Differences in health perception and coping styles are advocated as contributing explanatory variables but were not examined in this study. Disease activity at baseline was the most important predictor of direct societal costs. Considering the new treatment options of AS by biologic agents, it will be important to know if the beneficial effect of these treatments on disease activity and function will result in reduction of the lifetime patient costs and can provide acceptable costeffectiveness and cost-utility ratios. When exploring the determinants of the direct costs from a financial point af view, it was noteworthy that also presence of extraspinal disease was associated with higher costs. This is not surprising since in the financial perspective the direct medical costs contribute more to the 
fotal direct costs and extraspinal disease requires more medical attention. It is important to note that, after adjusting for the baseline differences in patient characteristics among countries, the differences in costs observed in univariate analysis, did not change significantly.

We already reported on the indirect costs by human capital approach as well as by the friction cost method in these patients. ${ }^{14}$ Using human capital approach $€$ 6,812 per patient per year; median $€ 90$ ), tolal mean annual costs of AS would mount to $€ 9,452 €$ per patient per year and the indirect costs would be $72 \%$ of the total costs. Using the friction cost method $€ 465.15$ per patient per year; median $€ 0 \%$, total mean annual casts would be $€ 3,105$ per patient per year, $16 \%$ of which due to indirect costs. Although the human capital approach might owerestimate the true societal costs, this method more accurately reflects the economic burden of disease since not only sick leave but also chronic work disability is captured in a monetary value. ${ }^{\text {th }}$

In the literature we found two $\mathrm{CO}$ studies in $\mathrm{AS} .{ }^{\circ .7}$ In a retrospective prevalence based study among 172 French patients with AS, annual AS related mean direct healthcare costs for the years 1978 and 1979 were $€ 2,686$ per patient per year fadjusted to 1998 values using consumer price index and expressed in $€$ using December 31,1998 currency) compared with the $€ 2,064$ per patient per year in the present French study. Although comparison should be done cautiously, the decrease over time in the average number of days of hospitalisation, which dropped from 6 days per patient per year in 1978 to 2.7 days in the present cohort, might explain this difference. ${ }^{6}$ A recent publication on a prospective study in 241 American patients with AS, reported mean annual direct AS related costs to be $€ 1,493$ (median $€ 951$ ) per patient (converted using December 31 1998 currency). ${ }^{7}$ Indirect costs assessed by the human capital approach amount to $47 \%$ and $74 \%$ of the total AS related costs in the French and US study respectively, compared with $72 \%$ of total costs in our COl study. The French study used disability benefits (and not true societal costs) as basis to calculate the productivity costs while in the US and in our study, the premorbid income (reflecting the true societal production loss) was estimated to value production loss. Both, the French and USA study showed that worse physical function was associated with higher costs.

In a systematic review, Cooper reported on the results of 16 prevalent COI in rheumatoid arthritis (RA) and adjusted costs by using 1996 consumer price index. ${ }^{42}$ Twelve studies provided data on direct costs and completed with wo more recent reports ${ }^{36,43}$, mean annual direct costs per patient in these studies ranged from $€ 1,626$ to $€ 6,155$ with one study reported higher costs of $€$ 9,832 . Results of our study in AS fall in the lower range of costs reported for RA. In addition to direct costs, six COl studies in RA reported on productivity costs, assessed by human capital approach. 42,43 Productivity costs contributed 30 to $66 \%$ to the total costs, compared with 72 to $74 \%$ in AS. Comparison of COl studies is limited, since economic evaluations still lack standardisation, especially on methods to collect data on resource use, methods to assess unit costs of resources, methods to analyse and report costs and methods to adjust for differential timing of the studies. It should be realised, we assessed the prevalent costs of patients with AS. Since AS starts usually at an earlier age than RA, the 
lifetime costs of AS might well be higher than of RA. In order to estimate liferime costs of AS, it will be necessary to assess the incidence costs of the disease (including the costs of the diagnostic phase as measured in an inception cohorf). Our study certainly has limitations. Patients were hospital and not community sampled and therefore, costs represent costs of patients followed by a haspitalbased theumatologist. Moreover, rheumatologists in the three participating centres have an academic affiliation. It is possible that differences in performance when providing medical care are larger among theumatologists in peripheral care centres or private practice, where market considerations may play a more important role. Further, data were callected through bimanthly and biannual questionnaires, but were not ascertained by ather data sources. Also, only AS related costs were calculated. Therefore, no conclusions can be drawn as to what degree these costs are additional to healthcare costs of an age and gender adjusted population without chronic disease. Ward showed in the US study that for $50 \%$ of patients, direct costs attributed to AS accounted for $90 \%$ of all-cause direct costs and for $66 \%$ of patients direct costs attributed to AS accounted for $75 \%$ of all-cause direct costs. Another methadolagical choice of our analysis is that resaunce use of two observation years was aweraged and valued with costs of the second observation year without discounting. However, in the two year's time frame of the study, there were no important changes in prices or tariffs. Missing values for resource use in the bimonthly questionnaires were imputed by the mean of the other observations in the same patient, but no sensitivity analyses with other methods have been performed. Most important, our study comprised only 209 patients, which is rather low for economic analyses. Especially the small number of Belgian patients included might have resulted in non-detected existing differences in costs among countries. The major problem in the international comparison, however, was the absence on true unit costs, which are required to calculate the societal perspective. We turned this problem into an advantage by applying the Dutch true unit costs "to the country specific health resource utilisation. This allowed us to compare directly health resounce utilisation. Of course, we should be careful by stating that the societal costs as calculated for France and Belgium reflect the true societal costs. Especially differences in wages for healhcare providers and differences in capital for healthcare (overhead) would cause differences in true costs estimations. However, if is not likely that these would differ greatly among three European countries with comparable economic prosperity.

Only few studies compared resource use and direct costs of theumatic diseases among countries. For 752 patients with systemic lupus erythematosus from the United Kingdom, Canada and the US significant differences in several cost categories were observed, but not in the overall direct costs. 4,45

In conclusion, direct costs due to AS are considerable from societal and financial perspective and the costs of hospitalisation are the major cost driver. Prevalent societal costs fall within the range of costs reported for RA, but lifetime costs of AS might well be higher than those of RA because of the usual earlier age at onset of the disease. Among three European countries, there are impontant differences in costs for several cost categories, but not in the overall direct costs. The higher discrepancy between direct costs from societal and financial 
perspective in both France and Belgium compared with The Netherlands suggest higher patient contributions in these countries. Worse physical function and higher disease activity are strong determinants of costs. 


\section{References}

1. Koopmonschap MA. Costotwillness studies. Useful for health policy? Phamacoeconomics 1998;14:143-148.

2. Hodgson TA. Costs of illness in cost-effectiveness andysis. A review of the methodology. Pharmacoeconomics 1994:6:536-552.

3. Bytord $\$$, Torgerson DJ, Raftery J. Economic note: cost of illness studies. BM $2000,320: 1335$.

4. Bloom BS, Bruno DJ, Maman DY, Jayadevapa R. Usefulness of US cost-ot-illness studies in heathcare decision making. Pharmacoeconomics 2001; 19:207-213.

5. Rice DP. Cost of illness studies: what is good about them? Inj Prev 2000;6:177-179.

6. Sailly JC, Lebrun T. Les conséquences économiques ef sociales de la pelvispondylie rhumatismale. Rev Epidem Santé Publ 1982;30:305-324.

7. Ward MM. Functional disability predicts total costs in patients with ankylosing spondylitis. Arthritis Rheum 2002; $46: 223-231$.

8. Braun J, Bollow $M$, Reminger $G$, Eggens U, Rudwaleil $M$, Distler $A_{i}$ el al. Prevalence of spondylarthropathies in HLA-B27 positive and negative blood donors. Anthritis Rheum 1998;41:58-67.

9. van der Linden SM, Valkenburg HA, de Jongth BM, Cals $A$. The risk of developing ankylosing spondylitis in HLA-B27 positive individuals. A comparison of relatives of spondylitis patients with the general population. Arthritis Rheum 19:84:27:241-249.

10. Calin A, Garrelt S, Whitelack H, Kennedy LG, OHea J, Mallarie P, et al. A new opproach to defining functional ability in ankylosing spondylitis: the development of the Bath Ankylosing Spondylitis Functional Index. J Rtheumatol 1994;21:2281-2285.

11. Dalyan M, Guner A, Tuncer $S$, Bilgic $A_{*}$ Arasil T. Disability in ankylosing spondylitis. Disabil Rehabil 1999;21:74-79.

12. Gran JT, Skomsvoll JF. The outcome of ankylosing spondylitis: a study of 100 patients. Br J Rheumatol 1997;36:766-771.

13. Makisara GL, Makisara P. Prognosis of functional capacity and work capacity in rheumatoid arthritis. Clin Rheumatol 1982;1:117-125.

14. Boonen A, van der Heijde D, Landewe R, Rutten M, Schouten H, Guiliemin F, et al. Work status and productivity costs due to ankylosing spondylitis: comparison among three European countries. Ann Rheum Dis 2002;61:in press.

15. Garrett S, Jenkinson T, Kennedy LG, Whitelock H, Gaistord P, Calin A. A new approach to defining disease status in ankylosing spondylitis: the Bath Ankylosing Spondylitis Disease Activity Index. J Rheumatal 1994;21:2286-2291.

16. Lubeck DP, Spiz PW, Fries JF, Wolfe F, Mitchell DM, Roth SH. A multicenter study of annual health service utilization and costs in theumatoid arthritis. Arthritis Rheum $1986,29: 488-493$

17. Verhoeven AC, Bibo JC, Boers M. Engel GL, van der Linden S. Cost-effectiveness and costutility of combination therapy in early rheumatoid arthritis: randomized comparison of combined step-down prednisolone, methotrexate and sulphasalazine with sulphasalazine alone. COBRA Trial Group; Combinatietherapie Bị Reumatoide Artritis. Br J Rheumatol 1998;37:1102-1109. 
18. Goossens ME, Rutten-van Maken MP, Vloeven JW, wan der Linden SM. The cost diary: a methad to measure direct and indirect costs in cost-effectiveness research. I Cin Epidemiol 2000,53:688-695.

19. Scott DL, wan Riel PL, van der Heijde D, Benke AS. Assessing disease activity in rheumatoid arthritis. The EULAR handbook of standard methods. The EULAR standing committee of International Clinical Studies, 1993.

20. Rutten-van Molken MPMH, Van Doorslaer EKA. Multinationale kosieneffectiviteitsanalyses. In: Van kosten tot effecten. Een handleiding voor evaluatiestudies in de gezondheidszorg. Maarssen: Elsevier gezondheidszorg; $2000: 131-149$.

21. Oostenbrink J, Koopmanschap M, Rutten F. Handleiding voor kostenonderzoek. Methoden en richthinprizen woor economische evaluaties in de gezondheidszorg. Amstelween: College voor zorgverzekeraars; 2000.

22. Evers S, wan Merade F, Paulus A. Directe kosten wan chronisch benigne pilinsyndroom. Maastricht: Departmen of Health Organisation, Policy and Economics. Universily Maastricht; 1999.

23. Taxe WTG. Den Haag: Koninklike Nederlandse Maatschappij ter bevordering van de Pharmacie: 1998.

24. Taxe niet-WTG, OTC en handverkoop. Den Hagg: Koninklijke Maatschappij ter bevordering van de Pharmacotherapie; 1998.

25. Tariefboek medisch specialisten, geneeskundige verstrekkingen en ziekenhuisopnames: Centraal orgaan tarieven Gezondheidszorg; 1998.

26. Nomenclatuur geneeskundige verstrekkingen. Brussel: Rijksinstituut ziekte en invaliditeitswerzekeringen; 1998 .

27. Terugbelalingsbarema ZIV. Brussel: Rijksinstituut Zielkte en Inwaliditeitsvenekering; 1998.

28. Nomenclature des Actes Professionnel. Paris; 1998.

29. Vidal, le dictionnaire. 74 ed. Paris: Editions du Vidal; 1998.

30. Prijslijst pharmacotherapeutische specialiteiten. Brussel: RIZIV; 1998.

31. Miedemo HS, van der Linden SM, Rasker UJ, Valkenburg HA. National database of patients visiting theumatologists in the Metherlands: The standard diagnosis register of heumatic diseases. A report and preliminary analysis. Br I Rheumatol $1998,37.555-561$

32. Eurostat European afficial statistics, a guide to databases. Luxembourg: Office for official publications of the European communities, 1997.

33. Organisation for Co-operation and Develpoment (OECD). Health Data File ICDROM]: 1999.

34. Yelin E, Meenan R, Nevit M, Epstein W. Work disability in rheumatoid arthrilis: effects of disease, social, and work factors. Ann Intern Med 1980;93:551-556.

35. Yelin EH, Henke C.I, Kramer JS, Neviti MC, Shearn M. Epstein W. A comparisan of the treatment of rheumatoid arthritis in health maintenance organizations and fee. for-service practices. N Engl J Med 1985;3112:962.967.

36. Yelin E. Herndorf A, Truin L, Sonneborn D. A national study of medical care expenditures for musculoskeletal conditions. The impad of heath insurance and managed care. Arhtritis Rheum 2001;44:1160-1169.

37. Esdaile JM, Sampalis JS, Lacaille D, Danoff D. The relationship of socioeconomic status to subsequent health statws in systemic lupus erythematosus. Anthritis Rheum $1988 \cdot 31: 423-427$ 
38. Karlson EW, Daltroy LH, Lew RA, Wright EA, Partridge AJ, Fossel AH, et al. The relationship of sacioeconomic status, race, and modifiable risk factors to outcomes in patients with systemic lupus erythematosus. Arthritis Rheum 1997;40:47-56.

39. Sutdiff N, Clarke A, Gordon C, Farewell V, Isenberg D. The association of socio economic status, race, psycho-sociall factors and oulcome in patients with systemic lupus erythematosus. Rheumatology 1999;38:1130-1137.

40. Rivest C, Lew RA, Welsing PM, Sangha O, Wright EA, Roberts WW, et al. Assaciation between clinical factors, socioeconomic status, and organ damage in recent onset systemic lupus erythematosus. I Rheumatol 2000;27:680-684.

41. Koopmanschap MA, Rutten FFH. A practical guide for calculating the indirect costs of disease. Pharmacoeconomics 1996; 10:460-466.

42. Cooper NJ. Economic burden of rheumatoid arthritis: a systematic review. Rheumatology 2000;39:26-33.

43. Newhall Perry K, Law NJ, Ramos B, Sterz M, Wong WK, Bulpitt KJ, et al. Direct and indirect costs associated with the onsel of seropositive rheumatoid arhtritis. I Rheumatal 2000;27:1156-1163.

44. Clarke A, Petri MA, Manzi S, Isenberg DA, Gordon C, Senecal J-L, ef all. An international perspective on the well being and healthcare costs for patients with systemic lupus erythematosus. J Rheumatol 1999:26:1500-1511.

45. Sutcliff M, Clarke A, Levinton C, Frost C, Gordon C, Isenberg C. Associates of health status in patients with systemic lupus erythematasus. I Rheumatol 1999;26:2352. 2356. 


\section{Appendix}

Appendix I Financing of healthcare a macro-economic level.

\begin{tabular}{llll} 
& The Netherlands & France & Belgium \\
\hline Social contributions from taxes & $4.80 \%$ & $5.90 \%$ & $34.80 \%$ \\
Public health insurance premiums & $73.80 \%$ & $6.40 \%$ & $40.60 \%$ \\
Private health insurance premiums & $14.10 \%$ & $9.10 \%$ & $5.80 \%$ \\
Patient contribution & $7.30 \%$ & $17.00 \%$ & $17.90 \%$ \\
Other sources & $0.00 \%$ & $0.80 \%$ & $1.00 \%$ \\
\hline
\end{tabular}


1201 Chapter 6

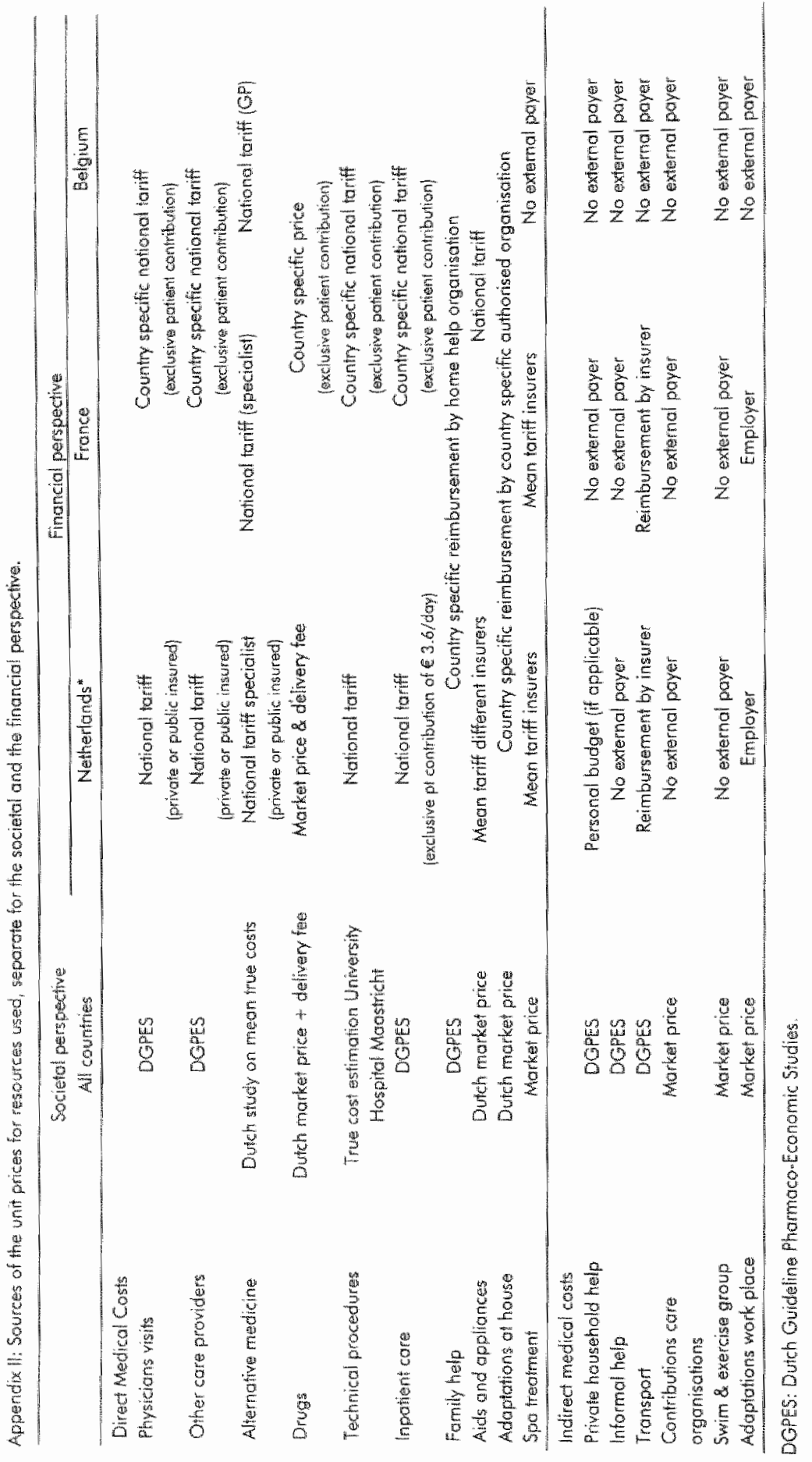



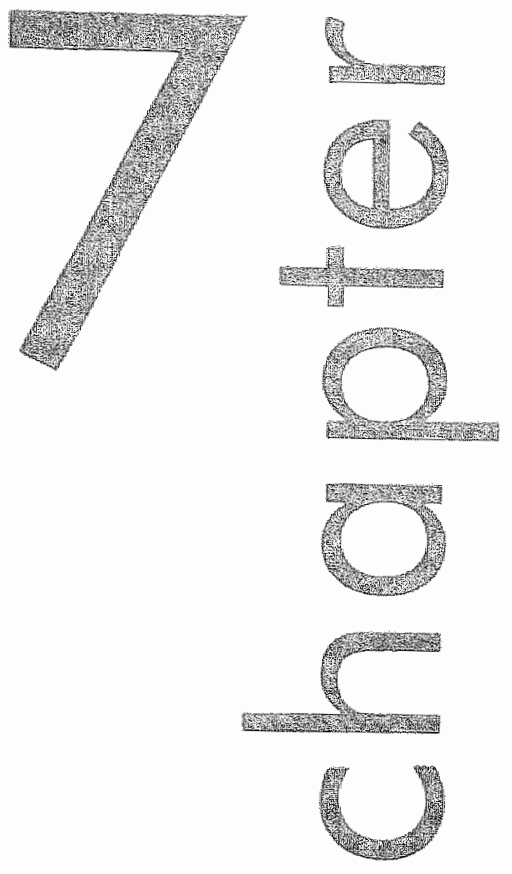

Work status and productivity costs due to ankylosing spondylitis A comparison among three European countries

A Boonen, D van der Heijde, RLandewe, A Spoorenberg. HSchouten. M Rutten-von Möken, F Gullemin, M Dougados, H Mielants, K de Vam. H van der Tempel, Si von der Linden 


\section{Abstract}

Aim

To compare work disability, sick leave and productivity costs due to ankylosing spondylitis among three European countries.

\section{Methods}

216 patients with ankylosing spondylitis form The Netherlands, France and Belgum participated in a two years' observational siudy. Employment and work disobility rates at baseline were adjusted for age and gender. Productivity costs were calculated by both friction cost method and human capital approach. The adjusted contribution of the country to employment, work disability and hoving an episode of sick leave were assessed by logistic regression and the contribution of the country to days sick leave and casts by Cox's proportional hazard analysis.

\section{Results}

209 patients completed the wwo years' follow-up with sufficient data for cost analysis. Adjusted employment was $55 \%$ in The Nethertands opposed to $72 \%$ in both olher countries and was only in the Netherlands lower than expected in the general population. Adjusted work disability was $47 \%, 23 \%$ and $9 \%$ in The Netherlands, France and Belgium and was in all countries higher than expected in the general population. In those with a paid job, the mean number of days of sick leave per year because of ankylasing spondylitis was 19 (range: 0-130), 6 (range: 0-77) and 9 (range: 0-60l days per patient per year in The Netherlands, France and Belgium respectively. Applying the friction cost method to those with a paid job resulted in mean cosis per patient per year of $€ 1,257$ (ronge: $0-7,356), 428$ (range: $0-5,979$ ) and 476 (range: $0-2,354$ ) in The Netherlands, France and Belgium. Applying the human capital approach to the whole group resulfed in mean costs per patient per year of $E 8,862$ (range: $0-46,818$ ), 3,188 irange: 0 43,550 ) and 3,309 (ronge: 0-34,320) in the thee cauntries respectively. Atter adjusting for sociodemographic and disease characteristics, living in The Neherlands, as compared with both other countries, was associated with a higher chance to be work disabled IOR: 3.82; $95 \%$ CI:1.33.11.011, but not with the risk to have an episode of sick leave. Similarly, living in The Netherlands contributed independently to the number of days sick leave (OR:0.65; $95 \%$ Cl:0.43-0.97), a higher amount of friction costs (OR: 0.63; $95 \%$ C: $0.42-0.96$ ) and a higher amount of human capital costs (OR: $0.46 ; 95 \%$ Cl: $0.32 \cdot 0.681$

\section{Conclusion}

There ore rematkable differences in work status and productivity costs among the three European countries. This has implications for the generalisability of heatheconomic studies. 


\section{Introduction}

Economic endpoints are increasingly important in observational and clinical studies. Costs due to loss of productivity, also referred to as indirect costs, are an important part of the total costs of chronic rheumatic diseases. ${ }^{1.7}$ In rheumatoid arthritis praductivity costs account for 25 to $71 \%$ of the total costs $s^{3,711}$, varying between US\$ 1,467 and 37,501 per patient per year lafter conversion of all figures to 1996 US dollars).$^{3,4,7-12}$ Economic endpoints are not only influenced by patient and disease characteristics butt also by international differences in medical practice and differences in finance and organisation of healthcare and social security systems. ${ }^{13}$ Methodolagical aspects of comparability of health economic analyses among countries have received little attention. This is surprising given the potential impact of the findings.

Ankylosing spondylitis (AS) is a chronic rheumatic disease that can lead to important functional limitations not only because of spinal but also because of extraspinal disease. The condition usually starts in the third decade of life. In Western Europe its prevalence is estimated at 0.075 to $0.85 \%{ }^{14.35}$ Men are affected three times as often as women. In a cross-sectional study among 658 Dutch patients with AS, we have shown that labour force participation was $11 \%$ lower and AS related work disability 15\% higher in comparison to the general population. In thase with a paid job, mean number of AS related days sick leave per patient was 10 days per year. ${ }^{16}$ In the present study, we focused on international differences in work disability and sick leave in AS in three European countries: The Netherlands (NL), France (F) and Belgium (B). Further, we compared productivity costs of AS and assessed its determinants in an international perspective.

\section{Methods}

\section{Patients}

Patients were selected from the rheumatology departments of four hospitals in three countries, the University Hospital Maastricht and the Maasland Ziekenhuis Sittard in The Netherlands, L'Hôpital Côchin Paris in France and the University Hospital Ghent in Belgium. In The Netherlands, all patients who were registered with the diagnasis AS in the Dutch Standard Diagnosis Register of Rheumatic Diseases (SDR), were sampled. ${ }^{17}$ In Belgium, consecutive outpatients and in France consecutive out- and inpatients with AS were sompled during a pre-sel time period of 6 months. Plain films of the sacroiliac joints of all patients were checked to ascertain they fulfilled modified New York criteria for AS. The hospitals of Maustricht, Paris and Ghent have a regional and referral (academic) function. Sittard is a regional hospital cooperating in research projects with the University Hospital Maastricht. In all three countries traditionally patients with a 
chronic rheumatic disease are referred to a theumatologist. Patients were included beween September 1996 and March 1997 and were Lollowed for wo years. The last follow-up patient for this part of the study was evaluated in Aprill 1999.

\section{Questionnaires}

At baseline and every six months patients underwent a clinical examination and completed questionnaires assessing sociademographic data (among which work status) and disease characteristics including AS specific physical function measured by Bath Ankylosing Spondylitis Functional Index (BASFl) (range 0.10; higher values indicating worse function). In addition, every 2 months patients filled out an economic questionnaire on AS related health resource use in the past 2 months, the Bath Ankylosing Spondylitis Disease Activity Index (BASDAll, measuring AS specific disease activity (range 0.10; higher values indicating higher disease activity) and the EuroQol, a generic quality of life (QoL) measure (maximum value 1; higher values indicating better QoL) ${ }^{20,21}$ Economic questionnaires were adapted for each country with respect to language, educational system, income, possible categories of work stotus, currency of costs, social security system and health insurance system. To estimate gross monthly income, ten predefined categories were given feach with a ronge of 500 Eural as well as a possibility to provide the exact income. For classification of profession, a list of 26 passible professions in 7 categories, as used by Statistics Netherlands, was applied. ${ }^{22}$ For the purpose of statistical analysis educational level was dichotamised into more than twelve years formal education as opposed to twelve years or less, whereas professions were divided into manual jobs (job in agricultural, industrial and transport sector) and nonmanual jabs flob in administrative, commercial, servicing and specialist/managerial sectar).

\section{Definition of outcome measures}

This cost-of illness analysis was designed as prevalence based, prospective, disease specific (AS related) study from a sacietal perspective, using patient derived data. Productivity costs refer to the societal cosis associated with loss of paid production and not to lass of unpaid production or loss of leisure time. The active population refers to those between 16 and 65 years who are working or willing to work. Consequently, those on elderly retirement, students and housewives are excluded from this group, but those economically unemployed or work disabled are included. Work disability is defined as officially recognized inability to perform paid work because of AS according to the criteria of each country.

The three countries have social security legislation since the first half of the last century. In The Netherlands, no medical certification is required for sick leave. Since $1996^{2 a}$, the payment of sickness benefit is the responsibility of the employer during the entire first year of sick leave and varies beween 80 to $100 \%$ (depending on the employment contuact) of the former gross wage. After 3 months of sick leave the occupational physician of the employer storts a 
rehabilitation plan and part-time wark can be part of this. After one year of continuous sick leave, the Social Security Association, being an official governmental organisation, can grant permanent (full or partial) work disability in case of objective medical restrictions to perform paid work. Seven categories of wark disability exist and disability between 80 and $100 \%$ is regarded as full while the other categories are considered as partial work disability. In case percentage of disability exceeds $15 \%$ a benefit will be allowed ranging from $25 \%$ to $70 \%$ of the former gross wage. The percentage of work disability and associated benefit are based on restriction to earn the wage of the last or a comparable job. Patients with partial work disability are encouraged to continue working in a partitime job. The period of attributed disability is restricted to a maximum of 5 years. After this period reassessment of disability is obliged.

In France, medical certification for sick leave is required. The sick leave benefit is paid from the 4th day onward and is $50 \%$ of the mean gross wage during the first month and $66 \%$ afterwards. The maximum duration of sick leave is one year, although in exceptional conditions, such as chronic diseases, sick leave can be as long as three years. During this period, the expert of the Social Security Insurance can allow part-time work. After one (or three) years of sick leave, work disability (disability pension) can be allocated by a committee of expert physicians (designated by the Social Security Insurance and COTOREP, a Social Security Organisation committee) if the person can earn anly $33 \%$ or less of his income. In case the patient is considered to be able to perform a (parttime) profession, a disability benefit of $30 \%$ of the former gross wage is allocated. In case the person is considered to be unable to perform paid work, a disability benefit of $50 \%$ of the former gross wage is granted (with a minimum and a maximum level and supplemented if others depend on this person).

In Belgium medical certification for sick leave is required. When sick leave lasts less than 14 days, the sickness benefit starts on the 2 nd day and is $100 \%$ of the gross wage for the first 8 days of sick leave and $85 \%$ for the second week. When sick leave lasts llonger, the sickness benefit is $100 \%$ during the first week, $85 \%$ during the second week and $60 \%$ afferwards. Part-time work during this period is only exceptionally allowed. After a maximum duration of one year sick leave, the expert physician of the Sacial Security Organisation can grant permanent work disability if the person is restricted to $33 \%$ to perform any job lon the general labour market). If work disability is attributed, part-time work is only exceptionally possible. The disability benefit ranges from 45 to $60 \%$ of the former gross wage. The social security system for those employed by the government is slightly different. The sickness benefit starts from the first day of sickness and is $100 \%$ of the gross wage during 30 days. After that period eligibility for disability is judged according to the same criteria as described for other employers. The disability benefit is $80 \%$ of the gross wage.

In all countries, persons who are self-employed receive a sickness or disability benefit only affer private insurance. Reinsurance against income loss because of sickness or work disability is possible in all countries for persons with a paid employment. 


\section{Reference data from the general population}

National figures on population size per age and gender categories, employment, unemployment, work disability, days of sick leave, income, educational level, professional class and national expenditures on social security were refrieved from Eurostat for 1997 and $1998 .^{24}$ In addition, for lacking data or for reasons of comparison, the OECD 2000 Health Data CD-ROM, several internet sites providing information on national and European statistical data and the internet sites of the Ministries of Health Care and/or Social Affairs of the three countries were consulted.

\section{Cosit estimation}

Two methods to calculate the productivity costs were used: the friction costs method (FC) and the human capital approach (HC). ${ }^{25}$ At the time of the study (1998) the length of the friction period in The Netherlands was set at four months. ${ }^{26}$ The FC method limits the time of productivity loss to the period of sick leave until replacement of the worker has taken place (friction period). The friction period largely depends on the unemployment rate. The HC method includes productivity costs from the first until the last day of absence from work and productivity casts from the first day of work disability till the last day of work disability or legal age of retirement. For both methods the production value per workday was calculated for each patient based on incident self-reported gross wage per month (if applicable adapted for the number of contractual work days per month and the income out of work disability according to the specific benefit scheme of each country). If questionnaires assessing days absent at work were missing, the mean number of days absent for the other periods in the same patient was imputed. If the income of the patient was missing, the mean of other patients of the same gender, age category, professional class, work status and country was used. All costs are calculated in Euros. On December 31, 1998 the Euro currency was set at NLG 2.20, FF 6.56 and BEF 40.34. At that time $E$ I was US\$ 1.17 .

\section{Statistics}

Results are presented for patients completing two years of follow-up and having filled out at least 9 out of 12 bimonthly questionnaires. Demographic and disease characteristics and socioeconomic status are presented using descriptive statistics. Overall differences among countries were tested by Chi-square for proportions or by One-Way Anowa for parametric variables. In case the overall differences among countries were significant at the 0.05 level, the level of significance between 2 countries was sought by Chi-square for proportions or Anova with least significant difference (LSD) for parametric variables.

Baseline employment and work disability nates are calculated as raw rates and were adjusted for age and gender using the general population of each country as reference. Direct standardisation was chasen because rates for part-time employment and work disability for the required age and gender categories (necessary for indirect standardisation) were not available for all countries. 
Sick leave and productivity costs are presented as means and ranges. The differences between countries are presented as mean difference with the $95 \% \mathrm{Cl}$ assessed by bootstrapping with 10,000 replications. ${ }^{27.29}$

To evaluate if the country remains a significant contributor to the risk of incurring an episade of sick leave or work disability after adjusting for baseline differences in patient characteristics, logistic regression analyses with backward elimination according to the likelihood ratio test were performed (probability for removal 0.1). Similarly, Cox's proportional hazard regression with backward elimination with days of sick leave or amount of costs as dependent variable was used to assess the contribution of the country to length of sick leave or amount of costs. For FC and HC cosis Kaplan-Meier survival curves were computed. The populations used for the regression analyses were those at risk for the outcome studied: (1) those with a paid job in case sick leave or FC were the outcome $(n=113)$ and (2) the active population $(n=186)$ in case work disability or HC costs were the outcome. Independent variables in all models were age, gender, education, profession, disease duration (since diagnosis), presence of inflammatory bawel disease, presence of peripheral arthritis, time averaged disease activity (BASDAI), physical function (BASFI) and country (dummy).

Finally we explored (1) if sick leave or work disability resulted in worse QoL measured by the EuroQol 5 dimensions instrument (EQ-5D) and (2) if this effect was different among the countries studied. Multiple Cox's proportional hazard regression analysis with $E Q-5 D$ as dependent variable was used, since the distribution of the values of the EQ-5D was skewed. As independent variables gender, age, educational level, disease duration, IBD, peripheral arthritis, country (dummy) and work disability or sick leave (in those with a paid job) were entered in a backward elimination regression analysis. Possible interactions between the country and work disability or sick leave were sought.

\section{Sensitivity analysis}

Among health economists the FC method is considered to reflect best the societal productivity costs and was therefore chosen for the reference case. ${ }^{30,31}$ In order to adjust for several assumptions that were made to calculate the reference case, sensitivity analyses were performed. First, FC was extended for total and not exclusive AS related sick leave. Second, costs were reanalysed by considering the number of days of sick leave to be equal to no sick leave in case of missing questionnaires and next by assuming the patient was on sick leave during the entire missing period. Third, the length of sick leave in patients being absent at work for six months or longer during the two years of follow-up, was replaced by the mean duration of sick leave in the remaining patients of that country and in a following analysis the same was done for paitients reporting more than three months of sick leave. In a last sensitivity analysis, cauntryspecific production values (adjusted for part-time work or partial work disability for each individual patient) were used instead of patient reported income. 
Eurostat data on income per working day as well as data from each caunty's national bureau of statistics were used because data differed according to the different sources.

\section{Results}

\section{Patients}

In total 135 Dutch, 54 French and 27 Belgian patients with AS started the study. Of the intital 137 Dutch patients, sampled from the Standard Diagnosis Register of Rheumatic Diseases (SDR), wo did not fulfil radiologic criteria for AS and were therefore not included. In the course of the two years' follow-up, five Dutch, one French and one Belgian patient stopped participation. Of the 5 Dutch patients who ended the study prematurely, one was a housewife, one a man being on elderly retirement and the other three were male patients with full wark disability because of AS. The French patient was a 39 years old male having a parttime jab and partial wark disability. The Belgian patient was a 34 years old woman working full-time. All patients who completed the wo years" follow-up had completed at least nine out of twelve questionnaires. Sociodemographic characteristics of patients who completed the study are presented in Table 7.1. Dutch patients were somewhat older, had on average a lower educational level and reported worse physical function (BASFI). Belgian patients had less often peripheral arthritis. Of the French patients, fewer had a manual job and none of these patients had concomitant inflammatory bowel disease.

Table 7.1. Baseline characteristics of patients with AS completing the study.

\begin{tabular}{|c|c|c|c|}
\hline & $\begin{array}{l}\text { The Netherlands } \\
n=130\end{array}$ & $\begin{array}{c}\text { France } \\
n=53\end{array}$ & $\begin{array}{c}\text { Belgium } \\
n=26\end{array}$ \\
\hline Mole: $\%$ & 70 & 69 & 74 \\
\hline Age: years: mean (SD) & $46(12)$ & $38(12)$ & $42(14)$ \\
\hline [range] & {$[23-77]$} & {$[19-67]$} & $\llbracket 18-74 !$ \\
\hline Formal education $\leq 12$ years " \%" & 83 & 48 & 64 \\
\hline Manual profession; $\%$ & 44 & 23 & 45 \\
\hline Disease duration (diagnosis): mean (SD) & $12(9)$ & $9(7)$ & $11(10)$ \\
\hline Inflammatory bowel disease; \% & 10 & 0 & 8 \\
\hline Peripheral authritis; $\%$ & 28 & 26 & 8 \\
\hline BASFI: mean $(S D)^{\prime \prime}$ & $3.9(2.4)$ & $2.5(2.9)$ & $2.6(2.3)$ \\
\hline BASDAl; mean (SD) & $3.7(2.1)$ & $2.8(2.3)$ & $3.1(1.9)$ \\
\hline EuroQol 5-dimensions; mean (SD) & $0.69(0.16)$ & $0.63(0.29)$ & $0.67(0.14)$ \\
\hline
\end{tabular}

BASFl: Bath Ankylosing Spondylitis Functional Index; BASDAl: Bath Ankylosing Spondylitis Disease Activity Index; "difference between The Netherlands and France: $p<0.05$; difference between The Netherlands and Belgium: $p<0.05 ;$ "difference between France and Belgium: $p<0.05$. Chi-square was used to tesl differences in proportions and Oneway Anova for parametric voriables. 
Work status and sick leave

Table 7.2 presents the baseline socioeconomic status of all completers. Including the patients with incomplete follow-up did not change the results significantly (maximal difference of $1 \%$ with the presented figures, dato not shown).

Table 7.2. Economic activity af baseline per country for patiems with AS completing the study.

\begin{tabular}{lccc}
\hline & $\begin{array}{c}\text { The Netherlands } \\
n=130 \\
\text { number }(\%)\end{array}$ & $\begin{array}{c}\text { France } \\
n=53 \\
\text { number }(\%)\end{array}$ & $\begin{array}{c}\text { Belgium } \\
n=26 \\
\text { number }(\%)\end{array}$ \\
\hline Working and no work disability & $47(36 \%)$ & $35(66 \%)$ & $15(58 \%)$ \\
Working and work disability & $11(9 \%)$ & $5(9 \%)$ & $5(20 \%)$ \\
Work discability but no work & $51(39 \%)$ & $5(9 \%)$ & $2(8 \%)$ \\
Economically unemployed & $3(2 \%)$ & $2(4 \%)$ & $1(4 \%)$ \\
Students & $3(2 \%)$ & $3(6 \%)$ & $1(4 \%)$ \\
Housewiwes & $5(4 \%)$ & $2(4 \%)$ & $2(8 \%)$ \\
Elderly retirement & $8(6 \%)$ & $1(2 \%)$ & - \\
Other reason no job & $2(2 \%)$ & - & \\
\hline
\end{tabular}

"difference between The Netherlands and France: $p<0.05$ (Chi-square); "difference between The Netherlands and Belgium: $p<0.05$ (Chi-squore).

Employment in NL is lower and work disability higher than in both other countries (Chi-square $<0.05$ ). In the course of the 2 years' follow-up, one Dutch, three French and one Belgian patient received a new official work disability status and in two of the Dutch patients the disability level was increased. In the Dutch group two patients went on elderly retirement as well as two in the French and one in the Belgian group.

For those with a paid job (NL: $n=58, F: n=40$ and $B: n=15$ ) the number of patients reporting AS related sick leave was $30(52 \%), 19(48 \%)$ and $7(47 \%)$ (Chi-square: $p=0.8$ ). Mean days of sick leave per working patient and the average duration of one episode of sick leave are presented in Table 8.3 and were significantly (bootstrapping) higher in the Dutch than in the French patients. In NL eight (14\%) patients had sick leave longer than the friction periad (4 consecutive months) compared with two (5\%) F and one (7\%) B patient.

To compare employment and work disability in patients with AS with the general population, raw rates were adjusted for age and gender using the population of each country as reference. In NL adjusted employment [and adjusted part-time employment] was in $55 \%[24 \%]$, opposed to $72 \%[79 \%]$ and $72 \%[24 \%]$ in $\mathrm{F}$ and $B$ respectively. Adjusted work disability [and adjusted partial work disability] was $41 \%[14 \%], 23 \%[16 \%]$ and $9 \%[0 \%]$ in $\mathrm{NL}, \mathrm{F}$ and $\mathrm{B}$ respectively. Using different sources, national employment figures in 1998 ranged from $65 \%$ to $68 \%$ for $\mathrm{NL}$, was about $60 \%$ in $\mathrm{F}$ and between 54 to $59 \%$ in B. National work disability rates ranged from 4.5 to $7 \%$ in NL and from 0.3 to about $1.8 \%$ in F. For $B$ a figure of $3.9 \%$ was found. National unemployment rates at that time were $5.2 \%, 12.4 \%$ 
and $9.2 \%$ in NL, F and B respectively. Mean national sick leave was $11.2,15.7$ and 7.1 days per working person in $N L$, in $F$ and in $B .^{32}$

Within potients with AS and after adjusting for baseline differences in patient characteristics, living in F (opposed to both other coumtries) was associated with a higher chance to be hoving a paid job (OR: 4.00; $95 \% \mathrm{Cl}: 1.02-15.65$ ). On the other hand, living in NL (opposed to both other countriesl was a significant contributor to the risk of being work-disabled (OR: 3.82; $95 \%$ Cl. 1.33-11.01) as well as to the length of sick leave (OR: $0.64 ; 95 \% \mathrm{Cl}: 0.43-0.97$ ). Country did not contribute to the difference in risk of having an episode of sick leave during the follow-up period. Table 7.4 shows the results of the predictive models to identify risk factors for (1) having an episode of sick leave during the two years follow-up and (2) the number of days of sick leave. While manual professions and physical function are associated with having an episode of sick leave, the length of sick leave is higher for those living in NL, those having inflammatory bowel disease and those having higher cumulative disease activity.

\section{Productivity costs}

Table 7.3 presents for each country the mean FC in Euros per patient per year for those with a paid jab and Table 7.5 presents the FC and $\mathrm{HC}$ costs for all the patients in the study. For the HC costs, not only the tatal costs but also the part because of absence at work and the part because of work disability are given separately. In univariate analysis (bootstrapping) mean FC in thase with a paid job and $\mathrm{HC}$ costs in all potients were significantly higher in NL compared with $F$ and $B$. Clearly, using the human capital approach results in higher productivity costs. After adjusting for several confounders in multivariate analysis, living in NL opposed to F and B was significantly associated with higher FC IOR: 0.63 ; $95 \% \mathrm{Cl}: 0.42-0.96$ ) and $\mathrm{HC}$ costs (OR: $0.46 ; 95 \% \mathrm{Cl}: 0.32-0.68$ ). The results of the full predictive multivariate madel to assess determinants of FC are shown in Table 7.4.

Figures 7.1 and 7.2 present the Kaplan-Meier curves with assaciated log-rank probability estimates of the FC (in those with a paid job) and HC costs lin the active population). They illustrate for each level of costs the proportions of patients having incurred these or even higher casts. Figure 7 . I shows that in all countries approximately 50\% of the patients gemerate friction costs. Two thousand Euros FC per year or more are incurred by $20 \%$ of patients in NL as opposed to $7 \%$ of patients in F and $B$. 

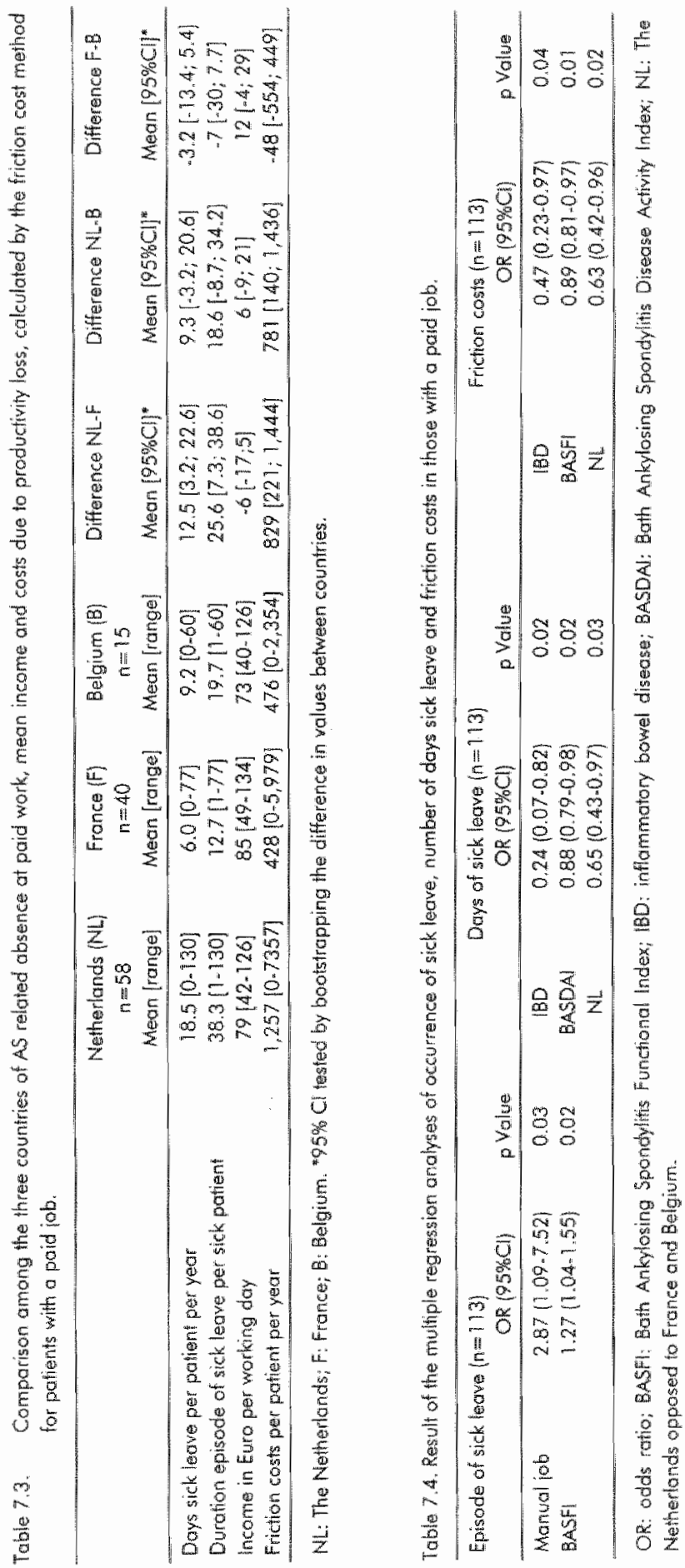


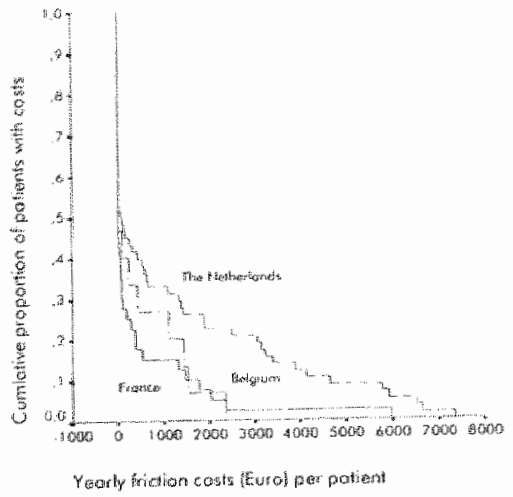

Figure 7.1. Kaplan-Meier curve of patients with AS with a paid job, illustrating the proportion of patients incurring a specific level of friction costs in each country separately.

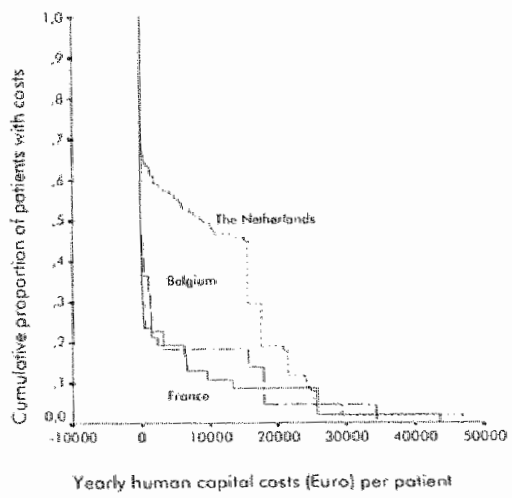

Figure 7.2. Kaplan-Meier curve of the active working population illustrating the proportion of potients with AS incurring a specific level of human copital costs in each country separately.

Figure 7.2 shows that the proportion of patients having $\mathrm{HC}$ costs is far higher in NL. In NL, $50 \%$ of patients have more than $E 10,000 \mathrm{HC}$ costs per year as opposed to $18 \%$ of patients in $\mathrm{B}$ and $10 \%$ in $\mathrm{F}$. The curve in the Dutch patients seems to have 2 parts which can be explained by presence of two separate groups of potients contributing to the HC costs: those with partial work disability and those with full work disability. 


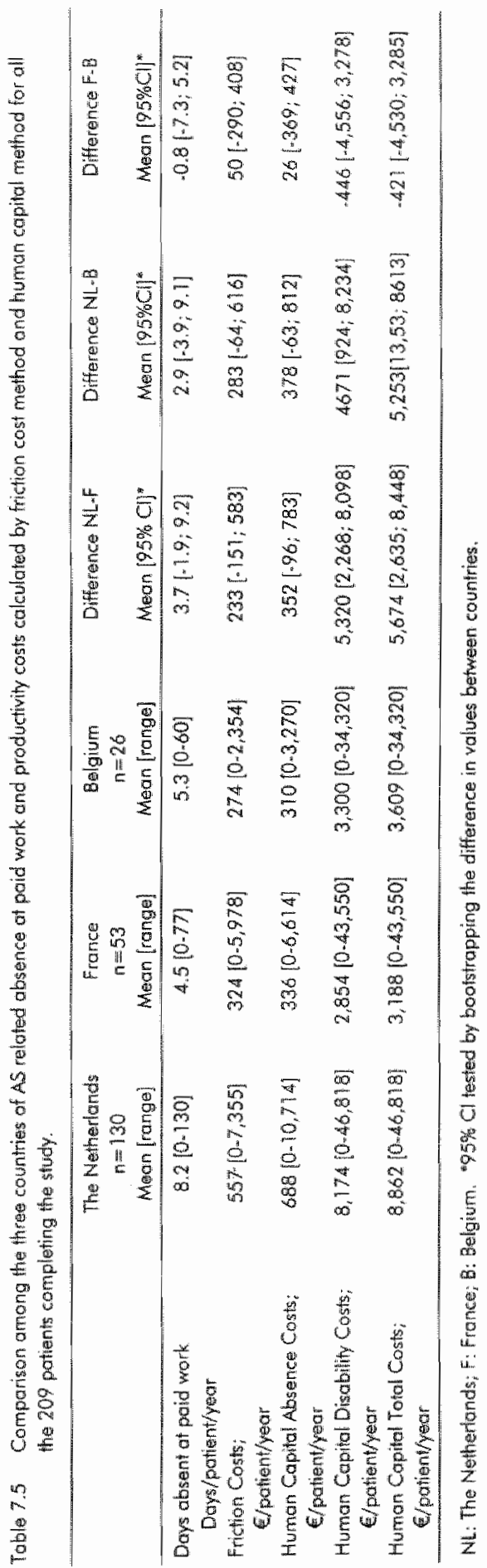




\section{National costs}

Accepting a minimal point prevalence of AS of $0.075 \%$ in each country ${ }^{15}$ and population sizes of 15.5 million for NL, 57.4 million for $F$ and 10.2 million for $B^{24}$ the number of patients with AS in each country would be 11,250 patients in NL, 43,062 in F and 7,646 in B. Assuming our cross-sectional study sample would be representative for the national group of patients with AS, the fotal yearly friction costs would be 6.3 million Euros in the $\mathrm{NL}, \mathbb{4 . 0}$ million Euros in $\mathrm{F}$ and 2.1 million Euros in B. The total yearly human capital cosis would be Euros 103.7 million in NL, 151.2 million in F and 52.3 million in B. For the FC, this represents $0.018,0.011$ and $0.009 \%$ of the gross national product of each country and for the $\mathrm{HC}$ costs $0.29,0.17$, and $0.23 \%$.

\section{Sensitivity analysis}

Table 7.6 shows the results of the sensitivity analyses of the reference case (FC for those with a paid jab). In a first sensitivity analysis the total days absence at work were used instead of the disease specific absence. Seventy five percent of the Dutch, $48 \%$ of the French and $73 \%$ of the Belgian patients with a paid job reported an episode of sick leave, resulting in 23 (range: 0-141), 7 (range: 0 77) and 15 (range: 0-60) days per patient per year in the three countries respectively. Associated friction costs remained significantly higher in NL as opposed to both other countries.

In those with a paid job, the proportion of patients with one or more missing questionnaires was $100 \%, 32 \%$ and $93 \%$ and the proportion of missing questionnaires was $15.5 \%, 4.2 \%$, and $12.2 \%$ in NL, F and B respectively. The method to impute missing values did not change the differences in costs among countries. However, assuming that each missing questionnaire represents absence at work for that entire 2 months' period would result in an impontant increase in costs compared with the reference case.

The numbers of patients with more than six months sick leave during the two years follow-up was $6(10.3 \%), 1(2.5 \%)$, and $0(0 \%)$ patients in $\mathrm{NL}, \mathrm{F}$ and $\mathrm{B}$ respectively. When replacing the length of sick leave of the outliers by the mean duration of sick leave of the remaining patients of the same country, the difference between NL and B lost statistical significance, reflecting the sensitivity of the analyses to the length of the period of sick leave. The same observation was done when replacing duration of sick leave of those patients with more than 3 months sick leave (11 patients (19\%) in NL as opposed to $3(7.5 \%)$ in $\mathrm{F}$ and 1
$(6.7 \%)$ in $\mathrm{B})$.

Finally, country specific average production values, first from Eurostat and next from each country's national bureau of statistics were used instead of patient reported production values. Eurostat reported an awerage income per working day of $€ 88$ for NL, $€ 82$ for $F$ and $€ 96$ for $B$. The National Bureau of Statistics of each country reported an average income per warking day of $€ 94, € 115$ and $€ 92$ in NL, F and B respectively. Again, the difference in FC between NL
and B lost significance. 
Table 7.6. Sensitivity analysis of the friction casts (E/patient/year) for those with a paid job.

\begin{tabular}{|c|c|c|c|}
\hline & $\begin{array}{l}\text { The Netherlands } \\
n=58 \\
\text { Mean }[95 \% \mathrm{Cl}]^{\circ}\end{array}$ & $\begin{array}{c}\text { France } \\
n=40 \\
\text { Mean }[95 \% \mathrm{Cl}]^{\circ}\end{array}$ & $\begin{array}{c}\text { Belgium } \\
n=15 \\
\text { Mean } 195 \% \mathrm{Cl}\end{array}$ \\
\hline $\begin{array}{l}\text { Reference case } \\
\text { (AS related days of SL) }\end{array}$ & 1,257 & 427 & 475 \\
\hline Tatal days SL" & $\begin{array}{c}166-1.80 \\
1.693\end{array}$ & $\begin{array}{c}{[156-799]} \\
466\end{array}$ & $\begin{array}{c}{[138-885]} \\
697\end{array}$ \\
\hline (AS related and not related) & $\llbracket 1,094 \times 2,833 \rrbracket$ & {$[171-865]$} & {$[389-1,072]$} \\
\hline $\begin{array}{l}\text { Missing walues: } \\
\text { cansidered as no sick leave }\end{array}$ & $\begin{array}{c}1027 \\
{[634-1,426]}\end{array}$ & $\begin{array}{c}423 \\
{[143-814]}\end{array}$ & $\begin{array}{l}419 \\
{[111-805]}\end{array}$ \\
\hline $\begin{array}{l}\text { Missing values: } \\
\text { replaced by maximal sick leave": }\end{array}$ & $\begin{array}{c}4,745 \\
{[3,727-6,237]}\end{array}$ & $\begin{array}{c}1,767 \\
{[1,038-2,599]}\end{array}$ & $\begin{array}{c}3,564 \\
{[2,557-4,621]}\end{array}$ \\
\hline $\begin{array}{l}\text { Country specific production walue: } \\
\text { Eurostat }\end{array}$ & $\begin{array}{c}1,328 \\
{[802-1,920]}\end{array}$ & $\begin{array}{c}490 \\
1156-930]\end{array}$ & $\begin{array}{c}755 \\
{[204-1,469]}\end{array}$ \\
\hline $\begin{array}{l}\text { County specific production value: } \\
\text { mational burecu of statistics" }\end{array}$ & $\begin{array}{c}1,527 \\
{[897 \cdot 2,253]}\end{array}$ & $\begin{array}{c}669 \\
{[220-1,250]}\end{array}$ & $\begin{array}{c}739 \\
{[195-1,402]}\end{array}$ \\
\hline $\begin{array}{l}\text { Days SL outliers (>3 mo) replaced } \\
\text { by country specific group-mean }\end{array}$ & $\begin{array}{c}577 \\
{[362-818]}\end{array}$ & $\begin{array}{c}205 \\
{[9-344]}\end{array}$ & $\begin{array}{c}365 \\
{[102-669 \rrbracket}\end{array}$ \\
\hline $\begin{array}{l}\text { Days SL outliers (>6 mo) replaced } \\
\text { bycountry specific group-mean }\end{array}$ & $\begin{array}{c}976 \\
{[577-1,452]}\end{array}$ & $\begin{array}{c}306 \\
[1] 29-515]\end{array}$ & $\begin{array}{c}475 \\
{[131-1,120]}\end{array}$ \\
\hline
\end{tabular}

SL: sick leave; mo: manths; $95 \% \mathrm{Cl}$ assessed by bootstrapping; "Difference bewween NL and $\mathrm{F}$ statistical significant ftested by bootstrapping the difference in values between countries); Difference between NL and B statistically significant (tested by bootstrapping the difference in values between countries).

\section{Effect on Quality of life}

In the whole group QoL, measured by EQ-5D, was worse in those with chronic work disability (OR: 1.67; 95\% Cl: 1.2-2.3; p-value 0.002). Despite the higher work disability rate in NL, QoL was better among the Dutch patients compared with the $\mathrm{F}$ and $\mathrm{B}$ patients (OR: $0.37 ; 95 \% \mathrm{Cl}: 0.26-0.53 ; \mathrm{p}$ Value <0.000 ). However, the absence of interaction between work disability and the country makes if unlikely that the effect of work disability on QoL in NL differs from both other countries. Therefore the better $\mathrm{QoL}$ of Dutch patients cannot be explained by the difference in work disability. QaL in those with a paid job was not inflluenced by having or not having an episode of sick leave and no interaction between the country and having sick leave was observed.

\section{Discussion}

In AS disease related work disability, absence from paid work and productivity costs are substantial. In addition, there are significant differences in these outcomes among three European countries. Work disability rates as well as days absent from paid work were higher in NL compared with F and B. These differences persisted affer adjusting for sociodemographic and disease 
characteristics, suggesting that differences in the organisation of the social security system contribute to this observation. We had suspected that the possibility provided by the social security system to allow partial work disability while continuing a partime job (which is possible in NL and F but not customary in B), would have resulted in better employment in these countries. This was certainly not observed in Dutch palients with AS. Passibly, the more favourable disability benelit in NL is an incentive for withdrawal from the labour force. This however, remains a hypothesis because in all countries reinsurance against loss of income is possible and we have no patient specific data on this issue.

Interestingly, although the mean number of days of sick leave was higher in NL, the proportion of patients having an episade of sick leave over the two years" period was similar in the three countries. While manual professions and worse physical function were predictors of incurring sick leave, the length of sick leave was associated with higher cumulative disease activity, suffering from associated inflammatary bowel disease and living in NL. Again, it can only be hypothesised that the more favourable sick leave benefit in NL is a kind of incentive to prolong sick leave.

Since we were inclined to attribute the higher work disability rate and increased length sick leave in the NL to the more favourable social security system, we wondered if this explained the better QoL experienced by Dutch patients with AS, despite the higher disease activity and worse physical function in this group. However, in all countries work disability (but not sick leave) was associated with worse QoL and this effect was not different among the countries studied. The better QoL reported by the Dutch system can therefore not be attributed to the differences in work disability and sick leave

We calculated societal productivity costs by both FC method and $\mathrm{HC}$ approach. FC in those with a paid job as well as $\mathrm{HC}$ costs in the active population were higher in NL than in both other countries. This difference remained after adjusting for sociodemographic and disease characteristics. As expected, HC costs were higher than FC in all countries, but this was more pronounced in NL, reflecting the higher work disability rate. We agree with other health economists that FC provide a better estimate of the true societal costs of productivity loss (indirect costs) and therefore have chosen this method as our reference case. ${ }^{30,31}$ However, it is clear that the impact of disease due to work disability is not reflected in monetary terms when using FC in costs-of-illiness studies.

In the sensitivity andysis of the FC in those with a paid job, our model proved sensitive to the number of days sick leave. The difference in costs between NL and $B$ lost significance when replacing the duration of sick leave of outliers by the country specific group mean. Although this might be due to the small number of patients included in the Belgian group, this observation has potential implications for the precision to collect data on sick leave and the method to impute missing data on days of sick leave. In our study, sick leave was collected by bimonthly questionnaires. A recent study showed that recall for health resource utilisation is reliable for a period up to two months. ${ }^{33}$ However, this was only one observation and there are no data yet on the best way to impulte missing values. These issues should be studied more closely. The association 
between the country and FC was also sensitive to the choice of the production value per working day. The difference in FC between NL and B lost significance by using the country specific (average) production values instead of patient reported production values. Comparing the patient reported income with the national reparted mean income, we feel that more Belgian patients must have underreported their income. To our knowledge, there are no (cross-cultural) studies wallidating self-report of income.

There is no consensus on the best way to present and test cost data, which are usually highly skewed, also after lag-transformation. Since bootstrapping has been recommended as the preferable method ${ }^{29}$ we have chosen this technique to test the difference in days sick leawe and costs uniwariate. Interestingly, the results were identical when One-Way Anova (with post-hoc analysis) was used. Only the difference in FC in those with a paid job between NL and B lost significance, probably as a consequence of the small number of patients in the B group. Further, to adjust for confounders and to analyse determinants of days of sick leave and costs we have chosen a Cox's proportional hazand analysis. In contrast to limear regression analysis, Cox's regression can handle skewed data. Moreover, survival statistics allow to compute Kaplan-Meier curves and to visualise differences in proportions of patients having a specific amount of costs. for each country.

In the literature we found only one cost-of-illness study in AS, conducted in France in 1979. Of 172 patients in this retrospective survey " 127 belonged to the active population (16 to 65 years). Twenty percent were permanently work disabled and $6.6 \%$ tempararily. This resulted in societal productivity costs of 8,045 FF per patient per year. ${ }^{34}$ The method used in this publication is comparable to the HC approach used in our study. For our French patients belonging to the active population, $\mathrm{HC}$ costs were $€ 3,595$ or $23,581 \mathrm{FF}$ per year, which is almost four times higher than 21 years before. For rheumatoid arthritis several studies calculated the indirect costs of disease. Using data from the review by Cooper ${ }^{1}$ and completed with more recent studies ${ }^{3,4}$, productivity costs for RA (converted to 1996 US dollar, using consumer price index) would range from US\$1,467 to US\$37,501 (E 1,254 to E 32,052 using 1998 Euro currency) per patient per year. Studies are not directly comparable due to differences in the patient population studied, differences in the method to collect data and the method chosen to colculate the productivity costs. Most studies adapted the HC approach and results of HC costs in our patients with AS fall whin the limits of these studies.

Our study certainly has limitations. First, the number of patients included is small, especially in the Belgian group, which might be responsible for a nondetected difference in economic outcomes between $F$ and $B$. Second, patients were hospital sampled and they may have more severe disease resulting in worse impact on work status. ${ }^{5}$ Also, in NL all patients from the register were recruited while in $F$ and $B$ consecutive outpatient were included. The latter method might lead to inclusion of patients with more severe disease, but baseline characteristics do not suppont this. Moreover, patients with more severe disease would have had higher and not lower costs. Third, information on work status, days of sick leave and income was collected through bimonthly 
questionnaires and not ascertained by other sources. Fourth, while we can interpret the multwariate madels on days of sick leave and FC in this prospective study as predictive models, the same can not be done for work disability and (assaciated) HC costs since the vast majority of work disabled patients had been granted this status before entering the cohort.

There were specific difficulties when comparing data amang different countries. First, there is scance epidemiological literature to find out if cross-sectional differences in sociodemagraphic characteristics and disease characteristics reflect true differences or are a possible consequence of sampling. Second, it is difficult to find reference data on educational level, professional class, income, work disability or sick leave from the national papulations in a comparable format and these data are certainly not up-dated yearly. This is impontant since our figures on work disability and sick leave in AS might partly reflect national differences in work disability and sick leave among the countries studied. In NL work disability was higher in AS but also in the general population. However, since population data on sick leave and work disabillty per age and gender categories were not available for all countries due to the above mentioned problems, we were not able to calculate the precise risk difference for patients compared with contrals within each country. Also, our results show that the choice of the mean national production value from different (and slightly conflicting) sources atter the productivity costs. Case control studies would be a solution for some of these problems but are not always feasible. Although some authors studied the effect of the country ${ }^{36}$ or the health insurance systems ${ }^{37}$ on health resource utilisation in rheumatic diseases, the influence of country or social security system on work disability and productivity cosits has not received much attention. A comparison of the total indirect costs (HC approach) of diseases between NL, Sweden and the US confirms important differences among countries. It was shown that the share of indirect costs to the gross domestic praduct was $19 \%$ in NL (in 1988), $14 \%$ in Sweden (in 1983) and $8 \%$ in the USA (in 1980). ${ }^{38}$ Zink reports that in RA as well as in AS, the work disability rates in Eastern and Western Germany before the re-unification differed significantly. It is discussed that differences in the economic prosperity (reflected in unemployment) in both countries is the most likely explanation for the observed difference. ${ }^{39}$ In addition, we think that differences in organisation of the social security system can pose different incentives or disincentives to leawe or remain in labour force.

In conclusion, the impact of AS on labour force participation and productivity costs is influenced not only by sociodemographic and disease characteristics but also by coumtry (or state), reflecting differences in social security system and/or economic prosperity. This has important implications for generalisability of hedth economic analysis across countries. 


\section{References}

1. Cooper NJ. Economic burden of theumatoid arthritis: a systematic review. Rheumatology $2000,39: 26-33$.

2. Sutclife $N$, Clarke $A E$, Taylor R, Frost $C$, Isenberg DA. Total costs and predictors of costs in palients, with systemic lupus erythematosus. Rheumatology $2001 ; 40: 37-47$.

3. Newhall-Perry K, Low NJ, Ramos B, Sterz M, Wong WK, Bulpitt KJ, at al. Direct and indirect costs associated with the onset of seropositive rheumatoid arhtritis. I Rheumotol 2000,27:1156-1163.

4. Merkesdal S, Ruof J, Schöffski O, Bernitt K. Zeidler $H_{*}$ Mou W. Indirect medical costs in early rheumatoid arthritis. Composition of and change in indirect costs within the first three years of disease. Arthritis Rheum 2001;44:528-534.

5. Gabriel SE, Crowson CS, Campion ME, WM OF. Indirect and nonmedical costs among people with rheumatoid arthritis and osteourhritis compared with nonarthritic controls. J Rheumatol 1997:24:43-48.

6. Tulder wan MW, Koes BW. Bouter LM. A cost-of-illness study of bock-pain in The Netherlands. Pain 1995;62:233-240.

7. Jonsson D, Husberg M. Socioeconomic costs of rheumatic diseases. Implications for technology assessment. Int I Technol Assess Health Care 2000; 16:1193-1200.

8. Meenan RF, Yelin EH, Henke CJ. The costs of rheumatoid arthritis. A patientoriented study of chronic disease costs. Arthritis. Rheum 1978;21:827-833.

9. Clarke AE, Zowall H, Lewinton C, Assimakopoulos H, Sibley IT, Haga M, ef al. Direct and indirect medical costs incurred by Canadian patients with rheumaloid arthritis: a 12 year study. I Rheumatol 1997,24: 1051-1060.

10. Jonsson B, Rehmberg C, Borgquist L, Larsson SE. Locomotion status and costs in destructive rheumatoid arthritis. A comprehensive study of 82 patients from a population of 13,000. Acta Orthop Scand 1992;63:207-212.

11. Mclitosh E. The cost of rheumaloid arthritis. Br J Rheumatol 1996;35:781-790.

12. Gabriel SE, Crowson CS, Campion ME, WM OF. Direct medical costs unique 10 people with arthritis. J Rheumatol 1997:24:719-725.

13. Rutten. wan Molken MPMH, wan Doorslaer EKA. Multinationale kosteneffectiviteits. analyses. In: Van kasten tot effecten. Een handleiding voor evaluatiestudies in de gezondheidszarg. Maarssen: Elsevier gezondheidszorg 2000;131- 149.

14. Braun J, Bollow M, Remlinger $G$, Eggens U, Rudwaleit M, Distler $A$, et al. Prevalence of spondylarthropathies in HLA.B27 positive and negative blood donors. Arthritis Rheum 1998;41:58.67.

15. Linden van der SM, Valkenburg HA, de Jangh BM, Cats. A. The risk of developing ankylosing spondylitis in HLA.B27 positive individuals. A comparison of relatives of spondylitis patients with the general population. Arthritis Rheum 1984;27:241-249.

16. Boonen $A$, Chonus $A$, Miedema H, van der Heilde D, van der Tempel H, van der Linden Si. Employment, work disability, and work days lost in patients with arkylosing spondylitis: cross sectional study of Dutch patients. Amm Rheum Dis $2001,60: 353-358$ 
17. Miedema HS, Wanderlinden SM, Rosker JJ, Valkenburg HA. National databose of potients wisiting rheumatologists in the Netherlands: The standard diagnosis register of rheumatic diseoses. A report and preliminary analysis. Br I Rheumatol $1998,37: 555.561$.

18. Calin A, Garrett S, Whitelock H, Kennedy $L G$, OHea J, Mallorie P, ef al A new approach to defining functional ability in ankylosing spondylitis: the development of the Bath Ankylosing Spondylitis Functional Index. J Rheumatol 1994;21:2281 12285 .

19. Garrett S, Jenkinson T, Kennedy LG, Whitelock H, Gaisford P, Calin A. A new approach 10 defining disease status in ankylosing spondylitis: the Bath Ankylosing Spondylins Disease Activity Index. I Rheumatol 1994;21:2286-2291.

20. The EurQol group. The Euroqol: A new facility for the measurement of health related quality of life. Health Policy 1990: 199-208.

21. Dolan P. Modeling valuations for Euraqol Health States. Medical Care 1997;35:1095-1108.

22. Statistisch Jaarbook 1998. Vaarburg/Heerlen: Centraal Bureau voor Statistiek; 1998.

23. Kroniek van de sociale verzekeringen. Zoetermeer; 1997.

24. Eurostat European official statistics, a guide to databases. Luxembourg: Office for official publications of the European communities; 1997.

25. Koopmanschap MA, Rutten FFH. A practical guide for calculating the indirect costs of disease. pharmacoeconomics 1996;10:460-466.

26. Brouwer $W$. Koopmanschap $M$. Overige kosten binnen en buiten de gezondheidszorg. In: Rutten-wan Mölken MPMH, wan Busschbach JI, Rutten FFH, editors. Van kasten tot effectem. Een handleiding woor evaluatiestudies in de gezondheidszorg. Maarssen: Elsevier Gezondheidszorg 2000;43-61.

27. Efron B, Tibshirani R. Bootstrap methods for standard errors, confidence intervals. and other measures of statistical accuracy. Siatistical Science 1986;1:54.77.

28. Briggs A, Gray A. The distribution of healh care costs and their statistical analysis for economic evaluation. Joumal of Health Services Research \& Policy 1998,3:223-245.

29. Thompson SG, Barber JA. How should cost data in pragmatic trials be analysed? $\mathrm{Br}$ Med J 2000,320:1197-2000.

30. Koopmanschap MA, Rutten FFH. The impact of indired costs: the consequences of production loss or increased costs af production. Med Core 1996;34:0559-68.

31. Koopmanschap MA, Rutten FFH. The impoct of costs on outcomes of health care progroms. Health econonics 1996:3:383-393.

32. Organisation for Co-operation and Develpoment (OECD). Health Datc File ICD. ROM] 1999.

33. Severens JL, Mulder J, Laheij RFF, Verbeek ALM. Validity of retrospective assessment at productivity casts. 16 th annual meeting of the international society of technology assessment in health care. 2000 (Abstract)? 2.

34. Sailly JC, Lebrun T. Les consequences economiques ef sociales de la pelvispondylite theumatismale. Rev Epidem Sante Publ 1982,30:305-324.

35. Gran IT, Husby G. Ankylasing spondylitis: a comparative study of patients in an epidemiological survey, and those admitted to a deparment of rheumatology. I Rheumatol 1984; 11:788-793. 
36. Clarke A, Perri MA, Manzi S, Isenberg DA, Gordon C. Senecal JL, et al. Ar international perspective on the well being and health care costs for patients with systemic lupus erythematosus. I Rheumatol 1999;26:1500-1511.

37. Yelin E. Hermdort A, Truin L, Sonneborn D. A national study of medical care expenditures for musculoskeletal conditions. The impact of health insurance and managed cone. Arhtritis Rheum 2001:44:1160-1169.

38. wan Raijen L, Koopmanschap MA, Rutten FFH, van der Mous PJ. Indirect costs of disease; an infermotional comparison. Health Policy 1995: 15-29.

39. Zink A, Braun J, Listing J, Wollenhoupt J. Disability and handicap in rheumatoid arthritis and ankylosing spondylitismesults from the German theumatalagical database. German Collaborative Arthritis Centers. $₫$ Rheumatol 2000;27:613-622. 

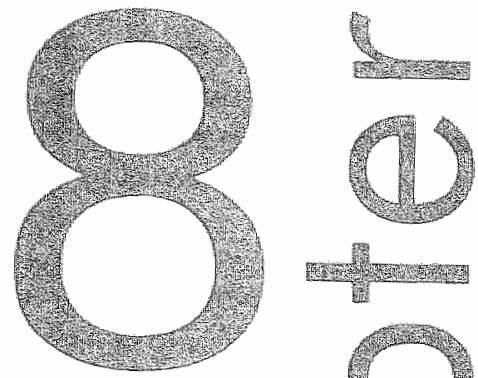

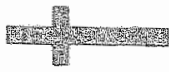
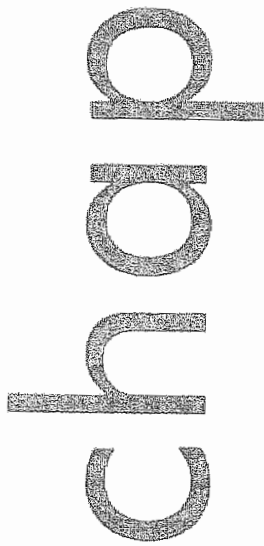

Costs of ankylosing spondylitis in three European countries The patient's perspective

A Boonen, D van der Heije, Randewe, F Gullemin, A Spoorenberg, H Schouten, MRumen-von Molken, M Dougodos. H Melonis, K de Vlam, H wan der Tempol. Si van der Linder

Submitted for publication 


\section{Abstract}

\section{Aim}

To assess patient's out-of-pocket costs, income lass, fime consumption and quallity of life (QoL) due to ankylosing spondyllitis. (AS) in three European countries and to asses which variables can predict these outcomes.

\section{Methods}

216 patients with AS from The Netherlands, France and Belgium participated in a two years' observational shudy. Health resource utilisation, days absent from work, time lost because of AS and quality of life (QOL) were assessed by bimonthly questionnaires. AS related healthcare and non-healthcare expenditures by the patients as well as income loss were calculated taking into account country specific regulations on health insurance and social securify. QoL was delermined by EuroQol. Prediction of patient's costs, time consumption and QoL were assessed using Cox proportional hazard regression analysis with costs, fime or QaL os outcome.

\section{Results}

209 patients provided sufficient data for cost analysis. Average annual patient's out-of packet (healthcare and non-healthcare expenditures were $€ 431$ (median $€ 172$ ) per patient and average annual income loss because of absence at paid work or work disability was E 1,371 (median 0 ol per patient. No differences were noted in the thotal patient's costs thealth care expenditures and income loss combined) among the three countries after adjusting for baseline confounders. However, Belgian patients had significantly higher and French patients significantly lower contributions for healthcare cosis, while Dutch patients had significantly higher non-healthoare costs compared to each of the other countries. Higher total patient's costs were associated with higher age (HR: 0.97; $95 \% \mathrm{Cl}: 0.90-0.99$ ) and worse physical function (BASFI) (HR: 0.78; $95 \% \mathrm{Cl}$ $0.73-0.83)$ (HR $<1$ indicate higher costs). On average, a patient with AS has to spend 75 (median: 45) minutes per day because of AS. Time consumption did not differ significantly among countries. Worse physical function (BASFI) (HR: 0.89; 95\% C1:0.83 0.97 ) and higher disease activity (BASDAI) (HR: $0.87 ; 95 \% \mathrm{Cl}: 0.79-0.96$ ) were predictars of the amount of time lost (HRs $<1$ indicate more time consumed). QoL was significantly worse in the Belgian (HR: 2.03; $95 \% \mathrm{Cl}: 1.30-3.17$ ) and French patients (HR: 2.94; $95 \%$ Cl: $1.99-4.42$ ) as companed with the Dutch, after adjusting for baseline confounders. In addition, peripheral arthritis (HR: 1.46: 95\% Cl: 1.02-2.09). worse physical function (BASFI) (HR: 1.34; $95 \% \mathrm{Cl}: 1.27-2.09$ ), higher disease activily (BASDAl) (HR: $1.28 ; 95 \%$ $\mathrm{Cl} 1.13 .1 .44$ ) but also loss of income due to AS (HR: $1.41 ; 95 \% \mathrm{Cl}: 1.04-1.92)$ contributed to worse QoL. (HR $>1$ indicate worse $Q$ OL).

\section{Conclusion}

AS is a time consuming disease associated with substantial out-of-packet costs. The Belgian potients incur the highest healthcare out-of-pocket payments. In all patients, poor physical function increases patient's costs and requires more time from patients. Loss of income is associoted with lower QoL in all countries studied. 


\section{Introduction}

Traditional outcome measures aim to assess the impact of the disease on the patients themselves. However, in most economic analyses the costs of a particular disease are calculated from a point of view different from the patient's perspective, such as the societal or the health insurer"s perspective. This is surprising, since an illness can have important economic consequences for patients including out of-pocket payments and income loss but also the effect of the disease on time consumption and quality of life $1 \mathrm{Q} O \mathrm{~L}$ ) reflecting the intangible costs. Recently we performed a cost-of-illness (COI) study among patients with ankylosing spondylitis (AS) in three European countries, the Netherlands, France and Belgium. Results of the direct and productivity costs from a societal perspective have been analysed previously. ${ }^{1,2}$ In the present analysis, we determine the costs, time consumption and QoL due to AS, for patients with the disease. Patient's costs, time consumption and QoL were compared among three countries. In addition, determinants of these outcomes are explored.

\section{Methods}

\section{Patients}

Patients were recruited from the rheumatalogy departments of four hospitals in three European countries, the University Hospital Maastricht and the Maasland Ziekenhuis Siftard in The Netherlands, L'Hôpital Universitaire Côchin Paris in France and the University Hospital Gent in Belgium. The detalled description of patient recruitment have been published before. "All patients had radiological sacroilitis. The hospitals of Maastricht, Paris and Ghent have a regional and referral (academic) function. Traditionally, in all three countries patients with a chronic theumatic disease are referred to a rheumatologist. Patients were included between September 1996 and March 1997 and were followed for two years.

\section{Questionnaires}

At baseline and ewery six months patients underwent a clinical examination and completed questionnaires assessing sociodemographic and economic features but also disease characteristics including presence of AS related comorbidity and AS specific physical function measured by the Bath Ankylosing Spandylitis Functional Index (BASFI) (range 0-10; higher values indicating worse function). 3 Peripheral arthritis was defined as presence at baseline of at least one swollen joint out of 44 possible joints assessed the physician", and inflammatory bowel disease (IBD) was defined as self-reported presence at baseline of IBD for which a visit to the specialist had been necessary the preceding year. Every 2 months 
patients completed the Bath Ankylosing Spondylitis Disease Activity Index (BASDAl) (range 0-10; higher values indicating higher disease activity) and the EuraQal-5 dimension (EQ-5D) allowing to calculate utilities.' In addition, patients had to fill out bimonthly and six-monthly economic questionnaires. These were developed for this study, using examples from other cost studies in rheumatic diseases as a guide. ${ }^{8.10}$ Every six months patients were asked about changes in demographic status and warking status, and about contributions to patient societies, aids and appliances purchased or adaptations at house performed. Every two months patients had to report the number of visits to all kinds of healthcare providers, kinds and dosages of medications used, numbers and kinds of lectrical procedures that had been performed, numbers of days of in-patient care, number of days absent from paid work, number of weekly hours of formal and intormal home care received and hours of time per day or week last because of AS in the past two months. Because of the international character of the study, questionnaires were adapted for each country with respect to language, educational system, currency of costs, health insurance system, possible sources of reimbursement of costs and patient out-of-pocket costs if applicable. For the purpose of statistical analysis educational level was dichotomised into more than helve years formal education as opposed 10 Awelve years or less.

Health Insurance System and Social Security System of the three countries

All three countries have an obligatory health insurance system. People with a lower income in the Netherlands (public insured) and all subjects in both other countries contribute a proportion of their gross wage for healthcare insurance. In the Netherlands this is 17.25\% (5.85\% paid by employer), in France 19.6\% $112.8 \%$ paid by the employer but this figure includes contribution for sick leave and work disability) and in Belgium $7.35 \%$ (3.55\% paid by the employer). In The Wetherlands, people with a higher income, have an (obligatory) private insurance for the basic insurance packet, which is approximately $€ 1,036$ per subject per year. Two-thirds of the Dutch population is public insured and one third (obligatory) private. In addition to the above mentioned income related contribution, all Belgians have a small personal yearly contribution (about $€ 4$ per year) to their health insurance company. In contrast to the situation in The Netherlands, patient contributions in France and Belgium are substantial. In The Netherlands, there are no patient contributions for provisions included in the basic coverage package. This package covers most health care provisions. In France, patients with severe AS can become officially exempted from personal contributions. In all countries, there is a possibility for reinsurance for personal contributions. In The Netherlands, there is a strong primary care acting as a gatekeeper towards access to secondary or tentiary care but most patients with a chronic theumatic disease are referred to the rheumatologist. In both other countries, access to primary, secondary and tertiary care is unrestricted. General practitioners and specialists in The Netherlands are paid on a capitation basis for care provided lo public insured patients but on a fee for service system for privately insured parients. In France and Belgium, most healthcare providers are 
paid on a fee per service system. In all countries, healthcare providers working in academic hospitals are salaried and ambulatory working physiotherapists are paid on a fee per service basis. In the Netherlands, but not in both other countries, hospitals are strictly budgeted.

Sick leave benefits in The Netherlands are $100 \%$ of the subject's grass wage for the first year of disease while in both other countries there is an important decrease in income in case of sick leave $160 \%$ from the second month of sick leave onward). Disability benefits in The Netherlands and Belgium are (maximal) $60 \%$ of the former gross wage opposed to $50 \%$ in France. In The Netherlands and France, patients with partial work disability can continue in a paid job while this is very unusual in Belgium. Sick leave and disability benefits in The Netherlands are mainly financed through social contributions from the employer while in France and Belgium employer and employee pay part of these sacial contributions. Reinsurance against loss of income due to sickness is possible in all three countries.

\section{Health resource utilisation and time consumption}

AS related healthcare and non-healthcare resource utilisation, absence from paid work due to sick leave or chronic work disability and time consumed due to AS were assessed. Effects of spinal and extraspinal manifestations of AS were included. Healthcare utilisation included (1) the number of visits to the general practitioner, specialists (rheumatologist and other specialists), alternative medicine, physiotherapist and other paramedical care providers (rheumatology nurse practitioner, ergotherapist, social worker or psychotherapist); (2) the number of days of inpatient care (emergency department, hospitalisation and rehabilitation clinic); (3) the number of technical pracedures performed (venal punctures, conventional radiographic examinations and all other technical pirocedures including CT-scan, MRI, ultrasound, all types of endoscopies, joint aspirates, fundoscopic exams, pre-operative ECGs, spirometry, etc); (4) all medications taken in tablets per days and number of prescriptions purchased; (5) number and duration of spa treatments; (6) number and type of assistive devices; (7) number of adaptations at the house or at the work place and (8) the weekly number of hours of formal home care. Non-healthcare resource utilisation because of AS or its extraspinal manifestations included (1) number of times a swimming or exercise group was attended, (2) renewals of memberships. to AS societies or health care providing arganisations; (3) weekly number of hours of informal care by paid private household help or unpaid help from family or friends and (4) kind of transport and distance to all healthcare providers. In addition, absence from paid work due to sick leave lexpressed as number of working days absent from paid wark) was assessed in the bimonthly economic questionnaires and changes in working hours, work disability and income were assessed in the six monthly economic questionnaires. Finally, time loss because of disease comprised the amount of hours the patients spent daily to rest and exercise at home, time lost because of in- or outpatient healthcare, time lost because of participation in group physical exercise or swimming group and time lost because of AS related absence at paid work. The total time lost 
was corrected for days hosplalised in order to ovoid double counting. Resource utlisation, absence from work and time consumption were not ascertained by comparison with other data sources.

\section{Definition and estimation of costs}

Cosis were calculated from the patient's perspective. Expenditures for healthcare related resources are called healthcare parient's costs. Expenditures for nonhealthcare resources are called non-healthcore patient costs and income loss refers to loss of income because of days absent from paid work (sick leave) or chronic work disability. Total patient's costs comprises the sum of healthcare, non-healthcare patient's costs and income loss.

For the healthcare patient's costs the official country specific patient's contributions were used for each unit of health resource. 11.18 Specific national regulations on reimbursements of costs were taken inta account. For example, Dutch and Belgian patients can be granted reimbursement of physiotherapy for an unlimited number of sessions per year. For alternative medicine, we assumed that patients only visited recognised physicians for which there is a reimbursement as a regular visit. During the period of our study, Dutch patients had to pay the first $€ 45.45$ per year of healthcare costs and $€ 3.6$ per hospitalisation day. Patient's out-of-pocket costs were not corrected for differences in social contributions among countries. Patients with an additional private insurance were considered to pay the non-reduced contribution and the additional premium was not considered as an extra out-of-pocket cost.

For the mon-healthcare patient's costs, patient's reported financial contributions were used whenever available. If these were missing, costs as reported by other patients from the same country for the same resource were used. For travel costs the variable costs per $\mathrm{km}$, based on the country specific mean fuel prices over the period studied, were used. For help from private paid household help, the country specific mean wage of a female handworker was used as reported for 1998 by Eurostat ( $€ 11.00$ per hour in The Netherlands; $€ 10.25$ per hour in France and $E 12.00$ Euro per hour in Belgium. ${ }^{19}$ All known sounces of rembursement to the patient were taken into account.

Where applicable, taxes were included in the cost estimates. All costs were expressed in Euros (December 31, 1998 currency). The currency of one Euro was set at NLG 2.20, FF 6.56 and BEF 40.34 . On the same date 61.00 was worth US\$ 1.17.

An overview of the sources used to colculate the patient's out-of-pocket costs can be found in Appendix 1.

\section{Statistical analyses}

Results are analysed for patients completing a two years' follow-up and having filled-out at least 9 out of 12 bimonthly questionnaires. For missing values of healty resource utilisation in the wa monthly questionnaires, the mean for the same patient of the completed questionnaires was imputed. Demographic and disease characteristics are presented using descriptive statistics. The EQ-5D questionnaire was calculated using the patient's rating and transformed into a 
utility scale ranging from zero (death) to one (perfect health) by applying the York weights?. To better represent the overall QoL during the two years" followup, the time averaged EQ-5D was used in the analysis. Differences of the wariables among countries were assessed by Chi-square for proportions and by ANOVA for continuous variables. Far health resource use, firstly the proportions of patients having used this resource category over the period studied has been assessed, next the mean annual number of units of each resource and finally the annual out-of-pocket costs or time consumed per resource. Since the distribution of costs and time were skewed not only means but also medians are presented to provide a better reflection of the distribution. To compare the difference in out-of-pocket costs and time consumption among the three countries, univariate analyses were performed by Kruskall-Wallis or Mann-Whitney U test.

Determinants of costs, time consumption and QoL were explored by Cox's proportional hazand regression analyses with out-of-pocket costs, time consumption or QoL as dependent variable. As independent variables several sociodemographic and baseline disease characteristics were chosen: gender, age, disease duration since diagnosis, educational level (dichotomised into $\leq 12$ years or $>$ than 12 years formal education), presence of peripheral arthritis, presence of inflammatory bowel disease, BASFI, BASDAl and country (dummy) were considered. When assessing determinants of the EQ-5D utility score, time averaged BASFI and time averaged BASDAl were used within the independent variables. Because differences of the outcomes among countries was our primary interest, the dummy country was entered into a first block and all other variables in a second block using a backward elimination likelihood procedure. Interactions between the variables of the final model and country were explored. Cox's proportional hazard regression analysis was chosen because cost and time data were skewly distributed, even after log transformation. HRs below 1 indicate a positive association between the independent (for example worse BASDAl) with the dependent variable (for example higher costs or better quality of life).

All regression analyses were repeated by eliminating patients with extreme values and by including and excluding patients with extraspinal disease. All procedures were performed using SPSS 9.0 .

\section{Results}

\section{Patients}

In total 216 (135 Dutch, 54 French and 27 Belgian) patients with AS fulfilled modified New York criteria and started the study. In the course of the follow-up five Dutch, one French and one Belgian patient stopped participation. All patients who completed follow-up had filled out at least nine out of twelve questionnaires. The proportion of patients with one, two or three missing bimonthly questionnaires was $84 \%$ and the proportion of missing questionnaires was $10 \%$. Sociodemographic characteristics of patients who completed the study are presented in Table 8.1 for each country separately. When comparing patient 
characteristics among countries, Dutch patients were older, had on average a lower educational level and reported worse physical function (BASFI). None of the French patients had concomitant inflammatory bowel disease. Of the Dutch patients, $77 \%$ were public insured and $23 \%$ private. Of the French patients, $72 \%$ were completely rembursed by the Securite Sociale and $4 \%$ had an additional private insurance. Of the Belgian patients, $4 \%$ had an additional insurance for costs of hospitalisations.

Table 8.1. Charocteristics of patients completing the study.

\begin{tabular}{|c|c|c|c|c|}
\hline & $\begin{array}{c}\text { Total } \\
n=209\end{array}$ & $\begin{array}{l}\text { The Netherlonds } \\
\qquad n=130\end{array}$ & $\begin{array}{c}\text { France } \\
n=53\end{array}$ & $\begin{array}{c}\text { Belgium } \\
r_{1}=26\end{array}$ \\
\hline Male; \% & 70.3 & 70.8 & 67.9 & 73.1 \\
\hline Age; mean yearsi & 43.1 & 45.6 & 37.4 & 41.9 \\
\hline Irangel" & {$[18-77]$} & {$[23.77]$} & $\lfloor 19-67\rfloor$ & $\llbracket 18-74 \rrbracket$ \\
\hline Education $\leq 12$ years*; \% & 71.8 & 82.8 & 48.1 & 65.4 \\
\hline Disease duration; mean & 11.1 & 11.9 & 9.2 & 10.8 \\
\hline (sd) & (8.9) & $(9.2)$ & $(7.4)$ & $(703)$ \\
\hline $\mathrm{BBD}^{*}: \%$ & 7.2 & 10.0 & 0.0 & 7.7 \\
\hline Peripheral arthritis: $\%$ & 25.4 & 28.5 & 26.4 & 8.7 \\
\hline BASFI baseline; mean & 3.3 & 3.9 & 2.5 & 2.6 \\
\hline$(s d)^{*}$ & $(2.6)$ & $(2.4)$ & $(2.9\}$ & $(2.3)$ \\
\hline BASDAl baseline: mean & 3.3 & 3.7 & 2.8 & 3.1 \\
\hline (sd) & $(2.1)$ & $(2.1)$ & $(2.3)$ & $(17.9)$ \\
\hline Time averaged EQ-5D: mean & 0.67 & 0.68 & 0.63 & 0.67 \\
\hline (sd) & $(0.19)$ & $(0.16)$ & $(0.23)$ & $(0.14)$ \\
\hline
\end{tabular}

$p$ Value for difference among countries <0.05 ltested by Chi-square for proportions and ANOVA for continuous variables); IBD: inflammatory bowel disease; BASFI: Bath Ankylosing Spondylitis functional index (range 0.10 , higher values indicating worse function); BASDAl: Bath Ankylosing Spondylitis disease activity index (range 0.10, higher values indicating higher disease activity): EQ-5D: EuroQul 5 dimensions 10 equals death and 1 pertiect bealthy.

\section{Health resource use and patient's costs}

The overall mean total annual patient's costs (healthcare costs, non-healthcare costs and income loss combined) were $\in 1,795$ (median 6351 ) per patient Table 8.21. Income loss accounted for $76 \%$ of the total patient's costs. For healthcare and non-healthcare costs combined, the non-healthcare costs were the cast drivers, comprising $40 \%$ of the out-of-pocket expenditures for private household help, $15 \%$ for transportation and $9 \%$ for contributions to societies or exercise or swimming groups. In univariate analysis, totall patient's costs, nonhealihcare costs and income loss were the highest in The Netherlands compared to France and Belgium. Although the Belgian patients had the lowest nonhealthcare costs and the lowest income loss, they had the highest healthcare patient's contributions reflecting the higher resource use but also the higher patient's payments for these cost categories. In multivariate analysis, the country was the only variable significantly contributing to the variation in patient's 
healthcare costs (Table 8.3). Higher patient's non-healthcare costs could be predicted by living in The Netherlands but also by female gender and worse physical function (Table 8.3). The association behween female gender and nonhealthcare costs could be explained by the high costs because of private household help in female patients (data not shown separately). Income loss was associated with worse physical function (BASFl). Finally, total patient casts were associated with worse physical function (BASF) but also with higher age (Table 8.3). When eliminating the patients with extreme values or patients with extraspinal disease from the regression analyses, the regression coefficients did not change importantly (data not shown separately).

\section{Time consumption}

Table 8.4 illustrates the amount of time patients with AS lose because of disease for different time categories. Excluding the time lost because of sick leave, patients with AS lose on average 1.25 hours per day because of the disease. Mare than $75 \%$ of this time loss is due to time needed for additional day-time rest and time to exercise; $71 \%$ of patients reported to take regular rest at home and on average patients rest 40 minutes per day; $62 \%$ reported to exercise regularly at home and on average a patient exercises 19 minutes per day. An average visit to a healthcare provider consumes two hours, a visit to the physiotherapist one hour and attending group physical exercises takes on average two hours. Technical procedure lasts on average one hour. Travel and waiting time are included, if applicable. There were no important differences in the amount of disease related time consumption in the three countries. Worse physical function (BASF) (HR: 0,89; 95\% Cl: 0.83-0.97) and higher disease activity (BASDAl) (HR: 0.87; 95\% Cl: $0.79-0.96$ ) were predictors of the amount of tatal time lost. In addition to personal time lost, $7.6 \%$ of the patients reported to need regular help from farmily or friends. Time invested in AS by family or friends was 4.6 minutes per day if averaged over all patients with AS, but 60 minutes (median 35 minutes) per day if averaged over patients requiring this type of help.

\section{Relation with QoL}

There was no difference in time integrated QoL (assessed by EQ-5D) in univariate analysis in the three countries. However" after adjusting for sociodemographic and disease characteristics, QoL was worse in France and Belgium compared to The Netherlands. As can be seen in Table 8.5. lower education, presence of peripheral arthritis, worse physical function and higher disease activity were additional determinants of worse quality of life. An interaction was seen between educational level and country and also between presence of peripheral arthritis and country. The effect of education on Qol was stronger in the Netherlands and the effect of peripheral arthritis on $\mathrm{QOL}$ was stronger in France. 
$152 \mid$ Chapter 8

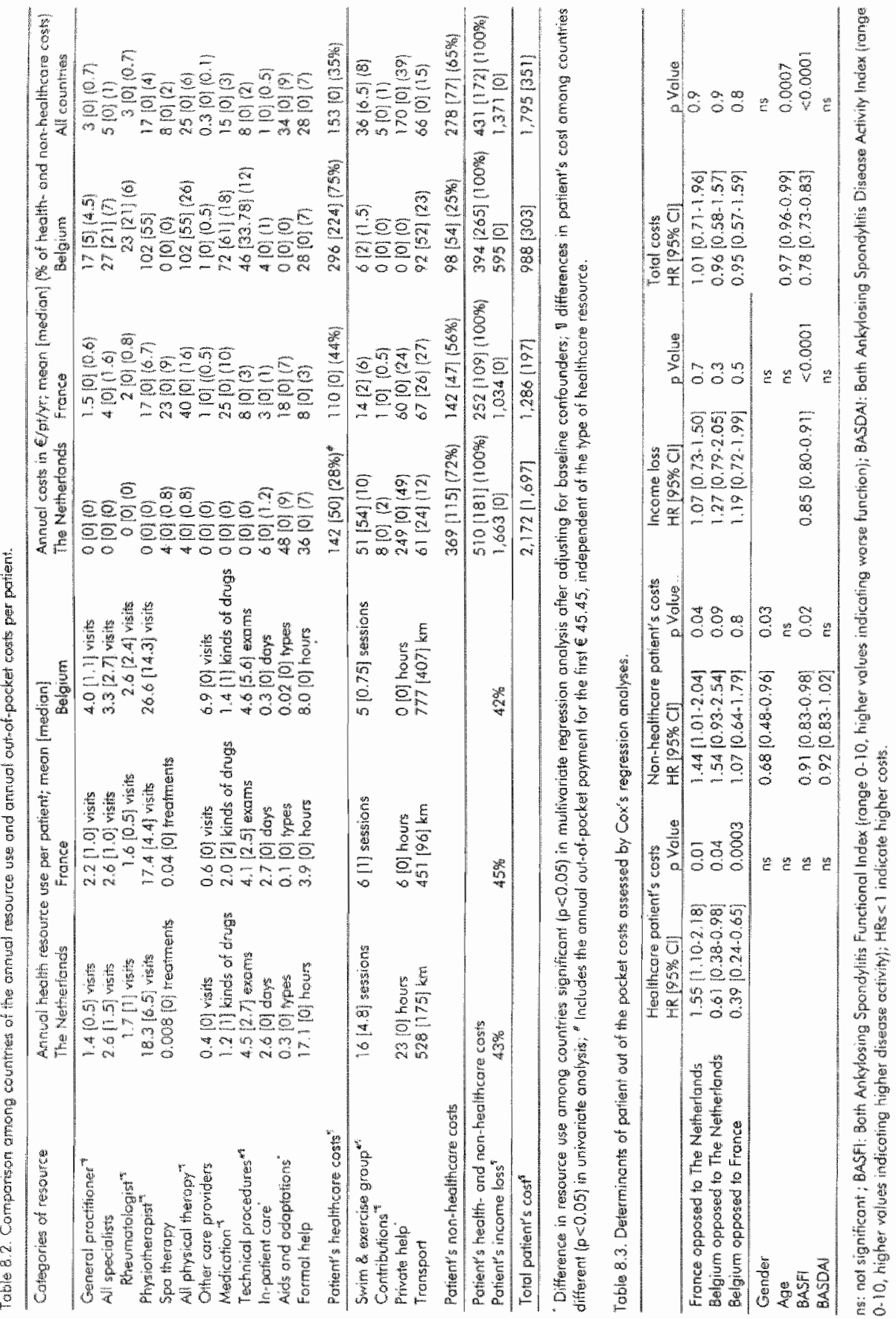


Adding one by one the different categories of patient's costs, fime consumption or income to the independent variables of the regression model, higher income loss (HR for occurring income loss: $1.41 ; 95 \% \mathrm{Cl}$ : 1.04-1.92) but not other outof-pocket costs, time consumption or income was associated with a small but significant deterioration in Qol. No interactions between the variables of the final model and QoL were found. Cox's analysis allows to compute survival curves and to visualise the difference in QoL among the countries. Figure 8.1 illustrates that a QoL of 0.7 or better is reported by $60 \%$ of the Dutch patients opposed to $30 \%$ of the French patients.

Moreover, survival statistics allow to compute Kaplan-Meier curves and to visualise differences in proportions of potients having a specific amount of costs for each country.

Table 8.4. Annual time consumption (hours per patient) due to AS for different categories of time loss.

\begin{tabular}{lcccc}
\hline Time category & $\begin{array}{c}\text { \% patients with } \\
\text { time loss }\end{array}$ & $\begin{array}{c}\text { Mean (median) [\% of total hime] } \\
\text { Hours/patient/year }\end{array}$ \\
\hline Visits to healthcare providers & 81 & 9.94 & $(4.36)$ & {$[2 \%]$} \\
Attending technical pracedures & 90 & 4.97 & $(3.00)$ & {$[1 \%]$} \\
Visits to physiotherapy & 60 & 18.87 & $(0)$ & {$[4 \%]$} \\
Aftending group exercises & 56 & 20.43 & $(0)$ & {$[4 \%]$} \\
Rest at home & 63 & 242.96 & $(72.00)$ & {$[53 \%]$} \\
Exercise at home & 71 & 118.23 & $(29.40)$ & {$[26 \%]$} \\
Inpatient's cane & 9 & 39.74 & $(0)$ & {$[9 \%]$} \\
\hline Medical patient's lime loss & & 455.15 & $(215.43)$ & {$[100 \%]$} \\
\hline Time loss due to sick leave & 27 & 55.37 & $(0)$ & \\
\hline Total patient"s time lost & & 506.44 & $(278.00)$ & \\
\hline
\end{tabular}

Table 8.5. Determinants of time integrated quality of life assessed by time averaged EuraQol-5 dimensions assessed by Cox ${ }^{\prime \prime}$ regression analyses.

\begin{tabular}{lcc} 
& HR [95\% CI] & P.Value \\
\hline France apposed to The Netherlands & $2.94[1.99-4.43]$ & $<0.0001$ \\
Belgium opposed to The Netherlands & $2.03[1] 30-3.17]$ & 0.002 \\
Belgium opposed to France & $0.69[0.41-1.15]$ & 0.5 \\
$\leq 12$ years education & $1.92[1.33-2.75]$ & 0.0005 \\
Peripheral arthritis & $1.46[1.02-2.09]$ & 0.04 \\
BASFl (time averaged) & $1.34[1.21-1.49]$ & $<0.0001$ \\
BASDAl (time averaged) & $1.28[1.13-1.44]$ & 0.0001 \\
\hline
\end{tabular}

IBD: inflammatory bawel disease; BA5F: fime averaged Bath Ankylosing Spandylitis Functional Index (range 0-10, higher values indicating worse function); BASDAI: time overaged Bath Ankylosing Spondylitis Disease Activity Index Irange 0-10, higher values indicaling higher disease activityl, HRs $>1$ indicate warse quality of life. 


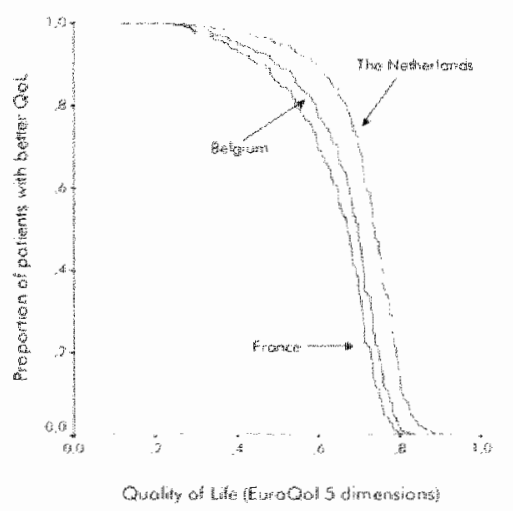

Figure 8.1. Survival curve illustrating the proportion of patients reporting a specific level of quality of Life (QOL], for each country separately.

\section{Discussion}

For the patients, AS is a time consuming disease and is associated with substantial out-of-pocket costs and lass af income. On average patients with AS need 75 minutes additional time per day because of their disease. Sevenly-eight percent of this time is spent on daytime rest and exercises at home. Patients with a worse physical function, higher disease activity and peripheral arthritis require more time. Among 84 Dutch patients with RA average time consumption was 110 minutes per day within the first six years of disease. ${ }^{20}$ Comparable to aur study, this was mainly due to the need for additional rest but also because of extra time needed to perform usual daily activities. Also, worse physical function was associated with mare time consumption.

Apart from time consumption, patients also experience considerable out-ofpocket expenditures because of their disease and suffer substantial income loss. The mean total annual patient's casts mounted to $\in$ 1,795 (median: 351 ) per patient of which $76 \%$ were due to income loss because of work disability or sick leave. The inventory of out-of-pocket costs was rather conservative because some personal extra expenditures such as extra costs for heating the house and for extra clothing (such as sportswear) were not included in the questionnaires. We also assumed that patients out-of-pockel costs for alternative medicine equalled a contribution for a regular physician visit. This will possibly be an underestimation of these costs. Important differences in patient's out-af-pocket payments among the three European countries were noted. Due to characteristics of the national healthcare organisation with high out-of-pocket payments in Belgium, patients with AS in that country have substantially more healthcare contributions. Also in France, out-of-pocket payments are part of the healthcare system. However, the system includes exemption of financial contributions for patients with a (severe) chranic disease (such as severe AS) reducing substantially the overall healthcare contributions. In our study, $87 \%$ of 
French patients had this special status. Interestingly, the higher patient's contributions in Belgium, did not result in lower healthcare utilisation. Strong believe in effectiveness of medical care and supplier induced demand can contribute to explain this phenomenon. Although Belgian patients had the highest healthcare expenditures, they had the lowest non-healthcare expenditures and the lowest income loss resulting in the lowest total patient's costs. In contrast, Dutch patients had high expenditures for aids and adaptations, formal and informal help and financial contributions to societies or exercise groups. They also experienced the highest income loss. These high potient's costs were observed in spite of higher reimbursement rates for aids and adaptations and for formal care and by the relatively more favourable sick leave and work disability benefits compared to both other countries. Apparently, the more favourable re-imbursement and benefit schedules might be an incentive for resource utilisation, prolonged sick leave and work disability. Also, different health believes and cultural attitudes toward paid employment despite disease might explain some of the differences. In this study, health believes, coping with disease or willingness to pay for health have not been assessed and their possible contribution to differences in healthcare utilisation and sick leave or withdrawal from work cannot be explored. It should be noted that the differences in patient's out-of-pocket costs among the countries studied should be interpreted in the light of difference in social contributions and insurance premiums. Country was not the only predictor of the total patient's costs. Older age and worse physical function were also associated with higher patient's costs. In addition, non-healthcare costs, were higher in female patients and this could entirely be attributed to the expenditures for private household help.

Perceived QoL, as a substitute for the intangible costs, was significantly better in Dutch patients and in those with higher education, absence of peripheral joint involvement, better physical function and lower disease activity. Although Dutch patients more often had lower education and had somewhat worse physical function, they experienced better QoL than patients in both other countries. Unknown factors or variables not measured such as health believes and coping with disease might be important contributors to QoL. Interestingly, while income was not associated with reduced QoL, income loss due to work disability resulted in worse experienced QoL.

During the study, none of the patients was treated with one of the new biologic drugs. Since worse physical function is a predictor of patient's out-of pocket costs, income loss, fime consumption and QoL and since the new biologic treatments have proven effect on physical function, it seems likely that these drugs can substiantially improve economic outcome for the patients.

In condusion, for patients suffering from AS, the disease is time consuming and is assaciated with substantial out-of-pocket costs, income loss and reduction in quality of life. There are striking differences in patient's costs and experienced quality of life among countries. In all countries, patients with worse physical function lose more time, suffer the highest total costs and experience worse QoL. 


\section{References}

1. Boonen $A$, van der Heide $D$, Landewe $R$, Rutten $M$, Schouten $H$, Gullemin $F$, elt al. Work status and productivity costs due to ankylosing spondylitis: comparison among three European countries. Ann Rheum Dis 2002;61:429-437.

2. Boonen $A$, van der Heijde D, Guillemin F, Landewe $R$, Dougados M, Mielonts $H$, et al. Health resource use in ankylosing spondylitis. A two years follow-up. Ann Rheum Dis 2000;59 suppll :abstract.

3. Calin A, Garreti S, Whitelock H: Kennedy LG, OHea J, Mallorie P, et al. A new approach to defining functional ability in ankylosing spondylitis: the development of the Bath Ankylosing Spondylitis Functional Index. I Rheumatal 1994;21:2281-2285.

4. Scott DL, van Riel PL, van der Heijde D, Benke AS. Assessing disease activity in rheumatoid arthritis. The EULAR handbook of standard methods. The EULAR standing committee of International Clinical Studies, 1993.

5. Garrett $S$, Jenkinson $T$, Kennedy LG, Whitelock H, Goisford P, Calin A. A new appraach to defining disease status in ankylosing spondylitis: the Bath Ankylosing Spondylitis Disease Activity Index. J Rheumatol 1994;21:2286-2291.

6. The EuroQol group. A new facility for the measurement of thealth related quality of life. Health Policy 1990:199-208.

7. Dolan P. Madeling valuations for Euroqal Health States. Medical Care 1997;35:1095-1108.

8. Goossens ME, Rutten-van Molken MP, Vlaeyen JW, wan der Linden SM. The cost diary: a method to measure direct and indirect costs in cost-effectiveness research. J Clin Epidemiol 2000;53:688-695.

9. Lubeck DP, Spitz PW, Fries JF, Wolfe F, Mitchell DM, Roth SH. A multicenter study of annual health service utilization and costs in theumatoid arthritis. Arthritis Rheum $1986: 29: 488-493$.

10. Verhoeven $A C$, Bibo JC, Boers M, Engel GL, wan der Linden Si. Cost-effectiveness and cast-utility of combination therapy in early rheumatoid arthritis: randomized comparison of cambined step-down prednisolone, methotrexate and sulphasalazine with sulphasalazine alone. COBRA Trial Group; Combinatietherapie Bij Reumatoide Artritis. Br J Rheumatol 1998;37:1102-1109.

11. Tariefboek medisch specialisten, geneeskundige verstrekkingen en ziekenhuisopnomes. Den Haag: Centraal orgaan tarieven Gezondheidszorg; 1998.

12. Terugbetalingsbarema ZIV. Brussel: Rijksinstituut Ziekte en Invaliditeitswerzekering; 1998.

13. Nomenclatuur geneeskundige verstrekkingen. Brussel: Rijksinstituut ziekte en involiditeitswerzekeringen; 1998.

14. Nomenclature des Actes Professionnelles. Poris; 1998.

15. Prijshijst pharmacotherapeutische specialiteiten. Brussel: RIZIV; 1998.

16. Vidal, le dictionnoire. $74 \mathrm{ed}$. Poris: Editions du Vidal; 1998.

17. Taxe niet-WTG, OTC en handverkoap. Den Haag: Koninklijke Maatschappij ter bevordering van de Pharmacotherapie; 1998. 
18. Taxe WTG. Den Haag: Koninklijke Nederlandse Maatschappij ter bevordering van de Pharmacie; 1998.

19. Eunastat European official statistics, a guide to dalabases. Luxembourg: Office for official publications of the European communities; 1997.

20. Albers $\mathrm{M}$, Kuper $H H_{\text {, }}$ van Riel PL, Prevoo ML, wan 'I Hof MA, van Gestel AM, et al. Socio-economic consequences of rheumatoid arthritis in the first years of the disease. Rheumatol 1999:38:423-430. 


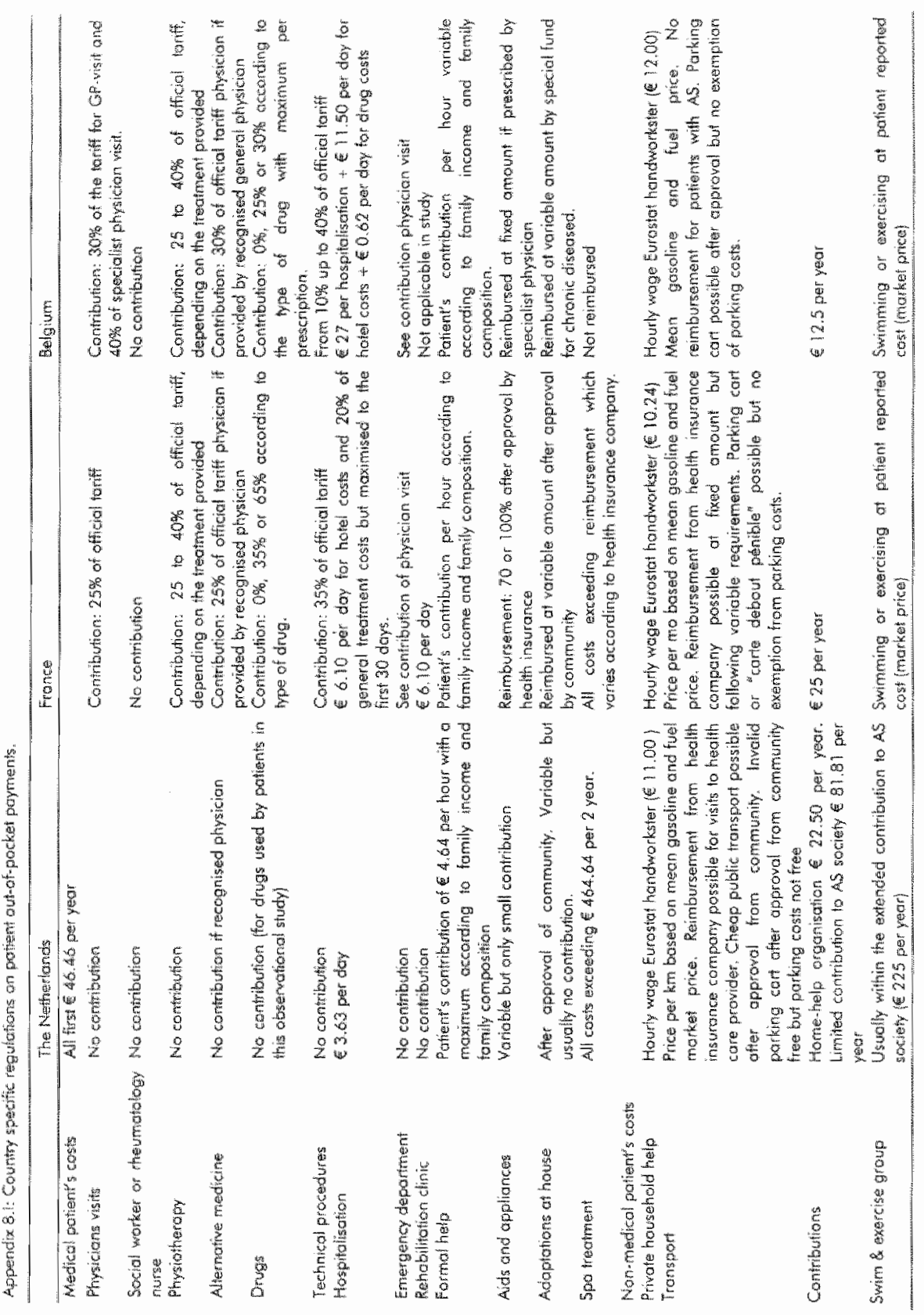



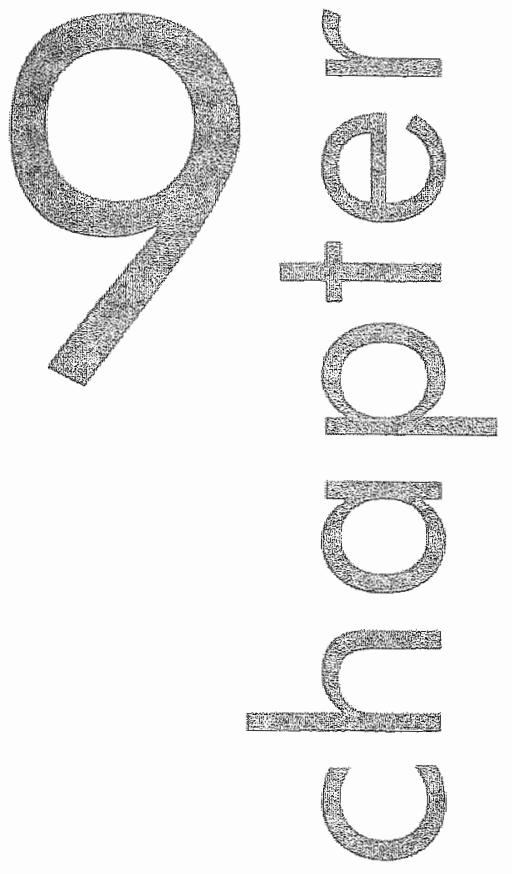

A tale of two cities

A comparison of hospitalisation costs in 1897 and 1997

The longer you con look bock. the better you can look forward

Sir Winston Churchill

A Boonen, JH Severens, Sivon de: Lmden

Submitted to publication 


\section{Abstract}

Aim

To find out when transition to paid haspital care took place, to know by which method the cost of a hospitalisation was calculated and to compare the historic with the present costs.

Methods

Municipal and hospital archives of two cities, Mastricht in The Netherlands and Tongeren in Belgium, were studied systematically for reports of costs.

\section{Results}

From the second part of the nineteenth century onward, the casts of a patient"s hospitalisation were claimed. An annually determined day price and the number of days the patient was admitted, served as the base for the total costs of a haspitalisiation. The day price was calculated yearly by total cast averaging. Nutrition accounted for nearly $50 \%$ of all expenses. Differences with the current situation are striking. Management makes up more than seventy percent of the present expenditures. Compared to the spending power of people on important increase in costs is noted.

\section{Conclusion}

Hospitalisation day prices have already been used for abaut 150 years to determine the hospitalisation costs. Since then, not only the total hospital expenditures but also the relative cost components have changed considerably. 


\section{Introduction}

Aithough hospitalisations are the comerstone of present healthcare, they are a recent phenomenon in the history of medicine. 'For centuries, the sick have been cared for within the family. Only the ill without relalives needed a shelter. During the entire Middle Ages the sick poor found a caring spoce in the almshouses on hospices of the monasteries. Such hospices were mainly intended for pilgrims and paupers but often housed an infirmary or lazaretto. The thirteenth and fourteenth century saw the rise of the cities. The increasing number of wanderers and poor in the towns became o threat for the citizens becouse they brought criminality and epidemics such as leprosy and cholera. Slowly, charity became channelled in public social structures. The famous Mensae Sancti Spiritus (Tables. of the Holy Spirit) organised distribution of food for the needy and the first municipal haspices and leper house emerged. These "hospitals" continued to provide the traditional welfare serwices of which medical care was merely a side product. Although these institutions were civil, the execution of care was still parish based and dependent on the clergy. Financially, the Mensae Sancti Spiritus and municipal hospices were self-supporting through management of the properties they acquired from legacies and gitts. The next step towards madern healthcare came with the philosophy of the Enlightenment in the eighteenth century. Application of the enlightened vision resulted in an expansion of clinical medicine and in the belief that sickness could be controlled. The knot between poor relief and medical care was slowly cut in all European cities. At the same time, the important anti-derical movement, following the French Revolution, made an end to the interference and influence of the Church on secular structures. Rational (civil) state organisation appeared. By law, the new French government replaced the former Mensae Sancti Spiritus by the "Bureaux de Bienfaisance" (Offices of Welfare) and the management of the hospitals came under the responsibility of the "Commissions des Hospices Civils" (Commissions of Municipal Hospitals). After the defeat of Napoleon at Waterloo in 1815 and after the independence of Belgium and The Netherlands in 1830 , the structure of the French health care system was maintained in both countries. The new governments only changed the nomes of the institutions, which were now called "almshouse administrations". They were more or less independent municipal organisations, run by civic-minded businessmen. In the nineteenth century sick care became more complex, especially because of developments in the field of bacterialogy, anaesthesia and aseptic surgery. The infectious disease and surgical ward were separated from the medical ward. Because of the increasing number of patients admitted to hospitals and the increasing costs of medical care, the managers had to find salutions to face up this financial burden. In this study we try to find out when the transition to paid hospital care took place and how costs of hospitalisation were calculated. We also compare the histaric expenditures with the present situation. In order to 
understand to what extent these findings are generalisable over European countries, we did our search in two hospitals in two different countries.

Overview: Major historical steps in the development of thealtheare, its organisation and financing.

\begin{tabular}{|c|c|}
\hline Period & Description historical situation. \\
\hline 8-12th century & $\begin{array}{l}\text { For centuries the ill are looked after by their family. } \\
\text { The ill withouf family are cared for by the Church as part of } \\
\text { charity, which included support for the insane, orphans, } \\
\text { wanderers, poor. Occasionally special infirmaries or hospices are } \\
\text { built. }\end{array}$ \\
\hline 13-18th century & $\begin{array}{l}\text { Wanderers and poor concentrate in the cities and are a threat ta } \\
\text { public health. The municipalities become increasingly involved } \\
\text { with provision and financing of healthcare. The Tables of the Holy } \\
\text { Spirit (for the distribution of faod) and haspices emerge in each } \\
\text { lown. The organisation of healthcare is still mainly on a parish } \\
\text { base. }\end{array}$ \\
\hline $\begin{array}{l}1792-1815 \\
\text { (French Period) }\end{array}$ & $\begin{array}{l}\text { Charity becomes secularized. The existing institutions are } \\
\text { replaced by the "Commissions des Hospices Civils" (coordinating } \\
\text { the organisction of the different hospices in each town) and the } \\
\text { "Bureaux de Bienfaisance" (continuing the work of the Tables of } \\
\text { the Holy Sprit). The structure of this organisation remains, also } \\
\text { after the defeat of the French. The name of the organisation } \\
\text { changes into "poor laws administration" and they regain some } \\
\text { independence from the municipality. }\end{array}$ \\
\hline $\begin{array}{l}\text { Second half } \\
19 t h \text { century }\end{array}$ & $\begin{array}{l}\text { Increasingly, medicine becomes fechnical and care for the ill } \\
\text { concentrates in the hospitals instead of within the family. At the } \\
\text { same time the costs increase and the institutions are no longer } \\
\text { self-supporting. }\end{array}$ \\
\hline 20 th century & $\begin{array}{l}\text { Consequently, costs have to be claimed to the patients or their } \\
\text { representatives. } \\
\text { In order to ossure equal access to healtheare gradually local } \\
\text { insurance companies emerge. More and more there is } \\
\text { governmental involvement resulting in legislation on social } \\
\text { security. }\end{array}$ \\
\hline
\end{tabular}

\section{Methods}

A systematic search of the municipal archives of Maastricht, the oldest fown in The Netherlands, and of Tongeren, the oldest town in Belgium, was performed. We started to study the archives of the year 1900 and went backwards in time as for as needed to find the first reports on costs. For Maastricht, we consulted the "Fonds Burgerlike Instellingen Weldadigheid" (Fund of the Public Institutions of Welfare, Maastricht)", accessable through an inventory since $1987^{3}$ and the annual "Verslagen van den toestand der gemeente Maastricht" (Extensive Reports of the Situation of the City of Maastricht). "For Tongeren the "Fonds Godshuizen" (Fund Almshouses)", also having an inventory", was explored. In 
this article we present the data of the year 1897 because for that year they were complete in both archives.

Current expenditures were retrieved from the year accounts of 1997 , one hundred years ofter the historic data. Because Maastricht became a universily hospital in 1976 and costs of such hospitals are higher, we also used the 1997 year account of Sittard", a nearby Dutch regianal hospital.

In order to estimate how costs relate to the spending power of people, it is recommended by economic historians to perform comparisons with the price of a one $\mathrm{kg}$ bread and the day wage. For Belgium bread prices for 1897 were avalable. 10.11 In The Netherlands, official records of the bread prices were not obliged anymore after 1865 and therefore that year's price was used. ${ }^{1213}$ The lower estimate of the Belgian price can be attributted to the agricultural crisis due to import of corn from the USA in the early $1880^{\prime}$ 's resulting in devaluation. For Belgium several sources of day wages for the region and period studied were found. "4, For The Netherlands, the national data on mean overall income were used, affer adjusting for region and profession by a weighing factor. "For 1997 , the official price of a wholemeal bread and the national day wage of an industrial worker ${ }^{17}$ were used.

To compare costs between Belgium and The Netherlands, we expressed Belgian francs (BEF) as Dutch guilders (NLG) for the former as well as for the present prices. For the prices in the late mineteenth century, the official currency exchange rate as reported by the Belgian National Bank was used. ${ }^{18}$ The currency was set by law at 2.0832 Belgian francs to one Dullch guilder and was. stable from 1875 till the Great War. ${ }^{18}$ For prices of 1997 , the currency of December 31, 1997 was used. At that time 18.23 Belgian francs equalled one Dutch guilder. Exactly one year later, the official Euro currency was introduced. One Euro equals NLG 2.20 or BEF 40.34.

\section{Results}

\section{Costs of hospitalisation and hospital day price}

From the middle of the nineteenth century onward, the costs of the hospitalisation of a patient were claimed and a doy price was the basis to calculate the total casts. In Belgium, the use of a day price to determine the hospitalisation costs became obliged by the law of February 18, $1845^{19}$ This law aimed at reducing the variability in the cost of a hospitalion among cities. A clear description of the method to calculate the day price was given in an accompanying executive report. It took however until 1856 before the law was generally applied. In the Netherlands no such law existed, but the law on the municipalities of 1851 included an obligation to the almshouse administrations to report yearly expenditures and number of patients admitted. ${ }^{20}$ We observed day prices were calculated systematically from that time onward.

In both countries the yearly expenditures per cost category were written by hand on preprint documents, which also reparted the number of patients admitted and the total number of hospitalisation days. From these data the day price was 
calculated by total cost averaging, this is dividing the total expenditures by the total number of hospitalisation days of that period. In Belgium, the final annual day price was an average of the past 10 years and strikingly the in-living personmel was included in the tatal number of hospitalisation days. The Belgian law required the national government to approve the price proposed by the municipal almshouse administration. In both countries, the final cost of one hospitalisation was calculated by multiplying the day price by the number of days the patient was admitted. Table 9.1 shows characteristics of both haspitals in 1897 and Table 9.2 the day price and its components. The day prices in both countries were remarkably comparable. All expenses were considered including the pure medical costs, but also costs of management (including salaries) and costs of food, linen, cleaning, funerals and energy. Nutrition was the most important cost driver, exceeding the expenses of medical care and management. In Maastricht, three categories of day prices were distinguished from 1891 onward: one for private patients (accounting for $6.9 \%$ of the total hospital days), one for the poor (92.8\% of the total days) and one for patients with contagious diseases $10.3 \%$ of the total days). For private patients the costs of salaries (private patients had a private nurse), food (without the wine, which the rich brought themselves), heating and cleaning were higher but costs of the physician's honoraria and the funerals were not included in the day price, because these had to be paid for separately. In contrast, for patients staying on the contagious diseases ward, casts of maintenance of the building, cleaning and heating, and funerals were higher. This resulted in a day price of 1.84 guilders for private patients, 1.07 guilders for the poor and 3.38 guilders for the patients on the infectious disease ward. Since cost price calculations were available for the periad 1887 to 1897 , it could be seen that they were remarkably stable at that time. In Maastricht the casts varied bewween 0.79 (1888) and NLG 1.17 (1894) per day and in Tongeren between 0.81 (1895) and NLG 0.97 (1893) per day. In Maastricht, a rise of $24 \%$ in totall day price was noticed in 1891. That year the patients and personnel moved into the new haspital, resulting in a steep increase in casts of management, maintenance of buildings, heating and cleaning.

Table 9.1. Characteristics of the two cities and hospitals in 1897 and 1997.

\begin{tabular}{lcccc} 
& \multicolumn{2}{c}{ Maastricht } & \multicolumn{2}{c}{ Tongeren } \\
& 1897 & 1997 & 1897 & 1997 \\
\hline Number of inhabitaris & 34,125 & 115,149 & 8,967 & 56,638 \\
Number of hospital beds & 120 & 685 & $42^{\circ}$ & 385 \\
Number of patients admitted/year & 922 & 21,645 & $338^{\circ}$ & 12,204 \\
Number of hospitalisation days/year & 35,793 & 192,776 & $15,454^{\circ}$ & 106,409 \\
Mean duration hospital stay; days/pt & 38.8 & 8.9 & $76.5^{\circ}$ & 8.7 \\
Total number of personnel & 46 & $2,777 \mathrm{fte}$ & $12^{\circ}$ & $5.15 \mathrm{fte}$ \\
\hline
\end{tabular}

He: full time equivalent; " average over the previous decade. 
Table 9.2. Comparison of the day price and its components for 1897 and 1997 in the two hospitals.

\begin{tabular}{|c|c|c|c|c|}
\hline & \multicolumn{2}{|c|}{ Maastricht } & \multicolumn{2}{|c|}{ Tongeren } \\
\hline & 1897 & 1997 & 1897 & 1997 \\
\hline Doy price (by averaging); NLG/day" & 1.13 & $2,261[9910, c]$ & 0.91 & $769^{\circ}$ \\
\hline Officiall day price (tariff); NLG/day & 1.13 & $973[6540]$ & 0.91 & 340 \\
\hline Salaries & $7.4 \%$ & $50.4 \%$ & $7.9 \%$ & $57.3 \%$ \\
\hline Other management costs & - & $32.4 \%$ & $\cdot$ & $15.5 \%$ \\
\hline Maintenance buildings \& furniture & $9.8 \%$ & - & $3.2 \%$ & - \\
\hline Nutrition & $48.4 \%$ & $0.9 \%$ & $56.1 \%$ & $1.6 \%$ \\
\hline Hotel costs & $18.4 \%$ & $1.9 \%$ & $10.0 \%$ & $6.3 \%$ \\
\hline Clothing & $3.9 \%$ & na & $3.2 \%$ & na \\
\hline Linen & $1.9 \%$ & no & $1.1 \%$ & no \\
\hline Loundry & $2.0 \%$ & na & $0.5 \%$ & na \\
\hline Lighting & $2.7 \%$ & no & $0.5 \%$ & na \\
\hline Heating & $5.4 \%$ & na & $4.2 \%$ & no \\
\hline Cleaning & $2.5 \%$ & na & $0.5 \%$ & no: \\
\hline Medical care & $7.8 \%$ & $14.3 \%$ & $13.2 \%$ & $18.9 \%$ \\
\hline Drugs & $7.3 \%$ & - & $14.8 \%$ & - \\
\hline Funerals and public worshipping & $0.9 \%$ & - & $3.2 \%$ & - \\
\hline Divers & - & - & $0.5 \%$ & $0.33 \%$ \\
\hline
\end{tabular}

Na: not available

- Since December 31, 1998 one Euro equals 2.20 Dutch guilders and 40.34 Belgian francs; ${ }^{b}$ Day price for Siftard, a regional hospital near Maastricht; "Day price calculated by total cost averaging, as was done in 1897 idividing the total expenditures of the hospital by the total number of hospital days); ather management costs include general casts fadministration, communication, insurancel, costs to mainteriance of the building (including energy costs), interests, leasings, rents.

Comparison with the current situation

Table 9.1 illustrates to what extend both cities and hospitals expanded over a period of 100 years. Adjusted for the increase in population size, the number of beds increased 1.69 times in Maastricht and 1.45 times in Tongeren and the number of admissions 6.95 and 5.76 times in both cities respectively. This could only be realised by an important decrease in the duration of the hospitalisation (factor 0.23 in Maastricht and 0.11 in Tongeren). Adjusted for the hospitalisation days, personnel increased over the past 100 years 11 and 6 fimes in Maastricht and Tongeren respectively. In other words, in 1897 each member of personnel in Maastricht looked after 778 hospital days in 1897 but only after 69 days in 1997. Caring for the ill became much more laborious. Table 9.2 presents the 1997 day price calculated by averaging the real hospital expenses by the number of hospitalisation days, similar to the methad used in 1897. In addition, the components of this virtual day price are reported. The cost categories considered, remained quite comparable. What was referred to as "maintenance of buildings and furniture" in 1897 can be compared to the "other management costs" in 1997, comprising direct maintenance costs but 
also rents on loans. The total management casts are now the major contributor to the tatal costs while nutrition accounts for the smallest expense. When comparing both hospitals at the present time we have to realise Maastricht became an academic hospital providing more complex and high technology care. Therefore, a "real" day price was calculated from the year accounts of a nearby Dutch regional hospital (Maasland Hospital Sittard) with 709 beds. The price by averaging was NLG 991.0, more comparable with the Belgian hospital. At present, the tariff replaces the "Irue" cost price. In The Netherlands the tariff is negotiated within the global hospital budget between the health insurance company and the hospital, taking into account capacity and function luniversity or regional) of the hospital. A different tariff is set for the public $(70 \%)$ and the private $(30 \%)$ insured patients. In Belgium the tariff is decided annually by the Ministry of Social Affairs and is based on the function and size of the hospital but also on the true costs of the previous years. It should be realised that costs of drugs, fechnical procedures and the physicians' honoraria (except for the Dutch public insured patients) are not included in the tariff but are claimed separately.

\section{Relationship between day price and spending power of people}

To illustrate what the hospital day price means in terms of the spending power of people, we compared the price of one hospital day with the price of one bread and the income of one day's work, a method which is classically advised in historic economic evaluations. Table 9.3 presents the number of breods and the number of day wages required to pay one day in hospital in 1897 and in 1997. In addition, the number of breads one can buy with a one day wage is provided. Compared with the spending power of people, the costs of hospitalisation have increased disproportional. Expressed in this way, hospitalisation is nowadays extremely expensive.

Table 9.3. Comparison of the hospitalisation costs in 1897 and 1997 in relation to the spending power of people.

\begin{tabular}{lcccc} 
& \multicolumn{2}{c}{ Maastricht } & \multicolumn{2}{c}{ Tongeren } \\
& 1897 & 1997 & 1897 & 1997 \\
\hline Price of bread; NLG & 0.34 & 2.99 & 0.17 & 2.51 \\
Day wage; NLG/day & 0.70 & 161.0 & 0.80 & 179.0 \\
Haspital day price; NLG/day & 1.13 & 973.0 & $0.91^{12}$ & 339.5 \\
$\begin{array}{l}\text { Number of breads one can buy for one } \\
\text { day wage }\end{array}$ & 2.1 & 53.7 & 4.8 & 71.2 \\
$\begin{array}{l}\text { Number of breads to pay for one day in } \\
\text { hospital }\end{array}$ & 3.3 & 325 & 5.3 & 159 \\
$\begin{array}{l}\text { Number of work days to pay for one } \\
\text { day in hospital }\end{array}$ & 1.6 & $6.1^{\circ}$ & 1.1 & 2.2 \\
\hline
\end{tabular}

- Since December 31, 1998 one Euro equals 2.20 Dutch guilders and 40.34 Belgian francs; average over the previous 10 years; "A hospitalisation in Sittard in 1997, a peripheral hospital near Maastricht, would cost 218.2 breads or 4.1 work days. 


\section{Discussion}

About 150 years ago, the almshouse administrations started to dom contributions for the hospitalisation costs of the ill. Although hospitals had been financially self-supporting until that time, the increasing number of patients admitted and the rising expenses for technical procedures forced managers to charge for the increasing costs. From the statt, the annually determined day price and the number of days of hospitalisation were the basis for the total casts of one stay in haspital. While at present the day price is a negotiated tariff, the historic price reflects the real average cost of one day in hospital. Already in 1897, a day in hospital was expensive: while a land worker could buy 2 to 5 breads with one day wage, he had to work 1.6 to 2.2 days to pay for one day in hospital. When comparing the historic data with the present situation, there is a six-fold increase in the number of admissions and an up to 10-fold increase in personnel necessary to operationalise one hospital day. Over the same time period there is an enormous rise in the day price, not only in absolute costs but also proportional to the spending power of people. It was interesting to notice that the historic data were quite comparable between two countries, as well for the period one started to claim casts as for the method to calculate the day price and the absolute hospital costs. This is in sharp contrast to the present situation where tariffs differ importantly amang European countries, compromising comparability.

We realize our study has several limitations. Historic research has its own methodalogy and weaknesses. At present, data are stored systematically but this is in striking contrast to former times. Reports on hospital costs in Maastricht before 1887 could not be found and were missing for the period 1898 to 1907 for Tongeren. Therefore we presented the 1897 figures. Similar problems were encountered when searching for the historic price of bread and the day wage of a land worker, figures that were neccassary to relate hospital costs to spending power of people. The difference in source of the estimates contributes to the observed discrepancy in results between the countries.

The comparison of the historic costs with the present data should be interpreted cautiously. In contrast to the situation in 1897, the majority of drug costs are nowadays not included in the expenditures since these are claimed directly to the health insurance companies. Honoraria for physicians lexcept for the public insured patients) were never included in the hospital expenditures but are likely to have increased substantially. Therefore, the observed increase of the casts of hospital care is definetely underestimated. On the other hand, Maastricht became a university haspital providing more complex care and having a research and teaching responsibility resulting in extra expenditures. The main drawback is that hospitals nowadays also organise autpatient care, a facility not existing 100 years ago. For our study it was impossible to separate expenditures for out- and inpatient care.

When comparing the impact of the day price on the spending power, one should realize that the hospital costs were not necessarily payed by the patients themselves. In 1897 costs were only charged directly to wealthy citizens. For the 
poor patients foreign to the city, costs were claimed to the almshouse administration of the municipality of origin. However, increasingly also the poor belanging to the own municipality had to pay. This resulted in unequal access to healthcare and the idea of solidarity emerged. First, local initiatives offered health insurance and insurance against work disability for persons with a paid job. It took until the middle of the twentieth century before national laws on social security and healthcare were approved in both countries. At the present time, in bath countries an obligatory health insurance system exists. Direct charges to the patients are minimal but charges are indirect through taxes and insurance premiums.

Notwithstanding these limitations the results clearly illustrate the increasing need, but also the increasing costs of hospital care, the shift in total expenditures from nutrition to managerial costs and the disproportionate increase in costs in relation to the spending power of people. In onder to make current hospital financing more translucent, health economists are nowadays discussing methods to calculate a day price reflecting again the true costs. ${ }^{21.22}$ Methods which may seem simple and old fashioned, are now applied in a modern jacket. The past can tell about the future, or as Sir Winston Churchill said: "The longer you can look back, the better you can look forward". 


\section{References}

1. Risse G.B. Mending bodies, saving souls. A history of haspitals. New York, Oxford: 7999.

2. GA Madustricht, Fonds BIWM, inv. nrs. 1475; $1489 ; 4890 ; 5184-5186 ; 5405$. $5477 ; 5460-5461 ; 5478-5554 ; 5481 ; 5594 ; 5595 ; 6242 ; 6243 ; 6530 ; 6529$; $6955 ; 7100$.

3. Raebroeks F.H.M. en Luyten J.J.G. Inventaris wan de archieven van de Burgerlijke Instellingen wan Weldadigheid te Maastricht 1796-1964. Maastricht: 1993

4. Verslagien van den loestand der gemeente Maastricht uitgebracht aan den gemeenteraad door burgemeester en wethouders. Maastrich: Leier-Nipels, 1880-1901.

5. SA Tongeren, Fonds Godshuizen, inv. nrs. $65 ; 86 ; 629 ; 630 ; 637 ; 642 ; 645 ; 646$; $740 ; 741$

6. Boillien H. Inventaris fonds van de Godshuizencommissie. Tongeren: 1977.

7. Academisch Ziekenhuis Maastricht. Jaarrekening 1997. Maastricht: AzM, 1998.

8. Algemeen Ziekenhuis Vesalius Tongeren. Jaarrekening 1997. Tongeren: 1998.

9. Stiching Ziekenzorg Westelijke Mijnstreek. Jaarrekening 1997. Sittard: 998.

10. Vandenbroeke Chr. Sociale geschiedenis van het Vlaamse volk. Beveren-Niimegen: Orion; 1981

11. Vhiebergh E. De Kempen. Leuven: Davidsfonds; 1908. p. 137-138.

12. Gales B.P.A., Luyten, Kreukels en Roebroeks.F.H.M. Het Burgerlik Armenbestuur. Twee eeuwen zorg woor armen, zieken en ouderen te Maastricht. 1796-1996. Stichting Historische Reeks, Moastricht: 1997.

13. Rutten W. Bevalking, gezondheid en levensstandaard in Limburg in de 19 de eeuw. Een overzicht. In: Studies over de sociaclmeconomische geschiedenis van Limburg. Jaarboek wan het Saciaal-Histarisch Centrum voor Limburg, deel XLIII-1998. Madastricht: 1999.

14. de Meere J.M.M. Daglonen in Belgie en Nederland in 1819, een anwulling. In: Tijdschrift voor socicle geschiedenis. Den Haag: M. Nighoff BV; 1980.

15. Rijksarchief Hasselt. Fonds Elen. Landbouwtelling: 1880.

16. Van Zanden J.L. Ecomomische groei in Medertand in de 19die eeuw. Enkele resultaten. In: Economisch en sociaal-historisch jaarboek. Amsterdam: NEHA (Deel $50 \%: 1987: 51-76$

17. Eurostat: European official statistics, a guide to databases. Luxembourg: Office for Official Publications of the European Communities: 1997

18. Janssens V. De Belgische Frank. Anderhalve eeuw geldgeschedenis. Brussel: $1998: 430$.

19. Het Belgisch Stantsblad. art.22. (18 februari 1845)

20. Het Nederlands Staatsblad, or. 85, art. 182 (1851).

21. Dranove D, White W. Recent theory and evidence on competitions in hospital markets. Journal of Economics and Management Strategy 1994;3:169-209.

22. Kesteloot $K$, Voet $N$. Incentives for cooperation in quality impravement among hospitals. The impact of the rembursement system. Journal af Health Economics. $1998 ; 17: 701-728$ 


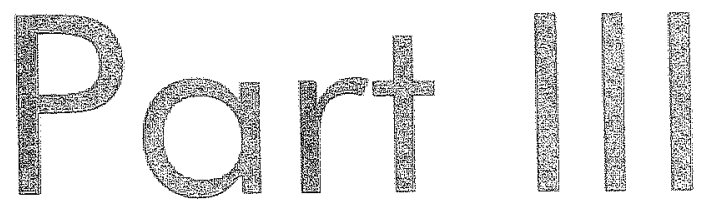

Cost-effectiveness in ankylosing spondylitis 

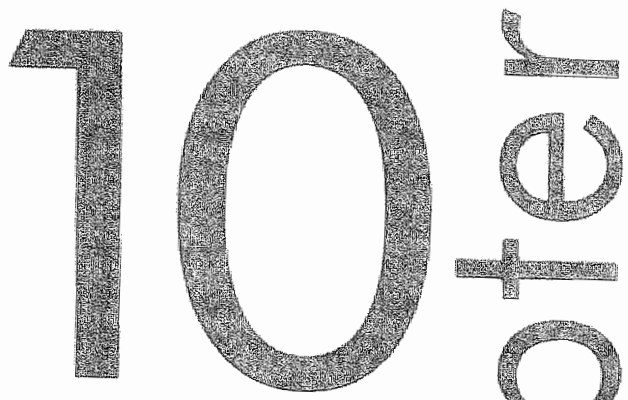

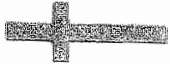
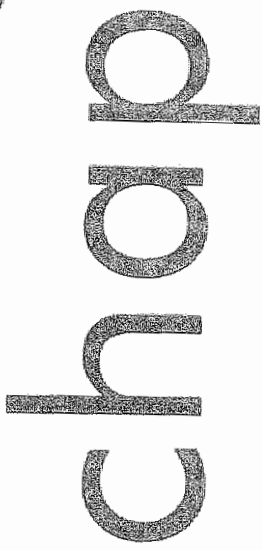

Cost-effectiveness of combined spa exercise therapy in ankylosing spondylitis

A randomised controlled trial

A von Tubergen, A Boomen, R Londewe. M Ruten-von Moken, $\mathrm{D}$ wan der theide. A Hidding, Sy van den Lnden 
174 Chopter 10

\section{Abstract}

Aim

To evaluate the casteffectiveness and cost-utility of a 3 weeks' course of combined spa exercise therapy in addifion to standard treatment consisting of anti-inflammatory drugs and weekly group physical therapy in patients with ankylosing spondylitis (AS).

\section{Methods}

A total of 120 Dutch AS outpatients were randomly allacated into three groups of 40 patients each. Group 1 was treated al a sparesort in Bad Hofgastein. Austria; group 2 at a spo resont in Arcen. The Netherlands. A control group stayed at home and continued their usual activities and standard treatment during the intervention weeks. After the intervention all patients followed weekly group physical therapy. The totall study period was 40 weeks. Effectiveness of the intervention was assessed by functional ability (Bath Ankylosing Spondylitis Functional Index [BASFI]). Utilities were measured with the

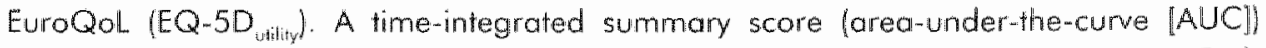
defined the clinical effects (BASFI-AUC) and utilities (EQ-5D urility AUC) over time. Both direct thealthcare and non-healthcare) and indirect costs were included. Resource utilisation and absence from work were registered weekly by the patients in a diary. All cosis were calculated from a sociefial perspective.

\section{Results}

A total of 111 patients completed the diary. The between-group difference $195 \%$ confidence interwaly for the BASFH-AUC was $1.0(0.4-1.6, p=0.001)$ for group 1 versus controls and $0.6(0.1-1.1, p=0.020)$ for group 2 versus controls. The between-group difference for $E Q-5 D$ willy $-A U C$ was $0.17(0.09-0.25, p<0.001)$ for group 1 versus contrals and $0.08(0.00-0.15, p=0.04)$ for group 2 versus controls. The mean total casts per patient (including costs for spa therapy) during the study period were $\in 3,023$ for group 1, $€ 3,240$ tor group 2 , and $€ 1,754$ for the contral group. The incremental costeffectiveness ratio per unit effect gained in functional ability $10-10$ scole) was $\notin 1,269$ (497-3,316) for group 1 and $E 2,477(601-12,098)$ for group 2. The costs per QALY goined were $\in 7,465(3,294-14,686)$ for group 1 and $€ 18,575(3,678-174,257)$ for group 2.

\section{Conclusion}

Combined spa exencise therapy in addition to standard treament with drugs and weekly group physical herapy is nore effective and shows favorable cost-effectiveness- and costu-utility ratios compared with standard treatment alone in patients with AS. 


\section{Introduction}

Treatment of ankylosing spondylitis (AS) is aimed at reducing symptoms and preventing or at least minimising spinal deformity and disability. Standard treatment in active AS consists of non-steraidal anti-inflammatory drugs (NSAIDs), which reduce pain and stiffness, and physical therapy which improves or maintains mobility, fitness and strength, and prevents deformity.' Patients are advised to exercise daily and to follow weekly group physical therapy. In addition, patients may annually take courses of spa therapy in a spa resont. Spa therapy has a longstanding history, but apart from the opinions of participants, its value is largely unknown. If is usually considered expensive and reimbursement by insurance companies is inconsistent.

Recently in a randomized controlled trial in patients with AS, we have demonstrated considerable and persistent improvements in a variety of clinical outcomes after a 3 weeks' course of spa therapy in combination with physical exercises in addition to standard treatment with anti-inflammatory drugs and weekly group physical therapy compared with standard treatment alone. ${ }^{2}$ In this paper we present the results of incremental cost-effectiveness and cost-utility analyses of spa exercise therapy in patients with AS.

\section{Patients and methods}

\section{Design}

This economic evaluation, performed from a societal perspective, was designed alongside a randomised controlled trial on the efficacy of combined spa exercise therapy in AS. The methodology of this trial has been published elsewhere. ${ }^{2}$ In brief, 120 Dutch patients with active AS were recruited and randomly allocated into three groups of 40 patients each. Group 1 received spa theropy at a spa resort in Bad Hofgastein, Austria. Group 2 received spa therapy at a spa resort in Arcen. The Netherlands. The control group stayed at home and continued their usuall activities, drug treatment, and followed weekly group physical therapy during the 3 intervention weeks. Spa exercise therapy was standardised and consisted of group physical exercises, walking, postural correction therapy (lying supine on bed), hydrotherapy, sports, and thermal treatment by either visits to the so-called Heilstollen (Austria) or the sauna (The Netherlands). After the intervention period, all patients from the three groups continued weekly group physical therapy for another 37 weeks, consisting of 1 hour of physical exencises, 1 hour of sports and 1 hour of hydrotherapy. During the intervention and the follow-up period, all patients continued their usual drug treatment, but were allowed to change this.

Spa exercise therapy took place from $T_{0 \text { w }}$ (start of spa therapy) to $T_{3 w} / 3$ weeks after start spa therapy]. Assessments, consisting of questionnaires, were 
performed at baseline $\left(2\right.$ weeks prior to spa therapy; $\left.T_{2}\right)$, and at 4 weeks $\left(T_{4 w}\right)$.

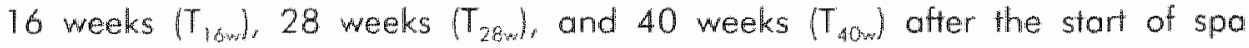
exercise therapy.

\section{Effectiveness measurement}

The primary outcomes of the study were functional ability lassessed by the Bath Ankylosing Spondylitis Functional Index [BASFl] $]^{3}$ pain $(10 \mathrm{~cm}$ visual analogue scale [VAS)], global well-being $(10 \mathrm{~cm}$ VAS), and duration of morning stiffness (in minutes). The BASFI contains 10 questions concerning activities of daily living, scored on a $10 \mathrm{~cm}$ VAS, with anchors "easy" and "impossible" at either side. The mean of the iferns defines the final score, ranging from 0 (best) to 10 (worst). The BASFI has been shown to be a valid, reliable, and responsive instrument for measuring function in AS. ${ }^{3.7}$ Here, the results on the BASFI are used to express effectiveness of the intervention and to calculate the costeffectiveness ratio. The scores on the pain and global well-being question range from 0 (best) to 10 (worst).

\section{Utility measurement}

Utilities refer to preferences individuals or society may have for any particular health state. ${ }^{8}$ For the present study, the EuroQol (EQ-5D uritity ) was chosen to assess utility from a societal perspective. The EQ-5D uility measures quality of life in five dimensions: mobility, self-care, usual activities, pain/discomfort, and anxiety/depression. Each dimension can be divided into three levels of severity: "no problems", "some problems", and "severe problems". The levels for each dimension are combined into one health state. For each of the possible health states a utility is attributed from a societal point of view, based on a large population survey using the time-trade-off procedure. 10,11 The final utility score ranges from 0 (representing death) to 1 (full health). The results of a cost-utility analysis are expressed as quality-adjusted life years (QALYs). A QALY is a composite index that includes effects in terms of both quality of life (utility) and the duration of time in such a health state. ${ }^{8}$

\section{Costs}

In this incremental cost-effectiveness and cost-utility analysis the recommendations proposed by the Dutch Guidelines for Pharmaco-Economic Analyses were followed as closely as possible. "2 Direct (healthcare and non-healthearel as well as indirect (non-healthcare) costs were included. Only costs with respect to AS were considered, including predefined AS related disorders such as uveitis, inflammatory bowel disease, and psoriasis. The time horizon to measure costs was limited to the duration of the study ( 40 weeks). 
CEA of spo theropy in AS

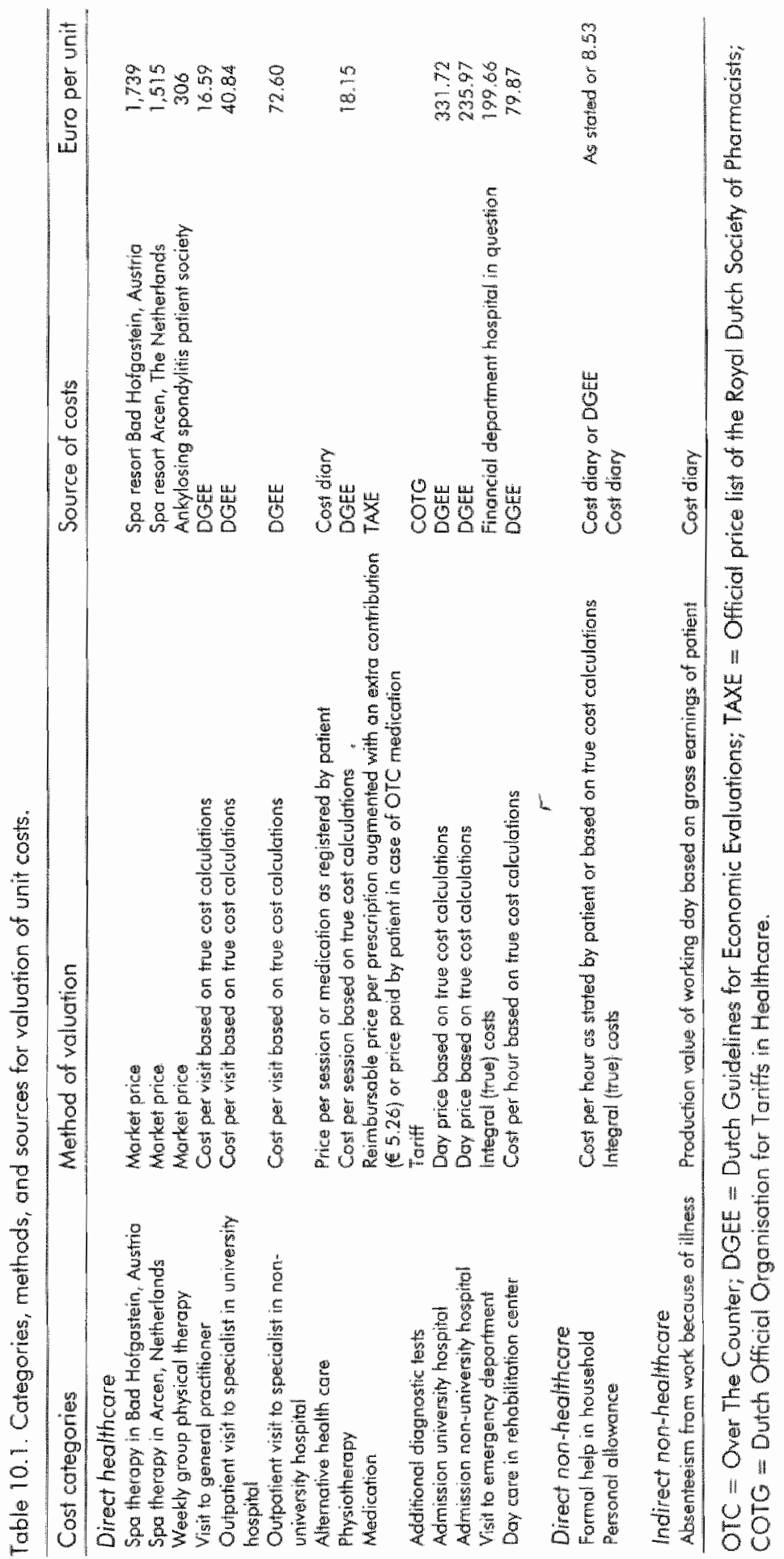


Direct and indirect costs. All direct and indirect costs included are presented in Table 10.1. Acquisition of aids and appliances or adaptations to house or car were excluded, because they were considered not to be influenced by the intervention. For transport cosis, only transport to and from the spa resart was considered (incorporated in the overall costs for spo exercise therapy). Costs of informal (non-paid) help and patients' reported loss of time due to AS were not included in the base-case analysis. We assumed that the time spent on informal help was done in leisure time, i.e. not creating productivity loss of the helping person. Similarly, inactivity was also considered as taking place in leisure time, otherwise, this would have been registered as days of illness related absence from work.

Resources. All resource utilisation and number of days of illness related absence from work were measured during the entire study periad in a cast diary adapted from Goossens ef all. ${ }^{13}$ Data from the day the intervention groups left for spa exercise therapy up to 40 weeks afterwards were used for analysis. Patients judged themselves whether costs were related to AS or not.

Valuation of costs. For the valuation of the healthcare cosis, opportunity costs (representing market prices) are preferred from a theorefical point of view. ${ }^{2}$ In this comparative study they are best reflected by integral (i.e. true) costs. In The Netherlands, integral costs are not available for all resources. ${ }^{14}$ In these cases tariffs were used (prices negotiated by health insurance companies). In Table 10.1 the method of valuation and source of all cast categories are presented and, if applicable, with costs specified. The market price was used for the total costs of the spa exercise therapy (see Table 10.2) and weekly group physical therapy (consisting of the honorarium of the physiotherapisti(s), rent of sports and swimming accommodation, materials, and administrative costs). For the costs due to loss of productivity attributable to AS or related disorders, the friction cost method was used. . $^{5,16}$ In this method the period of production loss due to illness is limited to the time needed to replace a sick worker or to reorganise the production process (4 months). The production value of this friction period was based on the reported gross earnings of the patients, corrected for part-time wark and, if applicable, for the percentage of disability benefits.

Table 10.2. Market price for spa therapy at the wa spa resorts.

\begin{tabular}{lcc}
\hline & $\begin{array}{c}\text { Spo therapy, } \\
\text { Bad Hofgastein, } \\
\text { Austria (group 1) }\end{array}$ & $\begin{array}{c}\text { Spa therapy, Arcen, } \\
\text { The Netherlonds } \\
\text { (group 2) }\end{array}$ \\
\hline $\begin{array}{l}\text { Travel costs from home to spa resort } \\
\text { Hotel accommadation (all meals included) }\end{array}$ & 102 & 11 \\
and attendant \\
$\begin{array}{l}\text { Travel costs from hotel to spa resont during } \\
\text { treatment period }\end{array}$ \\
$\begin{array}{l}\text { Therapy costs and medical treatment } \\
\text { Tofal costs }\end{array}$
\end{tabular}

Costs per potient in Euros. 
All costs were calculated in Euro currency. Costs of 1999 were used and if not available for 1999, they were adapted using the Dutch health specific price index. ${ }^{14}$

\section{Statistical analysis}

The clinical trial was designed as an intention-to-treat analysis and the sample size was based on clinical outcomes. ${ }^{2}$ Between-group differences in clinical outcomes and utilities were analysed by Student's t-tests for unpaired observations. Non-normally distributed data were analysed by Mann-Whitney U test. A time-integrated summary score, the area-under-the-curve (AUC), defined the effects and utilities over time. The AUC of the change from baseline was calculated with the trapezium rule standardised by the study duration. ${ }^{7,18}$

Resource utilisation and costs are reported as arithmetic means (standard deviation) per patient per group. ${ }^{19}$ The differences in volumes of resource utilisation were analysed by Mann-Whitney $U$ test. The $95 \%$ confidence interval $195 \% \mathrm{Cl})$ around the mean total costs per patient and the between-graup differences in mean total costs were estimated with bootstrapping, repeating the analysis 10,000 times. ${ }^{20}$

The incremental cost-effectiveness ratio was calculated by dividing the extra costs for the intervention group by the extra effects derived from it. The incremental cost-utility ratio was calculated by dividing the extra costs for the intervention group by the extra utilities derived from it, and expressed as costs per QAlY' gained. The $95 \% \mathrm{Cl}$ of the ratios were estimated with bootstrapping. Because the time horizon of this study was less than 1 year, neither costs nor effects were discounted.

\section{Sensitivity analysis}

Four one-way sensitivity analyses were performed:

[1] Costs of informal (non-paid) help were added to the base-case analysis. The costs per hour were based on a shadow price of $€ 7.94$.

[2] Cosis of patient-reported inactivity were added to the base case analysis. In the cost diary only the number of days lost due to inactivity was registered. Therefore, two analyses were performed considering a doy of inactivity being either 4 or 8 hours. The costs per hour were based on a shadow price of $\epsilon 7.94$. [3] The number of days of sick leave during spa exercise therapy was varied. Only a few patients from the intervention groups reported sick leave during the 3 intervention weeks; most patients had voluntarily taken days off from work. The mean total costs and costs per QALY were recalculated first assuming that all patienls would be on sick leave during the 3 infervention weeks and second assuming that all patients would need to voluntarily take days off from work.

[4] The outcome measures "global well-being" and "pain" were used as. measure of effectiveness of the intervention in the incremental cost-effectiveness ratio. Morning stiffness was not investigated in a sensitivity analysis. First, because it has a different scale (0 to infinite) compared with the other outcome measures (0 to 10), which could be misleading in cost-effectiveness ratios, and second because morning stiffness is not sensitive to change. 


\section{Results}

Of the 120 participating patients, 9 did not complete the cost diary $(2$ from group 1, 4 from group 2, 3 from the control groupl, but they did not differ from the patient groups with respect to gender, age, work and education. All analyses are based an the 111 (93\%) patients who completed the cost diary. The baseline characteristics of the groups are presented in Table 10.3. All characteristics, except gender, were well balanced among the groups. Relatively less women than men were randomly allocated to the control group compared with both intervention groups.

Table 10.3. Baseline characteristics of the 111 patients who completed the diary.

\begin{tabular}{|c|c|c|c|}
\hline & $\begin{array}{c}\text { Group 1 } \\
\text { (n=38) } \\
\text { Spa heropy } \\
\text { Austria }\end{array}$ & $\begin{array}{c}\text { Group } 2 \\
(n=36) \\
\text { Spo iherapy } \\
\text { The Netherlands }\end{array}$ & $\begin{array}{l}\text { Contirols } \\
\text { (n=37) } \\
\text { Group physical } \\
\text { therapy, Home }\end{array}$ \\
\hline Men/ Nomen & $24 / 14$ & $24 / 12$ & $31 / 6$ \\
\hline Age years; mean $(S D)$ & $\begin{array}{c}47(10) \\
\text { (range } 29-68)\end{array}$ & $\begin{array}{c}48(9) \\
\text { (range } 25-66)\end{array}$ & $\begin{array}{c}48(10) \\
\text { (range } 29-63)\end{array}$ \\
\hline Disease duration: years; mean (SD) & $11(6)$ & $12(5)$ & $10(6)$ \\
\hline Inflammalory bowel disease; yes/no & $7 / 31$ & $5 / 31$ & $9 / 28$ \\
\hline Uveitis; yes/no & $10 / 28$ & $15 / 21$ & $18 / 19$ \\
\hline Psoriasis; yes/no & $4 / 34$ & $4 / 32$ & $4 / 33$ \\
\hline Education; years: mean ISD! & $12(4)$ & $12(4)$ & $13(4)$ \\
\hline Manual/non-manual profession; numbers & $15 / 20$ & $6 / 27$ & $16 / 20$ \\
\hline Paid wark; yes/no & $21 / 17$ & $\pi 7 / 19$ & $23 / 14$ \\
\hline \multicolumn{4}{|l|}{ Reasons no work; numbers } \\
\hline Household & 3 & 3 & $\Downarrow$ \\
\hline (Early) retirement & 2 & 4 & 2 \\
\hline Work disabilily & 13 & 12 & 12 \\
\hline Unemployment & 0 & 1 & 0 \\
\hline Own choice & 0 & 4 & 0 \\
\hline
\end{tabular}

Multiple onswers were allowed.

\section{Clinical outcomes and utilities}

The clinical outcomes and utilities of the 111 patients are listed in Table 10.4. Improvements in all primary outcomes, except for morning stiffness, were found in both intervention groups after spa exercise therapy. The between group differences $(95 \% \mathrm{Cl})$ in the AUC for the BASFI of $1.0(0.4-1.6)$ for group 1 versus controls and of $0.6(0.1-1.1)$ for group 2 versus contrals were both statistically significant $(p=0.001$ and $p=0.020$, respectively). After adiustment for the score of the control group, the mean improvement during the entire study period in BASFI was $20 \%$ compared with baseline for group 1 and $14 \%$ for group 2 . 
CEA of spo theropy in AS

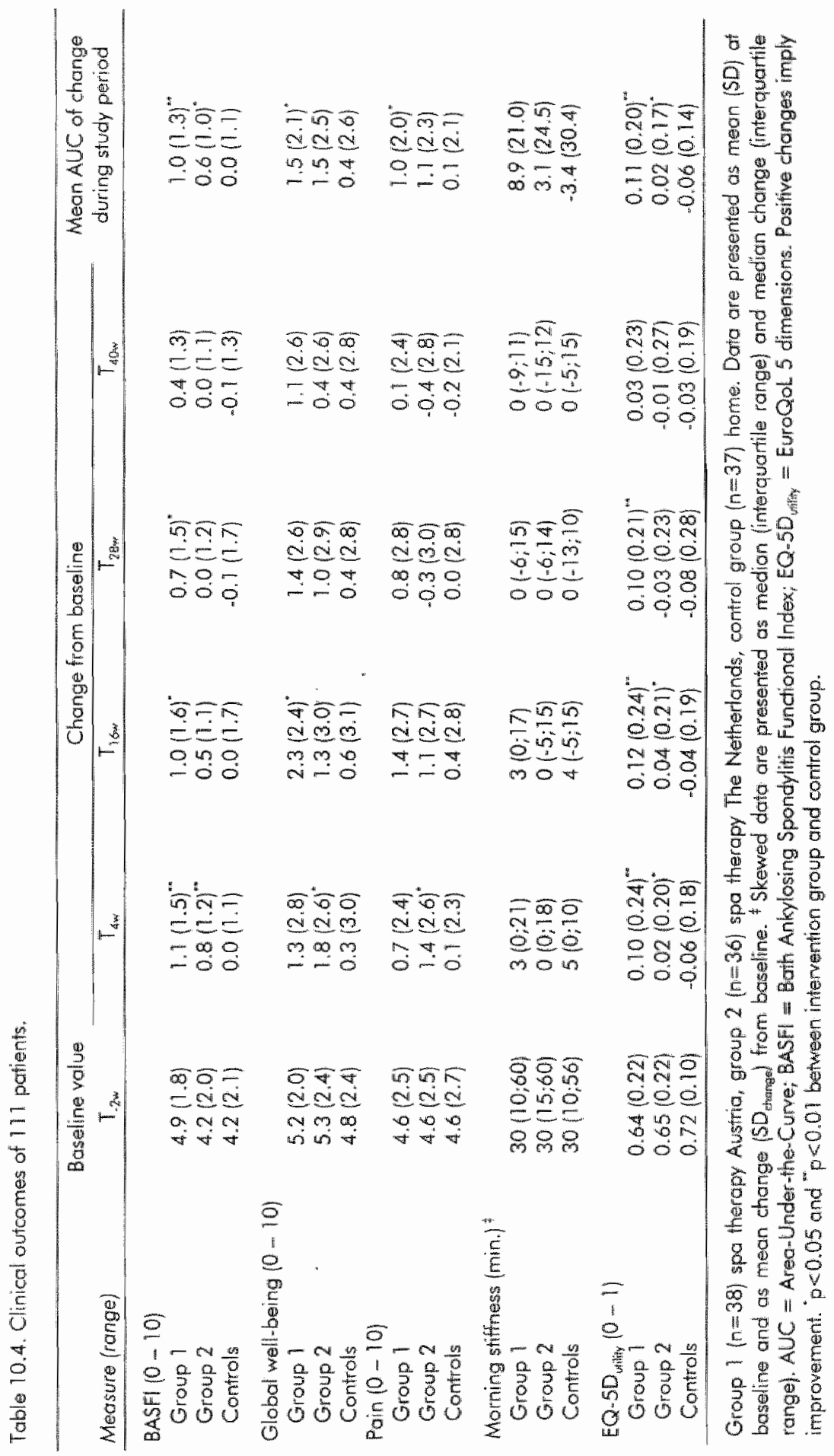


The between-group difference in the AUC of the EQ-5D witity was $0.17(0.09$ $0.25, p<0.001)$ for group 1 versus controls and $0.08(0.00-0.15, p=0.04)$ for group 2 versus controls.

\section{Health resource utilisation and casts}

The volumes of healthcare and non-healthcare utilisation during the follow-up period are listed in Table 10.5. The number of prescribed and over-the-counter (OTC) medication was significantly lower in both intervention groups compared with controls $(p=0.006$ group 1 versus controls; $p=0.032$ group 2 versus controls). The number of hours and costs of formal help in household were higher in both intervention groups compared with the control group, but the differences were not statistically significant.

Table 10.5. Volumes of healthcare and non-healthcare utilisation during study period (40 weeks).

\begin{tabular}{lccc}
\hline & $\begin{array}{c}\text { Group } 1 \\
(n=38) \\
\text { Spa therapy } \\
\text { Austria }\end{array}$ & $\begin{array}{c}\text { Group } 2 \\
(n=36) \\
\text { Spat therapy } \\
\text { The Netherlands }\end{array}$ & $\begin{array}{c}\text { Controigroup } \\
(n=37) \\
\text { Home }\end{array}$ \\
\hline Visits to general proctitioner & $1.6(2.5)$ & $1.3(2.0)$ & $1.7(2.1)$ \\
Visits to specialists [oulpatient & $2.0(2.0)$ & $1.9(2.3)$ & $2.5(2.9)$ \\
Physiotherapy sessions & $17.0(20.9)$ & $14.9(21.9)$ & $21.5(24.3)$ \\
Prescribed and OTC medication & $4.3(6.0)^{\circ}$ & $4.5(4.8)^{\circ}$ & $6.1(4.5)$ \\
Prescribed and OTC allemative medication & $0.5(1.8)$ & $0.2(0.7)$ & $0.1(0.7)$ \\
Visits to alternative practitioner & $0.4(1.7)$ & $0.3(1.2)$ & $0.8(2.7)$ \\
Formal hellp in household thours] & $17.3(45.0)$ & $12.7(31.7)$ & $11.5(34.8)$ \\
\hline
\end{tabular}

Mean number (SD) per patient; OTC $=$ Over The Counter; $p<0.05 ; " p<0.01$ compared with the contral group (Mann-Whitney U test).

Of the patients with a paid job, seven from group 1 (33\%), four from group 2 $(24 \%)$, and nine (39\%) from the control group reported AS related absence from work during the study period, including three patients from group 1 and four patients from group 2 who reported sick leave during the spa therapy period. The mean number of days of illness due to AS for the entire group was 2.5 (6.5), 6.4 (26.4), and 6.1 (15.8) for group 1, 2, and control group, respectively. Direct and indirect costs per patient for each category are listed in Table 10.6 . Mean total costs were $€ 3,023(2,728-3,359)$ for group $1, \in 3,240(2,553$ $4,391)$ for group 2 , and $€ 1,754(1,268-2,402)$ for the control group. The mean total incremental costs were $€ 1,269(565-1,867)$ for group 1 and $€ 1,486(501$. $2,707)$ for group 2 . 
Table 10.6. Resuls of costs during study period (40 weeks) of 111 potients

\begin{tabular}{|c|c|c|c|}
\hline & $\begin{array}{c}\text { Group } 1 \\
\text { (n=38) } \\
\text { spo therapy } \\
\text { Austria }\end{array}$ & $\begin{array}{c}\text { Growp } 2 \\
\text { n= } 361 \\
\text { Spa therapy } \\
\text { The Netherlands }\end{array}$ & $\begin{array}{c}\text { Control group } \\
(n=37) \\
\text { Home }\end{array}$ \\
\hline \multicolumn{4}{|l|}{$\begin{array}{l}\text { Direct costs } \\
\text { Healthcare costs }\end{array}$} \\
\hline $\begin{array}{l}\text { Healthcare costs } \\
\text { Spa therapy }\end{array}$ & $1,739(0)$ & $1.5 \times 15(0)$ & \\
\hline $\begin{array}{l}\text { Spratherapy } \\
\text { Group physical therapy }\end{array}$ & 30060 & 306101 & $306(0)$ \\
\hline Heolthcore professionals [GP and specialist] & $112(109)$ & $107(1,2)$ & $163(168)$ \\
\hline Physiotherapy & $308[379]$ & $27(398)$ & 391440 \\
\hline Medications [prescripilon and OTC] & $153(239)$ & $182(234)$ & $206(177)$ \\
\hline Additional diagnostic tests & $38(72)$ & $2480\}$ & $23(39)$ \\
\hline Hospitalisation and day care rehabilitation & $24(174)$ & $26(157)$ & $86(525)$ \\
\hline Alternative healthcare & $24(89)$ & $3(12)$ & $35(106)$ \\
\hline Sum direct healthcare costs (excl. spa therapy) & $964(744)$ & $919(625)$ & $1,210(785)$ \\
\hline Sum direct healthcare costs (indl. spa therapy) & $2,703(744)$ & $2,434(625)$ & 1.2101785 \\
\hline \multicolumn{4}{|l|}{ Non-healthcore costs } \\
\hline Formal help in household & $106(275)$ & $100(256)$ & $72(220)^{\prime}$ \\
\hline Personal allowance & 2110 & $14(83)$ & 1167 \\
\hline \multicolumn{4}{|l|}{ lindirect cosis } \\
\hline Absenfeeism from work & $211(549)$ & $693(2,864)$ & $461(1,204)$ \\
\hline Sum direct and indirect costs (excl. spa therapy) & $1,284(1,009)$ & $1,725(2,988)$ & $1,754(1,772)$ \\
\hline Sum direct and indired costs (incl. spo therapy) & $3,023(1,009)$ & $3,240(2,988)$ & $1,754(1,772)$ \\
\hline
\end{tabular}

Mean (SD) costs per patient in Euros; $G P=$ General Proctitioner; OTC $=$ Over The Cownter.

Cost-effectiveness and cost utility

The incremental cost-effectiveness ratio per unit effect gained in function ability on a 0 -10 scale (based on the AUC of the BASFl) was $€ 1,269 / 1.0=€ 1,269$ (497-3,316) for group 1 and $€ 1,486 / 0.6=€ 2,477$ (601-12,098) for group 2 . Assuming that the difference in $A \cup C$ of the $E Q-5 D_{\text {utiity }}$ will be equal to 0 during the last 3 months of the year after a 3 week course of spa exercise therapy, and that the costs will be equal in all three groups (since no extended effect of the intervention is expected, the cost will presumably equate the costs of the control group), the cost per QALY gained would be $€ 1,269 / 0.17=€ 7,465(3,294$ $14,686)$ for group $\gamma$ and $€ 1,486 / 0.08=€ 18,575(3,678-114,257)$ for group 2 .

Sensitivity analysis

In Table 10.7 the mean total costs per patient per group and the mean cosis per QALY gained are shown for each of the additional costs or alternatives calculated in the sensitivity analysis.

informal help. The mean (SD) number of hours of informal help was 22.9 (67.7) in group 1,25.4 (76.4) in group 2, and $19.9(76.6)$ in the control group. Additional costs for informal help would be $€ 182$ (537) for group 1, $€ 202$ (607) for group 2, and $€ 158(608)$ for the control group. The costs per QALY goined would slightly increase (Table 10.7.) 
184 Chopter 10

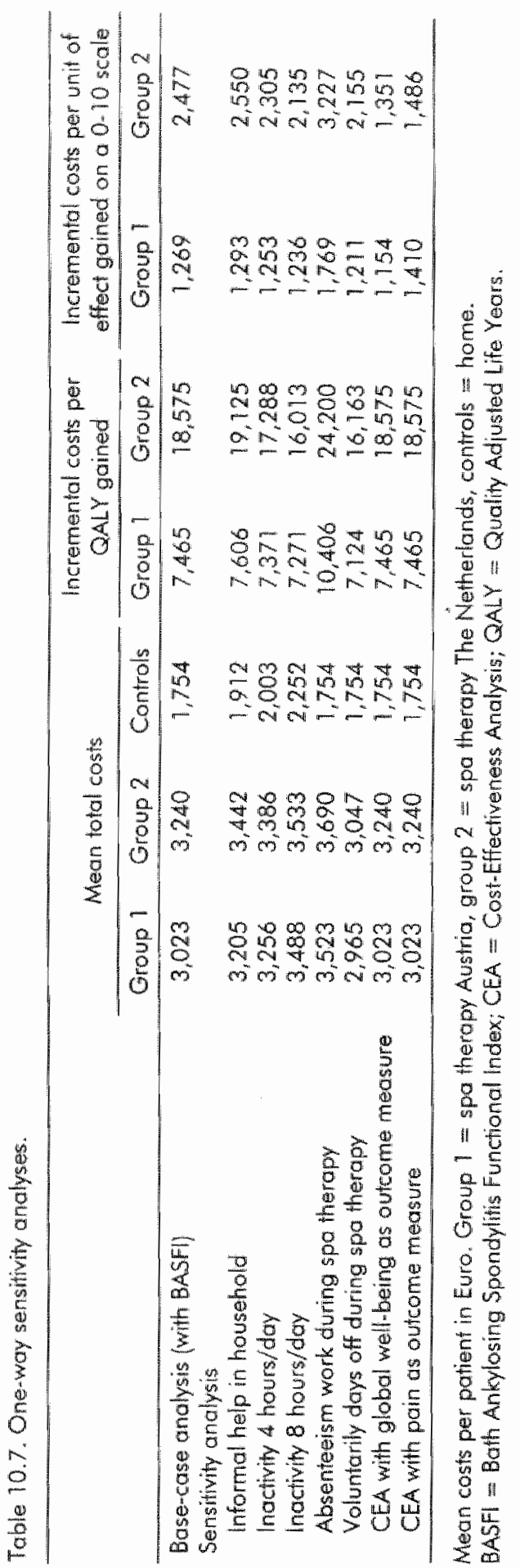


Inactivity. The mean number of days of inactivity was $7.3(19.1)$ in group $1,4.6$ (12.5) in group 2, and 7.8 (21.3) in the control group. Applying 4 hours per day as the mean number of hours of inactivity, the additional cosis would be $€ 233$ (606) for group 1, $€ 146$ (398) for group 2, and $€ 249$ (678) for the control group. In case a day of inactivity would represent 8 hours, the additional costs would be $€ 465(1,212)$ for group 1, $€ 293(795)$ for group 2 , and $€ 498$ $(1,356)$ for the control group. Due to higher reported inactivity in the control group, the costs per QALY gained would decrease for both intervention groups (Table 10.7).

Absenteeism from work. In case all patients who work would be on sick leave during spa therapy, the mean number of days of illness would be $7.5(9.2)$ in group 1 , and $10.9(26.3)$ in group 2 , both significantiy more than the control group $(p=0.020$ group 1 versus controls, $p=0.032$ group 2 versus controls). The costs per QALY gained would increase to $€ 10,406$ for group 1 and $€ 24,200$ for group 2 . In case all patients would need to voluntarily take days off to follow spa therapy, the mean number of days of illness would decrease to 1.9 (5.7) for group 1 and 4.7 (23.8) for group 2. The costs per QALY gained would decrease to $€ 7,124$ for group 1 and $€ 16,163$ for group 2 .

Cost-effectiveness. When "global well-being" and "pain" are used as outcome measures in the cost-effectiveness study, the incremental costs per unit of effect gained are more or less similar for both intervention groups. Compared with the base-case analysis, group 2 showed considerable fewer incremental costs per unit of effect gained (Table 10.7).

\section{Discussion}

This economic evaluation shows that a 3 week course of spa exercise therapy in addition to standard treatment has favarable cost-effectiveness and cost-utility ratios compared with standard treatment alone in patients with $A 5$. Cost savings were found for both intervention groups compared with the control group with respect to visits to healthcare professionals, physiotherapy, and use of respect to visits to healthcare profession. In the sensitivity analyses the results were rabust to variation in
medication.
several cost categories, but were sensitive to variation in indirect costs. The incremental cost ratios would considerably increase for both intervention groups in case all patients with a paid job would be on sick leave during spa exercise therapy instead of considering the freatment period as regular holidays.

Only one cost analysis of spa therapy could be found in the English literature. ${ }^{21}$ The study aimed at evaluating the cost-effectiveness of (undefined) spa therapy company's perspective. Effectiveness was assessed indirectly through determination of healtheare utilisation before and after the intervention, based on reimbursement claims. No decrease in healthcare utilisation was found in the groups that received spa therapy compared with controls. However, some groups that received spa therapy compared with con the study with respect to
concerns have been raised about the methodolagy of the dack of baseline description of the groups, the
parient recruitment, lack 
randomisation procedure, and inadequate statistical procedures. ${ }^{22}$ So, no reasonable comporison with the present study can be made.

Expressing the effects of an intervention in terms of "cost per QALY gained" has become increasingly popular in recent years. The primary argument was to facilitate the allocation of healthcare resources by decision makers, because the QALY-concept allows comparison across different interventions in different diseases. ${ }^{23}$ Incremental cost-utility ratios cam be listed in so-called league tables, in which the costs per QALY gained for each study are visible at a glance. There are, however, a number of disadvantages in using league tables. ${ }^{24}$ League tables suggest homogeneify in, and comparability among, study designs. However, studies included in league tables might have been conducted in different years with consequently different technologies and relative prices; the appraaches to measure utilities differ greatly among studies; some studies include only direct costs, whereas others also report indirect costs; and not all studies apply discounting, if necessary. In addition, the amount of costs per QALY gained is dependent on the alternative program. An intervention will show fewer costs per QALY gained if compared with "doing nothing" instead of with the "best alternative treatment".

The incremental costs per QALY gained for each of the intervention groups (E 7,465 for group $1 ; \in 18,575$ for group 2) are relatively high compared with the rather low prevalent costs for patients with AS (E 1,754). This probably reflects the absence of effective (curative) treatment for AS. Drug treatment is mostly limited to NSAIDs. Also, the costs for weekly group physical therapy are relatively low. ${ }^{25}$ These low prevalent costs contrast with the important impact the disease has with respect to pain, well-being, and work ability. ${ }^{26,27}$ The latest developments in the treatment of AS comprise the administration of tumor necrosis factor alpha (TNF-a) inhibiting drugs, which have been reported to yield dramatic improvements. ${ }^{2 B, 29}$ Due to the huge casts of anti-TNF-a treatment (approximatelly $\in 11,000 /$ patient/year) it is not to be expecled that cost-utillity analyses with respect to these new drugs will reveal costs per QALY gained that are lower than demonstrated by us. These studies might probably show even larger discrepancies between the costs per QALY gained for the intervention groups, compared with the prevalent costs of the control group.

A few methodological issues should be considered. First, the data as reported by the patients in the diaries were not ascertained by consulting other dato sources. It is conceivable that patients might hove had different opinions on what is related to AS. Second, there were no data available on (non-) healthcare axpendifures and days of illness related absence from work during the pretrial period. Therefore, no comparison with the previous year can be made and preexisting differences in (non - ) healthcare utilisation between the groups can not be excluded. Third, the ability to generalise the study findings is restricted to Dutch patients with active AS who follow weekly group physical therapy and hove a diseose duration of $<20$ years. The results might differ when other spa resorts are visited or different programs are provided. Similarly, the costs are likely to be different for other countries with other healthcare systems.

In The Netherlands reimbursement for spa therapy is provided by a few insurance companies for a limited number of diseases (usually rheumatoid 
arthritis and AS anlyl, with a maximum reimbursement level. It is estimated that $0.1 \%$ of the Dutch population suffers from AS $\left(-16,000\right.$ patients). ${ }^{30}$ Approximately $20 \%$ of them follow weekly group physical therapy. If reimbursement for spa therapy would be limited to these 3,200 patients, who have proved to be compliant with ireatment by following weekly group physical therapy, then the incremental societal costs for providing spa therapy would annually be $€ 4,408,000$. In exchange of these costs, a large -although temporary-improvement in functional outcome and quality of life will be gained in a group of patients for whom no curative treatment is yet available.

In conclusion, a 3 weeks course of combined spa exercise therapy in addition to standard treatment with anti-inflammatory drugs and weekly group physical therapy provides beneficial effects compared with standard treatment alone, and can be regarded as cost-effective in patients with AS. 


\section{References}

1. van Tubergen A, Landewé R, van der Linden S. Spondylarthropathies: options for combination therapy. Springer Semin Immunopathol $2001 ; 23: 147$ - 163 .

2. van Tubergen $A$, Landewé $R$, wan der Heijde $D$, et al. Combined spa-exercise therapy is effective in patients with ankylosing spondylitis: a randomized controlled trial. Arthritis Rheum 2001:45:430-438.

3. Calin A, Garret S, Whitelock $H$, et al. A new approach to defining functional ability in ankylosing spondylitis: the development of the Bath Ankylosing Spondylitis Functional Index. I Rheumatol 1994;21:2281-2285.

4. Calin A, Nokache JP, Gueguen A, et al. Outcome variables in ankylosing spondylitis: evaluation of their relevance and discriminant capacity. I Rheumatol $1999 ; 26: 975-979$.

5. Ruof J, Stucki $G$. Comparison of the Dougados Functional Index and the Bath Ankylosing Spondylitis Functional Index. A literature review. J Rheumatol $1999 ; 26.955-960$.

6. Ruof J. Sangha $O$, Stucki $G$. Comparative responsiveness of 3 functional indices in ankylasing spondylitis. Sheumatol 1999;26:1959-63.

7. Spoarenberg $A$, van der Heijde $D$, de Klerk $E$, et al. A comparative study of the usefulness of the Bath Ankylosing Spondylitis Functional Index and the Dosgados Functional Index in the assessment of ankylosing spondylitis. I Rheumatol $1999 ; 26: 961-965$.

8. Drummond M. Methods for the economic evaluation of health care programs. 2nd ed. Oxford: Oxford Medical Publications 1997.

9. The EuroQuL Group. Euragol-a new facility for the measurement of health-related quality of life. Health Palicy 1990;16:199-208.

10. Dolan P, Gudex C, Kind P, Williams A. The time trade-off method: results from a general population study. Health Econ 1996;5:141-154.

11. Dolan P. Modeling valuations for EuroQol health states. Med Care 1997;35:10951108.

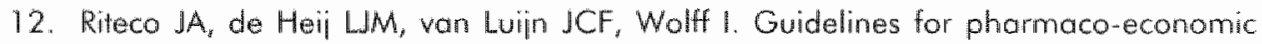
research [in Dutch]. Amstelveen: Coll ege voor zorgverzekeringen 1999.

13. Goossens ME, Rutten-van Malken MP, Vlaeyen JW, van der Linden SM. The cost diary: a method to measure direct and indirect costs in cost-effectiveness research. I Clin Epidemiol 2000; $53: 688-695$.

14. Oostenbrink JB, Koopmanschap MA, Rutten FFH. Guidelines for cost-analysis. Methods and guideline prices for economic evaluations in health care [in Dutch]. Amstelveen: College voor zorgverzekeringen 2000.

15. Koopmanschap MA, wan Ineveld BM. Towards a new appraach for estimating indirect costs of disease. Soc Sci Med 1992;34:1005-1010.

16. Koopmanschop MA, Rutten FFH. A practical guide for calculating indirect cosis of disease. PharmacoEconomics 1996;10:460-466.

17. Matthews IN, Altman DG, Campbell MJ, Royston P. Analysis of serial measurements in medical research. BMU 1990;300:230-235. 
18. Phom B, Cranney A, Boers $M$, et al. Validity of area-under-the-curve analysis to summarize effect in theumatoid arthritis dinical trials. J Rheumatol 1999;26:712-6.

19. Thompson SG, Barber JA. How should cost data in pragmatic randomised trials be analysed? BMJ 2000,320:1197-1200.

20. Efron B, Tibshirani RJ. An introduction to the boatstrap. New York: Chapman and Hall 1993.

21. Allard P, Deligme J, van Bockstael $V$, Duquesnoy B. Is spa therapy cost-effective in rheunatic disorders? Rev Rhum [Engl Ed] 1998;65:173-180.

22. Graber"-Duvernay B. Letter to the editor aboul the article: Is spa therapy costeffective in theumatic disorders? Rev Rhum [Engl Ed] 1998;65:600-602.

23. Mason J, Drummand $M$, Torrance $G$. Some guidelines on the use of cost effectiveness league tables. BMJ 1993;306:570-572.

24. Drummond $M$, Torrance $G$, Mason $\mathbb{d}$. Cost-effectiveness league tables: more ham than good? Soc Sci Med 1993;37:33-40.

25. Bakker C, Hidding A, wan der Linden Si, wan Doorslaer E. Cost effectiveness of group physical therapy compared to individualized therapy for ankylasing spondylitis. A randomized controlled trial. J Rheumatol 1994;21:264-268.

26. Zink A, Braun J, Listing J, Wollenhaupt J. Disability and handicap in theumatoid arthritis and ankylosing spondylitis-results from the German heumatological database. German Collaborative Arthritis Centers. J Rheumatol 2000;27:613-622.

27. Boonen $A$, Chorus $A$, Miedema $H$, et al. Employment, work disability, and work days lost in patients with ankylosing spondylitis: a cross sectional study of Dutch patients. Ann Rheum Dis 2001; 60:353-358.

28. Brandt J, Haibel $H$, Cornely $D$, et al. Successful treatment of active ankylosing spondylitis with the anti-tumor necrosis factor al pho monadonal antibody infliximab. Arthriits Rheum 2000;43:1346-1352.

29. Van den Bosch F, Kruithof $E$, Baeten D, et al. Effects of a laading dase regimen of three infusions of chimeric monoclonal antibady to tumour necrosis factor alpha (infliximab) in spondyloarthropatty; an open pilot study. Ann Rheum Dis 2000;59:428-433.

30. van der Linden $S M$, Valkenburg $H A$, de Jongh $B M$, Cats $A$. The risk of developing ankylosing spondylitis in HLA-B27 positive individuals. A comprarison of relatives of spondylitis patients with the general population. Arthritis Rheum 1984:27:241-249. 

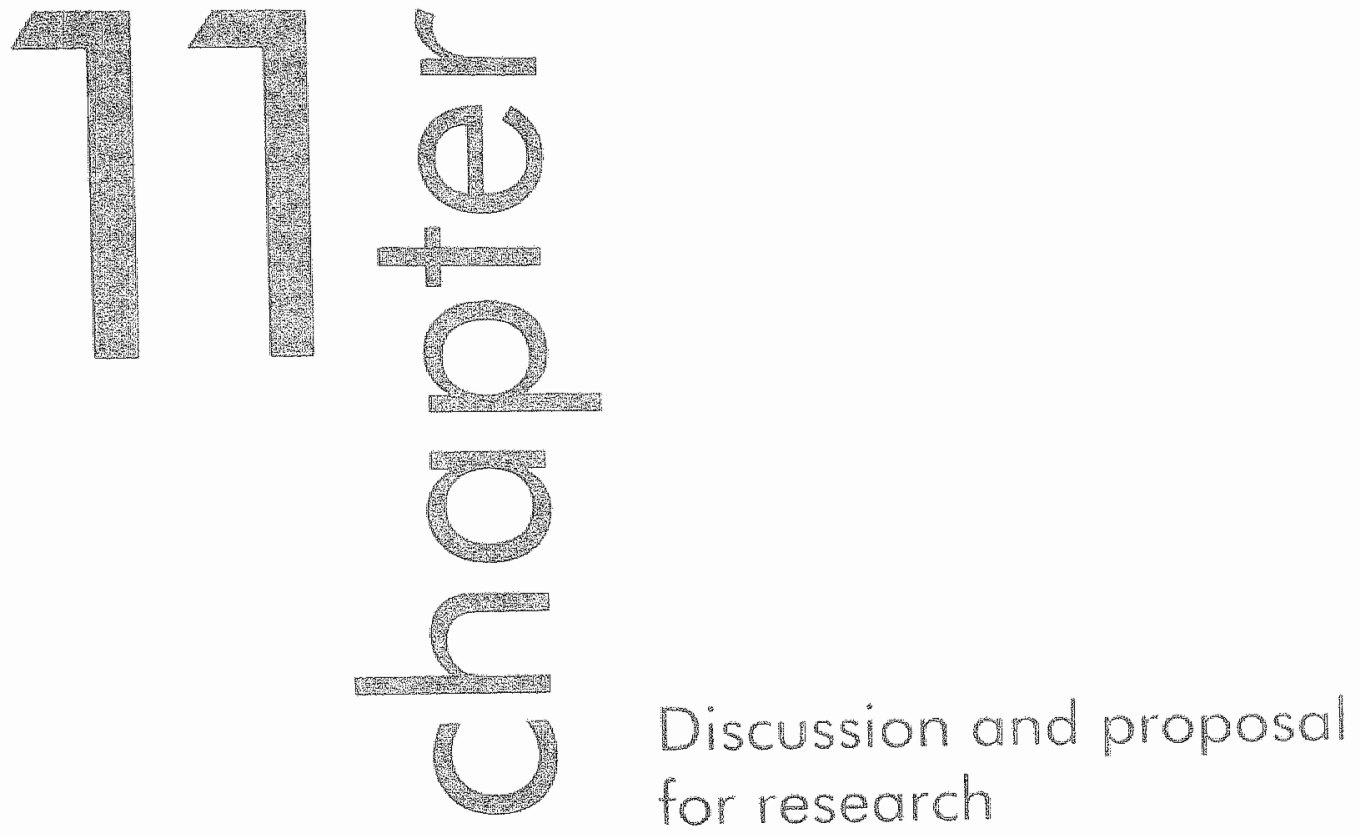
192 Chopter 11 


\section{General Discussion}

This thesis addresses the full socioeconomic consequences of ankylosing spondylitis (AS). First, the impact of the disease on labour force participation (LFP) is addressed, next the direct and productivity costs of the disease and finally the result of a cost-effectiveness analysis in AS is presented.

\section{Ankylosing spondylitis and labour force participation}

From the available literature, it was difficult to appraise the impact of AS on ability to participate in paid employment. This was mainly because reference data from the general population (or another reference population) were not provided but also because the figures were not adjusted for age and gender, which is essential in a study group of mainly male and young patients. In our survey among 658 Dutch patients we corrected for these shortcomings. The raw figures suggested that employment in patients was $3 \%$ lower than in the general population. However, after adjusting for age and gender the decrease in employment was $11 \%$. It seems likely that until now the impact of AS on employment has been underestimated because of this methodological inadequacy.

The increase in work disability of $15 \%$ among the Dutch patients with AS was disproportionatly higher compared to the reduction in employment of $11 \%$. This could be explained by the proportion of patients, which had a (partial) disability benefit but continued in a (part-time) paid employment. Although this possibility is not unique to the Dutch social security system, it is certainly nat offered in all countries. Therefore, results of the Dutch study cannot simply be generalised to patients in other countries. Limitation of international generalisability of studies on LFP was confirmed in our trination study comparing working status in The Netherlands, France and Belgium. In The Netherlands the reduction in employment as well as the increase in work disability was more pronounced than in both other countries. Although the Dutch and French social security systems both offer the possibility to continue in a (part-time) paid employment while having a (partial) work disability benefit, work disability in The Netherlands was not only higher than in Belgium but also in France. Therefore, other factors such as the level of the benefit and cultural differences in attitudes towards employment and work disability or coping must play on important role.

Considering the important increase in wark disability, variables associated with withdrawal from work were further explared. Similar as in our survey, nearly all studies identified in the literature had a retrospective design. Variables associated with work disability in such studies cannot be interpreted as predictors. In our analyses on determinants of withdrawal from the labour farce in Dutch patients with AS, we included anly variables which were unlikely to have changed after onsel of disease, such as gender, age at start of disease, profession and coping strategies (considered to be a stable personally trait). In addition to age at onset of disease and profession, coping characterised by 
limiting or adapting octivites was most strongly associated with withdrawal from the labour force. The volue of coping as a determinant of functional outcome seems to have been underestimated. Several questions on coping remain unanswered. Is coping truly stable over lime and not influenced by severty of disease and is it possible to influence coping strategies in order to improwe functional outcome, including LFP? When interpreting the determinants of withdrawal from work ut remained unclear if these risk factors were specific tor patients with AS or whether they were non-specific and also present in the general population (or patients with other diseases). A longitudinal study including a control group, would provide methodologically the best answer to this question. However, by using recent Dutch population data on age- and job specific withdrawal rates, we were able to compare the effect of age and type of job on withdrawal in potients with the population. It could be shown that older age is a risk factor for withdrawal for both patients and normal subjects but when compared with the general population, the younger patients have the highest increase of the risk to withdraw from work. As for the effect of protession on withdrawal from work, manual jobs increased the risk of withdrowal in patients and in the general population, but this effect was stronger in patients. Therefore, risk factors for withdrawal from work within patients can be different than risk factors compared with the general population. Both will give independent and additional information. The effect of coping on withdrawal from work was never investigated in the general population, therefore the differential effect of this risk factor could not be determined.

Sick leave in thase with a paid job as an economic outcome measure received only occasionally attention in socioeconomic outcome research. This is surprising since sick leave is often the forerunner of work disability and sick leave can compromise career perspectives. In the literature, absence at paid work is reported in many different ways, limiting comparability. The proportion of working patients having sick leave, the annual number of days of sick leave per warking patient and the average length of sick leave per sick patient provide independent and additional information. Impontantly, some studies report disease specific sick leave while other studies report total (disease specific and non-specific) sick leave. In the tri-nation study AS specific as well as aspecific sick leave were assessed. It was shown that disease aspecific sick leave was lower than the average national sick leave in the working population. Therefore, adding disease specific sick leave to the average national sick leave wauld overestimate days absent at paid work within patients. Whether patients with AS are reluctant to stay at home for minor not disease related illness or whether patients can't distinguish beween disease related or non-related sick leave remains unresolved. In studies measuring sick leave we advise to record total sick leave and optionally specify the reason of sick leave. It should be realised that only few validated methods exist to assess sick leave. 1,2 The differences in the method explains part of the discrepancy in the annual sick leave in the crosssectional Dutch study (10 days per working patient) as opposed to the annual sick leave in the Dutch subgroup of the prospective tri-nation study 119 days per working patient). In the cross-sectional study the Health and Labour Questionnaire was used, which extrapolates sick leave during the past two 
weeks to annual sick leave.' In the prospective trination study bimonthly cost questionnaires were used. There is an urgent need for validation including construct validity, repeatability and responsiveness of the different methods. The prospective tri-nation study allowed exploring risk factors for sick leove. Patients with a manual jab and having a worse physical function are at risk to have an episode of sick leave while the length of sick leave was highest in patients with associated inflammatory bowel disease, higher disease activity but also in those living in The Netherlands.

A point of discussion often neglected is the patient's point of view on employment and work disability. Do we have to try to keep all patients in the labour force even if this is against the wish of the patient? A study among patienis with malignancies showed that labour force participation contributed to experienced quality of life. ${ }^{3}$ In our national Dutch study we also noted that quality of life was better among patients with paid employment compared to patients with work disability. However, the retrospective design of the study does not allow to conclude if this difference could really be attributed to difference in employment status since work disabled patients were also older, reported worse physical function and might have had more severe disease. Moreover, it cannot be excluded that patients who experience a lower quality of life (independent of disease characteristics), are more inclined to leave the labour force. More insight into the importance of labour force participation from the perspective of the individual patient is necessary. This information in addition to other identified risk factors of sick leave and withdrawal from work might be helpful in designing intervention studies aiming at keeping patients in labour force.

\section{Cost-of-illness in ankylosing spondylitis}

The costs-of-illness (COI) study presented in this thesis was a prevalence based analysis addressing the sacietal perspective, the healthcare payer's perspective and the perspective of patients with AS under care of a rheumatologist. Although instruments to assess health resource utilisation and absence at work are insufficiently validated, there is some evidence that recall is reliable for periods of up to 2 months. ${ }^{2,4}$ Therefore we constructed bimonthly economic questionnaires to assess AS specific resource use. Costs were compared among three European countries.

Isolated figures on the direct (healthcare and non-healthcare) and productivity costs are difficult to interpret without reference figures on costs of diseases. Since rheumatoid arthritis (RA) is the disease rheumatologists are most familiar with, we compared the costs of AS with those reported in studies on RA. W. Within the methodological limits of comparisons, it could be concluded that the overall societal costs of AS foll within the range of costs reported for RA. When comparing the COI of AS and RA, it is important to realise that the present study concentrated on the prevalent costs of AS. Since the disease affects mainly men and starts much earlier in life than RA, it is likely that the life time costs of an individual patient with AS will be higher than the lifetime costs of RA. Estimation of the lifetime costs of AS requires cost data from an inception cohort as well as mortality rates but no such data are available at this time. 
Cost drivers of the direct costs of AS were costs of hospitalisations $(27 \%)$, costs of physiotherapy $(13 \%)$, cosis of drugs $(13 \%)$ but also costs for formal $(8 \%)$ and informal care (13\%), reflecting the impact of the disease on physical function. Of the fotal cosis, the productivity costs were $72 \%$ when the human capital $(\mathrm{HC})$ approach was used but 15\% when the friction cost (FC) method was applied. We share the opinion of the health economists that the $\mathrm{HC}$ approach overestimates the true societal productivity costs of disease because production loss for society only occurs during the period the diseased person is not replaced (friction period). ${ }^{2.8}$ However, $\mathrm{HC}$ costs allow expressing in monetary terms the effect of disease on LFP and might therefore have additional value. Additionally, there are still difficulties when calculating the productivity cost, which are insufficiently explored. We already commented on the recall period when assessing loss of productivity. However, consensus should be reached on the best unit of production (an hour of work, half a day of work, a full day of work) and the value for such unit (personal gross income, average national income, added production value). In the discussion on the proposed value of the unit of production, considerations on ethical implications and consequences on international generalisability of the data should be included. Production lass in unpaid work was not assessed in our survey and therefore not included in the productivity costs. Our COI study estimated only the AS related costs, including the extraspinal disease manifestations. It will be interesting to know the total healthcare costs of a patient with AS in order to assess the proportion of AS specific contribution to these costs.

In the international comparision of the costs, the productivity costs by $\mathrm{HC}$ as well as by FC method, these were significantly higher in The Netherlands. This reflects the higher work disability rate and longer sick leave among the Dutch patients. The difference among countries remained after adjusting for demographic and clinical confounders and after sensitivity analyses varying for uncertainties in the assessment of days of sick leave and value of one production day. On the other hand, the total societal direct costs were only marginally different among the countries with a tendency for costs to be higher in the Netherlands. The small number of patients in the French and especially in the Belgian group might be responsible for a non-detected difference because of insufficient power. The major difficulty when calculating the societal direct costs in this international comparative study was to value the unit cost of each resource. The societal perspective of direct costs implies true cost prices are applied to the resources. For the period of the study, true cost prices were available for The Netherlands but not for France and Belgium. It was out of the scope of this study to perform true cost calculations in each of the countries studied. It was decided to apply the Dutch true cost prices to the resource utilisation of all countries. An alternative solution would have been to adjust the Dutch cost prices using purchasing power parities (PPP) of the other countries. However, medical PPPs differ from consumer PPPs and are not yet completely reliable. ${ }^{10}$ Medical PPPs are mainly influenced by wages in the healthcare sector and interest on rents and goods. We hypothesised these would not greatly differ among three European Unity countries with similar economic prosperity. However, in order to enhance comparability and generalisability of the societal 
perspective of health economic data we urgently need more international cooperation to perform true cast estimates and research into methods to extrapolate costs from one country to other countries. Our choice to use uniform cost prices had the additional advantage that the societal costs would accurately reflect resource utilisation among the countries. Although the total societal direct costs (reflecting resource utilisation) were only marginally different among countries, some interesting differences for subcalegories of direct costs were abserved, which remained after adjusting for baseline demographic and clinical confounders. While the Belgian patients had higher costs for ambulatory care, this difference was offset by lower costs for inpatient care. Dutch patients had more costs for aids and devices, adaptations at the home and for formal and informal care. Explaining these differences among countries remains hypothetical, but variation in medical performance, cultural differences in attitudes toward health and organisational aspects of healthcare provision (such as payment system! must play a role. The difference between the large contribution of the country towards differences in productivity costs compared with the less obvious contribution to the direct costs is interesting. Among the factors already mentioned to explain international differences, information inequality between patient and physician is likely to be higher in decisions on health resource use than in decisions on sick leave and work disability.

in addition to the societal perspective, the COl were calculated from the financial perspective of the healthcare payer. For all countries the costs from healthcare payer's perspective were significantly lower than the sacietal costs. The exclusion of cost categories, which are irrelevant in the healthcare payer"s perspective but also the difference between true costs and tariffs account for this difference. Interestingly, for several cost categories, the rank of the countries for the level of costs changed when comparing the societal and financial perspective. Relative differences between true cosis and toriffs among countries explain this phenomenon. This observation emphasises the importance of the perspective of the study. It is of note that the full consequence of the choice of the perspective on the cost categories included and the valuation of the unit price is often not respected in many health economic studies. The healthcare payer's costs allow theoretically to calculate and compare the national expenditures for the disecse. For national data on healthcare expenditures we used the OECD-data." Again, such comparisons have limitations. The type of healthcare services included differ among countries and are not always clear. For example, in The Netherlands costs of homes for the elderly, are included in the fotal national healthcare expenditures while this is not so in France and Belgium. A recent study comparing healthcare expenditures among six counfries showed that expenditures for musculoskeletal diseases (ICD-9) varies between $5.4 \%$ and $12.6 \%$ reflecting a coefficient of variation of $36 \%$. Still, the difference in national expenditures for AS remains surprising. More insight into the distribution of national expenditures for different (rheumatic) diseases would be of interest!

Since in our survey a variaty of demagraphic and dinical wariables were collected together with health care consumption, it was possible to identify predictors of costs. Interestingly, total societal costs /direct costs and friction cosis 
combined could be predicted by AS related disease activity (BASDAI) and AS related physical function (BASFl) at entry into the study and costs correlated well with cumulative disease activity and physical function during the study. Importantly, pottients with extraspinal disease manifestations had significantly higher costs than those without extraspinal disease. Since this group was characterised by high disease activily, extraspinal disease was not retained as an independent risk factor. It is of note that patients with a lower educational level incurred higher costs also after adjusting for clinical differences when compared with the more highly educated patients. The relation beween healthcare consumption and educational level has been shown previously ${ }^{3.18}$ but explanations remain hypathetical.

We used Cox's regression analyses to assess determinants of costs. To our knowledge this method has not yet been applied for cost data. We have chosen Cax"s survival analyses since dato on costs were skewed also after log transformation. Moreover, Cox's regression is not influenced by possible colinearity between the independent variables. In addition, based on the weights derived from the coefficients groups of patients at risk for higher costs can be defined $^{17}$ and survival curves can visualise differences in costs between patient groups. Further validation of this method would be interesting, comparing Cox's regression to untranstormed linear regression, log-transformed linear regression and also logistic regression.

Finally, we addressed the patient perspective of costs including out-of-pocket expenditures, income loss, time consumption and quality of life (reflecting the intangible costs). Ht was shown that for the patient, AS is an expensive and time. consuming disease. Again, striking differences among countries in patient outof-pocket expenditures and income loss were observed. Not only differences in health resource utlisation but also differences in patient contributions for healthcare provisions explain the observed difference. Our analyses could not correct for differences in social contributions or (private) healthinsurance premiums among the countries. In The Netherlands the (income dependent) insurance premiums are higher than in France and Belgium while the patient's contribution for the individual healthcare provisions is minimal. Such type of insurance system reflects a higher solidarity principle in the Dutch healhcare system since healthy subjects help financing the costs of the diseased persons. In France, patients with severe chromic disease are protected against high individual costs by a system, which exempls patients with a severe chronic disease from contributions to individual healthcare provisions. Strikingly, after adiusting for demographic and clinical variables, there were striking differences in experienced qualify of life among the countries. Exploring cullural differences (of contributors to) quality of life is an interesting area of research which needs more attention, certainly since quality of life is an important endpoint in many intervention trials and economic analyses.

Cost-effectiveness in ankylosing spondylitis

In addition to determining the cost-of-illness of AS, a full economic evaluation was performed assessing the cost-effectiveness and cost-utility of spa treatment 
compared with usual care. Since a societal expenditure of up to $E 20.000$ to gain one quality adjusted life year is thought to be acceptable, spa treatment in As con be considered to have an acceptable cost-utility ratio. Recently new biolagic agents have shown large effects on disease activity, function and qualify of life. These treatments however, are expensive. The results from the costeffectiveness analysis of spa treament showed that improvement of function and quality of life reduces resource utilisation and therefore can result in acceptable cost-effectiveness ratios. Since registration of a new drug requires data on economic consequences of the treatment, we urgently need to asssess if the benefits of the biologic agents for the patients can be reached at acceptable societal costs. The data of the COI study provide a valuable source to develop an economic model to help answering this question.

\section{Research questions resulting from this thesis}

\section{Methodologic issues}

- Improving methods and reaching consensus on the preferred way to collect and analyse economic data in order to enhance comparability of economic studies also in international resectich. Priority goes to validation of methods to collect health economic data, international consensus on cost price estimation with development of cost price databases, further validation of methods to analyse skewed data and to present data on cost analyses, methods to extrapolate economic data from one country to other countries

- Research into the characteristics of healthcare and social security systems. and their influence on the (socioeconomic) outcome of the disease.

\section{Clinical issues}

- Insight into epidemiologic differences in expression of AS among countries.

- What is the patient's opinion on labour force participation.

- Is coping stable over time and are there interventions, which can change adverse coping strategies and will improve social and functional outcome?

- Can withdrawal from the labour force be limited by (multidisciplinary and integrated) core? Are such interventions costeffective in daily life implementation?

- Incidence based COI estimates for AS and thus lifetime costs of AS, requiring figures on incidence costs and mortality. Idenifification of predictors of lifetime cosis.

- Contribution of AS specific costs to the total healthcare costs of an patient with AS.

- Relation between socioeconomic impact and Quality of Life. What constitutes cultural differences in quality of life?

- Can the medical benefits of new biologic treatments be reached within an acceptable change in (longterm) costs. This implies data on fongterm 
efficacy, side effects and appropriate methods to translate these findings into cost-effectiveness and cost-utility ratios. Will the results based on models and controlled trials hold true in daily practice? 


\section{References}

1. wan Roijen L. Essink Bot ML, Koopmanschap MA, Bonsel G, Rutten FF. Labior and health status in economic evaluation of health care. The Health and Labor Questionnaire. Int I Technol Assess Health Care 1996;12:405-415.

2. Severens JL, Mulder J, Laheif RJ, Verbeek AL. Precision and accuracy in measuring absence from wark as a basis for calculating productivity costs in The Nethertands. Soc Sci Med 2000;51:243-249.

3. Warr P. Work, unemploymemt and mental health. Oxford: Clarendon Press; 1987.

4. Goossens ME, Rutten-van Molken MP, Vlaeyen JW, van der Linden SM. The cost diary: a method to measure direct and indirect costs in cost-effectiveness research. I Cin Epidemiol 2000,53:688-695.

5. Cooper NJ. Economic burden of rheumatoid arthritis: a systematic review. Rheumalolagy 2000;39:26-33.

6. Pugner KM. Scott DI, Holmes JW, Hieke K. The costs of theumatoid arthritis: an internationall long-term view. Semin Arthritis Rheum 2000;29:305-320.

7. Koopmanschap MA, Rutten FFH. A practical guide for calculating the indirect costs of disease. pharmacoeconomics 1996;10:460-466.

8. Koopmonschap MA, Rutten FFH. The impact of indirect costs: the consequences of production loss or increased costs of production. Med Care 1996;34:DS59-68.

9. Oostenbrink J, Koopmanschap M, Rutten F. Handleiding voor kostenonderzoek. Methaden en richtlinprijzen voor economische evaluaties in de gezondheidszorg. Amstelveen: College woor zorgverzekeraars: 2000.

10. Rutten-van Molken MPMHt, Van Doorslaer EKA. Multinationale kostteneffectiviteitsanalyses. In: Van kosten tot effecten. Een handleiding vaor evaluatiestudies in de gezondheidszorg. Mararssen: Elsewier gezondheidszorg; 2000. p. 131-14.9.

11. Organisation for Co-operation and Develpoment (OECD). Health Data File [CD. ROM] 1999.

12. Palder J], Meerding WJ, Bonneux L, van der Maas PJ. A cross-national perspective on cost of illness. Rotterdam: Erasmus University Roterdam; 2001.

13. Ward MM. Examining heath disparities in systemic lupus erythematosus. Arthritis Rheum $2001 ; 44: 2711-2714$

14. Bloom BS, Bruno DJ, Maman DY, Jayadevappa R. Usefulness of US cost-of-illiness siudies in healthcare decision making. Pharmacoeconomics 2001;19:207-213.

15. Esdaile $J M$, Sampalis $1 S$, Lacaille $D$, Danoff $\mathbb{D}$. The relationship of socioeconomic status to subsequent health status in systemic lupus erythematosus. Arthritis Rheum $1988,31: 423-427$

16. Fex E, Larsson BM, Nived K, Eberhardt K. Effect of theumatoid arthritis on work status and social and leisure time activities in patients followed 8 years from onsel. I Rheumatol 1998,25(1):44-50.

17. Karlson EW, Doltroy LH, Lew RA, Wright EA, Partridge Al, Fossel AH, el al. The relationship of socioeconomic status, race, and modifiable risk factors to outcomes in pafients with systemic lupus erythematosus. Arthritis Rheum 1997;40:47-56. 
18. Rivest C, Lew RA, Welsing PM, Sangho O. Wright EA, Roberts WN, ef al. Association between clinical factors, sacioeconomic stalus, and organ damage in recent onset systemic lupus erythematosus. J Rheumatol 2000;27:680-684.

19. Pocock SJ, McCormack V. Gueyffier F. Boutine F. Fagard RH, Boissel JP, el al. A score for predicting risk of death from cardiovascular disease in adults with raised blood pressure, based on individual patient data from randomised controlled trials. BMJ 2001;323: 75-81. 
Summary 


\section{Summary}

In this thesis the full socioeconomic consequences of ankylosing spondylitis (AS) are explored. Chapter I contains some introductory considerations on ankylosing spondylitis and on socioeconomic studies. In Part I the effect of AS on labour farce participation is described as well as the possible explanatory factors associated with withdrawal from the labour force. In Part II the costs of the disease are presented from societal perspective but also from the healthcare payer's and the patient's perspective. Results were compared among three European countries and predictors of costs, including the country of care, are reported. As a give-away to this part of the thesis, we illustrates how the costs of hospital care increased over time by comparing the hospital day price 100 years ago with the present one. In Part Illl the cost-effectiveness and cost-uitility ratios of spa therapy in AS compared with usual care are presented. Finally, chapter 11 discusses the overall conclusions of the thesis and proposes a research agenda for future studies on economic consequences of AS.

The next paragraphs summarise the main findings of the individual chapters.

\section{PART I Labour force participation in ankylosing spondylitis}

Chapter 2 comprises a systematic review of the available literature published between January 1980 and March 2000 on labour force participation in AS in the English, French and German language. Sixteen full articles and 2 abstracts were identified, describing work status in 14 patient groups. Employment ranged from $34 \%$ to $96 \%$ in patients with disease duration of 45 and 5 years respectively, and work disability from $3 \%$ to $50 \%$ in patients with disease duration of 18 and 45 years respectively. Annual sick leave varied from 12 to 46 days per patient among those who had a paid job. Determinants of wark status were reported in 9 studies. Age, education and physical function were shown in several studies to be associated with work disability, while peripheral joint disease was associated with sick leave. However, it was difficult to draw solid conclusions from these siudies. There was not only a large heterogeneity among the patient populations studied but also a large variation in definitions of the studied endpoints. Most importantly, dato were not adjusted for age and gender most likely resulting in overestimation of labour force participation (LFP) in a predominantly male and young patient population. In addition, reference data of a comparison population were almast always absent, making interpretation of the results difficult. Finally, most studies were retrospective, compromising the results of the analyses on determinants of work disability and sick leave. Chapters 3 to 5 describe extensively the effect on LFP in a cross- 
sectional study group of 658 Dutch patients with AS sampled from the Dutch Register of Rheumatic diseases. Chapter 3 shows that unadjusted LFP was $3 \%$ lower and work disability $27 \%$ higher when compared with the general Dutch population. However, after adjusting data for age and gender it was found that employment was $11 \%$ lower and work disability $15 \%$ higher than expected in the general population. The discrepancy between the higher increase in work disability compared with the reduction in employment can be explained by the possibility in the Dutch social security system to continue in a (part-time) job while having a (partial) work disability benefit. In this survey $38 \%$ of patients with a work disability benefit were at the same time engaged in paid employment. When extrapolating reported sick leave during the past two weeks to yearly sick leave in patients with a paid job, a person with AS has on average 10 days sick leave per year because of AS compared with the national non-specific annual sick leave of 12 days. In Chapter $4 a$, the issue of withdrawal from the labour force in patients with a paid job at onset of disease was further explored. Age and gencler adjusted withdrawal was found to be 3.1 [95\% Cl: 2.5-3.7] times increased when compared with withdrawal from paid work in the general Dutch population. Five percent of patients had left work within the first year of disease, $21 \%$ after 10 years and $31 \%$ after 20 years. Within patients older aged at diagnosis, manual jabs and coping characterised by limiting or adapting activities were predictors of withdrawal. Chapter $4 \mathrm{~b}$ compared some risk factors for withdrawal from work in patients with the general population. It was shown that it were the younger patients and those with a manual job who had an extra risk to withdraw form work. Chapter 5 addressed the specific job-related factors in relation to withdrawal from work. Adjusted for demographic and disease related variables, withdrawal from work was assaciated with difficult access to the workplace, insufficient support and negative attitude of colleagues or management, lack of additional training after diagnosis, working in smaller companies and absence of ergonomical adjustments. In addition, it was shown that age and gender adjusted labour force participation was not influenced by disease duration.

\section{PART II Cost-of-illness in ankylosing spondylitis}

The costs of AS were analysed from a two years' longitudinal cost-of-illness study completed by 209 patients and compared among three European countries: The Netherlands, France and Belgium. In Chapter 6 the direct healthcare and nonhealthcare costs from societal and financial perspective among the three countries are presented. Mean annual societal direct costs per patient were $€ 2,640$ (median $€ 1,242$ ) of which $82 \%$ were direct healthcare costs and $18 \%$ direct non-healthcare costs. Longer disease duration, lower education, worse physical function (BASFI) at entry into the study and higher disease activity [BASDAl] at entry, were predictors of higher direct societal costs. Although there were differences in costs of several cost categories among the countries, the total direct costs were only marginally different. Mean annual direct costs from 
financial perspective were $€ 2,122$ (median $€ 747$ ), $€ 1,402$ (median $€ 989$ ) and $€ 941$ (median $€ 631$ ) per patient in The Netherlands, France and Belgium respectively. For each cauntry, costs from financial perspective were significantly lower than casts from societal perspective, illustrating the importance of the perspective of an economic analysis. Chapter 7 reports on labour force participation and productivity costs in the three countries. Adjusted work disability was $41 \%, 23 \%$ and $9 \%$ in The Netherlands, France and Belgium respectively and was in all countries higher than expected from the general population. It is noteworthy that in The Netherlonds and France but not in Belgium patients with a work disability benefit can continue in (part-time) paid employment. In those with a paid jab, the mean number of days of sick leave per year because of ankylosing spondylitis was 19 (median: 1.4), 6 (median: 0) and 9 (median: 0) days per patient per year in The Netherlands, France and Belgium respectively. Applying the friction cost method (taking into account productivity losses only for the average period of job vacancy which was 4 months at the time of the study), the mean annual costs per working patient were $€ 1,257$ (median $€ 78$ ), 428 (median $€$ ) and 476 (median $€$ of in The Netherlands, France and Belgium respectively. Applying the human capital approach (tcking into account productivity losses for the whole period of sick leave and work disability) to the whole group resulted in mean annual costs per patient of $€ 8,862$ (median $€ 2,484$ ), $€ 3,188$ (median $€ 0$ ) and $€ 3,309$ (median $€ 0$ ) in the three countries respectively. After adjusting for sociodemagraphic and disease characteristics, living in The Netherlands, as compared with both other countries, was associated with a 3.8 times higher chance to become work disabled. For sick leave, there was no difference among countries in the number of working patients having an episode of sick leave. However, Dutch patients with sick leave were significantly longer absent. Consequently, living in The Netherlands contributed independently to a higher amount of friction costs and a higher amount of human capital costs. In addition, inflammatory bowel disease and worse physical function at entry into the study were independent predictors of friction costs. The fotal annual costs per AS patient were $€ 9,463$ (median $€ 2,894$ ) when using the human capital approach as method to calculate the productivity costs and $€ 3,116$ (median $€$ $1,489)$ when using the friction cost method to calculate the productivity costs. The difference among countries was significantly different only when using the human capital approach, total costs being $€ 11,786$ (median $€ 8,769$ ) per patient per year in The Nefherlands compared with 5,748 (median $€ 1,427$ ] and $€ 5,399$ (median $€ 1,255$ ) in France and Belgium respectively. Chapter 8 reports on the socioeconomic consequences of the disease for the patients themselves. Total annual patient aut-of-pocket healthcare expenditures were $€ 431$ (median $€$ 172) Euro per patient and annual income loss because of absence at paid work or work disability was $€ 1,371$ (median $€ 0$ ) per patient. No differences were found in total patient costs among countries after adjusting for baseline confounders. However, Belgian patients had significantly higher and French patients significantly lower personal contributions for healthcare costs, while Dutch patients had significantly higher non-healthcare costs. Higher total patient costs were associated with higher age and worse physical function. AS is 
a time consuming disease since patients lose on average one hour and 75 minutes (median: 45 minutes) per day because of the disease. Time consumption did not differ significantly among countries and worse physical function and higher disease activity were predictors of the amount of time lost. Quality of life (EuroQol-5D) was significantly worse in the Belgian and French patients as compared with the Dutch, after adjusting for baseline confounders. In addition, peripheral arthritis, worse physical function, higher disease activity but also loss of income due to AS contributed to worse quality of life. Since in economic research there is much discussion on the appropriate way to assess the unit costs of healthcare provisions such as the hospital day price, we were interested how this was done historically, at the time such prices were calculated for the first time. In Chapter 9 it can be read that monetary valuation of a hospital day price started in the second half of the nineteenth century in The Netherlands as well as in Belgium. In 1897 the day prices were calculated by total cost averaging (averaging the total annual expenditures over the number of hospitalisation days). Nutrition accounted for nearly $50 \%$ of the costs. At the present time the hospitalisation day price is a negotiated tariff. More than seventy percent of the true hospital expenditures are now incurred by management (including salaries). The hospital day price increased dramatically over time, not only in absolute values but also when related to the purchasing power of people.

\section{PART III Cost-effectiveness evaluation in ankylosing spondylitis}

Chapter 10 explored if the beneficial clinical effects of interventions in AS can be achieved at acceptable costs and presents the incremental cost-effectiveness and costuutility ratio's of spa treatment in patients with ankylosing spondylitis. A total of 120 Dutch AS patients were randomly allocated into three groups of 40 patients. Group 1 was treated for three weeks at a spa resort in Bad Hofgastein, Austria and group 2 at a spa-resort in Arcen, The Netherlands. Group 3 stayed at home and continued standard treatment. A total of 111 patients completed a cost diary during the 40 weeks study period. In these patients the cumulative gain in physical function for group 1 compared with group 3 was 1.0 and 0.6 (scale 0-10) for group 2 compared with group 1. The cumulative gain in utility for group 1 compared with group 3 was 0.17 (scale $0-1$ ) and 0.08 for group 2 compared with group 3 . The mean total costs per patient were $€ 3,023$ for group 1, $€ 3,240$ for group 2 and $€ 1,754$ for the control group. The incremental cost-effectiveness ratio per unit effect gained in functional ability was $€ 1,269$ (95\% Cl: $497-3,316)$ for group I and $€ 2,477(95 \% \mathrm{Cl}: 601$. $12,089)$ for group 2 compared with contrals. The incremental cost-utility ratio per unit effect gained in quality of life was $€ 7,465(95 \% \mathrm{Cl}: 3,294-14,686)$ for group 1 and $€ 18,575(95 \% \mathrm{Cl}: 3,678-114,257)$ for group 2 compared with controls. In the Dutch society these results are considered acceptable costeffectiveness values. 
Chapter 11 discusses the findings of the thesis in the light of the clinical implications and methodological limitations of health economic studies. In addition a priority list for research on socioeconomic consequences in $A S$ is suggested. 
210 
Samenvatting 
212 


\section{Samenvatting}

Dit proefschrift beschrifft de socio-economische gevolgen van ankyloserende spondylitis (AS). Hoofdstuk 1 bevalt enkele algemene beschouwingen over AS en over socio-economische studies. Deel I beschrifft de effecten van AS op de mogelijkheid tot arbeid en de verklarende factoren die kunnen leiden tot arbeidsongeschiktheid. In Deel III worden de kosten van AS beschreven voor de maatschappii, voor de gezondheidszorgbetaler en voor de patiënt. De onderzoeksresultaten worden vergeleken tussen drie Europese landen en voorspellers van kosten (inclusief per land) worden gerapporteerd. Hoofdstuk 9 is hierbij een economisch toemaatie dat geen directe relatie heeft met AS. Het illustreent hoe de hospitalisatiekosten in de loop der tiiden toenamen, en dit door de hospitalisatiedagpriijs van 100 jaar geleden te vergeliiken met de huidige kostprijs. In Deel III wordt ingegcian op de kosteneffectiviteits. en kostenutiliteitsratio's van kuurtherapie bij AS, in vergelijking met een traditionele behandeling. In hoofdstuk 11 tenslotte volgt een bespreking van de algemene canclusies van dit proefschrift en wordt een agenda voorgesteld met vragen woor toekomstig onderzoek naar de socio-economische gevolgen van AS.

De volgende paragrafen vatten de specifieke resultaten van de individuele hoofdstukken samen.

\section{Deel I Arbeidsparticipatie bii patiënten met ankyloserende spondylitis}

Hoofdstuk 2 is een systematische review van de beschikbare Engelse, Franse en Duitse literatuur, gepubliceerd Iussen januari 1980 en maart 2000 aver arbeidsparticipatie bij AS-patiënten. Zestien artikels en twee abstracts werden geidentificeerd, waarin de arbeidsstatus van 14 groepen patiënten beschreven ziin. Arbeidsparticipatie varieerde wan $3 \%$ tot $50 \%$ bif patiënten met een ziekteduur van respectievelijk 18 en 45 jaar. Het ziekteverzuim varieerde wan 12 tot 46 dagen per jaar bij patiënten met betaald werk. Determinanten van de arbeidsstatus werden beschreven in 9 studies en een verband werd aangetoond tussen arbeidsongeschiktheid en leeftiid, opleiding en fysiek functioneren, terwijl eveneens verband werd gevonden tussen ziekteverzuim en perifeer gewrichtlijden. Tach is het niet mogeliik eenduidige conclusies te formuleren uit deze studies. Niet alleen was er een grote heterogeniteit onder de bestudeerde patiëntenpopulaties, maar ook een grote verscheidenheid in de definities van de onderzochte eindpunten. Hef belangrijkste tekort was echter dot de gegevens niet gestandaardiseerd waren voor leeftijd en geslacht, wat waarschiinliik resulteerde in een overschatting van arbeidsparticipatie in een hoofdzakelijk mannelijke en jonge patiëntenpopulatie. Daarbii valt ook op te merken dat gegevens over een referentiegroep zoals de algemene populatie haast altijd 
antbraken, waardoor interpretatie van de resultaten bemoeilikt werd. De meeste studies tenslotte waren retrospectief, waardoor ook de resultaten van de analyses over de determinanten van arbeidsongeschiktheid en ziekteverzuim slechis een beperkte validiteit hebben. Hoofdstukken 3 fot 5 beschrijuen vitvoerig de effecten van AS op de deenome aan de arbeidsmarki (LFP) en dit aan de hand van eross-sectioneel onderzoek van 658 Nederlandse AS-patiënten uit de Standaard Diagnose Registratie der Nederlandse Reumatologen. Hoofdstuk 3 toont dat niet-gestandaardiseerde arbeidsparticipatie met $3.3 \%$ was verlaagd en arbeidsongeschiktheid $27 \%$ hoger was in vergelijking mel de algemene Nederlandse bevolking. Na standaardisering van de gegevens volgens leeffijd en geslacht bleek arbeidsparticipatie evenwel $11 \%$ lager te zijn en arbeidsongeschiktheid $14.8 \%$ hoger dan in de algemene Nederlandse bevolking. De discrepantie tussen de hogere arbeidsongeschiktheid, in vergelijking met de reductie van arbeidsparticipatie kan verklaard worden door de magelijkheid die het Nederlands sociaal zekerheidssysteem aan (gedeelteliik) arbeidsongeschikten biedt om (deeltijdse) betaalde arbeid te verrichten. Uit dit overzicht blijkt dat $38 \%$ van de patiënten met een vitkering wegens arbeidsongeschiktheid tezelfdertijd betaald werk verrichten. Wanneer gerapporteerd ziekteverzuim gedurende de laatste twee weken geëxtrapoleerd wordt naar jaarlijks ziekteverzuim bii patiënten met betaald werk, dan stelt men bij AS-patiënten jaarlijks gemiddeld 10.1 dagen verzuim vast wegens AS, tegenover het nationale niet-specifieke jaarlijks ziekteverzuim van 12.3 dagen. Het niet-specifieke verzuim bij AS werd in deze studie niet gemeten. In hoofdstuk $4 a$ wordt ingegaan op vitual vit het werk bij patiënten met een betaalde job bij diagnose van hun ziekte. Na standaardisering voor leeftijd en geslacht bleek deze uitval 3.1 (95\% betrouwbarheidsinterval: 2.5-3.7) maal hoger dan bij de algemene Nederlandse bevolking. Viff procent van de ASpatiënten verloor zijn jab binnen het eerste jaar na diagnose, $21 \%$ na 10 jaar en $31 \%$ na 20 jaar. Bij patiënten bii wie de ziekte op hogere leettijd werd vastgesteld, die manuele arbeid verrichiten en coping strategieëm hadden, gekenrnerkt door "beperken" of "aanpassen" van de activiteiten, was de kans op uitval uit werk aanzienlijk toegenomen. Hoofdstuk $4 b$ toont echter aan, dat vergeleken met personen uit de algemene bevolking die stopten met werken, de jongere patiënten en patiënten met een manuele job, een extra risico liepen hun werk te verliezen. In hoofdstuk 5 wordt het specifieke verband tussen werkgerelateerde factoren en arbeidsverlies verder onderzocht. Gecorrigeerd voor demografische en klinische variabelen, werd arbeidsverlies geassocieerd met moeilike toegang tot de werkplaats, onvoldoende hulp en een negatieve houding van collega's of werkgever, gebrek aan biikomende scholing, het werken in kleinere bedrijuen en afwezigheid van ergonomische aanpassingen. Daarbii werd aangetoond dat na standaardisering van leeftijd en geslacht, arbeidsparticipatie niet beïnloed wordt daor de duur van de ziekte. 


\section{Deel II Ziektekosten van ankyloserende spondylitis}

De kosten veroorzaakt door AS werden gemeten binnen een 2 jaar durend longitudinaal ziektekostenonderzoek voltooid door 209 patiënten en vergeleken tussen drie Europese landen: Nederland, Frankrijk en België. In hoofdstuk 6 worden de directe medische en niet-medische gezondheidszorgkosten onderzocht vanuit een maatschappelijk en een financieel (derde betaler) perspectief in de drie landen. De gemiddelde joarlijkse maatschappeliike directe kosten bedroegen $€ 2,640$ per patient (mediaan $€ 1,242$ ), waarvan $82 \%$ bestond wit directe en $18 \%$ indirecte gezondheidszorgkosten. Een langere ziekteduur, lagere scholing, minder goed fysiek functioneren bij de start van het onderzoek en een hogere ziekteactiviteit bij de start van het onderzoek waren voorspellers van hogere directe maatschappelijke kosten. De totale directe kasten in de drie landen waren niet significant verschillend, maar er werden wel verschillen vastgesteld voor bepaalde kostencategorieën. De gemiddelde jaarlijkse directe kasten vanuit een financieel oogpunt bedroegen respectievelijk $€ 2,122$ (mediaan $€ 747$ ), $€ 1,402$ (mediaan $€ 989$ ) en $€ 941$ (mediaan $€ 631$ ) per patiënt in Nederland, Frankrijk en België. In elk land waren de kosten, berekend vanuit het standpunt van de gezondheidszorgbetaler beduidend lager dan de kosten berekend vanuit een maatschappeliik standpunt, feit dat het belang illustreert van het gekozen perspectief bij de analyse. In hoofdstuk 7 warden de arbeidsparticipatie en de productiviteitskosten in de drie landen besproken. Gestandacrdiseerde arbeidsongeschiktheid bedroeg bij ASpatiënten respectieveliik 47\%, 23\% en 9\% in Nederland, Frankrijk en Beigië en lag in de drie landen bij patiënten beduidend hoger dan bij de algemene bevolking. Maar dit was meer vitgesproken in Nederland dan in beide andere landen. Het is opmerkelijk dat zowel in Nederland als in Frankrijk, maar niet in België, patiënten met een vitkering wegens arbeidsongeschiktheid (deeltijds) betaald werk mogen blijven verrichten. Bij patiënten met een betaalde job bedroeg het aantal dagen ziekteverzuim wegens AS gemiddeld per jaar respectievelijk 19 (medican 1.4), 6 (mediaan: 0) en 9 (mediaan: 0) dagen in Nederland, Frankrijk en België. Wanneer men hierbii de frictiekosten-methode loepast (waarbij men rekening houdt met productiviteitsverlies slechts voor de gerniddelde periode van de vacante betrekking die gedurende de periode van het onderzoek 4 maanden bedroegl op patienten met betaald werk, dan bedroegen de gemiddelde jaarlijkse kosten per patiënt respectievelijk $€ 1,257$ (mediaan $€ 78$ ), $€ 428$ (mediaan $€$ 0) en $€ 476$. (mediaan $€ 0$ ) in Nederland, Frankrijk en België respectievelijk. Bij toepassing van de human capital approach (waarbij rekening wordt gehouden met het productiviteitsverlies voor de gehele periode van ziekteverzuim en arbeidsongeschiktheid) op de gehele groep, bedroegen de gemiddelde jacrliikse kosten per patiënt respectievelijk $€$ 8,862 (mediaan $€ 2,484$ ), $€ 3,188$ (mediaan $€ 0$ ) en $€ 3,309$ (mediaan $€$ ) in de drie landen. $\mathrm{Na}$ standaardisering van socic-demografische en ziektekarckteristieken blijkt dat wonen in Nederland, in vergelijking met beide andere landen, kam geassocieerd worden met een grotere kans op arbeidsongeschiktheid. Wat betreft ziekteverzuim was er geen verschil in het 
aantal werkenden dat verzuimde fussen de landen doch de Nederlandse patiënten met verzuim woren wel duidelijk langer atwezig. Als gevolg van deze bevindingen stelden we eveneens vast dat wonen in Nederland bijdraagt tot hogere frictiekosten en hogere human capital kosten. Ook blijkt dat inflammatoir darmlijden en een slechter fysiek functioneren bij de start van het onderzoek onathankeliike vaorspellers waren van frictiekosten. De totale jaarlijkse ziektekosten wegens AS bedroegen per patiënt $€ 9,463$ (mediaan $€ 2$,894), wanneer men gebruik maakt yan de human capital benadering als methode bil het berekenen van de productiviteitskosten en $€ 3,116$ (mediaan $\in(1,489)$ wanneer men de frictiekosten methode aanwendt. Het verschil in totale kosten tussen de landen was significant bil het gebruik van de human capital methode, met totale jaarkosten per patiënt in Nederland van $€ 11,786$ (mediaan $€ 8.769$ ), in Frankrijk $€ 5.748$ (mediaan $€ 1,427$ ) en in België $\in 5,399$ (mediaan $\in 1,255$ ). Hoofdstuk 8 toont wat de socio-economische gevolgen van de ziekte zijn voor de patiënt. De totale ziektekosten per jaar door de patiënt zelf te betalen bedroegen $€ 431$ (mediaan $€ 172$ ) en het jaarlijks verlies aan inkomsten wegens ziekteverzuim of arbeidsongeschiktheid bedroeg E 1,371 (mediaan $\in 0$ ) per patiënt. Geen verschillen werden wastgesteld uussen de drie landen wat de kosten betreft door de patient zelf te dragen. Na standaardisering voor demografische en klinische confounders betaalden de Belgische patiënten significant hogere persoonlijke bijdragen voor de medische kosten wan gezondheidszorg, terwijl Nederlandse patiënten beduidend hogere bijdragen betaalden voor de niet-medische gezondheidszorg. Hogere totale kosten voor de patiënt hangen samen met een hogere leeftijd en met een slechter fysiek functioneren. Gemiddeld verliest een AS-patiënt per dag één uur en 15 minuten aan tijd wegens ziin ziekte. Deze fijdsbesteding was niet significant verschillend tussen de drie landen maar slechter fysiek functioneren en hogere ziekteactiviteit waren voorspellers voor dit verlies aan tiij. Na standaardisering voor de baseline confounders bleek de levenskwaliteit significant slechter bii Belgische en Franse patiënten in vergelijking met de Nederlandse. Eveneens werd vastgesteld dat perifere artritis, slecht fysiek functioneren, hogere ziekteactiviteit, maar ook inkomensverlies te wijten aan AS bijdroegen tot een vermindering van de levenskwaliteit. Daar er bij economisch onderzoek vaak discussie ontstaat over de methode om de eenheidsprijs van medische prestaties, zoals de ziekenhuisdagprijs, vast te stellen, richtte zich onze belangstelling ook naar hel verleden en meer bepaald naar de tijd dat zulke dagprijs voor het eerst berekend werd. In hoofdstuk 9 wordt beschreven dat berekening van de hospitalisatiedagprijs een aanvang nam gedurende de tweede helft van de 19 de eeuw. In 1897 werd deze berekening verkregen door het totaal van de ziekenhuiskasten eenvoudig te delen door het totaal aantal ligdagen. Voeding telde hierbii voor bijna $50 \%$ van de kosten. Tegenwoordig is de hospitalisatiedagpriis een tarief dat vastgesteld wordi middels onderhandelingen. Meer dan $70 \%$ van de reële ziekenhuisuitgaven gaat thans naar management, inclusief salarissen. De ziekenhuisdagprijs is in de loop van de tijd op dramatische wijze gestegen en dit nief alleen in absolute cijfers maar ook in verhouding tot de koopkracht van de doorsnee burger. 


\section{Deel III Kosteneffectiviteitsonderzoek bij ankyloserende spondylitis}

In hoofdstuk 10 wordt anderzocht of de gunstige klinische effecten van behandelingen bij AS kunnen bereikt worden legen aanvaardbare kosten en dit aan de hand van de kasteneffectiviteits- en kostenutiliteitsanalyse van kuuroordbehandeling bij patiënten met AS. Een totaal van 120 Nederlandse ASpatiënten werd gerandomiseerd in drie groepen. Groep 1 werd drie weken lang behandeld in een kuuroord in Bad Hofgastein, Oostenriik. Groep 2 in een kuuroord in Arcen, Nederland en groep 3 bleef thuis en zette de gebruikelike behandeling verder. Een totaal van 111 patiënten hield tijdens de 40 weken durende onderzoeksperiode een kostendagboek bii. De cumulatieve winst aan fysiek functioneren bii groep 1 vergeleken met groep 3 bedroeg 1.0 punt (schaal 0 tot 10) en 0.6 punten voor groep 2 in vergelijking met groep 3 . De cumulatieve winst in kwaliteit van leven (utiliteit) voor groep 1 vergeleken met groep 3 bedroeg 0.17 (schaal 0 tot 1 ) en 0.08 en voor groep 2 vergeleken met groep 3. De gemiddeide algemene kosten per patiënt bedroegen $€ 3,023$ voor groep 1, $€ 3,240$ voor groep 2 en $€ 1,754$ voor de controlegroep. De incrementele kasteneffectiviteitsratio per eenheid toename in fysiek functioneren (schaal 0.10 ) bedroeg $€ 1,269$ (95\% betroumbaarheidsinterval: $497-3,316$ ) voor groep 1 en $€ 2,477$ (95\% betrouwbaarheidsinterval: $601-12,089$ ) voor groep 2 in vergelijking met de controlegroep. De incrementelle kostenutilliteitsratio per eenheid loename in levenskwaliteit (schaal 0-1) bedroeg $€ 7,465(95 \%$ betrouwbaarheidsinterval: $3,294-14,686)$ voor groep 1 en $€ 18,575$ (95\% betrouwbaarheidsinterval: $3,678-114,257)$ voor groep 2 in vergelijking met de controlegroep. Voor de Nederlandse maatschappii betekent dit dat kuren bii AS een gunstige verhouding heeft tussen kosten en effecten.

In hoofdstuk 11 worden de bevindingen van dit onderzoek besproken in het lichl van de klinische implicaties en de methodologische beperkingen van economische studies over gezondheidszorg, waarbij een lans wordt gebroken voor de prioriteit van onderzoek naar de economische gevalgen van AS. 
Dankwoord 


\section{Dankwoord}

\section{Dank aan de rechtstreeks betrokkenen,}

Dank aan Professor Kruseman, Rector van de Universiteit Maastricht en Professor Hillen, Decaan van de Faculteit Geneeskunde voor het waarborgen van een klimaat waarin onderzoek en promotietrajecten worden mogelijk gemaakt.

Dank aan milin promatoren en copromotor. Professor van der Linden, beste Sjef, uw visie dat clinici actief moeten deelnemen aan de ontwikkelingen binnen de gezondheidseconomie liggen aan de basis van deze promotie. Al vaker werd u in dankwoorden geprezen voor de wijze waarop u onderzoek begeleidt. Uw rustige en heldere benadering van problemen, uw zeldzame kritiek die slechts voor een aandachtig luisteraar te verstaan is en vooral het vertrouwen en de writheid die u kan geven, motiveren om steeds beter bij te dragen aan de kwaliteit van ons werk als vakgroep reumatologie. Professor van der Heiide, lieve Désiré, door het starten van het OASIS cohort bood iii me de kans om economische vraagstellingen te onderzoeken bij patiënten met ankyloserende spondylifis. Je creatieve manier om naar methodologische problemen en resultaten van analyses te kijken zijn verfrissend en inspirerend. Dat onze professionele interesse en onze vriendschap hand in hand gaan is voor ons beiden heel vanzelfsprekend. Dr Ruitten-Van Mölken, beste Maureen, jouw visie als gezondheidseconoom was onontbeerlijk bij thet fot stand komen van dit proefschrift. De besprekingen van de kostenartikelen bif je thuis waren niet alleen leerzaam maar ook gezellig.

Dank aan de leden van de beoordelingscommissie voor hun opbouwende en snelle reactie. Professor Severens, beste Hans, jouw komst naar Maastricht maakte de vitdagingen van de gezondheidseconomie in zijn volle breedte en diepte duidelik. Je enthousiasmerende openheid, energie, onderwijscapaciteiten en visie brengen terug dynamiek in het MTA onderzoek van de universiteif en het ziekenhuis. Ik kijk ernaar vit om aan de volgende projecten verder samen te werken. Professor van de Putte, beste Leo, naast onze toewijding voor reumatologie en reumatologisch onderzoek delen we ook Vlaamse wortels en de mening dat een beter inzicht in het verleden bijdraagt tot begrip van het heden en de toekomst.

Dank aan de leden van de corona, die in dit proefschrift uitdagingen zien om hierover verder van gedachten te wisselen. Dr Landewe, beste Robert, heel bijzondere dank gaat uit naar jou. Altijd toonde iii je bereid om mee te kijken naar de gegevens en te discussiëren over de juiste interpretatie van de resultaten. Deze uren behoren tot de beste herinneringen bij het werken aan dit proefschrift. 
Dank aan al de medeauteurs. Anneke Spoorenberg en Kurt de Vlam, dank voor hef verzamelen wan de data woor het OASIS cohort en het motiveren van de patienten de economische wragenlijsten correct te blijven invullen. Riekie de Vet, Astrid Chorus, Harald Miedema, Hubert Schouten. Hille van der Tempel, ieder van jullie had een onontbeerlijke en gewaardeerde bijdrage. Professeur Dougados, cher Maxim, je tiens à vous remercier pour l' intérêt que vous avez apporté à la partie économique de notre élude. Professeur Guillemin, cher Francis, votre contribution (surtout pendants les weekends!) était essentielle. Professor Mielanis, beste Herman, dank voor het aanmoedigend vertrouwen. Astrid van Tubergen, met jouw als onderzoeker aan een artikel werken is een feest. Wanneer je terugkeent naar Maastricht moelen we zeker de traditie verder zetten om ook niet medische literatuur met mekaar te delen.

Dank aan de paranymfen. Lieve Sabine, gewaardeerde collega, oprechte wriendin. Beste Bram, vriend zonder woorden, vriend voor altijd.

\section{Even oprechte dank aan al de anderen,}

Professor Van Trappen en Professor Fevery, mijn opleiders interne geneeskunde en Professor Dequeker en Professar Westhovens, mijn opleiders reumatologie die zorg droegen voor een aantrekkelijke opleiding tot internist en reumatoloog. Professor Fevery, dank dat u zag dat ik in mijn beroep de vitdaging van onderzoek zou nodig hebben.

De collega's in Maastricht. Professor Geusens, beste Piet, een betere kamergenoot als jii kon ik me nief wensen. Ik dank je voor je wijze adviezen. Zouden we ooit achterhalen of Rachmaninov echt in 1931 zijn pianosonate opus 36 herschreef omdat hij leed aan artritis? Marijke, Debbie en Thea, ik prijs me gelukkig met jullie als collega's. Maarten Boers en Ineke Blauw, jullie zijn al lang vertrokken vit Maastrichi, maar zeker nog niet vergeten.

Collega's in Heerlen, naast jullie actieve bijdrage tof dit onderzoek, wooral bedankt voor jullie stimulerende medewerking bij de organisatie wan hef regionale assistentenonderwijs. De artsen van het Medisch Centrum Maasmechelen, dank voor de vlotte samenwerking.

Zaalarts Peter Dubbeld en assistenten wit Leuven, Erik Ghiisels, Annemie Vandermarliere, Stefan Delen en Johan Scharpé. Met ieder wan jullie was het prettig samenwerken. Zuzana de Jong, iii bent en blifft één vil de duizend. Christine Langenaeken, voor jou was de zarg voor de patient belangrijker dan onderzoek, maar steeds toonde je interesse in de verdere ontwikkelingen wan de studie. Bowenal bleef iij een trouwe wriendin.

Alle huidige of vroegere onderzoekers, Arco Verhoeven, Simone Gorter, Guy Schulpen, Liesbeth Heuft, Karen Bruynesteyn en Astrid Wanders. De interesse in mekaars anderzoek was altijd wederzijds. Dear Jolanta Dadoniene from 
Lithuania en Carinai Mihai from Romania. E-mail has become prerequisite to perform international research.

MTA werkgroep Maastricht. Onze samenkomsten en discussies vermimden mijn kiik op de gezondheidseconomie.

Onderzoeksverpleegkundigen Anita, Nicole, Mieke, Jeanine, Els, Ellen en Thomas; reumaconsulenten Yronne, Ilse, Mehmet en Wolgang; alle medewerkers van de afdeling D5 reumatologie. Onderzoek kan alleen als je weet dat de patienten in goede handen zijn.

Lily Heusschen, jouw accuratesse bili het blinderen van röntgenfoto's is ongeëvenaard. Gisela Mulder, iii stond bii de wieg van OASIS. Ik kan me nu nog nauwelijks voorstellen dat ik in die tijd mijn eerste PC kreeg en je hulp nodig had voor alles dat meer was dan eenwoudig typen. Ellen, Edith, Maddy en de andere medewerkers van de poli reumatologie in Maastricht en Martine, Nicole, Linda, Mia en Idali van het Medisch Centrum in Maasmechelen, ik ben verwend daf jullie erin slagen de poli"s te organiseren volgens de individuele wensen van de artsen. Secretariaat reumatologie in Moastricht inclusief Diane, Mieke, Peggy en Liesbeth, ik ben erkentelijk voor jullie onmisbare secretariële ondersteuning. Yolanda, dank voor al het extra en onzichtbare werk. Jouw toewiiding en steun gaan veel verder dan het vanzelfsprekende.

Dank aan de patiënten, die de basis maar ook het doel van dit onderzoek zijn.

Erik de Klerk, zonder database geen analyses. Hoe goed iii ook alles vitlegde, een programmator heb je nief van me kunnen maken.

Madame Maryse Mezière. Les questionnaires économiques des patients Français étaient toujaurs remplis impécablement! Grand merci aussi, d'avoir répondu si vite à toutes mes questions additionelles. Willy Peeters, hartelijk dank om mi wegwijs te maken in de vaak ingewikkelde betalings- en terugbetalingssystemen in de Belgische gezondheidszorg.

Tiny, in onze vakgroep ben iij deel wan de traditie wan het promoveren. De weken waarin we werkten aan de vormgeving van de binnenkant van het proefschrift leerde ik je waarderen om je werkkracht, je flexibiliteit maar ook je optimisme. Dank je.

Mama en papa, onmogelijk waren or ouders die zoveel daadwerkelijke bijdragen leverden aan een proefschrift. Jullie verbondenheid gaat echter veel dieper. In je "thuis" liggen de wortels van je gevoelens, je waarden, je culfuur. Aan jullie draag ik dit proefschrift op. 
Curriculum vitae 



\section{Curriculum vitae}

De auteur van dit proefschrift, Annelies Boonen, werd geboren op 18 februari 1963 te Maaseik, België. Na haar middelbare studies aan de Vrije Humaniora voar Meisjes Maaseik, waar zij de afdeling Latijn-Wetenschappen volgde, startte zij de studie geneeskunde in 1981. In 1984 behaalde zij het kandidaatsexamen geneeskunde aan het Limburgs Universitair Centrum te Diepenbeek met grote onderscheiding en in 1988 behaalde zij het artsexamen aan de Katholieke Universiteit van Leuven eveneens met grote onderscheiding. Tiidens de geneeskundeopleiding werden de klinische stages kindergeneeskunde en gynaecologie doorlopen in het Victoria Hospital, Kirkaldy, Schotland en in King's College, Londen, Groot-Brittannië.

De specialisatie interne geneeskunde vond plaats van 1988 tot 1993 onder leiding van Professor Vantrappen vam de Katholieke Universiteit Leuven. Het tweede jaar van deze opleiding werd gevalgd bil Professor Coche aan de Université Catholique de Louvain te Brussel en het vijfde jaar bij Professor van der Linden, op de afdeling reumatolagie van het Academisch Ziekenhuis Maastricht. In juni 1993 vond in België de registratie plaats als internist. Na een extra opleidingsjaar reumatologie bii Professor Dequeker aan de Katholieke Universiteit Leuven werd 1994 de erkenning als reumatoloog behaald. Datzelfde jaar startte zij als junior-specialist reumatologie bij Professor van der Linden in het Academisch Ziekenhuis Maastricht, eerst in deeltijds en nadien in voltijds dienstverband. Snel volgde ook de Nederlandse registrotie tor reumatoloog en de aanstelling als staflid reumatologie in Maastrichtit. Het is eveneens op dezelfde afdeling dat zij onderzoek verricht naar de socioeconomische gevolgen van reumatische aandoeningen, hetgeen resulteerde in dit proefschrift. 
List of publications 


\section{List of publications}

Boonen A, Staessen J, Fagard $R$ en Amery A. Wat te denken over behandeling van hypertensie bij bejaarden? Medi-search 1988; 19:365-372.

Van Cutsem E, Boonen A, Geboes K, Hiele M, Vantroppen G, Rutgeents P. Risk factors which determine the long term outcame of Neodynium-Yag laser palliation of colorectal carcinoma. Int $\mathrm{J}$ Color Dis 1989; 1:9-11.

Boonen A, Lefebwre Ch, Lambert M, Ferrant A, Michaux J, Coche E. Hypothyraidism associated with myeloid neaplasia. About two cases. Acto Clin Belg 1993; 47:397-400.

Boonen A, Ghesquiere B, Westhovens R, Geussens P, Dequeker I. Vertebral fracture induced by chronic contained rupture of aortic aneurysm. Ann Rheum Dis 1995; 54 : 437.438.

Boonen A, Schrey $G$, van der Linden Sj. Clubbing in HV infection. Br I Rheumatol 1996; 35: 292-294.

Knockaert DC, Boonen AL, Bruyninckx FL, Bobbaers GJ. Electromyographic findings in ilioinguinal-iliohypogastric nerve entrapment syndrome. Acto Clin Belg 1996; 5: 156160 .

Boonen A, Verwilghen J, van der Linden Si, Westhovens R. Is SAPHO syndrome a spondylaarthropathy? A vasculopathy? Report of a case. Rev Rheum 1997; 64: 424-427.

Boers M, Verhoeven A, Markusse M, Van de Laar M, Westhovens R, Van Denderen J, Van Zeben S, Diikmans B, Peeters A, Jacobs $P$, Van den Brink $H$, Schouten $H$, Boonen A, van der Heijde D, van der Linden S.. Randomised comparison of combined step-down prednisolone, methatrexate and sulphasalazine alone in early theumatoid arthritis. The Lancet 1997:350:309-318.

Boonen A, van de Rest 1, Dequeker J, van der Linden Si. How Renoir coped with Rheumatoid arthritis. BMJ 1997,315: 1704-1708.

Boonen A, van der Linden Si. How critically to appraise an anticle on economic analysis. Rheumatology in Europe 1998; $27: 15-17$.

Boonen A, van der Linden Si. Arbeid en belastbaarheid bil spondylarthropathieen. In: Miedema HS, Rasker JJ, Handbaek Arbeid en Belastbaarheid. Reumatische aandoeningen. Spandylarthropathieen: Bohn Stafles Van Loghum; 1998: 50-56. 
Ortis Z, Shea B, Garcio Dieguez M, Boers M. Tugwell P. Boonen A, Wells $G$. The responsiveness of generic qualily of life instruments in theumatic diseases. A. Systematic Review of Randomized Controlled Trials. I Rheumatal 1999; 26:210-216.

Lassere M, Boers M, yan der Heijde D, Edmonds J, Soudan A, Verhoeven A, Boonen A. Smallest detectable difference in radiologic progression. J Rheumatol 1999; 26: 731 . 739.

Boonen A, Stockbrügger RW, van der Linden Si. Periconditis affer therapy with intierferona for chronic hepatifis C. Clin Rheumatol 1999; 18: 177-179.

Heijde van der $D$, Boonen $A_{*}$ Boers $M$, Kostense $P_{*}$ van der Linden Sj. Reading radiographs in chronologic order or as single films has impartanty implications fot the discriminative power of rheumatoid arthritis clinical trials. Rheumatology 1999; 38: $1213-1220$.

Boonen $A$, Rennenberg $\mathbb{R}$, van der Linden $S$. Thymoma associated systemic lupus erythematosus exocerbating after thymactomy. A case report and review of the literature. Rheumatology 2000; 39: 1044-1046.

Gorter S, van der Linden, Si, Brover J, van dr Heijde D, Houben H, Rethans JJ, Scherpbier A, Van der Vleuten C, Boonen A, Dinant H, Goei-The H, Griep E, van der Horst-Bruinsma I, Linssen $A$, van Santen-Hoeuff $M$, van der Tempel $H$, Wesigeest $T$. Rheumatologists" performance in daily practice. Arthritis Care Res 2001; 45: 16-27.

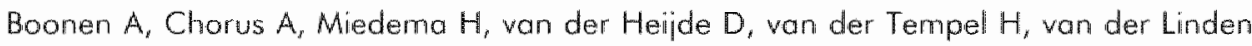
Si. Employment, wark disability and work days lost in patients with ankylosing spondylitis: a cross-sectional study of Dutch potients. Ann Rheum Dis 2001; 60: $353-358$.

Boonen $A$, de Vet $R$, van der Heijde $D$, van der Linden Si. Work-status and its determinants among patients with ankylosing spondylitis. A systematic review of the literature. J Rheumatol $2001 ; 28: 1056-1062$.

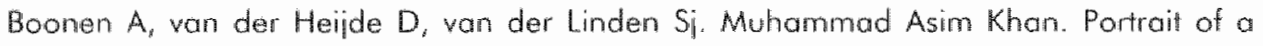
rheumatologist as a great artist. I Rheumatal $2001 ; 28: 843-844$.

Lassere M, van der Heijde D, Johnson K, Bruynesteyn K, Molenaar E, Boonen A, Verhoeven A, Emery P, Boers M. Robustness and generalisability of smallest defectable difference in radiological progression. I Rheumatol $2001 ; 28: 911.913$.

Bruwnesteyn $K$, van der Heirde D, Boers M, Lassere M, Boonen A, Edmonds J, Houben $H$, Paulus H, Pelosos P, Saudan A, wan der Linden Si. Minimal dinically important difference in radiological progression of joint damage over 1 year in rheumatoid arthritis: preliminary results of a validation sludy with clinical experts. J Rheumatol $2001 ; 28 ; 904$ 910. 
Boonen $A$, Chorus $A$, Miedema $H$, van der Heijde D, Landewe R, Schouten $H$, wan der Tempel $H_{4}$ van der Linden Si. Withdrawal from labor force due to work disabiling in palients with ankylosing spondylitis. Anm Rheum Dis 2001; 60: 1033-1039.

Landewe $\mathbb{R}$, Boers $M$, Verhoeven $A$, Westhowens $R$, wan de Laor M, Morkusse $H$, won Denderen $C$, Westedt ML, Peeters A, Dijkmans B, Boonen $A_{r}$ van der Heijde D, wan der Linden Si. COBRA-combination therapy in patients with early rheumatoid anthrits: Longterm structural benefits of a brief intervention. Anthritis Rheum 2002; 46:347-356.

Evers S, Paulus A, Boonen A, Integrated care across borders: possibilities and complexties. Int IIntergrated Core 2001; $1(4)$ : wwwilic.org/index 2hth

Tubergen van A, Coenen J, Landewe R, Spoorenberg A, Chorus A, Boonen A, van der Linden $S_{j}$. Assessment of fatigue in patients with ankylasing spondyltis. A psychometric analysis. Arthritis Care Res 2002; 47:8-16.

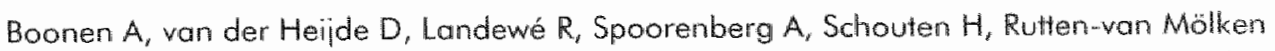
$M$, Guillemin $F$, Dougados $M$, Mielants $H$, de Vlam $K$, van der Tempel $H$, van der Linden SJ. Work status and productivity costs due to ankylosing spondylitis: comparison among three European countries. Ann Rheum Dis 2002; 61: 429-437.

Paulus A, Fecher F, van der Made 1, Evers $S$, Boonen A. The effectiveness of tailor made care: cross border care between Belgium and The Netherlands. Eur J Law Econom 2002; $14: 61-73$.

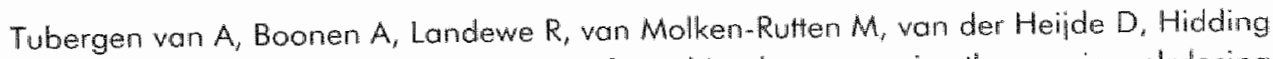
A, van der Linden Si. Cost-effectiveness of combined spa-exercice therapy in ankylosing spondylitis: a randomised controlled trial. Arthritis Care Res; Accepted.

Boonen A, van der Linden S.. Rheumatism in the early 18 th century. A physician's diary. Ann Rheum Dis 2002; 67 : 468 469.

Chorus A, Boonen A, Miedema $H$, Van der Linden Si. Employment perspeclives of potients with ankylosing spondylitis. Ann Rheum Dis 2002; 61: 693-699.

Boonen A, van de Putte L. Colchicum autumnale from Het Cruydiboeck by Rembertus Dodonaeus. Ann Rheum Dis 2002; $61: 492$.

Dadoniene 1, Uhlig T. Stropuviene S, Venalis A, Boonen A, Kvien TK. Disecse activity and health status in rheumatoid arthritis: A case-control comparison between Norway and Lithuania. Ann Rheum Dis; Accepted

Boonen A, Dagnelie PC. Feleus A, Hesselink MA, Muris JW, Stackbrügger MW, Russel GR. The impact of Inflammatory Bowel Disease on work-force participation: results of a population sampled case-contral study. Infl Bowel Dis; Accepted. 
A Boonen, Chons $A$, Landewé $R$, wan der Heịje $D$, Miedemo H, van der Tempel H, wan der Linden Si. Manual protessions increase risk to withdraw from labour force in ankylosing spondyitis, also when compared to the general population. Ann Rheum Dis $2002: 61: 658$

Gannero $P$, Landewé $R$, Boers $M$, van der Heijde D, Boonen A, Verhoeven $A$, van der Linden 5 , Geusens P. Baseline lewels of markers of bone and cartlage degradation are associated with long-term progression of joint damage in patients with early rheumatoid arthritis: the COBRA study. Arthritis Rheum; Accepted.

Bruynesteyn $K$, van der Heijde D, Boers $M$, Saudan $A$, Peloso P, Paulus $H$, Houben $H$, Griffiths B, Edmonds J, Bresnithan B, Boonen $A$, van der Linden Si. Detecting radiological changes in theumatoid arthritis that are considered important by dinical experts: influence of reading with or without known sequence. I Rheumatol; Accepted.

Boonen A, Severens J. Ankylosing spondyltis: socioeconomic impact and the cost-ofillness. Chapter 12 in Spondylarthropathies. Bailliere's Best Practice and Research; Autumn 2002.

Boonen A. Socioeconomic consequences of ankylosing spondylitis. Clin Exp Rheumatol $2002 ; 20(528): 23-26$. 
How sweet the moonlight sleeps upon this bank

there will I sit

and let the sounds of music creep into my ears

Shakespeare, The Merchant af Venice. 